Pacific Northwest

National Laboratory

Operated by Battelle for the

U.S. Department of Energy

\section{Technical Support Document for Version 3.4.0 of the COMcheck Software}

R Bartlett

LM Connell

K Gowri

MA Halverson

RG Lucas

EE Richman

RW Schultz

DW Winiarski

September 2007

Prepared for the U.S. Department of Energy under Contract DE-AC05-76RL01830 


\title{
DISCLAIMER
}

This report was prepared as an account of work sponsored by an agency of the United States Government. Neither the United States Government nor any agency thereof, nor Battelle Memorial Institute, nor any of their employees, makes any warranty, express or implied, or assumes any legal liability or responsibility for the accuracy, completeness, or usefulness of any information, apparatus, product, or process disclosed, or represents that its use would not infringe privately owned rights. Reference herein to any specific commercial product, process, or service by trade name, trademark, manufacturer, or otherwise does not necessarily constitute or imply its endorsement, recommendation, or favoring by the United States Government or any agency thereof, or Battelle Memorial Institute. The views and opinions of authors expressed herein do not necessarily state or reflect those of the United States Government or any agency thereof.

\author{
PACIFIC NORTHWEST NATIONAL LABORATORY \\ operated by \\ BATTELLE \\ for the \\ UNITED STATES DEPARTMENT OF ENERGY \\ under Contract DE-AC05-76RL01830
}

Printed in the United States of America
Available to DOE and DOE contractors from the Office of Scientific and Technical Information,
P.O. Box 62, Oak Ridge, TN 37831-0062;
ph: (865) 576-8401
fax: (865) 576-5728
email: reports@adonis.osti.gov

\begin{abstract}
Available to the public from the National Technical Information Service, U.S. Department of Commerce, 5285 Port Royal Rd., Springfield, VA 22161

ph: (800) 553-6847

fax: (703) 605-6900

email: orders@ntis.fedworld.gov

online ordering: http://www.ntis.gov/ordering.htm
\end{abstract}

This document was printed on recycled paper. 


\section{Technical Support Document for Version 3.4.0 of the COMcheck Software}
R. Bartlett
R. G. Lucas
L. M. Connell
E. E. Richman
K. Gowri
R. W. Schultz
M. A. Halverson
D. W. Winiarski

September 2007

Prepared for

the U.S. Department of Energy

under Contract DE-AC05-76RL01830

Pacific Northwest National Laboratory

Richland, Washington 99352 



\section{Summary}

COMcheck provides an optional way to demonstrate compliance with commercial and high-rise residential building energy codes. Commercial buildings include all use groups except single family and multifamily not over three stories in height. COMcheck was originally based on ANSI/ASHRAE/IES Standard 90.1-1989 (Standard 90.1-1989) requirements and is intended for use with various codes based on Standard 90.1, including the Codification of ASHRAE/IES Standard 90.1-1989 (90.1-1989 Code) (ASHRAE 1989a, 1993b) and ASHRAE/IESNA Standard 90.1-1999 (Standard 90.1-1999). This includes jurisdictions that have adopted the 90.1-1989 Code, Standard 90.1-1989, Standard 90.1-1999, or their own code based on one of these. We view Standard 90.1-1989 and the 90.1-1989 Code as having equivalent technical content and have used both as source documents in developing COMcheck.

This technical support document (TSD) is designed to explain the technical basis for the COMcheck software as originally developed based on the ANSI/ASHRAE/IES Standard 90.1-1989 (Standard 90.11989). Documentation for other national model codes and standards and specific state energy codes supported in COMcheck has been added to this report as appendices. These appendices are intended to provide technical documentation for features specific to the supported codes and for any changes made for state-specific codes that differ from the standard features that support compliance with the national model codes and standards. 



\title{
Communicating with BECP
}

The U.S. Department of Energy (DOE) and Pacific Northwest National Laboratory (PNNL) intend to refine and enhance the COMcheck materials over time in response to needs expressed by users. Many of the simplifications and enhancements developed for COMcheck have provided the technical basis for code changes submitted to the International Code Council (ICC). PNNL welcomes suggestions for improvements to the COMcheck materials and to this documentation. Suggestions can be communicated to PNNL using any of the methods listed below.

\author{
Email: techsupport@becp.pnl.gov \\ Fax: $\quad 1-509-372-4484$ \\ Mail: Attn. Pam Cole, MSIN K6-05 \\ Building Energy Codes Program \\ Pacific Northwest National Laboratory \\ P.O. Box 999 \\ Richland, WA 99352
}





\section{Contents}

Summary iii

Communicating with BECP. V

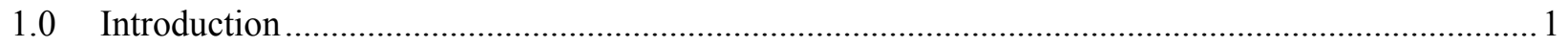

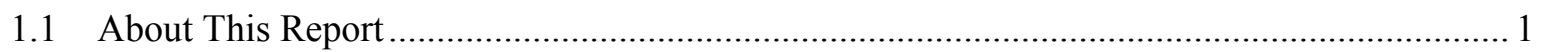

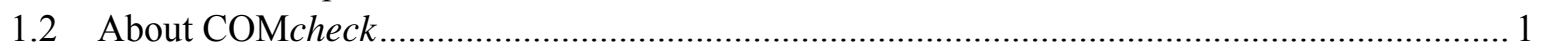

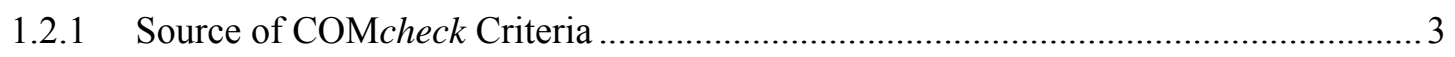

1.3 Relationship Between the 90.1-1989 Code and COMcheck ................................................ 4

1.4 Facilitating the Implementation of Commercial Building Energy Codes ................................ 6

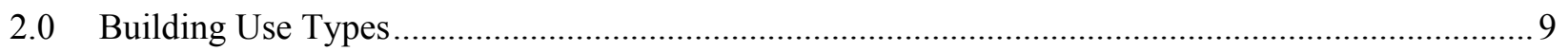

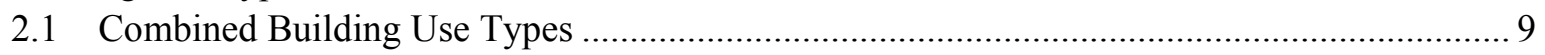

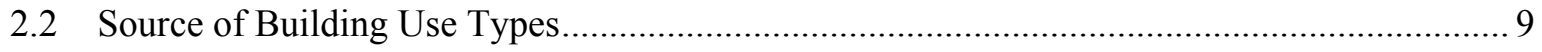

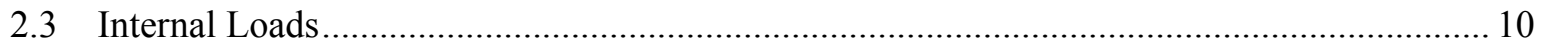

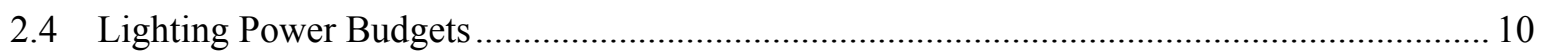

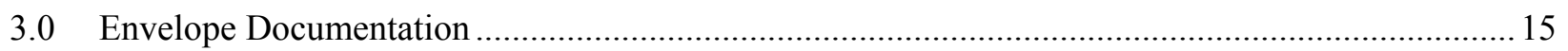

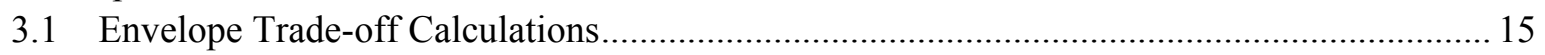

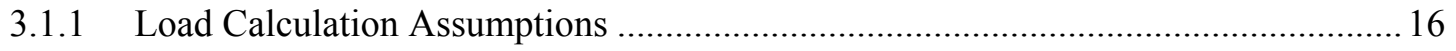

3.1.2 Requirements for Locations with Greater than 15,000 HDD65 …........................... 16

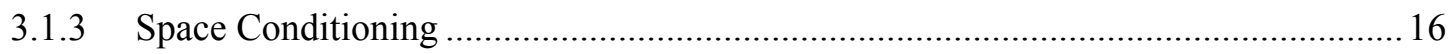

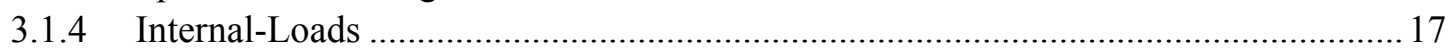

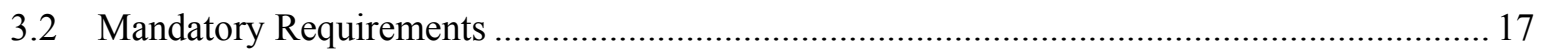

3.2.1 Calculations and Supporting Information (402.1) ............................................ 17

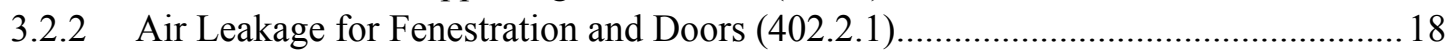

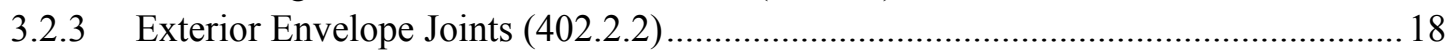

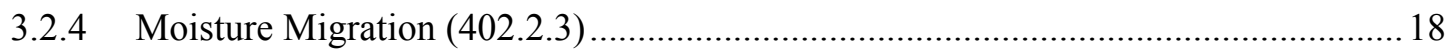

3.3 Assumptions in Developing Envelope Assemblies ........................................................... 19

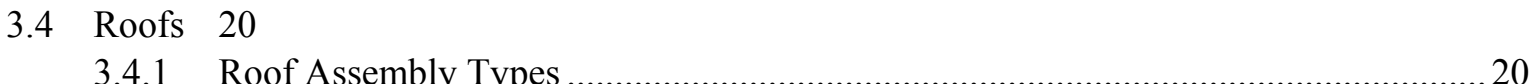

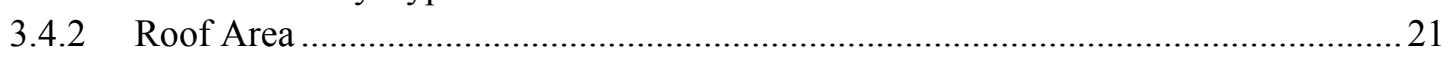

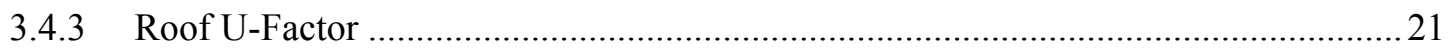

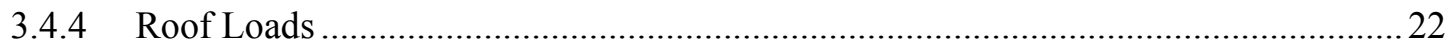

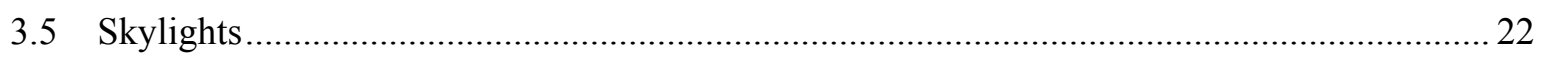

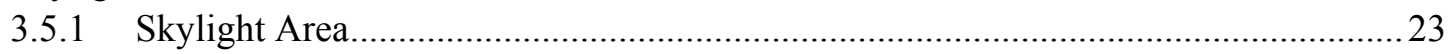

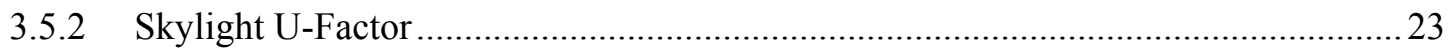

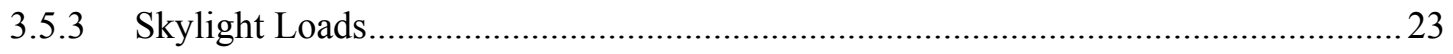

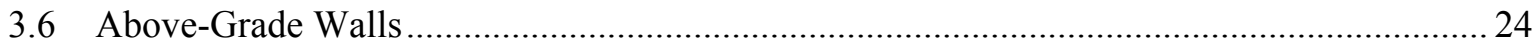

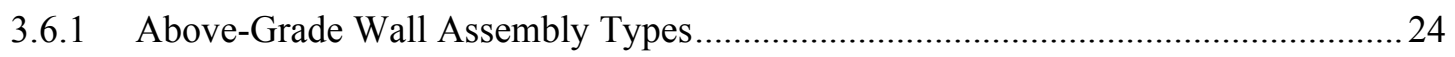

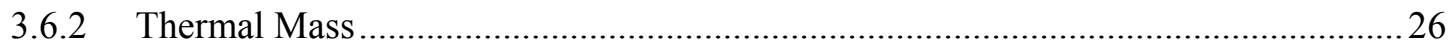

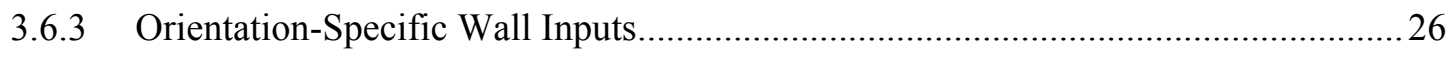

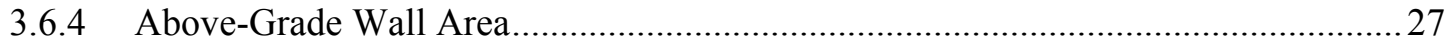




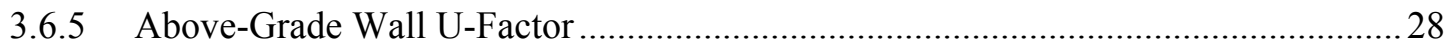

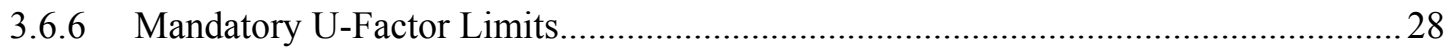

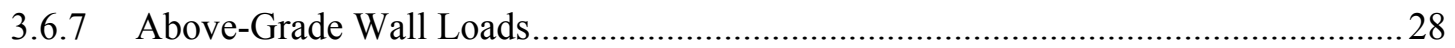

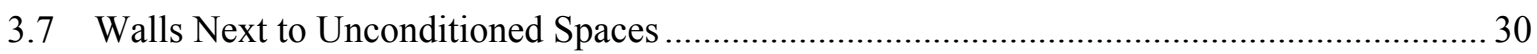

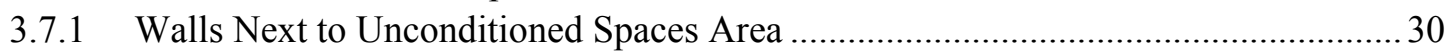

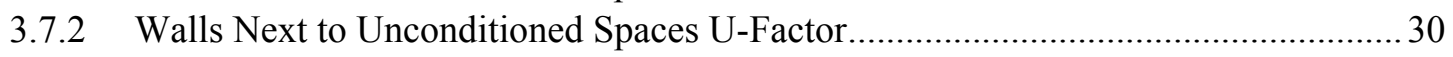

3.7.3 Walls Next to Unconditioned Spaces Loads .......................................................... 31

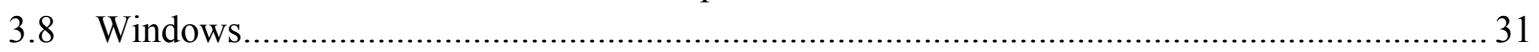

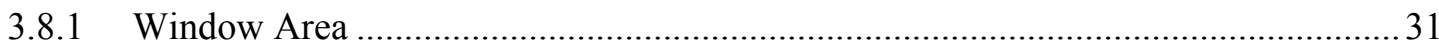

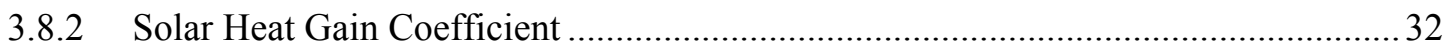

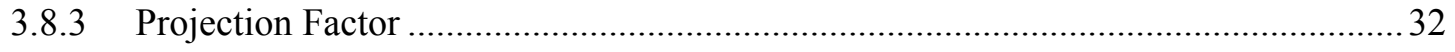

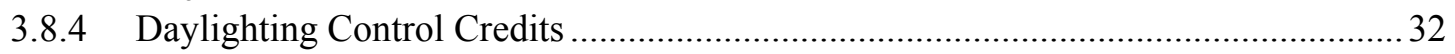

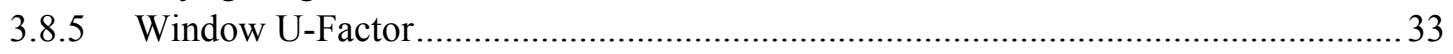

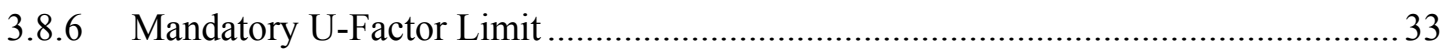

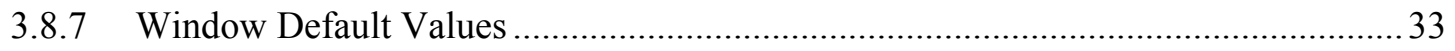

3.9 Doors 35

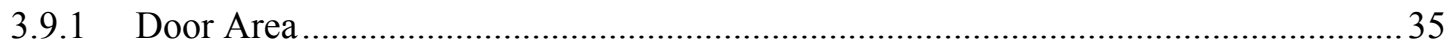

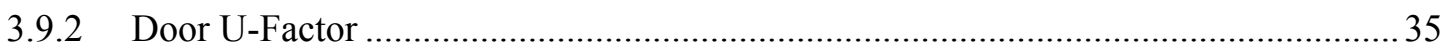

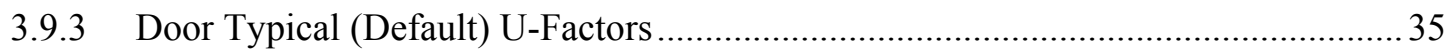

3.10 Floors 36

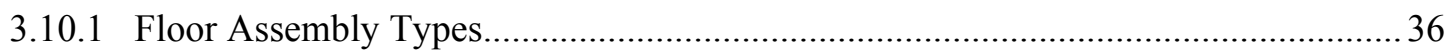

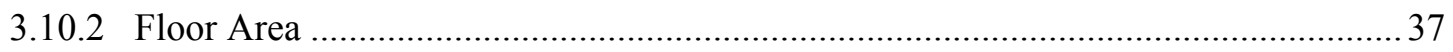

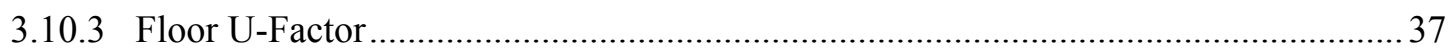

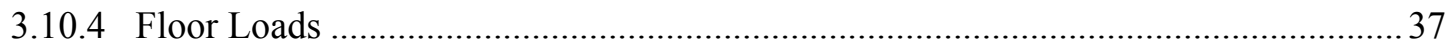

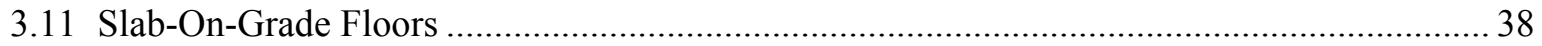

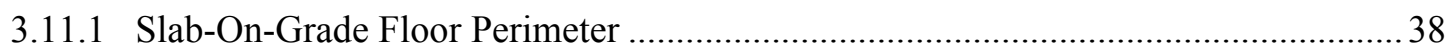

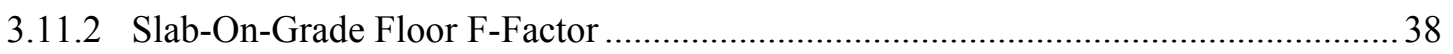

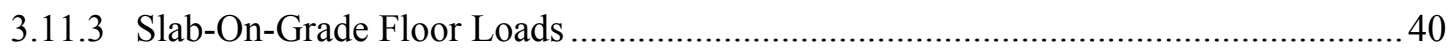

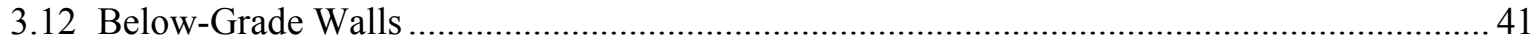

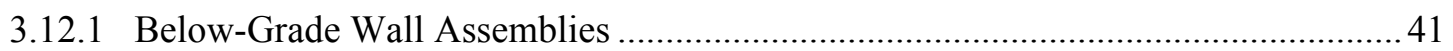

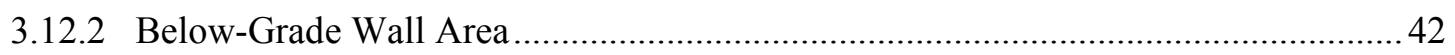

3.12.3 Below-Grade Wall R-Values and Heat Capacity ................................................ 42

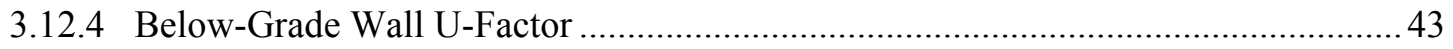

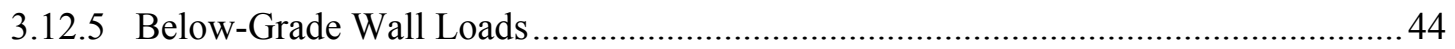

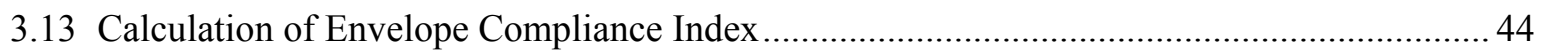

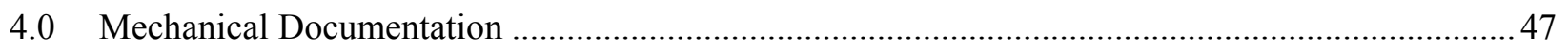

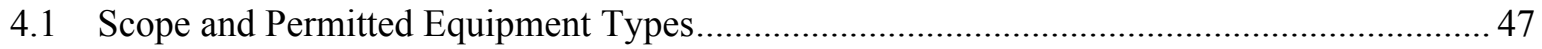

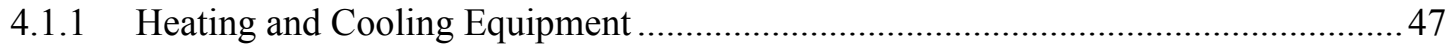

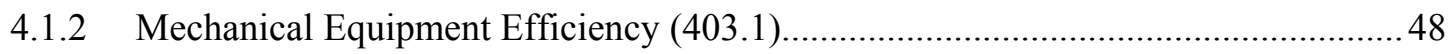

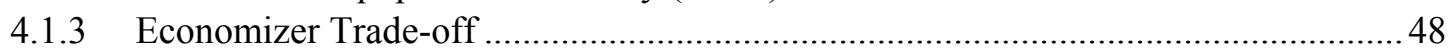

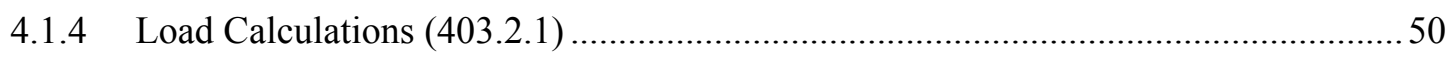

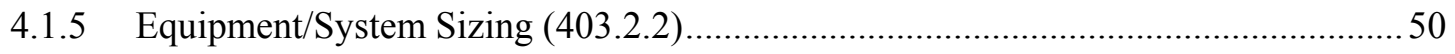

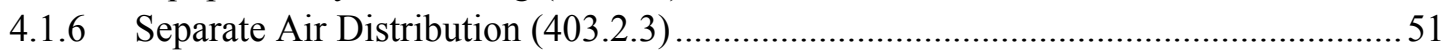

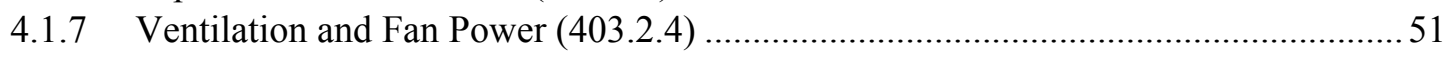

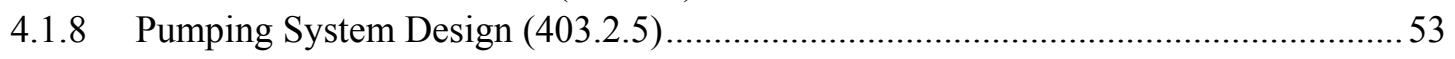




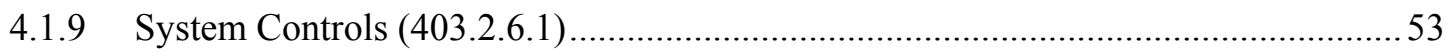

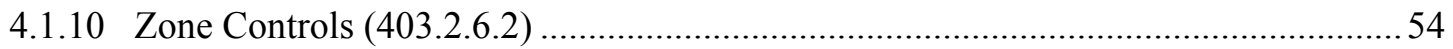

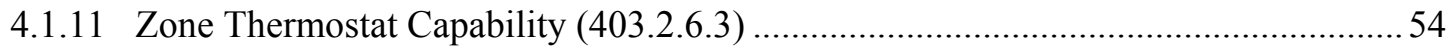

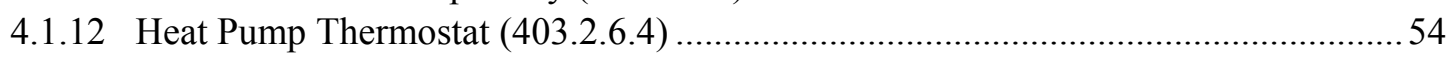

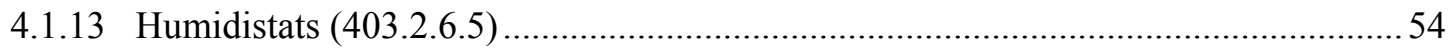

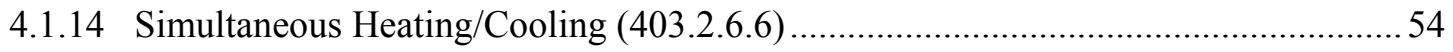

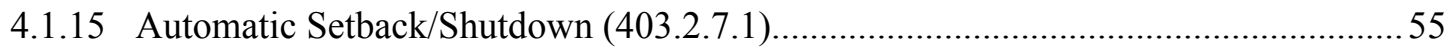

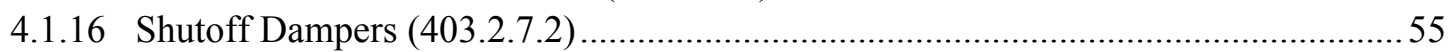

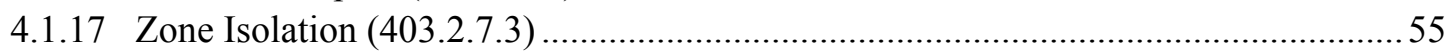

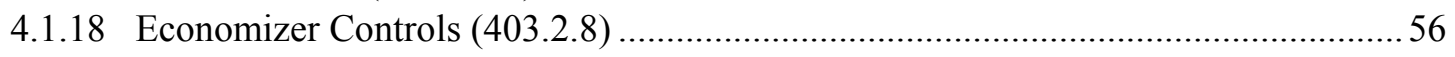

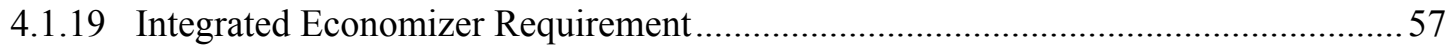

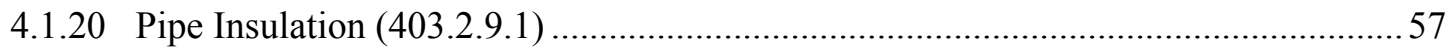

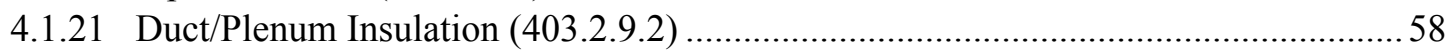

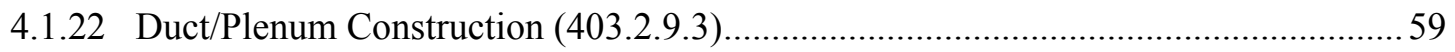

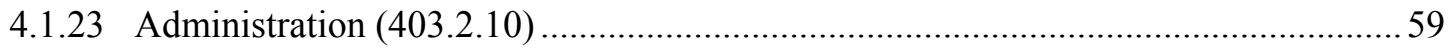

4.2 Service Water Heating (SWH) Systems and Equipment....................................................5 59

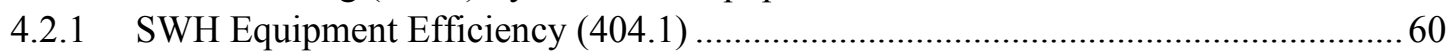

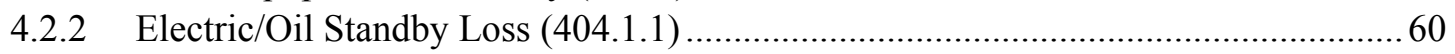

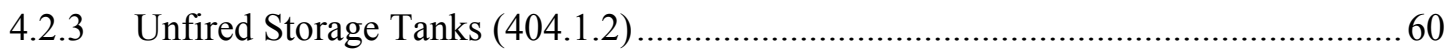

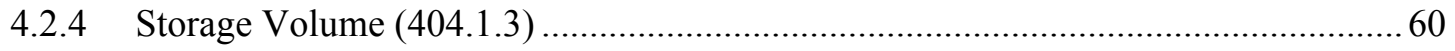

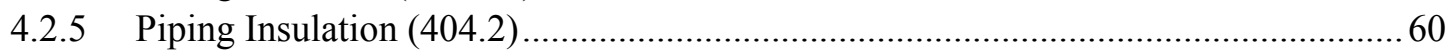

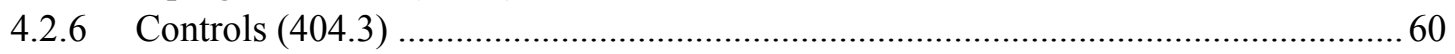

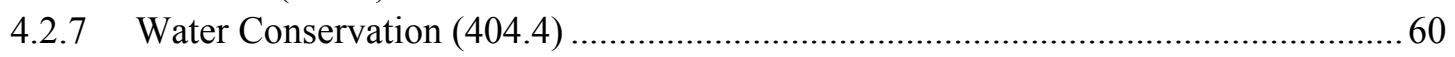

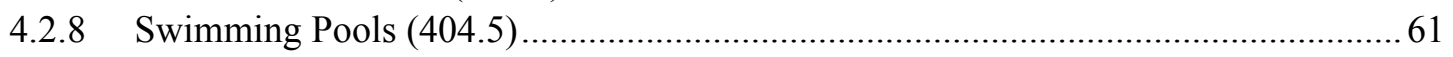

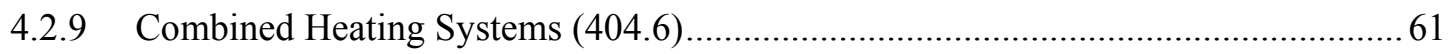

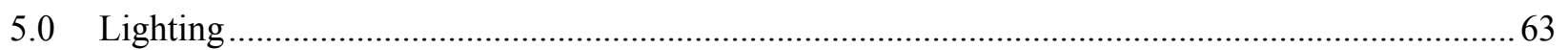

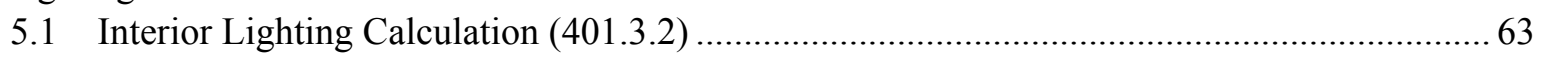

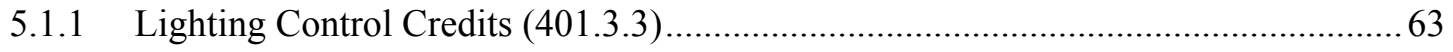

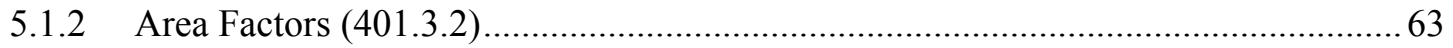

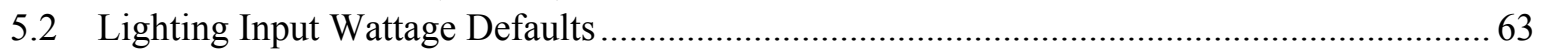

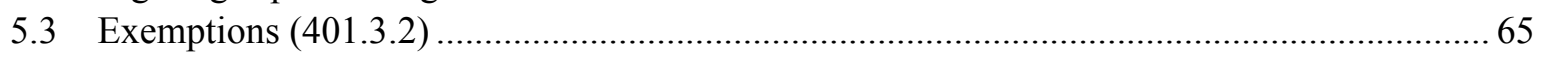

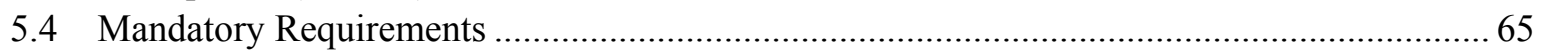

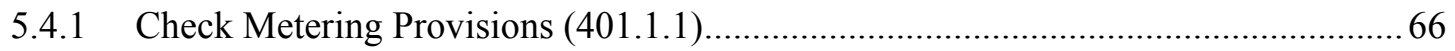

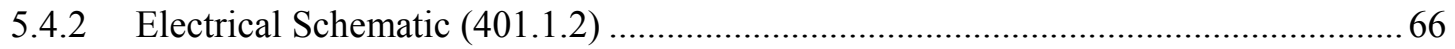

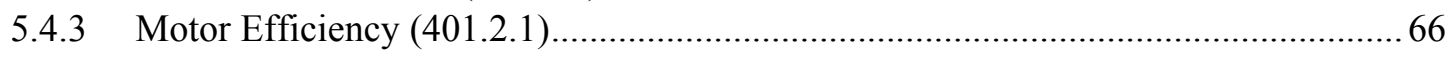

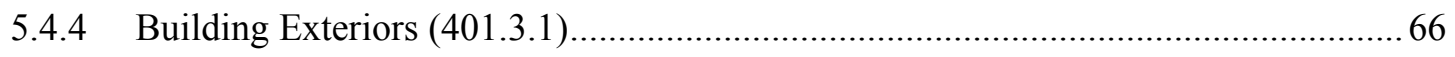

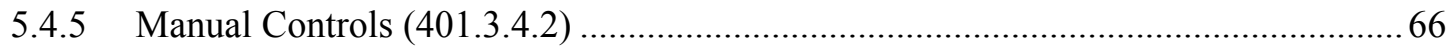

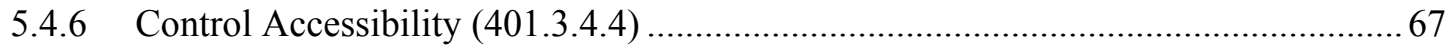

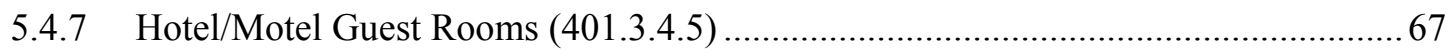

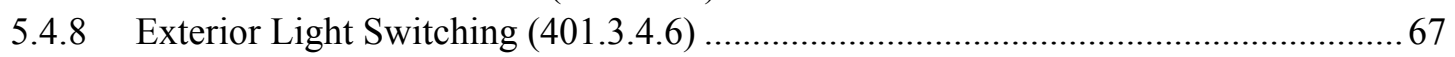

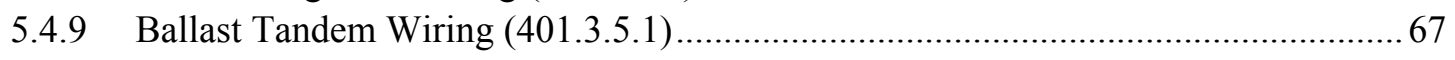

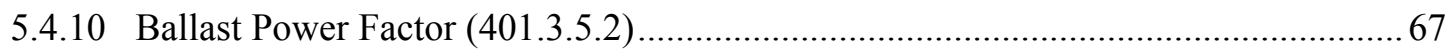

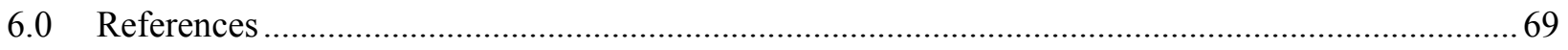

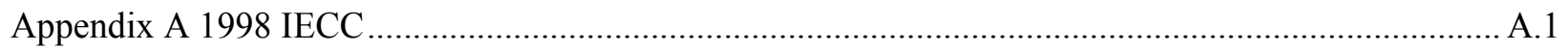




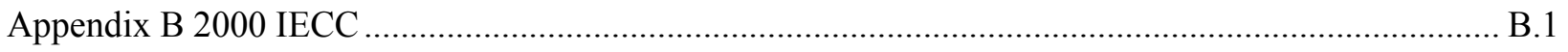

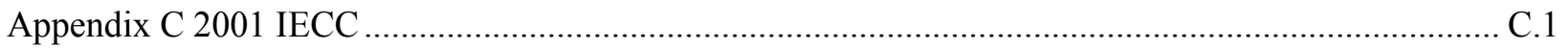

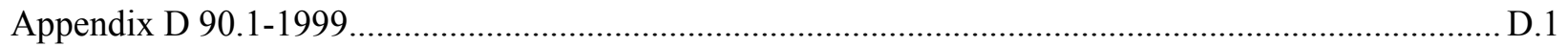

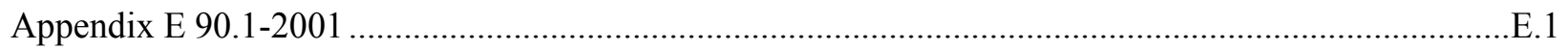

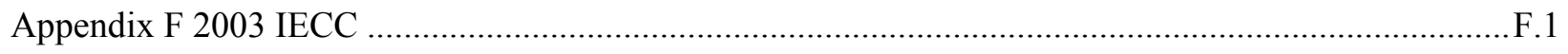

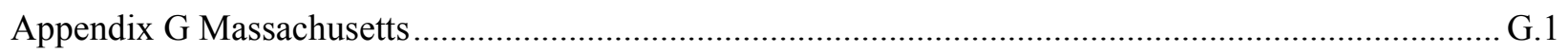

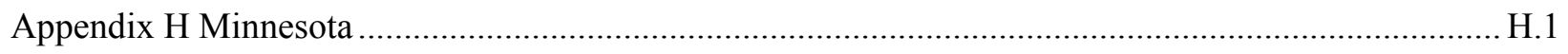

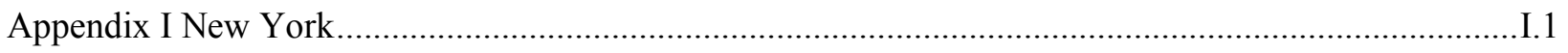

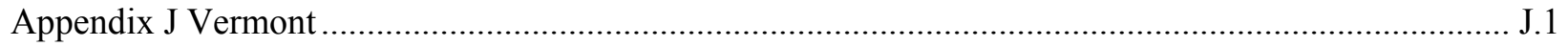

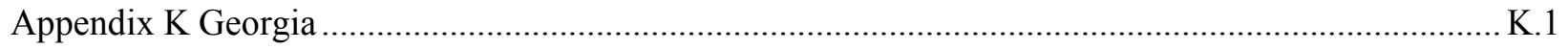

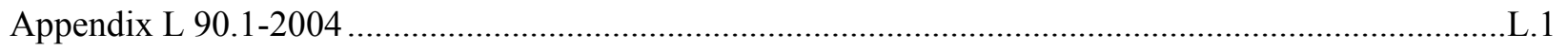

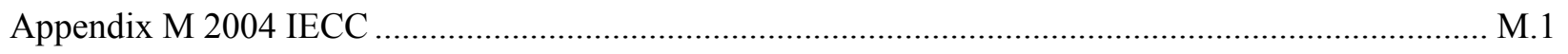

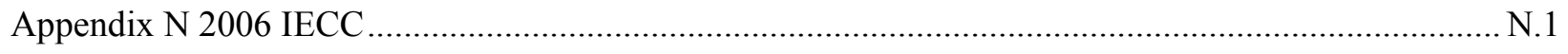

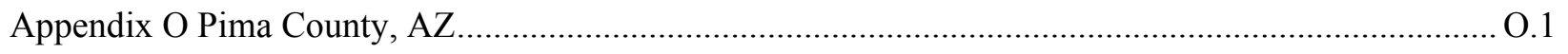




\section{Tables}

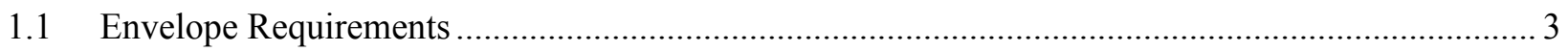

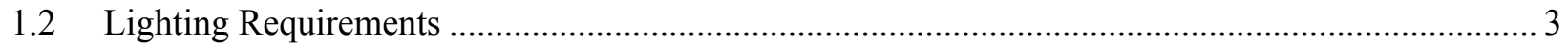

1.3 Relationship Between 90.1-1989 Code HVAC Requirements and COMcheck-EZ ......................... 4

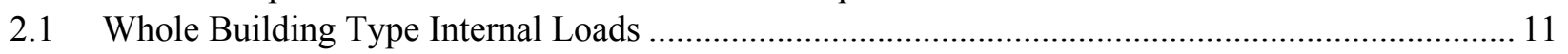

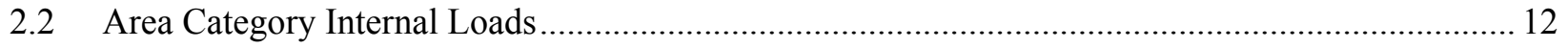

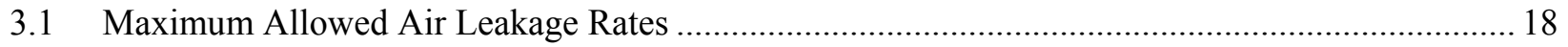

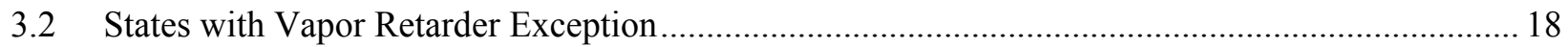

3.3 Balance of Assembly R-values for All-Wood Joist Roof........................................................... 20

3.4 Metal Building Roof (MBR) Assembly U-factors for Standard Insulation Thicknesses ................ 21

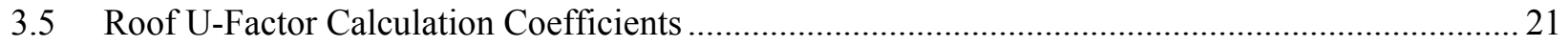

3.6 Balance of Assembly R-Values for Wood-Frame Walls .......................................................... 24

3.7 Balance of Assembly R-values for Steel Frame Walls ................................................................. 25

3.8 Balance of Assembly R-values for Above-Grade Masonry Walls ................................................2. 25

3.9 Metal Building Wall (MBW) Assembly U-factors for Standard Insulation Thicknesses ...............26

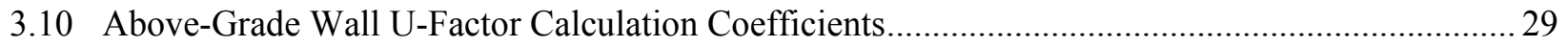

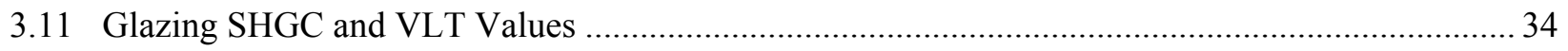

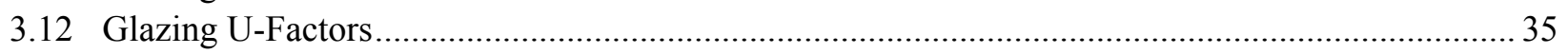

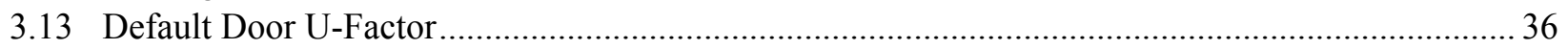

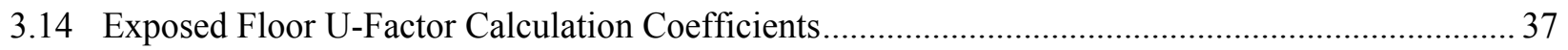

3.15 Assembly F-Factors for Slab-on-Grade Floors for Proposed Design ............................................ 39

3.16 Assembly F-Factors for Calculating Budget Loads for Slab-on-Grade Floors............................... 39

3.17 Balance of Assembly R-values for Below-Grade Walls........................................................... 41

3.18 Below-Grade Wall U-Factor Calculation Coefficients ............................................................... 43

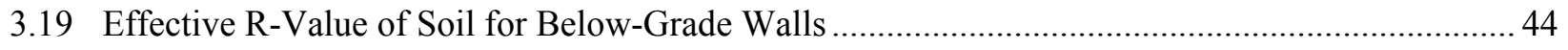

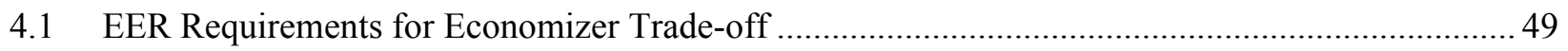





\subsection{Introduction}

\subsection{About This Report}

This technical support document (TSD) is designed to explain the technical basis for the COMcheck (formerly known as COMcheck-EZ) software as originally developed based on the ANSI/ASHRAE/IES Standard 90.1-1989 (Standard 90.1-1989). Documentation for other national model codes and standards and specific state energy codes supported in COMcheck have been added to this report as appendices. These appendices are intended to provide technical documentation for features specific to the supported codes and for any changes made for state-specific codes that differ from the standard features that support compliance with the national model codes and standards.

The primary objectives of this TSD are to identify where COMcheck differs from codes it supports and explain the technical basis and rationale for those differences. The primary intended audience for this report includes groups and individuals considering whether to adopt or approve technical provisions of codes supported by COMcheck or to accept use of the COMcheck software or submissions based on them. Other interested parties directly impacted by these codes or who require a detailed technical understanding of the COMcheck software may also have interest in this document. This document is not intended for use by the direct end-users of the COMcheck software; the Software User's Guide and help information are intended to offer sufficient explanation.

This report is a working document that will be revised and extended in the future as necessary to provide the appropriate level of technical detail required by readers.

\subsection{About COMcheck}

COMcheck provides an optional way to demonstrate compliance with commercial and high-rise residential building energy codes. Commercial buildings include all use groups except single family and multifamily not over three stories in height. COMcheck was originally based on ANSI/ASHRAE/IES Standard 90.1-1989 (Standard 90.1-1989) requirements and is intended for use with various codes based on Standard 90.1, including the Codification of ASHRAE/IES Standard 90.1-1989 (90.1-1989 Code) (ASHRAE 1989a, 1993b) and ASHRAE/IESNA Standard 90.1-1999 (Standard 90.1-1999). This includes jurisdictions that have adopted the 90.1-1989 Code, Standard 90.1-1989, Standard 90.1-1999, or their own code based on one of these. We view Standard 90.1-1989 and the 90.1-1989 Code as having equivalent technical content and have used both as source documents in developing COMcheck.

In developing COMcheck, we attempted to err on the side of stringency to give adopting authorities confidence that when they accept designs developed using COMcheck, the designs can confidently be deemed to comply with the supported codes. However, had we originally been completely rigid in always erring on the side of stringency, the resulting materials would have been significantly more stringent than Standard 90.1-1989 and the 90.1-1989 Code because of the cumulative effects of many provisions. Instead, we used a less rigid approach aimed at equivalency and a reasonable confidence level that a building complying with COMcheck will also comply with the code.

The COMcheck software was developed for the U.S. Department of Energy (DOE) by Pacific Northwest National Laboratory (PNNL) (DOE 1997). These materials are intended to facilitate more effective implementation of commercial building energy code requirements by making it easy for designers and 
builders to determine and understand the requirements and for building departments to enforce the requirements through plan review and site inspections.

While the original version of COMcheck was designed to be used primarily with simple buildings, the enhancements incorporated since Version 2.0 remove previous building height and HVAC system type restrictions. The software is a self-contained tool that addresses building envelope, HVAC, service waterheating, and lighting system requirements. Each major system must comply on its own; trade-offs between major systems are not permitted, although they are permitted under the Standard 90.1 Building Energy Cost Budget Method or under the Total Building Performance section in the IECC editions. The envelope and lighting sections include short lists of mandatory requirements reflecting Standard 90.1 provisions applicable to all buildings, such areas as window and door infiltration and requirements for caulking and sealing. The mechanical section uses a software "wizard" approach to provide a short, customized list of requirements applicable to the systems identified by the user. The lighting portion of the software automatically calculates the lighting power budget for a building based on building use and enables the user to document the installed lighting by selecting equipment with suggested lamp/ballast wattages. Compliance forms similar to those used in the printed guides are generated by the software for submission with plans and specifications.

Like Standard 90.1, COMcheck materials offer two compliance options for addressing envelope requirements - prescriptive packages and the COMcheck software. The Envelope section of the software is analogous to ENVSTD (Crawley et al. 1989), and the prescriptive packages are analogous to Appendix A in the 90.1-1989 Code and the Alternative Component Package (ACP) tables in Standard 90.1-1989. The software and the prescriptive packages share a common technical basis, and the prescriptive packages are generated using a special version of the COMcheck software.

The COMcheck software incorporates the same equations as those in Attachment 8B of Standard 90.1 and are used in ENVSTD for wall and window trade-offs (Crawley et al. 1989). The ENVSTD program enables Standard 90.1 users to only make trade-offs between above-grade wall and window components. Trade-offs allow the use of components exceeding minimum criteria to be used to offset components that fall below minimum criteria. COMcheck extends the Standard 90.1 trade-offs beyond those that are conveniently available when using Standard 90.1 directly. These trade-offs are clearly consistent with the intent of Standard 90.1 because the principle of unlimited trade-offs based on equivalent energy use is sanctioned under Section 13, Energy Cost Budget (ECB) Method in Standard 90.1-1989. As in Standard 90.1-1989, the basis for the trade-offs is equivalent cumulative annual space-conditioning (i.e., heating plus cooling) coil loads. Specific areas where new trade-offs have been added include

- roofs

- skylights

- interior walls
- below-grade walls

- floors

- slab edges.

Under Standard 90.1, these trade-offs are available only if you use the ECB Method. COMcheck makes these trade-offs available to anyone using the compliance software.

The impact of allowing trade-offs with additional building envelope components is that designs violating some of the Standard 90.1 prescriptive requirements (e.g., for roofs, below-grade walls, or slabs) may now comply if other envelope requirements are exceeded. To assist in code enforcement, the COMcheck Envelope Compliance Certificate lists the features used in the design and on which the determination of compliance is based. 


\subsubsection{Source of COMcheck Criteria}

The major sources for COMcheck criteria were the 90.1-1989 Code and Standard 90.1-1989. Tables 1.1 and $1.2 \& 1.3$ correlate code sections with sections in this TSD. A secondary but important source of technical content for COMcheck was the envelope trade-off equations from BSR/ASHRAE/IESNA Standard 90.1-1989R (Standard 90.1-1989R), First Public Review Draft. Section 3.2.1 explains in greater detail the rationale for using these equations.

The mechanical section contains a trade-off of economizer requirements for more efficient equipment. It allows a designer to substitute a high efficiency air-conditioner for an economizer. The basis for this trade-off was analytical work done at PNNL in support of Standard 90.1-1989R. This provision offers additional flexibility in specific climates where equivalent efficiency from the trade-off could be ensured.

The lighting section was substantially simplified from Standard 90.1 using an approach that mirrored work done in the development of California's Title 24 and Standard 90.1-1989R. Manual switching requirements were simplified and whole building types and area categories and power budgets were selected. Because the Standard 90.1-1989R work was still in draft version, the Title 24 categories were chosen for COMcheck. These categories were well defined and were reasonably comprehensive.

Table 1.1. Envelope Requirements

\begin{tabular}{|c|c|c|}
\hline \multicolumn{3}{|c|}{ 90.1-1989 Code Requirement } \\
\hline 90.1 Section No. & Section Topic & Section Reference in TSD \\
\hline \multicolumn{3}{|l|}{ Envelope Requirements } \\
\hline 402.1 & Calculations and Supporting Information & 3.2 .1 \\
\hline 402.2 .1 & Air Leakage for Fenestration and Doors & 3.2 .2 \\
\hline 402.2 .2 & Exterior Envelope Joints & 3.2 .3 \\
\hline 402.2 .3 & Moisture Migration & 3.2 .4 \\
\hline 402.3 & Thermal Performance Criteria & 3.3 \\
\hline 402.3 .1 & Roof Thermal Performance & 3.4 .3 \\
\hline 402.3 .1 & Floor Thermal Performance & 3.10 .3 \\
\hline 402.3 .1 & Wall Adj. to Uncond. Space Thermal Performance & 3.7 .2 \\
\hline 402.3 .1 & Skylight Thermal Performance & 3.5 .2 \\
\hline 402.3 .2 & Below-Grade Wall Thermal Performance & 3.12 .4 \\
\hline 402.3 .2 & Slab-on-Grade Thermal Performance & 3.11 .2 \\
\hline 402.4 & Wall Thermal Performance & 3.6 .5 \\
\hline 402.4 & Door Thermal Performance & 3.9 .2 \\
\hline 402.4 & Window Thermal Performance & 3.8 .5 \\
\hline
\end{tabular}

Table 1.2. Lighting Requirements

\begin{tabular}{|c|c|c|c|}
\hline \multicolumn{2}{|c|}{ 90.1-1989 Code Requirement } & \multicolumn{2}{|c|}{ COMcheck/IECC Requirement } \\
\hline 90.1 Section No. & Section Topic & How Requirement is Addressed & Section Reference in TSD \\
\hline \multicolumn{4}{|c|}{ Lighting Requirements } \\
\hline 401.1 .1 & Check Metering Provisions & None-no requirement in 90.1 & 5.4 .1 \\
\hline 401.1 .2 & Electrical Schematic & None-included in building code & 5.4 .2 \\
\hline 401.2 .1 & Motor Efficiency & None--motors covered by '92 EPAct ${ }^{(\mathrm{a})}$ legislation & 5.4 .3 \\
\hline 401.3 .1 & Building Exteriors & Use permitted lighting source types & 5.4 .4 \\
\hline 401.3 .2 & Building Interiors & Use COMcheck-EZ software or lighting worksheet & 5.1 \\
\hline 401.3 .3 & Lighting Control Credits & None--control credits eliminated & 5.1 .1 \\
\hline 401.3.4.2 & Manual Controls & Meet minimum mandatory control requirements & 5.4 .5 \\
\hline 401.3 .4 .4 & Control Accessibility & Provide readily accessible controls & 5.4 .6 \\
\hline 401.3 .4 .5 & Hotel/Motel Guest Rooms & Provide master switch at entry & 5.4 .7 \\
\hline 401.3.4.6 & Exterior-Light Switching & Use timer, photoelectric, or 7-day seasonal control & 5.4 .8 \\
\hline 401.3 .5 .1 & Tandem Wiring & Tandem wire 1- and 3-lamp fixtures & 5.4 .9 \\
\hline 401.3 .5 .2 & Power Factor & None & 5.4 .10 \\
\hline
\end{tabular}




\subsection{Relationship Between the 90.1-1989 Code and COMcheck}

The following tables provide an overview of how the requirements in the 90.1-1989 Code relate to requirements in COMcheck. Tables 1.1 and 1.2 address building envelope, lighting, and service water heating requirements, while Table 1.3 addresses HVAC requirements. The tables also serve as an index to the more detailed explanations found in this TSD.

The organization of Table 1.1 and some conventions used in it are explained below.

1. Column 1 contains section references to the 90.1-1989 Code.

2. Column 2 lists the topics addressed in the 90.1-1989 Code section.

3. Column 3 contains a summary of how the 90.1-1989 Code requirements are addressed in the COMcheck materials. Where entire lines appear shaded, the requirements have been omitted from the COMcheck materials, usually because the requirements are not applicable given the scope of COMcheck or because other factors ensure that the requirements will be met.

4. Column 4 identifies the section numbers in this TSD where the explanations of the technical basis for the change or interpretations of the code requirement begin. Where three dashes (---) appear, the requirement is not addressed further in this documentation because the rationale is self-evident or because the reason is fully explained in column 3 .

Table 1.3 is similar to Table 1.1 but adds two new columns containing check boxes, which indicate whether or not the topic is addressed in the Simple Systems and/or the Complex Systems section of the IECC and COMcheck Version 2.0 Mechanical Guide.

Table 1.3. Relationship Between 90.1-1989 Code HVAC Requirements and COMcheck

\begin{tabular}{|l|l|l|c|}
\hline \multicolumn{1}{|c|}{ 90.1-1989 Code Requirement } & \multicolumn{2}{c|}{ COMcheck/IECC Requirement } \\
$\begin{array}{l}\text { 90.1-1989 } \\
\text { Code Section } \\
\text { Number }\end{array}$ & \multicolumn{1}{|c|}{ Section Topic } & \multicolumn{1}{c|}{ How Requirement is Addressed } & $\begin{array}{c}\text { Section } \\
\text { Reference in } \\
\text { TSD }\end{array}$ \\
\hline \multicolumn{2}{|c|}{ HVAC Requirements } \\
\hline 403.1 & Mechanical Equipment Efficiency & $\begin{array}{l}\text { DOE covered equipment must be new. All other } \\
\text { equipment must meet efficiencies in tables. }\end{array}$ & 4.1 .2 \\
\hline 403.2 .1 & Load Calculations & Per ASHRAE Fundamentals or equivalent. & 4.1 .4 \\
\hline 403.2 .2 & Equipment and System Sizing & $\begin{array}{l}\text { No larger than loads calculated according to 703.2.1 or } \\
703.3 .1\end{array}$ & 4.1 .5 \\
\hline $\begin{array}{l}403.2 .2 \\
\text { Exception 1 }\end{array}$ & $\begin{array}{l}\text { Exception for Combination } \\
\text { Equipment }\end{array}$ & Similar to 90.1-1989 Code & --- \\
\hline $\begin{array}{l}403.2 .2 \\
\text { Exception 2 }\end{array}$ & Standby Equipment & Similar to 90.1-1989 Code & --- \\
\hline $\begin{array}{l}403.2 .2 \\
\text { Exception 3 }\end{array}$ & Multiple Staged Units & Similar to 90.1-1989 Code & --- \\
\hline 403.2 .3 & Separate Air Distribution & None & 4.1 .6 \\
\hline 403.2 .4 & $\begin{array}{l}\text { Ventilation } \\
\text { Fan Power }\end{array}$ & $\begin{array}{l}\text { Capability to operate at minimum ventilation rate } \\
\text { required by IMC Chapter 4. Fan control requirements } \\
\text { over 25 hp in place of fan power limitations. }\end{array}$ & 4.1 .7 \\
\hline 403.2 .5 & Pumping System Design & $\begin{array}{l}\text { Combined with 403.2.6.8 - reset requirements. Systems } \\
\text { must have reset, staged pumps, variable flow pumps, or } \\
\text { throttling control system. }\end{array}$ & 4.1 .8 \\
\hline
\end{tabular}


Table 1.3. (contd)

\begin{tabular}{|c|c|c|c|}
\hline \multicolumn{2}{|c|}{ 90.1-1989 Code Requirement } & \multicolumn{2}{|l|}{ COMcheck/IECC Requirement } \\
\hline $\begin{array}{c}\begin{array}{l}90.1-1989 \\
\text { Code Section } \\
\text { Number }\end{array} \\
\end{array}$ & Section Topic & How Requirement is Addressed & $\begin{array}{l}\text { Section } \\
\text { Reference } \\
\text { in TSD } \\
\end{array}$ \\
\hline 403.2 .6 .1 & System Controls & $\begin{array}{l}\text { Provide one temperature control per simple system. } \\
\text { Provide one temperature control per complex system zone. }\end{array}$ & 4.1 .9 \\
\hline 403.2 .6 .2 & Zone Controls & $\begin{array}{l}\text { Solid-state programmable per simple system. Automatic } \\
\text { temperature and time control per complex system zone. }\end{array}$ & 4.1 .10 \\
\hline 403.2 .6 .3 & Zone Thermostat Capability & $\begin{array}{l}\text { Automatic temperature and time control per complex } \\
\text { system zone. }\end{array}$ & 4.1 .11 \\
\hline 403.2.6.4 & Heat Pump Thermostat & Heat pump thermostat required with heat pumps & 4.1 .12 \\
\hline 403.2 .6 .5 & Humidistats & $\begin{array}{l}\text { Any system with humidification must have at least one } \\
\text { humidity control device. }\end{array}$ & 4.1 .13 \\
\hline 403.2 .6 .6 & Simultaneous Heating/Cooling & $\begin{array}{l}\text { Not allowed in simple systems. Complex systems must use } \\
\text { VAV multi-zone systems, or must sequence heating/cooling } \\
\text { to every zone }\end{array}$ & 4.1 .14 \\
\hline $\begin{array}{l}403.2 .6 .6 \\
\text { Exception } 1\end{array}$ & Variable Air Volume Systems & Not used - VAV is now required for all multi-zone systems & 4.1 .7 \\
\hline $\begin{array}{l}403.2 .6 .6 \\
\text { Exception } 2\end{array}$ & Special Pressurization Relationships & Included & --- \\
\hline $\begin{array}{l}403.2 .6 .6 \\
\text { Exception } 3\end{array}$ & $\begin{array}{l}\text { Reheat from Renewable/Recovered } \\
\text { Sources }\end{array}$ & Included & --- \\
\hline $\begin{array}{l}403.2 .6 .6 \\
\text { Exception } 4\end{array}$ & Special Humidity Requirements & Included & --- \\
\hline 403.2 .6 .6 & Zones $\leq 300 \mathrm{cfm}$ & Included & --- \\
\hline none & Minimum Ventilation Required & $\begin{array}{l}\text { New exception for zones where air flow is dictated by } \\
\text { minimum ventilation requirements. }\end{array}$ & 4.1 .7 \\
\hline none & $\begin{array}{l}\text { Systems that Sequence Heating and } \\
\text { Cooling }\end{array}$ & $\begin{array}{l}\text { Multi-zone systems that sequence supply of heating and } \\
\text { cooling to a zone don't need to be VAV }\end{array}$ & 4.1 .14 \\
\hline none & VAV Terminal Device Requirements & $\begin{array}{l}\text { Specific sequencing requirements for VAV and mixing } \\
\text { boxes }\end{array}$ & 4.1 .7 \\
\hline 403.2.6.7 & Temp. Reset - Air Systems & Included & --- \\
\hline 403.2.6.8 & Temp. Reset - Hydronic Syst. & See 90.1-1989 Code Section 403.2.5 & --- \\
\hline 403.2.7.1 & Automatic Setback/Shutdown & $\begin{array}{l}\text { Use setback/setup thermostats for simple systems. Use } \\
\text { setback/setup thermostats or automatic control system for } \\
\text { complex system zones. }\end{array}$ & 4.1 .15 \\
\hline \multicolumn{4}{|c|}{ HVAC Requirements } \\
\hline 403.2 .7 .2 & Shutoff Dampers & Use shutoff dampers systems with $>3000 \mathrm{cfm}$ & 4.1 .16 \\
\hline 403.2 .7 .3 & Zone Isolation & $\begin{array}{l}\text { None for simple systems - not applicable to single-zone } \\
\text { systems. Complex systems must have zone level automatic } \\
\text { controls. }\end{array}$ & 4.1 .17 \\
\hline 403.2 .8 & Economizer Controls & $\begin{array}{l}\text { Integrated air economizers required }>90 \mathrm{kBtu} / \mathrm{h} \text { or } 3000 \mathrm{cfm} \\
\text { except in Zones } 1,2 \text { and } 3 \mathrm{~b}\end{array}$ & 4.1 .19 \\
\hline 403.2 .8 & Water Economizer & $\begin{array}{l}\text { Allowed in place of air economizer on all complex systems. } \\
\text { Required on three-duct systems and single-fan dual-duct } \\
\text { systems. }\end{array}$ & 4.2 .18 \\
\hline none & \begin{tabular}{|l|} 
Exception for High Efficiency \\
Package Direct Expansion Cooling
\end{tabular} & Minimum efficiency varies by capacity and climate zone & 4.1 .3 \\
\hline $\begin{array}{l}403.2 .8 \\
\text { Exception } 1\end{array}$ & $\begin{array}{l}\text { Exception for Small, Fan-Cooling } \\
\text { Systems }\end{array}$ & Included in main code language instead of exception & 4.1 .18 \\
\hline $\begin{array}{l}403.2 .8 \\
\text { Exception } 2\end{array}$ & $\begin{array}{l}\text { Exception for Systems Requiring } \\
\text { Extensive Filtration }\end{array}$ & $\begin{array}{l}\text { Included, references Section } 403.3 \text { of International } \\
\text { Mechanical Code }\end{array}$ & 4.1 .18 \\
\hline $\begin{array}{l}403.2 .8 \\
\text { Exception } 3\end{array}$ & $\begin{array}{l}\text { Exception for Systems Where } \\
\text { Economizer Would Increase Energy } \\
\text { Use }\end{array}$ & Included, only allowed for open case refrigeration & 4.1 .18 \\
\hline $\begin{array}{l}403.2 .8 \\
\text { Exception } 4\end{array}$ & $\begin{array}{l}\text { Exception for Envelope- Dominated } \\
\text { Spaces }\end{array}$ & $\begin{array}{l}\text { Not included - Requires previous knowledge of the use of } \\
\text { the space, which is only required to be submitted for ECB } \\
\text { compliance }\end{array}$ & --- \\
\hline 403.2 .8 & Exception for Residential Spaces and & Not included $-90,000 \mathrm{Btu} / \mathrm{h}$ is usually adequate for these & --- \\
\hline
\end{tabular}


Table 1.3. (contd)

\begin{tabular}{|c|c|c|c|}
\hline \multicolumn{2}{|c|}{ 90.1-1989 Code Requirement } & \multicolumn{2}{|l|}{ COMcheck/IECC Requirement } \\
\hline $\begin{array}{c}90.1-1989 \\
\text { Code Section } \\
\text { Number }\end{array}$ & Section Topic & How Requirement is Addressed & $\begin{array}{c}\text { Section } \\
\text { Reference } \\
\text { in TSD }\end{array}$ \\
\hline Exception 5 & Hotel Rooms & 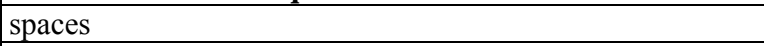 & \\
\hline $\begin{array}{l}403.2 .8 \\
\text { Exception } 6\end{array}$ & $\begin{array}{l}\text { Exception for Cooling from Site- } \\
\text { Recovered Energy }\end{array}$ & Not included - application is rare & --- \\
\hline $\begin{array}{l}403.2 .8 \\
\text { Exception } 7\end{array}$ & Exception for Operable Openings & Not included & --- \\
\hline 403.2 .9 .1 & Pipe Insulation & Table simplified to six entries with minimum k of 0.27 & 4.1 .20 \\
\hline 403.2 .9 .2 & Duct/Plenum Insulation & Insulate ducts and plenums & 4.1 .21 \\
\hline 403.2 .9 .3 & Duct/Plenum Construction & Meet IMC & 4.1 .22 \\
\hline 403.2 .10 & Administration & $\begin{array}{l}\text { Standard 90.1-1989R manual requirements, hydronic and } \\
\text { air balancing provisions }\end{array}$ & 4.1 .23 \\
\hline \multicolumn{4}{|c|}{ Service Water-Heating (SWH) Requirements } \\
\hline 404.1 & SWH Equipment Efficiency & Available new equipment meets requirements & 4.2 .1 \\
\hline 404.1 .1 & Electric/Oil Standby Loss & Meet standby loss criteria & 4.2 .2 \\
\hline 404.1 .2 & Unfired Storage Tanks & Meet standby loss criteria & 4.2 .3 \\
\hline 404.1 .3 & Storage Volume & Meet standby loss criteria & 4.2 .4 \\
\hline 404.2 & Piping Insulation & Piping insulation and heat traps required & 4.2 .5 \\
\hline 404.3 & Controls & Controls integrated within available products & 4.2 .6 \\
\hline 404.4 & Water Conservation & Hot water per NAECA ${ }^{(a)}$ plus public lavatory requirements & 4.2 .7 \\
\hline 404.5 & Swimming Pools & Switching and pool cover requirements & 4.2 .8 \\
\hline 404.6 & Combined Heating Systems & Combined SWH/space htg. equip. out of scope & 4.2 .9 \\
\hline
\end{tabular}

\subsection{Facilitating the Implementation of Commercial Building Energy Codes}

This section provides an overview of the context that motivated the creation of the COMcheck compliance materials (and subsequent adoption of Chapter 7 of the 1998 IECC). Chapter 1 of the IECC (formerly the Model Energy Code [MEC]) was amended with the 1998 edition to authorize use of computer software - such as the COMcheck software (and other similar compliance materials if approved by the building official) - as meeting the intent of the IECC.

The goal of commercial building energy codes is to ensure the design and construction of more energyefficient buildings. Within current commercial energy codes, this goal is implemented through minimum requirements for building envelope, mechanical, plumbing, electrical, and lighting systems and equipment. If these minimum requirements cannot be readily understood and acted upon by code users, the code requirements cannot be successfully implemented.

Most current commercial building energy codes are based on Standard 90.1-1989, the 90.1-1989 Code, or Standard 90.1-1999. To comply, architects, engineers, and other designers must first read and interpret the applicable code and then decide how to apply the requirements to their clients' needs and relevant plans and specifications. Those who construct buildings must also be able to understand the code requirements to ensure energy savings from the new building. Legislative and regulatory affairs personnel must be able to satisfy the concerns of interested and affected parties to adopt an energy code. Code enforcement personnel, lenders, utility company personnel and building owners interested in code compliance must be able to understand the code requirements. While each of these parties has a different function in creating a new building, they all need to easily understand what is required by the code.

(a) National Appliance Energy Conservation Act of 1987 (NAECA, Public Law 100-12).

Technical Support Documentation for COMcheck Through Version 3.4.0 (Software) 
Building, mechanical, plumbing, electrical, accessibility, and fire code requirements also vie for limited resources. Compared to health and life safety, energy is not considered a critical code issue and is generally given a lower priority. Complexity and low priority generally result in marginally effective implementation. Implementation has not been a particular problem for those voluntarily striving to achieve energy efficiency, and a minority of practitioners exist who are highly motivated and well equipped to go far beyond the efficiency levels required by the code. However, most practitioners follow minimum codes for health and life safety and are hard pressed to find time to address energy issues, especially when the code is perceived as unduly complicated or their clients are not interested in the cost of operating the building. Simple guidelines and tools that address the common plea-"just tell me what you want me to do so I can get approval of the design"- help facilitate the use of energy codes, and in so doing, enhance implementation even when energy efficiency remains a low priority. COMcheck is intended to provide these simple guidelines and tools.

The COMcheck materials help various users implement the energy code requirements and achieve the goal of more energy-efficient buildings in a number of different ways.

Architects are keenly interested in the size, shape, function, and aesthetics of a building design. 90.1 provides numerous requirements for building envelope components based on climate, internal loads, shading, and other factors. Architects can use the COMcheck software, which is both more flexible and easier to use than alternative methods, to more easily integrate energy code considerations into the multifaceted design process. The software also standardizes and streamlines the process by which energy feature specification and supporting compliance documentation is generated for those who will review the plans, order materials, construct the building, and inspect construction.

Designers or Builders may perform various design-related activities for small commercial buildings where a licensed design professional is not required. Designers and builders can use COMcheck to quickly determine energy code requirements, acceptable strategies to meet these requirements, and materials to order. During construction, when field substitutions are frequently necessary because of material availability or cost considerations, COMcheck allows a quick assessment of the acceptability of different materials or components such as an alternate insulation material or glazing type.

Engineers must design HVAC, plumbing, electrical, and lighting systems to comply with a wide range of different requirements in addition to energy code requirements. COMcheck allows engineers to quickly determine pertinent code requirements and to readily select complying equipment and system components.

Manufacturers use minimum code requirements as the basis for some of their products and for comparing their products to others to promote better-performing products. Standardization of codes, code interpretations, and compliance materials is helpful to manufacturers in reducing the fragmentation of markets and simplifying product selection. COMcheck can help manufacturers identify minimum requirements to help develop minimally compliant products and strategies for highlighting the benefits of those products.

Distributors can use minimum code requirements as a basis for determining the materials, systems, and equipment they should stock. Distributors also provide code guidance to builders and contractors as part of their marketing initiatives and product selection support. By making it easier to prescriptively determine which materials and products will meet or exceed the code requirements, 
COMcheck helps distributors get new business and ensure they carry the products necessary for energy code compliance.

Building Owners and Lenders are interested in their investment but may not readily comprehend the importance of energy efficiency or be capable of assessing the energy attributes of proposed designs. By making energy code compliance easier to understand, COMcheck can increase the awareness of financial institutions regarding their stake in cost-effective energy efficiency and facilitate the participation of lenders in decisions affecting the design and construction of energyefficient buildings.

Code Adopters (e.g., regulatory agencies and legislative staff) face conflicting mandates to encourage higher levels of building energy efficiency and to respond to the needs of their constituents and interested and affected parties. For example, one of the most commonly cited reasons for not adopting the Standard 90.1 has been complexity. By stating the requirements in a simpler manner and providing a clear path for effective implementation, COMcheck may make it easier for state and local jurisdictions to adopt commercial building energy codes based on 90.1-1989 code.

Code Enforcement Officials typically have too little time to adequately address energy issues either during plan review or construction inspections. The perceived complexity of the codes and standards and the time required to check calculations and conduct effective design review are key reasons why some codes have not been overwhelmingly implemented. Without guidance from the plan review process, field inspection activities cannot address energy issues. Even when inspectors are highly motivated, the complexity of the codes and lack of compliance materials oriented toward inspection make it difficult to conduct any type of compliance assessment in the field. The COMcheck materials have been developed with code enforcement officials as a primary audience. The compliance certificates and requirements checklists focus on areas where effective code enforcement can make a real difference in achieving energy-efficient buildings. 


\subsection{Building Use Types}

\subsection{Combined Building Use Types}

In COMcheck, internal loads and lighting power allowances are based on the user's designation of the building use. COMcheck Version 1.0 required separate designations of building use to establish internal gains for envelope compliance and to determine the lighting power allowance for lighting compliance. In COMcheck Version 2.0, building use types are entered once, rather than separately for envelope and lighting. Users may enter building use types as either whole building types or area categories.

To enable users to enter building use types in one step, it was necessary to associate all occupancy-related descriptors (e.g., receptacle loads and occupancy densities) with the same building use types as are used for lighting and to add minor extensions to cover uses that are exempt from lighting power density (LPD) requirements, such as multifamily residential living units. Three of the whole building types, Assembly, Hotel/Motel, and Multifamily, do not correspond to whole building lighting categories. These whole building types cannot be used for lighting compliance, either because the whole building type contains too much variability (Assembly) or because the predominant spaces are exempt from lighting power budgets (Hotel/Motel and Multifamily). If lighting compliance is required for these whole building types, the Area Category method must be used.

\subsection{Source of Building Use Types}

Like the 90.1-1989 Code, Standard 90.1-1989, and Standard 90.1-1999, COMcheck and the IECC use a two-tiered approach for controlling lighting power based on whole building types or area categories. The COMcheck building use types were chosen as representative of common building types for which the COMcheck compliance method would likely be used. The lighting building use types were adapted from the California Code of Regulations (CCR 1995). These categories originally took effect in July 1992 and had extensive testing and review by designers and code officials throughout the state of California. The results of the testing and review show that these categories accurately reflect a substantial cross section of building uses and are appropriate for use in determining allowed lighting power levels.

The 2000 IECC uses the same whole building types and area categories as the 90.1-1989 Code, except two new whole buildings types and three new area categories were added. These were later also added to the 90.1-1989 Code version of COMcheck to make it comprehensive and consistent with the 2000 IECC:

Whole Building Types

- Museum

- Religious worship

Area Categories

- Gymnasium playing surface

- Museum

- Restaurant 


\subsection{Internal Loads}

Tables 2.1 and 2.2 contain the internal-load assumptions that are used by the envelope engine in the calculation of heating and cooling loads for walls and windows in the software. Table 2.1 contains the data for whole building types, and Table 2.2 contains the data used for area category. Lighting budgets are based on the lighting power density for the designated building use type and are independent of values for the proposed design.

The equipment values in Table 2.1 were derived from Table 8-4 in Standard 90.1-1989, wherever Table 8-4 provided a good correspondence with the building use types. For building use types that did not align well with those in Table 8-4, values were drawn from the ECB Compliance Supplement to Standard 90.1-1989R, Table 7.1 (ASHRAE 1996). Occupant-sensible loads were based on occupant density assumptions from Table 13-2 in Standard 90.1-1989 and Table 7.1 in the ECB Compliance Supplement. The occupant-sensible load assumption was $230 \mathrm{Btu} /$ person-h. A $0.6 \mathrm{~W} / \mathrm{ft}^{2}$ value for occupant loads is embedded in the calculation, as is documented in Standard 90.1-1989, Section 8.5.5.2. The Total columns in Tables 2.1 and 2.2 show the total internal-load value, and not the adjusted value used in the calculation after subtraction of the $0.6 \mathrm{~W} / \mathrm{ft}^{2}$ average-occupancy value.

The impact of fixing internal loads at an average value for all commercial building types was evaluated. That option was rejected for the COMcheck software because it would have significantly undermined stringency for high-internal-load buildings and increased stringency for low-internal-load buildings. In the COMcheck prescriptive packages, it was necessary to fix internal loads at a single level to limit the number of requirement sets. The values in bold in the bottom line of Table 2.1 are for use in generating values for the COMcheck prescriptive packages (except for the low window-to-wall ratio category used extensively with warehouse). The values represent an average shaded toward the high side to maintain stringency.

\subsection{Lighting Power Budgets}

Lighting power budgets (also referred to as lighting power allowances) are derived from the lighting power density (LPD) values corresponding to each whole building type and area category in COMcheck. The Data Source columns in Tables 2.1 and 2.2 document how the LPDs in COMcheck were derived from Table 401.3.2 in the 90.1-1989 Code. Whole building type LPDs were derived under the assumption of buildings with gross lighted areas of 10,000 to $25,000 \mathrm{ft}^{2}$, reflecting the types of buildings for which the COMcheck materials were initially targeted. ASHRAE's Standing Standard Project Committee (SSPC) Standard 90.1 has abandoned the approach of basing power allowances on building size, and there does not appear to be a problem with applying these LPDs to buildings of any size.

One notable departure in scope from the lighting power budget requirements in the 90.1-1989 Code involves hotel guest rooms. Under the area category compliance method in the 90.1-1989 Code, hotel guest rooms are included as a specific area category. In COMcheck and the IECC, the category has been omitted for lighting compliance. The rationale for this is that the vast majority of lighting in hotel guest rooms is powered through receptacles and is not built in. Therefore, most lighting does not show up on building plans and specifications and is not subject to inspection. Because the LPD for hotel guest rooms clearly anticipates receptacle-based lighting equipment that is outside the scope of the building code, including guest room lighting in the calculation of lighting power budgets has the effect of inflating

Technical Support Documentation for COMcheck Through Version 3.4.0 (Software) 
Table 2.1. Whole Building Type Internal Loads

\begin{tabular}{|c|c|c|c|c|c|}
\hline $\begin{array}{c}\text { Whole } \\
\text { Building Type }\end{array}$ & $\begin{array}{c}\text { Lighting } \\
\left(\mathbf{W} / \mathrm{ft}^{2}\right)\end{array}$ & $\begin{array}{l}\text { Equip. } \\
\left(\mathbf{W} / \mathbf{f t}^{2}\right)\end{array}$ & $\begin{array}{l}\text { Occup. } \\
\left(\mathbf{W} / \mathbf{f t}^{2}\right)\end{array}$ & $\begin{array}{l}\text { Total }^{(\mathbf{a})} \\
\left(\mathbf{W} / \mathbf{f t}^{2}\right)\end{array}$ & Data Source for Lighting LPD \\
\hline Assembly & $2.07^{(\mathrm{c})}$ & 0.25 & 1.35 & 3.67 & \\
\hline Exercise Center & 0.90 & 0.25 & 0.22 & 1.37 & $\begin{array}{l}\text { This value was generated using space usage percentages for two } \\
\text { different exercise centers and the corresponding activity area power } \\
\text { allowances found in Table 401.3.2 in the 90.1-1989 Code. }\end{array}$ \\
\hline Grocery Store & 2.80 & 0.25 & 0.22 & 3.27 & $\begin{array}{l}\text { Unit Interior Lighting Power Allowance table, Specific Building } \\
\text { Area/Activity section, Retail establishments - Type } 5 \text { (Table 401.3.2c in } \\
\text { the 90.1-1989 Code) }\end{array}$ \\
\hline Hotel/Motel & $1.15^{(\mathrm{c})}$ & 0.25 & 0.27 & 1.67 & \\
\hline Library & 1.30 & 0.75 & 0.25 & 2.30 & $\begin{array}{l}\text { This value was generated using space usage percentages for two } \\
\text { different libraries and the corresponding activity area power allowances } \\
\text { found in Table } 401.3 .2 \text { in the } 90.1-1989 \text { Code. }\end{array}$ \\
\hline $\begin{array}{l}\text { Medical and } \\
\text { Clinical Care }\end{array}$ & 1.80 & 1.00 & 0.34 & 3.14 & $\begin{array}{l}\text { Unit Interior Lighting Power Allowance table, Specific Building } \\
\text { Area/Activity, Hospital/Nursing Home (Table 401.3.2c in the 90.1-1989 } \\
\text { Code) Equal weighting to the following categories: } \\
\text { Corridor } 1.3 \\
\text { Dental Suite/Examination/Treatment } 1.6 \\
\text { Emergency } 2.3 \\
\text { Laboratory } 1.9 \\
\text { Lounge/Waiting Room } 0.9 \\
\text { Medical Supplies } 2.4 \\
\text { Nurse Station } 2.1 \\
\text { Occupational Therapy/Physical Therapy } 1.6 \\
\text { Pharmacy } 1.7 \\
\text { Radiology } 2.1 \\
\text { Surgical and OB Suites: General Area } 2.1 \\
\text { Surgical and OB Suites: Recovery } 2.3 \\
\text { Average = 1.858 }\end{array}$ \\
\hline Multifamily & $1.15^{(\mathrm{c})}$ & 0.25 & 0.27 & 1.67 & \\
\hline Museum & 1.7 & 0.25 & 1.35 & 3.30 & $\begin{array}{l}\text { Added for consistency with the } 2000 \text { IECC; (internal gains assumed to } \\
\text { be same as Assembly and Theaters). }\end{array}$ \\
\hline Office & 1.70 & 0.75 & 0.25 & 2.70 & $\begin{array}{l}\text { Interior Lighting Power Allowance table, Office Type } 10 \text { to } 25 \text { thousand } \\
\text { square foot value (Table 401.3.2a in the } 90.1-1989 \text { Code) }\end{array}$ \\
\hline Restaurant & 1.70 & 0.10 & 0.67 & 2.47 & $\begin{array}{l}\text { Interior Lighting Power Allowance table, Food Service: Leisure } \\
\text { Dining/Bar } 10 \text { to } 25 \text { thousand square foot value (Table 401.3.2a in the } \\
90.1-1989 \text { Code) }\end{array}$ \\
\hline $\begin{array}{l}\text { Retails Sales, } \\
\text { Wholesale } \\
\text { Showrooms }\end{array}$ & 2.80 & 0.25 & 0.22 & 3.27 & $\begin{array}{l}\text { Interior Lighting Power Allowance table, Retail Type } 10 \text { to } 25 \text { thousand } \\
\text { square foot value (Table 401.3.2a in the 90.1-1989 Code) }\end{array}$ \\
\hline Religious Worship & 2.2 & 0.10 & 1.35 & 3.65 & Added for consistency with the 2000 IECC. \\
\hline School & 1.90 & 0.50 & 0.90 & 3.30 & $\begin{array}{l}\text { Interior Lighting Power Allowance table, Schools Type } 10 \text { to } 25 \\
\text { thousand square foot range, Jr. High/High School - middle value (Table } \\
\text { 401.3.2a in the } 90.1-1989 \text { Code) }\end{array}$ \\
\hline $\begin{array}{l}\text { Industrial and } \\
\text { Commercial } \\
\text { Storage }\end{array}$ & 0.60 & 0.10 & 0.00 & 0.70 & $\begin{array}{l}\text { Interior Lighting Power Allowance table, Warehouse/Storage } 10 \text { to } 25 \\
\text { thousand square foot value (Table 401.3.2a in the 90.1-1989 Code) }\end{array}$ \\
\hline $\begin{array}{l}\text { Theater-Motion } \\
\text { Picture }\end{array}$ & 1.10 & 0.25 & 1.35 & 2.70 & $\begin{array}{l}\text { This value was generated using space usage \%ages for four different } \\
\text { motion picture theaters and the corresponding activity area power } \\
\text { allowances found in Table 401.3.2 in the 90.1-1989 Code. }\end{array}$ \\
\hline $\begin{array}{l}\text { Theater - } \\
\text { Performance }\end{array}$ & 1.40 & 0.25 & 1.35 & 3.00 & $\begin{array}{l}\text { This value was generated using space usage \%ages for four different } \\
\text { performing arts theaters and the corresponding activity area power } \\
\text { allowances found in Table 401.3.2 in the 90.1-1989 Code. }\end{array}$ \\
\hline
\end{tabular}


Table 2.1. (contd.)

\begin{tabular}{|c|c|c|c|c|c|}
\hline $\begin{array}{c}\text { Whole Building } \\
\text { Type }\end{array}$ & $\begin{array}{c}\text { Lighting } \\
\left(\mathrm{W} / \mathrm{ft}^{2}\right)\end{array}$ & $\begin{array}{l}\text { Equip. } \\
\left(\mathbf{W} / \mathrm{ft}^{2}\right)\end{array}$ & $\begin{array}{l}\text { Occup. } \\
\left(\mathrm{W} / \mathrm{ft}^{2}\right)\end{array}$ & $\begin{array}{l}\text { Total } \\
(\mathbf{a}) \\
\left(\mathrm{W} / \mathbf{f t}^{2}\right)\end{array}$ & Data Source for Lighting LPD \\
\hline Others & $\begin{array}{c}0.60 / \\
1.60^{(\mathrm{b})}\end{array}$ & 0.40 & 0.60 & $2.60^{\mathrm{b}}$ & $\begin{array}{l}\text { The value of } 0.6 \text { was taken from the ' } 97 \text { California Title } 24 \text {, } \\
\text { Table 1-M for space type Others. The Unlisted Space category } \\
\text { value of } 0.2 \text { (Table } 401.3 .2 \mathrm{~b} \text { ) in the } 90.1-1989 \text { Code was judged } \\
\text { to be so limiting that it would preclude use of the condensed list } \\
\text { of space usage types in COMcheck by many users. The } 0.6 \\
\text { value was judged to be more reasonable than } 0.2 \text {, and its use was } \\
\text { felt to be warranted in the interest of making the materials easy } \\
\text { to use. }\end{array}$ \\
\hline $\begin{array}{l}\text { Average (for print } \\
\text { version) }\end{array}$ & 1.60 & 0.40 & 0.60 & 2.60 & \\
\hline $\begin{array}{l}\text { (a) The total is the sum } \\
\text { assumed } 0.6 \mathrm{~W} / \mathrm{ft}^{2} \\
\text { (b) The Others whole } \mathrm{l} \\
\text { (c) Assembly, Hotel/ } \mathrm{N}\end{array}$ & $\begin{array}{l}\text { ling type } \\
\text { l, and } \mathrm{M}\end{array}$ & $\begin{array}{l}\text { ises } 0.6 \\
\text { tifamily }\end{array}$ & $\begin{array}{l}\text { at, and oc } \\
\text { Crawle } \\
\text { wht } \mathrm{ft}^{2} \text { for } \\
\text { whole br }\end{array}$ & $\begin{array}{l}\text { cupants. } \\
\text { y et al. } 1 \text { } \\
\text { lighting } \\
\text { uilding ty }\end{array}$ & $\begin{array}{l}\text { The ENVSTD input is reduced by } 0.6 \mathrm{~W} / \mathrm{ft}^{2} \text {, to adjust for the } \\
\text { 989). } \\
\text { compliance, but } 1.6 \mathrm{~W} / \mathrm{ft}^{2} \text { for envelope compliance. } \\
\text { pes are provided for envelope compliance only. }\end{array}$ \\
\hline
\end{tabular}

Table 2.2. Area Category Internal Loads

\begin{tabular}{|c|c|c|c|c|c|}
\hline Area Category & \begin{tabular}{|c} 
Lighting \\
$\left(\mathrm{W} / \mathrm{ft}^{2}\right)$
\end{tabular} & $\begin{array}{l}\text { Equip. } \\
\left(\mathrm{W} / \mathrm{ft}^{2}\right)\end{array}$ & $\begin{array}{l}\text { Occup. } \\
\left(\mathrm{W} / \mathrm{ft}^{2}\right)\end{array}$ & $\begin{array}{l}\text { Total } \\
\left(\mathrm{W} / \mathrm{ft}^{2}\right)\end{array}$ & Data Source for Lighting LPD \\
\hline Auditorium & 1.60 & 0.25 & 1.35 & 3.20 & $\begin{array}{l}\text { Unit Interior Lighting Power Allowance table, Common } \\
\text { Area/Activity section, Auditorium (Table 401.3.2b in the 90.1- } \\
1989 \text { Code) }\end{array}$ \\
\hline $\begin{array}{l}\text { Bank/Financial } \\
\text { Institution }\end{array}$ & 2.00 & 0.75 & 0.25 & 3.00 & $\begin{array}{l}\text { Unit Interior Lighting Power Allowance table, Specific Building } \\
\text { Area/Activity section, Bank, equally-weighted combination of } \\
\text { Customer Area (1.1) and Banking Activity Area (2.8) (Table } \\
\text { 401.3.2c in the 90.1-1989 Code) }\end{array}$ \\
\hline Classroom/Lecture Hall & 2.00 & 0.50 & 0.90 & 3.40 & $\begin{array}{l}\text { Unit Interior Lighting Power Allowance table, Common } \\
\text { Area/Activity section, Classroom/Lecture Hall (Table } 401.3 .2 \mathrm{~b} \text { in } \\
\text { the } 90.1-1989 \text { Code) }\end{array}$ \\
\hline $\begin{array}{l}\text { Convention, Conference } \\
\text { or Meeting Center }\end{array}$ & 1.80 & 0.25 & 1.35 & 3.40 & $\begin{array}{l}\text { Unit Interior Lighting Power Allowance table, Common } \\
\text { Area/Activity section, Common Activity Areas, } \\
\text { Conference/Meeting (Table 401.3.2b in the } 90.1-1989 \text { Code) }\end{array}$ \\
\hline $\begin{array}{l}\text { Corridor, Restroom, } \\
\text { Support Area }\end{array}$ & 0.80 & 0.10 & 0.11 & 1.01 & $\begin{array}{l}\text { Unit Interior Lighting Power Allowance table, Common } \\
\text { Area/Activity section, Corridor and Toilet and Washroom (Table } \\
\text { 401.3.2b in the 90.1-1989 Code) }\end{array}$ \\
\hline Dining & 2.50 & 0.10 & 0.67 & 3.27 & $\begin{array}{l}\text { Unit Interior Lighting Power Allowance table, Common } \\
\text { Area/Activity section, Leisure Dining (Table 401.3.2b in the 90.1- } \\
1989 \text { Code) }\end{array}$ \\
\hline Exercise Center & 1.00 & 0.25 & 0.22 & 1.47 & $\begin{array}{l}\text { Version 1.1 New Category. Unit Interior Lighting Power } \\
\text { Allowance table, Indoor Athletic Area/Activity, Gymnasium, } \\
\text { General Exercising and Recreation Only (Table 401.3.2d in the } \\
90.1-1989 \text { Code) }\end{array}$ \\
\hline Exhibition Hall & 2.60 & 0.25 & 1.35 & 4.20 & $\begin{array}{l}\text { Unit Interior Lighting Power Allowance table, Specific Building } \\
\text { Area/Activity section, Hotel/Conference Center, Exhibition Hall } \\
\text { (Table 401.3.2c in the 90.1-1989 Code) }\end{array}$ \\
\hline Grocery Store & 2.80 & 0.25 & 0.22 & 3.27 & $\begin{array}{l}\text { Unit Interior Lighting Power Allowance table, Specific Building } \\
\text { Area/Activity section, Retail establishments - Type } 5 \text { (Table } \\
\text { 401.3.2c in the 90.1-1989 Code) }\end{array}$ \\
\hline $\begin{array}{l}\text { Gymnasium Playing } \\
\text { Surface }\end{array}$ & 1.5 & 0.10 & 1.35 & 2.95 & Added for consistency with IECC 2000 \\
\hline
\end{tabular}


Table 2.2. (contd.)

\begin{tabular}{|c|c|c|c|c|c|}
\hline Area Category & $\begin{array}{c}\text { Lighting } \\
\left(\mathrm{W} / \mathrm{ft}^{2}\right)\end{array}$ & $\begin{array}{l}\text { Equip. } \\
\left(\mathrm{W} / \mathrm{ft}^{2}\right)\end{array}$ & $\begin{array}{l}\text { Occup. } \\
\left(\mathrm{W} / \mathrm{ft}^{2}\right)\end{array}$ & $\begin{array}{l}\text { Total }^{(\mathrm{a})} \\
\left(\mathrm{W} / \mathrm{ft}^{2}\right)\end{array}$ & Data Source for Lighting LPD \\
\hline Hotel Function & 2.40 & 0.25 & 0.27 & 2.92 & $\begin{array}{l}\text { Unit Interior Lighting Power Allowance table, Specific Building } \\
\text { Area/Activity section, Hotel/Conference Center, Banquet } \\
\text { Room/Multipurpose (Table } 401.3 .2 \mathrm{c} \text { in the } 90.1-1989 \text { Code) }\end{array}$ \\
\hline $\begin{array}{l}\text { Hotel/Motel Guest } \\
\text { Room }\end{array}$ & $1.40^{(\mathbf{c})}$ & 0.25 & 0.27 & 1.92 & \\
\hline $\begin{array}{l}\text { Industrial Work, } \\
\text { General }\end{array}$ & 1.60 & 1.00 & 0.22 & 2.82 & $\begin{array}{l}\text { Unit Interior Lighting Power Allowance table, Common } \\
\text { Area/Activity section, Shop, Painting (Table 401.3.2b in the } 90.1- \\
1989 \text { Code) }\end{array}$ \\
\hline $\begin{array}{l}\text { Industrial Work, } \\
\text { Precision }\end{array}$ & 2.50 & 1.00 & 0.22 & 3.72 & $\begin{array}{l}\text { Unit Interior Lighting Power Allowance table, Common } \\
\text { Area/Activity section, Shop, Machinery (Table } 401.3 .2 \mathrm{~b} \text { in the } \\
\text { 90.1-1989 Code) }\end{array}$ \\
\hline Kitchen & 1.40 & 1.00 & 0.34 & 2.74 & $\begin{array}{l}\text { Unit Interior Lighting Power Allowance table, Common } \\
\text { Area/Activity section, Food Service - Kitchen (Table } 401.3 .2 \mathrm{~b} \text { in } \\
\text { the } 90.1-1989 \text { Code) }\end{array}$ \\
\hline Library & 1.50 & 0.75 & 0.25 & 2.50 & $\begin{array}{l}\text { Version 1.1 New Category. Unit Interior Lighting Power } \\
\text { Allowance table, Common Area/Activity, Library, Stack Area } \\
\text { (Table 401.3.2b in the 90.1-1989 Code) }\end{array}$ \\
\hline Lobby - Hotel & 1.90 & 0.25 & 0.27 & 2.42 & $\begin{array}{l}\text { Unit Interior Lighting Power Allowance table, Specific Building } \\
\text { Area/Activity section, Hotel/Conference Center, Lobby (Table } \\
\text { 401.3.2c in the 90.1-1989 Code) }\end{array}$ \\
\hline Lobby - Other & 1.00 & 0.25 & 0.27 & 1.52 & $\begin{array}{l}\text { Unit Interior Lighting Power Allowance table, Common } \\
\text { Area/Activity section, Lobby, Reception and Waiting } \\
\text { (Table 401.3.2b in the 90.1-1989 Code) }\end{array}$ \\
\hline Mall, Arcade, or Atrium & 1.40 & 0.10 & 0.34 & 1.84 & $\begin{array}{l}\text { Unit Interior Lighting Power Allowance table, Specific Building } \\
\text { Area/ Activity section, Mall Concourse (Table } 401.3 .2 \mathrm{c} \text { in the } 90.1- \\
1989 \text { Code) }\end{array}$ \\
\hline $\begin{array}{l}\text { Medical and Clinical } \\
\text { Care }\end{array}$ & 1.80 & 1.00 & 0.34 & 3.14 & $\begin{array}{l}\text { Unit Interior Lighting Power Allowance table, Specific Building } \\
\text { Area/Activity, Hospital/Nursing Home (Table } 401.3 .2 \mathrm{c} \text { in the } 90.1 \text { - } \\
1989 \text { Code) Equal weighting to the following categories: } \\
\text { Corridor } 1.3 \\
\text { Dental Suite/Examination/Treatment } 1.6 \\
\text { Emergency } 2.3 \\
\text { Laboratory } 1.9 \\
\text { Lounge/Waiting Room } 0.9 \\
\text { Medical Supplies } 2.4 \\
\text { Nurse Station } 2.1 \\
\text { Occupational Therapy/Physical Therapy } 1.6 \\
\text { Pharmacy } 1.7 \\
\text { Radiology } 2.1 \\
\text { Surgical and OB Suites: General Area } 2.1 \\
\text { Surgical and OB Suites: Recovery } 2.3 \\
\text { Average = } 1.858\end{array}$ \\
\hline Museum & 1.7 & 0.25 & 1.35 & 3.30 & Added for consistency with IECC 2000 \\
\hline $\begin{array}{l}\text { Multifamily Living } \\
\text { Units }\end{array}$ & $1.10^{(\mathbf{c})}$ & 0.75 & 0.27 & 2.12 & \\
\hline Office & 1.80 & 0.75 & 0.25 & 2.80 & $\begin{array}{l}\text { Unit Interior Lighting Power Allowance table, Common } \\
\text { Area/Activity section, Office Category 1, Reading, Typing, and } \\
\text { Filing (Table 401.3.2b in the 90.1-1989 Code) }\end{array}$ \\
\hline Religious Worship & 2.50 & 0.10 & 1.35 & 3.95 & $\begin{array}{l}\text { Unit Interior Lighting Power Allowance table, Specific Building } \\
\text { Area/Activity section, Church, Synagogue, Chapel, } \\
\text { Worship/Congregational (Table 401.3.2c in the } 90.1-1989 \text { Code) }\end{array}$ \\
\hline
\end{tabular}


Table 2.2. (contd.)

\begin{tabular}{|c|c|c|c|c|c|}
\hline Area Category & \begin{tabular}{|c|} 
Lighting \\
$\left(\mathrm{W} / \mathrm{ft}^{2}\right)$
\end{tabular} & $\begin{array}{l}\text { Equip. } \\
\left(\mathrm{W} / \mathrm{ft}^{2}\right)\end{array}$ & $\begin{array}{l}\text { Occup. } \\
\left(\mathrm{W} / \mathrm{ft}^{2}\right)\end{array}$ & $\begin{array}{l}\text { Total } \\
(\mathrm{a}) \\
\left(\mathrm{W} / \mathrm{ft}^{2}\right)\end{array}$ & Data Source for Lighting LPD \\
\hline $\begin{array}{l}\text { Retail Sales, Wholesale } \\
\text { Showroom }\end{array}$ & 3.10 & 0.25 & 0.22 & 3.57 & $\begin{array}{l}\text { Unit Interior Lighting Power Allowance table, Specific Building } \\
\text { Area/Activity section, Retail establishments - Type } 4 \\
\text { (Table 401.3.2c in the 90.1-1989 Code) }\end{array}$ \\
\hline Restaurant & 1.7 & 0.50 & 0.27 & 2.47 & Added for consistency with IECC 2000 \\
\hline $\begin{array}{l}\text { Storage, Industrial and } \\
\text { Commercial }\end{array}$ & 1.00 & 0.10 & 0.00 & 1.10 & $\begin{array}{l}\text { Unit Interior Lighting Power Allowance table, Common } \\
\text { Area/Activity section, Storage and Warehouse, Active Storage, } \\
\text { Fine (Table } 401.3 .2 \mathrm{~b} \text { in the } 90.1-1989 \text { Code) }\end{array}$ \\
\hline $\begin{array}{l}\text { Theater - Motion } \\
\text { Picture }\end{array}$ & 1.00 & 0.25 & 1.35 & 2.60 & $\begin{array}{l}\text { Unit Interior Lighting Power Allowance table, Specific Building } \\
\text { Area/Activity section, Theater, Motion Picture (Table } 401.3 .2 \mathrm{c} \text { in } \\
\text { the } 90.1-1989 \text { Code) }\end{array}$ \\
\hline Theater - Performance & 1.50 & 0.25 & 1.35 & 3.10 & $\begin{array}{l}\text { Unit Interior Lighting Power Allowance table, Specific Building } \\
\text { Area/Activity section, Theater, Performance Arts (Table 401.3.2c } \\
\text { in the } 90.1-1989 \text { Code) }\end{array}$ \\
\hline Others & $\begin{array}{c}0.60 / \\
1.60^{(\mathbf{b})}\end{array}$ & 0.40 & 0.60 & $\begin{array}{c}1.60 / \\
2.60^{(\mathbf{b})}\end{array}$ & $\begin{array}{l}\text { Unit Interior Lighting Power Allowance table, Common } \\
\text { Area/Activity section, Garage, Auto, and Pedestrian Circulation } \\
\text { Area (Table } 401.3 .2 \mathrm{~b} \text { in the } 90.1-1989 \text { Code). The value of } 0.6 \text { was } \\
\text { taken from the '97 California Title } 24 \text {, Table 1-M for space type } \\
\text { Others. The Unlisted Space category value of } 0.2 \text { (Table } 401.3 .2 \mathrm{~b} \text { ) } \\
\text { in the } 90.1-1989 \text { Code was judged to be so limiting that it would } \\
\text { preclude use of the condensed list of space usage types in } \\
\text { COMcheck by many users. The } 0.6 \text { value was judged to be more } \\
\text { reasonable than } 0.2 \text {, and it use was felt to be warranted in the } \\
\text { interest of making the materials easy to use. }\end{array}$ \\
\hline \multicolumn{6}{|c|}{$\begin{array}{l}\text { (a) The total is the sum of lighting, equipment, and occupants. The ENVSTD input is reduced by } 0.6 \mathrm{~W} / \mathrm{ft}^{2} \text {, to adjus } \\
\text { assumed } 0.6 \mathrm{~W} / \mathrm{ft}^{2} \text { average occupant load (Crawley et al. 1989). } \\
\text { (b) The Others area category uses } 0.6 \mathrm{~W} / \mathrm{ft}^{2} \text { for lighting compliance, but } 1.6 \mathrm{~W} / \mathrm{ft}^{2} \text { for envelope compliance. } \\
\text { (c) Hotel/Motel Guest Room and Multifamily Living Units area categories are exempt from lighting power density } \\
\text { requirements, but are included in this list for internal load density used in envelope compliance calculations. }\end{array}$} \\
\hline
\end{tabular}

the lighting power budget. To address this problem, we chose to exempt hotel guest room lighting. Similar reasoning led the SSPC 90.1 to exempt lighting in multifamily dwelling units in the 90.1-1989

Code. 


\subsection{Envelope Documentation}

\subsection{Envelope Trade-off Calculations}

The envelope trade-off calculations for opaque above-grade walls and windows in COMcheck are based on the system performance method in Standard 90.1-1989 (Attachment 8B). Like the ENVSTD program used to show compliance with the envelope requirements of Standard 90.1-1989 (Crawley et al. 1989), the COMcheck envelope trade-off calculations are based on envelope loads only: no provisions exist for trade-offs with other building systems such as HVAC or lighting. The envelope trade-offs in COMcheck simply add load components to the wall and window loads calculated as in ENVSTD. Like ENVSTD, the COMcheck program works by defining both a proposed design and a budget design and comparing the calculated loads. The proposed version is based on user input, while the budget version is based on minimum prescriptive requirements and the modeling rules detailed in Attachment 8B of Standard 90.1-1989.

The rationale for incorporating the additional component trade-offs in COMcheck is that Standard 90.1-1989 Section 13, Building Energy Cost Budget (ECB) Method, sanctions the use of alternative compliance methods provided they ensure equivalent energy efficiency. Enhancing design flexibility is generally understood to be desirable because it frequently allows the intent of the code to be achieved at a lower construction cost and generally reduces unnecessary constraints on building design. In fact, the initial technical work from which Standard 90.1-1989 was developed contained a roof trade-off, but the trade-off was not implemented for reasons of complexity (Jones 1983).

To establish an adequate technical basis for the additional trade-offs to be included in COMcheck, a range of available calculation methods were evaluated. A controlling criterion that served to rapidly narrow the range of options was that of rapid execution. There was a clear consensus that automatic re-execution of the trade-off calculations every time the user makes a change to the proposed design and near instantaneous (i.e., under one second) execution of the calculation was essential if the program was to receive widespread acceptance. This criterion restricted the calculation method to a simplified technique, such as a degree-day or temperature bin method, and precluded using any kind of hourly simulation. After reviewing the advantages and disadvantages of available methods, we chose to use the work of ASHRAE SSPC 90.1 as documented in Standard 90.1-1989R, the first public review draft of the proposed revisions to Standard 90.1-1989, which was made publicly available in the spring of 1996. The specific part of Standard 90.1-1989R containing documentation of the envelope calculation procedures is Appendix C, Building Envelope Trade-Off Option.

There were numerous reasons for selecting Standard 90.1-1989R as the primary source document for the additional trade-offs. The calculation method contains all trade-off components we were interested in including, met our execution time criterion, was generally regarded as technically solid, was deemed likely to have credibility with the intended users of COMcheck, had been implemented in available software thereby facilitating validation of our own software, was developed by some of the same individuals who had developed the original ENVSTD model with which integration was required, was readily available without royalty considerations, was documented in printed materials, and direct access to technical support was available. For these reasons, using the Standard 90.1-1989R trade-off methodology was judged to be clearly appropriate for the COMcheck trade-offs.

Technical Support Documentation for COMcheck Through Version 3.4.0 (Software) 
However, it is important to note that the rationale for using the Standard 90.1-1989R trade-offs was NOT that materials in proposed revisions to Standard 90.1-1989 are necessarily appropriate for use with materials that implement the current 90.1-1989 Code. Decisions relative to using work from Standard 90.1-1989R were based on technical criteria and practical considerations related to successfully achieving the objectives of creating easy-to-use compliance materials.

\subsubsection{Load Calculation Assumptions}

The cooling and heating loads for components are calculated based on the COOL and HEAT equations provided in the 90.1-1989R Appendix-C, Equation 6.21. COOL and HEAT are expressed in terms of $\$ / y e a r$, and this is converted to Btu/year by using equipment efficiencies and eliminating the cost multiplier. The conversion was performed using the following process:

For cooling load calculations:

1) multiply the cooling coefficient (CCoef) by the SEER (12.24)

2) multiply COOL by $1000 \mathrm{~W} / \mathrm{kW}$.

For heating load calculations:

1) multiply the heating coefficient (HCoef) by the AFUE (0.608488)

2) multiply HEAT by 100000 Btu/therm.

The details of cooling and heating coefficients calculations are documented for each envelope component separately in Sections 3.4 to 3.12 .

\subsubsection{Requirements for Locations with Greater than 15,000 HDD65}

Standard 90.1-1989 contains envelope requirements for locations with $>15,000$ heating degree days. COMcheck completely ignores all requirements in these locations because there are virtually no populated locations within the United States meeting this criterion. For example, of the 14 Alaska locations listed among the 234 TMY sites in Standard 90.1-1989, none meet this criterion. We expect this simplification to have no practical impact.

\subsubsection{Space Conditioning}

The envelope requirements tables in Appendix A of the 90.1-1989 Code are based on the assumption that the building is both heated and cooled. Appendix A requirements apply equally to buildings that are both heated and cooled and buildings that are heated only or cooled only. ENVSTD permits the user to specify whether the building is heated only, cooled only, or both heated and cooled, and the compliance calculations are adjusted according to the user's selection. COMcheck employs the same approach as is used in Appendix A of the 90.1-1989 Code and assumes that all buildings are both heated and cooled. The rationale for this decision is that it appears to be a generally conservative assumption that leads to greater consistency of requirements and fewer opportunities for users to manipulate compliance. 
Standard 90.1-1989 permits heating and cooling loads to be traded off against each other. The criteria underlying the standard were developed with a building that was both heated and cooled. Most new buildings in the United States are both heated and cooled. Buildings that are specified as heated only may later have cooling added. Even if mechanical cooling is not present, steps that minimize cooling loads are likely to increase the value of the building and the productivity of occupants. Finally, requiring that a building comply only on the basis of heating or cooling loads can, in some cases, significantly increase the stringency of the envelope requirements. Rather than add a seldom-used factor expected to produce requirements that are inconsistent with printed materials and often counter-intuitive in their impact, COMcheck was simplified by not providing these options.

The heated only and cooled only option should not be confused with the issue of semi-heated space types, such as warehouses. Standard 90.1 employs a simplified loads model that assumes normal occupied space temperatures and has no means for varying requirements based on partially-conditioned spaces. This would appear to subject partially-conditioned spaces to much more stringent envelope requirements than warranted. Warehouses - the largest partially-conditioned category - are compared against criteria based on typical office building window areas. Because warehouses usually have few if any windows, stringency is greatly reduced. Within the context of the 90.1-1989 Code, there does not appear to be an easy solution to the shortcomings in the treatment of semi-conditioned spaces, nor is it clear this creates a serious problem.

\subsubsection{Internal-Loads}

While ENVSTD requires that the user provide numerical inputs for equipment and lighting power (i.e., watts per square foot) and adjust this value for unusual occupancy levels, COMcheck requires only that the user specify one or more whole building types or area categories from a list. These building use types are to determine equipment and lighting power. See Section 2.0 for more information.

\subsection{Mandatory Requirements}

The following sections describe mandatory requirements that are listed in COMcheck. References to the specific pertinent 90.1-1989 Code sections are shown in parentheses in the section headings below.

\subsubsection{Calculations and Supporting Information (402.1)}

Section 402.1 addresses 1) data sources used in envelope calculations, 2) calculation procedures governing thermal transmittance calculations, and 3) requirements for how component areas are calculated.

1. In developing COMcheck, we used what we judged to be the best available data sources and have documented the data sources used. Additional data sources beyond those explicitly referenced in the 90.1-1989 Code have been used.

2. A major objective for the COMcheck materials was to eliminate the need for calculation by users. Thus, the results of the calculation methods required in Section 402.1 of the 90.1-1989 Code are embedded in the COMcheck materials. The calculations used to develop COMcheck component library values and convert user R-value inputs into overall thermal transmittance of assemblies are 
documented in Section 3.4. COMcheck eliminates the need for end-users to perform these calculations, except when the Other assembly categories are used.

3. COMcheck software help messages instruct users on area calculations consistent with Section 402.1.3 of the 90.1-1989 Code.

\subsubsection{Air Leakage for Fenestration and Doors (402.2.1)}

COMcheck specifies maximum leakage rates for manufacturers and directs the user to products certified by an accredited laboratory such as the National Wood Window and Door Association (NWWDA) or the Architectural Aluminum Manufacturers Association (AAMA). A reformatted table based on data in the 90.1-1989 Code Table 402.2.1 is provided in Table 3.1. The COMcheck table leaves out the reference standards, products for residential and heavy commercial applications, and lower leakage requirements for fixed-aluminum windows.

Table 3.1. Maximum Allowed Air Leakage Rates

\begin{tabular}{|l|c|c|c|}
\hline \multirow{2}{*}{} & \multicolumn{3}{|c|}{ Frame Types } \\
\cline { 2 - 4 } & Wood & Aluminum & PVC \\
\hline Windows (cfm per ft of operable sash crack) & 0.25 & 0.37 & 0.06 \\
\hline Sliding Doors (cfm per sq ft of door area) & N/A & 0.37 & 0.37 \\
\hline Swinging Doors (cfm per sq ft of door area) & 0.25 & 1.25 & N/A \\
\hline
\end{tabular}

\subsubsection{Exterior Envelope Joints (402.2.2)}

COMcheck contains a detailed list of envelope penetrations that must be sealed in place instead of the more generally stated requirement in the 90.1-1989 Code.

\subsubsection{Moisture Migration (402.2.3)}

COMcheck translates the general requirement for designing to limit moisture migration to specific requirements for vapor retarders in specific locations. This translation is based on work previously done for MECcheck (now REScheck), and its derivation is documented in the Methodology for Developing the REScheck ${ }^{T M}$ Software through Version 3.6.

The requirement for vapor retarders includes an exception that removes the vapor retarder requirement in specific climate zones in specific states. The locations qualifying for the exception are as follows in Table 3.2.

Table 3.2. States with Vapor Retarder Exception

\begin{tabular}{|l|c|}
\hline \multicolumn{1}{|c|}{ States } & Zones \\
\hline Texas & Zones 2-5 \\
\hline Alabama, Georgia, North Carolina & Zones 4-6 \\
\hline Oklahoma, South Carolina & Zones 4-6 \\
\hline Arkansas, Tennessee & Zones 6-7 \\
\hline Florida, Hawaii, Louisiana, Mississippi & All Zones \\
\hline
\end{tabular}


This requirement is based on the 90.1-1989 Code (402.2.3 Moisture Migration) and Standard 90.1-1989, which contain only general statements about designing to eliminate "moisture migration that leads to deterioration in insulation performance." Standard 90.1-1989 (8.4.5.3 Moisture Migration Requirements for Exterior Envelopes) includes a reference to ASHRAE Fundamentals. While both current research on moisture migration and these requirements are subject to varying interpretations on the appropriate use of vapor barriers, the COMcheck requirement appears to be an appropriate and technically accurate interpretation of the Standard 90.1-1989 intent and consistent with the residential vapor barrier requirements.

\subsection{Assumptions in Developing Envelope Assemblies}

One of the goals of COMcheck was to provide users true prescriptive envelope requirements expressed in terms of R-values rather than overall assembly U-factors. Standard 90.1 typically provides opaque envelope requirements as assembly U-factors and then specifies calculation procedures and correction factors to be used with these assembly U-factors in calculating the required amount of insulation. COMcheck uses the calculation procedures and correction factors found in Standard 90.1 and precalculates required insulation R-values for common assembly types.

The key to this process is identifying typical assemblies. While the correction factors and calculation procedures are taken directly from Standard 90.1, typical assemblies are not specified. For COMcheck, a series of assemblies used in the development of Standard 90.1-1989R were used. These assemblies are conservative in that material thicknesses were assumed to be as minimal as possible. For example, for wood-frame walls, the wall assembly is assumed to include 5/8-in. gypsum board on the inside of the cavity and stucco over the outside of the cavity. No additional R-value is assumed for exterior sheathing in the calculations. Interior and exterior air films are also included in the calculations. Similarly, a minimal roof system might be a metal deck with no ceiling and with insulation placed directly on top of the deck.

The basic assemblies described in the following sections were taken from Standard 90.1-1989R. Extensive discussion of these assemblies can be found in Code Compliance Considerations in the Development of the Building Envelope Requirements for ASHRAE/IESNA Standard 90.1-1989R (Hogan 1995). For COMcheck, the resulting U-factors were converted to a series of equations describing overall assembly U-factors as a function of installed cavity insulation R-value, installed continuous insulation Rvalue, and the balance of the assembly (BOA). BOA refers to the R-value of the assembly excluding any cavity or continuous insulation. Cavity insulation is defined as insulation subject to thermal bridging from framing or furring members. Continuous insulation is defined as insulation that is continuous across framing or furring members and not subject to thermal bridging. The BOA includes all non-insulation elements of the assembly that contribute to its overall U-factor such as air films, gypsum board, sheathing, and carpets and pads (for floors). Associated with the cavity insulation is an effectiveness factor that reduces the installed R-value of the cavity insulation to an "effective" R-value for cavity insulation. In some cases, the equations used in COMcheck have a constant value for this effectiveness factor, and in others the effectiveness factor is a function of the cavity insulation R-value. Continuous insulation is assumed to have an effectiveness factor of 1 .

Technical Support Documentation for COMcheck Through Version 3.4.0 (Software) 


\subsection{Roofs}

\subsubsection{Roof Assembly Types}

\subsubsection{COMcheck offers the following six roof types:}

All-Wood Joist/Rafter/Truss. The base assembly consists of a roof truss with a $2 \times 4$ bottom chord. The ceiling is attached directly to the bottom chord of the truss, and the attic space above is ventilated. Insulation is located directly on top of the ceiling, first filling the cavities between the wood, then continuously covering wood and cavity insulation. No credit is given for roofing materials, because they are above the ventilated space. The heat flow path through the wood members is calculated to be the same depth as the insulation. The assembly includes R-0.17 for the exterior air film, R-0.56 for 0.625 -in. gypsum board, and R-0.61 for interior air film with heat flow up. U-factors are calculated for standard framing, where insulation is tapered around the perimeter with resultant decreases in thermal resistance. Table 3.3 shows the balance of assembly R-value calculation details. Area weighting factors for the parallel paths are $85 \%$ full-depth insulation, $5 \%$ half-depth insulation, and $10 \%$ framing.

Table 3.3. Balance of Assembly R-values for All-Wood Joist Roof

\begin{tabular}{|l|c|c|}
\hline \multicolumn{1}{|c|}{ Description } & R-Value at Insulation & R-Value at Joists \\
\hline Outside Air Film & 0.17 & 0.17 \\
\hline Wood Joists/Cavity & 0 & 4.38 \\
\hline 5/8-in. Gypsum Board & 0.56 & 0.56 \\
\hline Inside Air Film & 0.61 & 0.61 \\
\hline Total Path R-value & $\mathbf{1 . 3 4}$ & $\mathbf{5 . 7 2}$ \\
\hline \multicolumn{2}{|c|}{ Total Assembly R-value $=1.0 /(0.85 / 1.34+0.05 / 1.34+0.10 / 5.72)=1.45$} \\
\hline
\end{tabular}

Non-Wood Joist/Rafter/Truss. The base assembly consists of a roof supported by metal joists with insulation between the joists. The assembly includes R- 0.17 for exterior air film, R-0 for metal deck, and R-0.61 for interior air film heat flow up. The performance of the insulation/framing layer is calculated using the parallel path correction factors found in Table 8C-1 of Standard 90.1-1989.

Structural Slab. The structural slab roof consists of a 6-in. concrete slab or concrete on metal deck. The assembly includes R-0.17 for exterior air film, R-0.33 for built-up roofing, R-0.13 for concrete slab on metal deck, and R-0.61 for interior air film heat flow up.

Metal Roof without Thermal Blocks and Metal Roof with Thermal Blocks. The base assembly consists of a roof where the insulation is draped over metal purlins and compressed where the metal structural members are attached to the metal purlins. R-values for additional continuous insulation may be added to the base assembly. Two cases of screw-down metal building roofs are considered in COMcheck. One case involves the use of a 1 in. $x 3$ in. foam thermal block (other than compressed insulation) between the purlin and metal roof members (NAIMA 1998). The other case is identical but without the thermal block material at the purlins. The base assembly R-value for uninsulated roofs is 0.78 , representing the interior and exterior air film coefficients. Balance of assembly U-factors and framing factors is used as coefficients of a linear regression equation developed to represent the assembly U-factors of standard insulation R-values for metal building roof assemblies, as listed in Table 3.4. 
Table 3.4. Metal Building Roof (MBR) Assembly U-Factors for Standard Insulation Thicknesses

\begin{tabular}{|c|c|c|}
\hline Insulation R-Value & $\begin{array}{c}\text { Assembly U-Factor } \\
\text { MBR with Thermal Block }\end{array}$ & $\begin{array}{c}\text { Assembly U-Factor } \\
\text { MBR without Thermal Block }\end{array}$ \\
\hline R-10 & 0.104 & 0.138 \\
\hline R-11 & 0.098 & 0.134 \\
\hline R-13 & 0.088 & 0.122 \\
\hline R-19 & 0.07 & 0.101 \\
\hline
\end{tabular}

Other. COMcheck allows the user to define a roof assembly by specifying its overall effective U-factor. This option permits the user to accurately describe the performance of any roof assembly not adequately covered by the predefined roof types.

\subsubsection{Roof Area}

Proposed Area. With COMcheck Version 2.0, skylight areas are subtracted from roof gross areas as input by the user to determine opaque roof areas, which is then used in the loads calculations.

Budget Area. The roof area $\left(\mathrm{Area}_{\mathrm{RF}}\right)$ used in calculating budget loads is the sum of the opaque roof area and skylight area in excess of 3\% of total roof area. The first 3\% of skylight area is ignored in calculating both loads for the proposed design and budget design loads (see Skylights for additional information).

\subsubsection{Roof U-Factor}

Proposed U-Factor. The U-factor for opaque roof assemblies is determined using the following equation:

$$
\mathrm{U}_{\mathrm{RF}}=1 /\left(\mathrm{R}_{\mathrm{RF}-\mathrm{BOA}}+\mathrm{R}_{\mathrm{RF}-\mathrm{CVI}} \times \mathrm{AF}_{\mathrm{RF}}+\mathrm{R}_{\mathrm{RF}-\mathrm{CNI}}\right)
$$

where $\quad \mathrm{U}_{\mathrm{RF}}=$ opaque roof assembly $\mathrm{U}$-factor input to the trade-off engine

$\mathrm{R}_{\mathrm{RF}-\mathrm{BOA}}=\mathrm{R}$-value for the balance of the assembly from Table 3.5 for roof type

$\mathrm{R}_{\mathrm{RF}-\mathrm{CVI}}=\mathrm{R}$-value for the cavity insulation as input by the user

$\mathrm{AF}_{\mathrm{RF}}=$ parallel path adjustment factor from Table 3.5 for roof type

$\mathrm{R}_{\mathrm{RF}-\mathrm{CNI}}=\mathrm{R}$-value for continuous insulation input by the user.

Table 3.5. Roof U-Factor Calculation Coefficients

\begin{tabular}{|c|c|c|}
\hline Roof Type & $\mathbf{R}_{\text {RF-BOA }}$ & $\mathbf{A F}_{\mathrm{RF}}$ \\
\hline All-Wood Joist/Rafter/Truss & 1.45 & 0.9 \\
\hline Non-Wood Joist/Rafter/Truss & 0.78 & $1-0.00738 * R_{\mathrm{RF}-\mathrm{CVI}}$ \\
\hline Structural Slab & 1.24 & $\mathrm{~N} / \mathrm{A}$ \\
\hline Metal Roof without Thermal Blocks & $\begin{array}{l}\text { If } R_{\text {RF-CVI }}=0,0.78 \\
\text { If } R_{\text {RF-CVI }}>0,4.25\end{array}$ & $\begin{array}{c}\text { If } \mathrm{R}_{\mathrm{RF}-\mathrm{CVI}}=0, \mathrm{AF}_{\mathrm{RF}}=\mathrm{N} / \mathrm{A} \\
\text { If } \mathrm{R}_{\mathrm{RF}-\mathrm{CVI}}>0,0.298251\end{array}$ \\
\hline Metal Roof with Thermal Blocks & $\begin{array}{l}\text { If } \mathrm{R}_{\mathrm{RF}-\mathrm{CVI}}=0,0.78 \\
\text { If } \mathrm{R}_{\mathrm{RF}-\mathrm{CVI}}>0,4.55\end{array}$ & 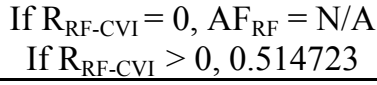 \\
\hline Other & \multicolumn{2}{|c|}{ User input is overall assembly U-factor. } \\
\hline
\end{tabular}

Budget U-Factor. The U-factor for roof assemblies $\left(\mathrm{U}_{\mathrm{RF}}\right)$ is based on Equation 8-7 in Standard 90.1-1989. 


\subsubsection{Roof Loads}

The cooling and heating loads for roofs $\left(\mathrm{CL}_{\mathrm{RF}}\right.$ and $\left.\mathrm{HL}_{\mathrm{RF}}\right)$ are calculated using Equations 3.2 and 3.3.

$$
\begin{aligned}
& \mathrm{CL}_{\mathrm{RF}}=\text { Area }_{\mathrm{RF}} \times \mathrm{CCoef}_{\mathrm{RF}} \times \mathrm{U}_{\mathrm{RF}} \times \mathrm{CDD} 50 \\
& \mathrm{HL}_{\mathrm{RF}}=\text { Area }_{\mathrm{RF}} \times \mathrm{HCoef}_{\mathrm{RF}} \times \mathrm{U}_{\mathrm{RF}} \times \mathrm{HDD} 65
\end{aligned}
$$

where $\quad \mathrm{CL}_{\mathrm{RF}}=$ cooling load for roof

$\mathrm{HL}_{\mathrm{RF}}=$ heating load for roof

Area $_{\mathrm{RF}}=$ roof area in square feet

$\mathrm{CCoef}_{\mathrm{RF}}=7.393$ (from Standard 90.1-1989R, Appendix C, Table C.6-11: 6.04E-04 × $12.24 \times$ $1000=7.393)$

$\mathrm{HCoef}_{\mathrm{RF}}=13.874$ (from Standard 90.1-1989R, Appendix C, Table C.6-11: 2.28E-04 $\times$ $0.608488 \times 100000=13.874)$

$\mathrm{U}_{\mathrm{RF}}=\mathrm{U}$-factor of roof assembly

CDD50 $=$ cooling degree-days base $50^{\circ} \mathrm{F}$ for the site.

HDD65 $=$ heating degree-days base $65^{\circ} \mathrm{F}$ for the site.

\subsection{Skylights}

Separate requirements for skylights have not been implemented in COMcheck because the skylight requirements in Standard 90.1-1989 are complex and would require several additional user inputs to implement. Standard 90.1-1989 and the 90.1-1989 Code permit qualifying skylights to be ignored when calculating roof conductance. Under favorable circumstances, skylight areas up to $12 \%$ of the gross roof area may be ignored in the conductance calculation. These requirements involve dependencies on electric lighting power density, design foot-candle levels, the presence of automatic daylighting controls, and an option for shading devices. Not only are these dependencies complex, but field experience has shown that daylighting controls are often not correctly installed or maintained.

COMcheck implements the skylight requirements for much greater simplicity. COMcheck limits the area of skylights to a range in which skylights are highly productive in daylighting the spaces below and relies on "casual daylighting" (i.e., the tendency of occupants to turn off unneeded lights) to provide lighting savings to offset the higher conductance and presumed increases in space-conditioning loads. The first $3 \%$ of skylight area is exempted from inclusion in the proposed and budget building loads calculations, regardless of whether automatic controls are included or not, provided only that they meet minimum U-factor requirements consistent with Standard 90.1. The U-factor requirements are consistent with Addendum F in Standard 90.1-1989.

The rationale for this exemption is that at low percentages of roof area, skylights typically more than offset their added thermal load with lower electric lighting usage and a lower cooling load from lights. This approach represents a conservative implementation of the requirements in Section 8.4.8 of Standard 90.1-1989, which exempts much higher percentages of skylight area provided automatic controls are present. Three percent represents the roof area fraction below which we feel confident detrimental energy use impacts will not result even in the absence of an explicit requirement for automatic controls. 
No SHGC requirements are associated with the skylights. In the $0 \%$ to $3 \%$ area range, setting a maximum SHGC would likely be counterproductive because of reduced daylight contribution from glazing with a reduced SHGC. Skylight areas above 3\% are permitted provided the additional loads are fully offset by space-conditioning load reductions achieved elsewhere in the envelope design.

\subsubsection{Skylight Area}

Proposed Area. The portion of skylight area that exceeds 3\% of total roof area (i.e., opaque roof plus skylights) is used in the proposed design loads calculation. The first $3 \%$ is ignored. Where more than one skylight type has been entered, the $3 \%$ exemption is allocated proportionally based on skylight area.

Budget Area. Skylights are not addressed separately in the calculation of budget loads. Skylight area above the $3 \%$ exemption is included in the overall roof area.

\subsubsection{Skylight U-Factor}

Proposed U-Factor. Skylight U-factors are used as entered by the user. Glass heat gain properties are entered by the user as SHGC and used in that form for calculations.

Budget U-Factor. Skylights above the 3\% exemption are included in the overall roof area and are subject to the roof $U$-factor requirement.

\subsubsection{Skylight Loads}

The cooling and heating loads for skylights $\left(\mathrm{CL}_{\mathrm{SK}}\right.$ and $\left.\mathrm{HL}_{\mathrm{SK}}\right)$ are calculated using Equations 3.4 and 3.5. Equation 3.4 was derived from Equation C.6-17 in Standard 90.1-1989R. However, an apparent error was discovered in that equation and a comment was formally sent to ASHRAE SSPC 90.1 as part of the public review. The error was that Area $\mathrm{SK}_{\mathrm{SK}}$ was erroneously divided by the conditioned building floor area. Review of the source document for this equation revealed that the equation had not been correctly normalized when it was brought into the draft standard. Note also that unlike the equations for the other components, the skylight equations require dividing by the unit fuel price, while in the other components based on Standard 90.1-1989R the price term canceled out of the equation.

$$
\begin{gathered}
\mathrm{CL}_{\mathrm{SK}}=\text { Area }_{\mathrm{SK}} \times \mathrm{CCoef}_{\mathrm{SK}} \times \mathrm{CDD} 50 \times \mathrm{CCoef}_{\mathrm{SK}-\mathrm{SOLAR}} \times \mathrm{SHGC}_{\mathrm{SK}} \\
\mathrm{HL}_{\mathrm{SK}}=\text { Area }_{\mathrm{SK}} \times \mathrm{HAF}_{\mathrm{SK}} \times \mathrm{HDD} \times\left(\mathrm{HCoef}_{\mathrm{SK}-\mathrm{COND}} \times \mathrm{U}_{\mathrm{SK}}+\mathrm{HCoef}_{\mathrm{SK}-\mathrm{SOLAR}} \times \mathrm{SHGC}_{\mathrm{SK}}\right)
\end{gathered}
$$

where $\quad \mathrm{CL}_{\mathrm{SK}}=$ cooling load for skylight

$\mathrm{HL}_{\mathrm{SK}}=$ heating load for skylight

Area $_{\mathrm{SK}}=$ area of skylight assembly

CCoef $_{\mathrm{SK}}=0.0109=$ cooling coefficient for skylights for nonresidential buildings from Standard 90.1-1989R, Table C.6-9. This coefficient is used for all buildings for simplicity.
CCoef $_{\text {SK-SOLAR }}=14229=0.093 \times 12.24 \times 1000 / 0.08($ from Standard 90.1-1989R, Equation C.6-17)
CDD50 $=$ cooling degree-days base $50^{\circ} \mathrm{F}$ for the site.
$\mathrm{SHGC}_{\mathrm{SK}}=\mathrm{SHGC}$ for skylight assembly based on National Fenestration Rating Council ratings (NFRC 1995).




$$
\begin{aligned}
\text { HAF }_{\mathrm{SK}}= & 60849=\text { heating adjustment factor for skylights }=0.56 \times 0.608488 \times \\
& 100000 / 0.56(\text { from Standard } 90.1-1989 \mathrm{R}, \text { Equation C.6-17) } \\
\text { HCoef }_{\text {SK-COND }}= & 0.000212=\text { heating coefficients for skylights from conductance }(\text { from } \\
& \text { Standard } 90.1 \mathrm{R}, \text { Table C.6-9) } \\
\mathrm{U}_{\mathrm{SK}}= & \mathrm{U} \text {-factor for skylight assembly } \\
\text { HCoef }_{\text {SK-SOLAR }=}= & -0.0001953=\text { heating coefficients for skylights from solar }=-0.000168 \times \\
& 1.163 \text { (from Standard } 90.1-1989 \mathrm{R}, \text { Equation C.6-17 and Table C.6-9). } \\
\text { HDD65 = } & \text { heating degree-days base } 65^{\circ} \mathrm{F} \text { for the site. }
\end{aligned}
$$

\subsection{Above-Grade Walls}

\subsubsection{Above-Grade Wall Assembly Types}

COMcheck considers six typical above-grade wall types:

Wood-Frame. The base assembly consists of a conventional framed wood wall with insulation installed between 2-in. nominal wood framing. Cavity insulation is full depth and headers are double 2-in. nominal wood framing. The assembly includes R- 0.17 for exterior air film, R-0.08 for stucco, R-0.56 for 0.625-in. gypsum board, and R-0.68 for interior air film--vertical surfaces. For most supported codes, COMcheck treats both 16-in. o.c. and 24-in. o.c. wood frame as the same assembly because performance was not found to be sufficiently different. The calculations are based on wood framing at 16 in. o.c. with cavities filled with 14.5-in.-wide insulation for both 3.5-in.-deep and 5.5-in.-deep wall cavities. Headers leave no cavity for insulation. Area weighting factors for parallel paths are $75 \%$ insulated cavity; $21 \%$ studs, plates, and sills; and 4\% headers. The wall assembly U-factor calculations are based on a balance of wall assembly R-value as shown in Table 3.6. The heat capacity of the wall (as defined in Standard 90.1-1989 for use with the ENVSTD program [Crawley et al. 1989]) is 1.0.

Table 3.6. Balance of Assembly R-Values for Wood-Frame Walls

\begin{tabular}{|l|c|c|}
\hline \multicolumn{1}{|c|}{ Description } & R-Value at Insulation & R-Value at Studs/Header \\
\hline Outside Air Film & 0.17 & 0.17 \\
\hline Stucco & 0.08 & 0.08 \\
\hline Wood Studs/Cavity & $0.91(\mathrm{a})$ & 4.38 \\
\hline 5/8-in. Gypsum Board & 0.56 & 0.56 \\
\hline Inside Air Film & 0.68 & 0.68 \\
\hline Total Path R-value & $\mathbf{2 . 4 0}$ & $\mathbf{5 . 8 7}$ \\
\hline $\begin{array}{l}\text { Total Assembly R-value }=1.0 /(0.75 / 2.40+0.21 / 5.87+0.04 / 5.87)=2.82 . \\
\text { (a) Represents the R-value of air space in the stud cavity. }\end{array}$ \\
\hline
\end{tabular}

Metal-Frame (16-in. and 24-in. o.c.). The base assembly consists of a wall with insulation between metal framing but with no metal exterior surface framing spanning members. The metal framing is 16-18 gauge. The assembly includes R-0.17 for exterior air film, R-0.08 for stucco, R-0.56 for 0.625-in. gypsum board, and R-0.68 for interior air film--vertical surfaces. The performance of the insulation/framing layer is calculated using the values in Table 8C-2 of Standard 90.1-1989. COMcheck deals with both standard framing (16-in. o.c.) and advanced framing (24-in. o.c.). The heat capacity of the wall is assumed to be 1.0. Table 3.7 shows the balance of assembly R-value calculation for metal frame walls. 
Table 3.7. Balance of Assembly R-values for Steel Frame Walls

\begin{tabular}{|l|c|c|}
\hline \multicolumn{1}{|c|}{ Description } & $\begin{array}{c}\text { R-Value for } \\
\text { Steel Frame 16-in. o.c. }\end{array}$ & $\begin{array}{c}\text { R-Value for } \\
\text { Steel Frame 24-in. o.c. }\end{array}$ \\
\hline Outside Air Film & 0.17 & 0.17 \\
\hline Stucco & 0.08 & 0.08 \\
\hline Stud Cavity & $0.79^{(\text {a) }}$ & 0.91 \\
\hline 5/8-in. Gypsum board & 0.56 & 0.56 \\
\hline Inside Air Film & 0.68 & 0.68 \\
\hline Total Assembly R-value & $\mathbf{2 . 2 8}$ & $\mathbf{2 . 4 0}$ \\
\hline
\end{tabular}

(a) Represents the R-value of air space in the stud cavity adjusted with a framing factor of 0.87 .

Structural Masonry. This assembly includes poured-in-place concrete walls, precast concrete panels, and concrete masonry units. Continuous insulation can be installed on the interior or exterior, concrete masonry units can have empty cells or cells insulated with loose-fill insulation or foam inserts, and wood or metal furring may be used in conjunction with cavity insulation on the interior of the wall. The base assembly includes R-0.17 for exterior air film and R- 0.68 for interior air film--vertical surfaces. For insulated walls, the U-factor also includes R-0.45 for 0.5-in. gypsum board. U-factors and heat capacities are calculated for six structural masonry wall types. The R-value for each wall type and its assumed density and thickness is given in Table 3.8 .

Table 3.8. Balance of Assembly R-values for Above-Grade Masonry Walls

\begin{tabular}{|c|c|c|c|c|c|c|}
\hline \multirow[b]{2}{*}{ Layer Name } & \multicolumn{2}{|c|}{$\begin{array}{c}\text { Solid Concrete or } \\
\text { Masonry }\end{array}$} & \multicolumn{2}{|c|}{ CMU w/Empty Cells } & \multicolumn{2}{|c|}{$\begin{array}{l}\text { CMU w/Integral } \\
\text { Insulation }\end{array}$} \\
\hline & $<8^{\prime \prime}$ & $>8 "$ & $<8 "$ & $>8 "$ & $<8^{\prime \prime}$ & $>8 "$ \\
\hline Outside Air Film & 0.17 & 0.17 & 0.17 & 0.17 & 0.17 & 0.17 \\
\hline Concrete/Masonry & $0.68^{(\mathrm{a})}$ & $1.02^{(\mathrm{b})}$ & $1.31^{(\mathrm{c})}$ & $1.57^{(\mathrm{d})}$ & $1.56^{(\mathrm{e})}$ & $2.36^{(\mathrm{f})}$ \\
\hline 1/2-in. Gypsum Board & 0.45 & 0.45 & 0.45 & 0.45 & 0.45 & 0.45 \\
\hline Inside Air Film & 0.68 & 0.68 & 0.68 & 0.68 & 0.68 & 0.68 \\
\hline Total Assembly R-value & 1.98 & 2.32 & 2.61 & 2.87 & 2.86 & 3.66 \\
\hline $\begin{array}{l}\text { (a) Assuming 6" solid co } \\
\text { (b) Assuming 9" solid cor } \\
\text { (c) Assuming 6" concrete } \\
\text { (d) Assuming 10" concret } \\
\text { (e) Assuming 6" concrete } \\
\text { (f) Assuming 10" concret }\end{array}$ & $\begin{array}{l}\text { ete with d } \\
\text { te with de } \\
\text { ck (unreil } \\
\text { lock (unre } \\
\text { ck (partly } \\
\text { lock (partl }\end{array}$ & $\begin{array}{l}\text { ity } 115 \mathrm{lb} \\
\text { ity } 115 \mathrm{lb} \\
\text { rced, cell } \\
\text { orced, cel } \\
\text { outed, ce } \\
\text { grouted, c }\end{array}$ & $\begin{array}{l}\text { apty) with } \\
\text { mpty) wit } \\
\text { nsulated) } \\
\text { insulated }\end{array}$ & $\begin{array}{l}\text { nsity } 115 \\
\text { lensity } 115 \\
\text { h density } 1 \\
\text { ith density }\end{array}$ & $\begin{array}{l}\mathrm{ft}^{3} \\
/ \mathrm{ft}^{3} \\
\mathrm{lb} / \mathrm{ft}^{3} \\
5 \mathrm{lb} / \mathrm{ft}^{3}\end{array}$ & \\
\hline
\end{tabular}

Metal Wall Without Thermal Blocks. The base assembly consists of wall insulation that is compressed between metal wall panels and the metal structure. The heat capacity of the wall is assumed to be 1.0. For un-insulated metal walls, the overall R-value for the assembly is 0.85 assuming only indoor and outdoor air film coefficient R-values of 0.17 and 0.68 . The balance of assembly R-value and framing factor for insulated metal building walls is used as coefficients in a linear regression equation developed to represent assembly $\mathrm{U}$-factors for various standard insulation R-values, as provided in Table 3.9 for metal building wall systems with $7 \mathrm{ft}$. girt spacing. 
Table 3.9. Metal Building Wall (MBW) Assembly U-factors for Standard Insulation Thicknesses

\begin{tabular}{|c|c|}
\hline Insulation R-value & $\begin{array}{c}\text { Assembly U-factor } \\
\text { MBW without thermal block }\end{array}$ \\
\hline R-10 & 0.138 \\
\hline R-11 & 0.134 \\
\hline R-13 & 0.122 \\
\hline R-19 & 0.101 \\
\hline
\end{tabular}

Other. COMcheck allows the user to define a wall assembly by specifying its overall effective U-factor. This option permits the user to accurately describe the performance of any wall assembly not adequately covered by the predefined wall types.

\subsubsection{Thermal Mass}

COMcheck accounts for thermal mass in walls using the same algorithms and parameters used in ENVSTD--heat capacity and insulation position. While in ENVSTD values for these inputs are entered directly by the user, in COMcheck default heat capacity and insulation position parameters are provided based on the user's selection of wall type. The exception to this is the Other wall category, for which users must specify the heat capacity.

All COMcheck compliance calculations assume that any insulation in an above-grade exterior wall (or above-grade portion of a below-grade wall assembly) is integral with the thermal mass of the wall, as opposed to assuming the insulation is either on the exterior or on the interior of the wall. This assumption was made because the insulation position has little impact, producing a maximum of about a $1 \%$ change in cumulative space-condition loads in a high-mass wall. In addition, for many wall assemblies it is difficult to determine which of the three options - interior, integral, or exterior - is the most appropriate.

This assumption also appears to be appropriate for the most common wall assemblies; e.g., metal stud walls. Coincidentally, the integral insulation position appears to result in the most favorable impact from high heat-capacity walls. Assuming integral insulation is the best case for advocates of masonry construction and effectively eliminates any grounds for criticism of simplifications in COMcheck in this area.

\subsubsection{Orientation-Specific Wall Inputs}

Unspecified Orientation. Wall and window areas can be input into the COMcheck software without designation of their orientation. Section 8B.2(a) in Standard 90.1-1989 calls for budget loads to be calculated based on a 2:1 aspect ratio with an elongated north-south building axis. COMcheck uses this aspect ratio for both the proposed and budget building when orientations are unspecified. A certain percentage of the area of each wall or window component is assigned to one of the four cardinal orientations. The benefits of this simplification are that required user inputs of wall and window areas are reduced by a factor of four, and users are no longer penalized for an unfavorable site (i.e., one that requires north-south axis elongation) or rewarded for a favorable site. The adverse consequences are that the modest incentive for favorable placement of fenestration and for favorable building massing and orientation is reduced.

Technical Support Documentation for COMcheck Through Version 3.4.0 (Software) 
Specified Orientation. With COMcheck Version 2.0 orientation-specific input became optional. Users can select from among the four cardinal orientations, and the inputs are mapped to the orientation-specific input in the original ENVSTD calculation. Cardinal orientations (as opposed to the eight orientations offered in ENVSTD) were deemed adequate, because the underlying ENVSTD model only supports four orientations. The intermediate orientations (e.g., NE) are achieved by splitting the area between adjacent cardinal orientations (e.g., $50 \% \mathrm{~N}, 50 \% \mathrm{E}$ ), resulting in a near identical result to simply requiring users to enter wall area to its nearest cardinal orientation.

When orientation is specified, the budget building is modeled after the proposed building design rather than the 2:1 aspect ratio described above. Recent development work on building energy codes reflects a rejection of basing criteria on prototypes in favor of basing them on custom budgets; i.e., neutralizing the effect of building massing. The envelope trade-off procedure in Standard 90.1-1989R, the energy cost budget method in Standard 90.1-1989R, California Title 24, and the performance path in the Commercial Energy Code in Canada all base performance criteria on the user's design and not on a prototype design. In addition, the ENVSTD 2 program bases criteria on the user's input of areas and orientations and does not implement the Standard 90.1-1989 Section 8B.2(a) requirement. No documentation could be found that explained the reason for the inconsistency. Given the history and recent developments, basing budget loads on the proposed design's aspect ratio was the only reasonable choice for COMcheck.

\subsubsection{Above-Grade Wall Area}

Proposed Area. Above-grade walls, windows, doors, and portions of below-grade wall assemblies (e.g., basement walls) that are above grade are all included in the above-grade wall calculations. Areas for above-grade portions of below-grade walls $\left(\mathrm{A}_{\mathrm{ABW}}\right)$ are determined according to the following formula:

$$
\begin{array}{ll}
\text { If, } & \mathrm{H}_{\mathrm{BG}}<=\mathrm{D}_{\mathrm{BG}} \\
& \mathrm{A}_{\mathrm{ABW}}=0 \\
\text { else, } & \mathrm{A}_{\mathrm{ABW}}=\mathrm{A}_{\mathrm{BW}} \times\left(\left(\mathrm{H}_{\mathrm{BG}}-\mathrm{D}_{\mathrm{BG}}\right) / \mathrm{H}_{\mathrm{BG}}\right)
\end{array}
$$

where $\mathrm{A}_{\mathrm{ABW}}=$ opaque above-grade area of below-grade wall assembly

$\mathrm{A}_{\mathrm{BW}}=$ opaque area of below-grade wall assembly

$\mathrm{H}_{\mathrm{BG}}=$ average height of below-grade wall

$\mathrm{D}_{\mathrm{BG}}=$ average depth below grade of the base of the below-grade wall.

The proposed window-to-wall ratio is a ratio of the sum of the area of all windows and glazed doors to the total gross area of exterior walls. The gross area of exterior walls is the sum of the gross areas of abovegrade walls and the areas of above-grade portion of below-grade walls.

Budget Area. The wall area $\left(\mathrm{A}_{\mathrm{WL}}\right)$ used in calculating budget loads is the sum of the opaque wall area, window area, and door area, plus the above-grade portions of below-grade assemblies as determined using Equation 3.6.

The window-to-wall ratio used in calculating the cooling and heating coil loads attributable to windows and opaque above-grade walls $\left(\mathrm{CL}_{\mathrm{ww}}\right)$ and $\left(\mathrm{HL}_{\mathrm{ww}}\right)$ are based on the equations illustrated in Figures $8 \mathrm{~B}-1$ or 8B-2 in Standard 90.1-1989, whichever yields the smaller value. 


\subsubsection{Above-Grade Wall U-Factor}

Proposed U-Factor. The U-factors for above-grade wall assemblies and above-grade portions of belowgrade assemblies are determined using the following equation:

$$
\mathrm{U}_{\mathrm{WL}}=1 /\left(\mathrm{R}_{\mathrm{WL}-\mathrm{BOA}}+\mathrm{R}_{\mathrm{WL}-\mathrm{CVI}} \times \mathrm{AF}_{\mathrm{WL}}+\mathrm{R}_{\mathrm{WL}-\mathrm{CNI}}\right)
$$

where $\quad U_{\mathrm{WL}}=\mathrm{U}$-factor for the opaque wall assembly

$\mathrm{R}_{\mathrm{WL}-\mathrm{BOA}}=\mathrm{R}$-value for the balance of the assembly from Table 3.10 based on wall type

$\mathrm{R}_{\mathrm{WL}-\mathrm{CVI}}=\mathrm{R}$-value for the wall cavity insulation input by the user

$\mathrm{AF}_{\mathrm{WL}}=$ parallel path adjustment factor from Table 3.10 for wall type

$\mathrm{R}_{\mathrm{WL}-\mathrm{CNI}}=\mathrm{R}$-value for continuous insulation input by the user.

Budget U-Factor. The U-factor for opaque wall assemblies $\left(\mathrm{U}_{\mathrm{WL}}\right)$ is based on Equations $8 \mathrm{~B}-17$ and $8 \mathrm{~B}$ 18 in Standard 90.1-1989. Wall heat capacity is set to 1 [per Standard 90.1-1989 Section 8B.2(h)], and insulation position is set to "Integral."

\subsubsection{Mandatory U-Factor Limits}

Standard 90.1-1989, Section 8.6.10.2(a), Constraints on Thermal Transmittance Values, Opaque Wall Assemblies, contains a requirement that the overall $\mathrm{U}$-factor of lightweight opaque exterior walls (i.e., those with $\mathrm{HC}<7 \mathrm{Btu} /\left[\mathrm{ft}^{2} \times{ }^{\circ} \mathrm{F}\right]$ ) not exceed the value given by Equation 3.8 (see Standard 90.1-1989, Figure 8-8). COMcheck enforces this mandatory requirement regardless of the envelope compliance index of the proposed design.

$$
\begin{array}{ll}
\text { If, } & \mathrm{HDD} 65<=540 \\
& \mathrm{U}_{\mathrm{OW}}=1.0 \\
\text { else, } & \mathrm{U}_{\mathrm{OW}}=0.0528+510.9 / \mathrm{HDD} 65 \\
\text { where } & \mathrm{U}_{\mathrm{OW}}=\text { maximum overall conductance of opaque wall sections with } \mathrm{HC}<7 .
\end{array}
$$

\subsubsection{Above-Grade Wall Loads}

COMcheck loads for the budget building opaque walls, windows, and doors are calculated using the same equations as are found in Standard 90.1-1989 Attachment 8B and embedded in the ENVSTD Version 2.4 program (Crawley et al. 1989). A program containing these algorithms written at Concordia University was used in COMcheck. The primary reason for using this program rather than ENVSTD Version 2.4 was that the Concordia University program was written in $\mathrm{C}++$. The Concordia University program has been validated against ENVSTD Version 2.4.

$\mathrm{HC}$ and insulation position are required inputs to the heating and cooling loads calculations. Input values for $\mathrm{HC}$ are given in Table 3.6 based on wall type. Insulation position is assumed to be "integral" with the thermal mass of the wall, as opposed to assuming the insulation is either on the exterior or on the interior of the wall. 
Table 3.10. Above-Grade Wall U-Factor Calculation Coefficients

\begin{tabular}{|c|c|c|c|}
\hline Wall Type & $\mathbf{R}_{\text {WL-BOA }}$ & $\mathbf{A F}_{\mathrm{WL}}$ & HC \\
\hline Metal Frame, 16 in. o.c. & 2.28 & $\begin{array}{c}\text { (Eq. a) If } \mathrm{R}_{\mathrm{WL}-\mathrm{CVI}}<11, \mathrm{AF}=0.78814-0.03274 * \mathrm{R}_{\mathrm{WL}-\mathrm{CVI}} \\
\text { If } 11>=\mathrm{R}_{\mathrm{WL}-\mathrm{CVI}}<30, \mathrm{AF}=0.54564-0.01069 * \mathrm{R}_{\mathrm{WL}-\mathrm{CVI}} \\
\text { Else, } \mathrm{AF}=6.7482 / \mathrm{R}_{\mathrm{WL}-\mathrm{CVI}} \\
\end{array}$ & 1 \\
\hline Metal Frame, 24 in. o.c. & 2.40 & $\begin{array}{c}\text { (Eq. a) If } \mathrm{R}_{\mathrm{WL}-\mathrm{CVI}}<11, \mathrm{AF}=0.94322-0.03872 * \mathrm{R}_{\mathrm{WL}-\mathrm{CVI}} \\
\text { If } 11>=\mathrm{R}_{\mathrm{WL}-\mathrm{CVI}}<30, \mathrm{AF}=0.65373-0.01241 * \mathrm{R}_{\mathrm{WL}-\mathrm{CVI}} \\
\text { Else, } \mathrm{AF}=8.4429 / \mathrm{R}_{\mathrm{WL}-\mathrm{CVI}}\end{array}$ & 1 \\
\hline Wood Frame & 2.82 & $\begin{aligned} \text { (Eq. c) If } \mathrm{R}_{\mathrm{WL}-\mathrm{CVI}}<11, \mathrm{AF} & =0.9921-0.03297 * \mathrm{R}_{\mathrm{WL}-\mathrm{CVI}} \\
\text { Else, } \mathrm{AF} & =0.62943\end{aligned}$ & 1 \\
\hline $\begin{array}{l}\text { Metal Wall Without Thermal } \\
\text { Blocks }\end{array}$ & $\begin{array}{l}\text { If } \mathrm{R}_{\text {WL-CVI }}=0,0.85 \\
\quad \text { Else, } 4.25\end{array}$ & $\begin{array}{c}\text { (Eq. d) If } \mathrm{R}_{\mathrm{WL}-\mathrm{CVI}}=0, \mathrm{AF}=\mathrm{N} / \mathrm{A} \\
\text { else, } \mathrm{AF}=0.298251\end{array}$ & 1 \\
\hline \multicolumn{4}{|l|}{$\begin{array}{l}\text { Solid Concrete or Masonry, } \\
8 \text { in. or less }\end{array}$} \\
\hline No Furring Strips & 1.98 & None & 11.5 \\
\hline Metal Furring & 1.98 & $\begin{array}{c}\text { (Eq. a) If } \mathrm{R}_{\mathrm{WL}-\mathrm{CVI}}<11, \mathrm{AF}=0.78814-0.03274 * \mathrm{R}_{\mathrm{WL}-\mathrm{CVI}} \\
\text { If } 11>=\mathrm{R}_{\mathrm{WL}-\mathrm{CVI}}<30, \mathrm{AF}=0.54564-0.01069 * \mathrm{R}_{\mathrm{WL}-\mathrm{CVI}} \\
\text { Else, } \mathrm{AF}=6.7482 / \mathrm{R}_{\mathrm{WL}-\mathrm{CVI}}\end{array}$ & 11.5 \\
\hline Wood Furring & 1.98 & $\begin{array}{l}\text { (Eq. d) } \text { If } \mathrm{R}_{\mathrm{WL}-\mathrm{CVI}}<11, \mathrm{AF}=0.9921-0.03297 * \mathrm{R}_{\mathrm{WL}-\mathrm{CVI}} \\
\text { Else, } \mathrm{AF}=0.78526-0.01417 * \mathrm{R}_{\mathrm{WL}-\mathrm{CVI}}\end{array}$ & 11.5 \\
\hline \multicolumn{4}{|l|}{$\begin{array}{l}\text { Solid Concrete or Masonry, }>8 \\
\text { in. thick }\end{array}$} \\
\hline No Furring Strips & 2.32 & None & 17.3 \\
\hline Metal Furring & 2.32 & Eq. a & 17.3 \\
\hline Wood Furring & 2.32 & Eq. d & 17.3 \\
\hline \multicolumn{4}{|l|}{$\begin{array}{l}\text { CMU, } 8 \text { in. or less w/ Empty } \\
\text { Cells }\end{array}$} \\
\hline No Furring Strips & 2.61 & None & 5.6 \\
\hline Metal Furring & 2.61 & Eq. a & 5.6 \\
\hline Wood Furring & 2.61 & Eq. d & 5.6 \\
\hline \multicolumn{4}{|l|}{ CMU, $>8$ in. w/ Empty Cells } \\
\hline No Furring Strips & 2.87 & None & 8.7 \\
\hline Metal Furring & 2.87 & Eq. a & 8.7 \\
\hline Wood Furring & 2.87 & Eq. d & 8.7 \\
\hline \multicolumn{4}{|l|}{$\begin{array}{l}\text { CMU, } 8 \text { in. or less } \\
\text { w/ Integral Insulation }\end{array}$} \\
\hline No Furring Strips & 2.86 & None & 8.4 \\
\hline Metal Furring & 2.86 & Eq. a & 8.4 \\
\hline Wood Furring & 2.86 & Eq. d & 8.4 \\
\hline \multicolumn{4}{|l|}{$\begin{array}{l}\text { CMU, }>8 \text { in. thick } \\
\text { w/ Integral Insulation }\end{array}$} \\
\hline No Furring Strips & 3.66 & None & 13.9 \\
\hline Metal Furring & 3.66 & Eq. a & 13.9 \\
\hline Wood Furring & 3.66 & $\begin{array}{ll}\text { Eq. d } \\
\end{array}$ & 13.9 \\
\hline Other & \multicolumn{3}{|c|}{ User inputs are U-factor and heat capacity. } \\
\hline
\end{tabular}

The output from the gross wall calculation is annual cumulative cooling and heating coil loads for $1200 \mathrm{ft}^{2}$ of wall area (which is associated with $1500 \mathrm{ft}^{2}$ of exterior-zone floor area). The output units are in $\mathrm{MBtu} / \mathrm{y}$ for 1,200 $\mathrm{ft}^{2}$ of exterior wall. The individual cooling and heating load terms in Equations 3.30 and 3.31 (e.g., $\mathrm{CL}_{\mathrm{ww}}$ and $\left.\mathrm{HL}_{\mathrm{ww}}\right)$ are in units of British thermal units per year $(\mathrm{Btu} / \mathrm{y})$ for the entire building. The following steps are required to convert the engine output to Btu/y: 
1) Multiply by $1,000,000$ (to covert from MBtu to Btu)

2) Multiply by total wall area divided by $1200 \mathrm{ft}^{2}$.

The cooling and heating loads for windows, opaque walls, and doors are calculated using Equations 3.9 and 3.10 .

$$
\begin{aligned}
& \mathrm{CL}_{\mathrm{WW}}=\mathrm{CL} \times 1000000 \times \mathrm{A}_{\mathrm{WL}} / 1200 \\
& \mathrm{HL}_{\mathrm{WW}}=\mathrm{HL} \times 1000000 \times \mathrm{A}_{\mathrm{WL}} / 1200
\end{aligned}
$$

where $\mathrm{CL}_{\mathrm{wW}}=$ cooling load for exterior walls, windows and doors

$\mathrm{HL}_{\mathrm{WW}}=$ heating load for exterior walls, windows and doors

$\mathrm{CL}=$ cooling loads for the proposed or budget building design output by the engine

$\mathrm{A}_{\mathrm{WL}}=$ total wall area for all orientations, opaque wall, windows, doors, and above-grade portions of below-grade walls.

$\mathrm{HL}=$ heating loads for the proposed or budget building design output by the engine.

\subsection{Walls Next to Unconditioned Spaces}

Walls next to unconditioned space are defined as walls that separate conditioned from unconditioned spaces but that are not exterior walls.

\subsubsection{Walls Next to Unconditioned Spaces Area}

Proposed Area. The area of these walls is not included in the calculation of window-to-wall ratio. For simplicity, the areas of doors or windows in these walls are included with the opaque wall area.

Budget Area. The area for determining budget loads for walls next to unconditioned spaces is identical to that used for calculating loads for the proposed design.

\subsubsection{Walls Next to Unconditioned Spaces U-Factor}

Proposed U-Factor. The U-factor for walls next to unconditioned spaces is determined using the following equation:

$$
\mathrm{U}_{\mathrm{WU}}=1 /\left(\mathrm{R}_{\mathrm{WU}-\mathrm{BOA}}+\mathrm{R}_{\mathrm{WU}-\mathrm{CVI}} \times \mathrm{AF}_{\mathrm{WU}}+\mathrm{R}_{\mathrm{WU}-\mathrm{CNI}}+0.29\right)
$$

where: $\quad \mathrm{U}_{\mathrm{WU}}=\mathrm{U}$-factor for the wall next to unconditioned space

$\mathrm{R}_{\mathrm{WU}-\mathrm{BOA}}=\mathrm{R}$-value for the balance of assembly (excluding insulation) for the above-grade wall type

$\mathrm{R}_{\mathrm{WU}-\mathrm{CVI}}=\mathrm{R}$-value for the cavity insulation as input by the user

$\mathrm{AF}_{\mathrm{WU}}=$ parallel path adjustment factor for cavity insulation for the above-grade wall type

$\mathrm{R}_{\mathrm{WU}-\mathrm{CNI}}=\mathrm{R}$-value for the continuous insulation as input by the user.

An R-value of 0.29 is added to R-values of walls next to unconditioned spaces to account for the tempering effect of the adjacent enclosed but unconditioned space. This assumption is consistent with that used in Standard 90.1-1989R for walls next to unconditioned spaces. The adjustment has been made 
here but not for floors next to unconditioned spaces because Standard 90.1 applies the same requirements to floors next to unconditioned spaces as to floors exposed to exterior conditions.

Budget U-Factor. The U-factor for walls next to unconditioned spaces is determined by the equation in Figure 8-8 of Standard 90.1-1989.

\subsubsection{Walls Next to Unconditioned Spaces Loads}

The cooling and heating loads for walls next to unconditioned spaces $\left(\mathrm{CL}_{\mathrm{WU}}\right.$ and $\left.\mathrm{HL}_{\mathrm{WU}}\right)$ are calculated using Equations 3.12 and 3.13.

$$
\begin{aligned}
& \mathrm{CL}_{\mathrm{WU}}=\text { Area }_{\mathrm{WU}} \times \mathrm{CCoef}_{\mathrm{WU}} \times\left(1 /\left(1 / \mathrm{U}_{\mathrm{WU}}+2\right)\right) \times \mathrm{CDD} 50 \\
& \mathrm{HL}_{\mathrm{WU}}=\text { Area }_{\mathrm{WU}} \times \mathrm{HCoef}_{\mathrm{WU}} \times\left(1 /\left(1 / \mathrm{U}_{\mathrm{WU}}+2\right)\right) \times \mathrm{HDD} 65
\end{aligned}
$$

where $\quad \mathrm{CL}_{\mathrm{WU}}=$ cooling load for walls next to unconditioned space

$\mathrm{HL}_{\mathrm{WU}}=$ heating load for walls next to unconditioned space

Area $_{\mathrm{WU}}=$ area of walls next to unconditioned spaces in $\mathrm{ft}^{2}$

$\mathrm{CCoef}_{\mathrm{WU}}=7.393=$ from Standard 90.1-1989R, Appendix C, Table C.6-11: 6.04E-04 × $12.24 \times$ 1000

$\mathrm{U}_{\mathrm{WU}}=\mathrm{U}$-factor of walls next to unconditioned spaces

$\mathrm{CDD} 50=$ cooling degree-days base $50^{\circ} \mathrm{F}$ for the site.

HCoef $_{\mathrm{WU}}=13.873=$ from Standard 90.1-1989R, Appendix C, Table C.6-11: 2.28E-04 $\times$ $0.608488 \times 100000$

HDD65 $=$ heating degree-days base $65^{\circ} \mathrm{F}$ for the site.

\subsection{Windows}

\subsubsection{Window Area}

Proposed Area. By default, orientation is not specified by the user. With orientation unspecified, the calculation of both design and budget loads is based on the following distribution of window area: 1/6 of the area facing north, 1/3 facing east, 1/6 facing south, and 1/3 facing west. Matching the orientation for the proposed design to the mildly adverse orientation specified in the budget design for calculating the requirements represents a conservative approach in that it tends to preserve stringency. Beginning with COMcheck Version 2.0, users have the option of designating cardinal orientations for each window and wall, and these inputs are used directly by the engine for both design and allowable loads. The area to which the window-to-wall ratio is applied is the sum of the net opaque wall area, window area, and door area, as specified by the user, plus the above-grade portions of below-grade assemblies.

Budget Area. Values for window-to-wall ratio, glass U-factor, and glass SC are based directly on requirements in Standard 90.1-1989.

The window-to-wall ratio used in calculating budget loads is based on either the equation shown in Figure 8B-1 or the equation shown in Figure 8B-2 in Standard 90.1-1989, whichever yields the smaller value. 


\subsubsection{Solar Heat Gain Coefficient}

Proposed SC. Glass heat gain properties are entered by the user as solar heat gain coefficients (SHGCs) and these values are converted to shading coefficients (SCs) for internal use by the program. The following equation is used in performing this conversion:

$$
\mathrm{SC}=\mathrm{SHGC} / 0.87
$$

The conversion value of 0.87 is for standard summer conditions and normal incidence angles and is from the 1993 ASHRAE Handbook of Fundamentals, page 27.19, Equation (39) (ASHRAE 1993a).

Budget SC. Shading coefficients (SCs) are based on Equations 8B-19 through 8B-22 of Standard 90.11989.

\subsubsection{Projection Factor}

Proposed Projection Factor. Projection factors are used as entered by the user.

Budget Projection Factor. Projection factors are set to 0.0 for consistency with Section 8B.2(e) and 8B.2(f) of Standard 90.1-1989.

\subsubsection{Daylighting Control Credits}

Beginning with Version 2.0, COMcheck offers compliance credit in the envelope section for using automatic controls for daylight utilization. Daylight control credits were not included in Version 1 of COMcheck because automatic daylighting controls were judged to be infrequently used and because daylighting performance is somewhat orientation-specific, and Version 1 did not permit orientationspecific inputs. This feature was later requested for the Massachusetts Code and was added as an optional feature with other Standard 90.1 based codes. When the daylighting control credit option is selected, orientation, visible light transmittance, and daylighting control factors are required from the user.

Daylighting control credits have been implemented according to the equations in Attachment $8 \mathrm{~B}$ of Standard 90.1-1989. The daylighting credit is calculated by adjusting the effective internal gain based on the fraction of the electric lighting controlled by automatic daylighting controls and the effective aperture for visible light transmission. The adjustments are made separately to the cooling and heating load equations. These adjustments apply only to the calculation of design loads and do not apply to the calculation of the allowable loads.

Equations 8B-3 and 8B-3a of Standard 90.1-1989 adjust the effective internal gain input in the cooling load equation based on daylighting control factor and glass visible light transmittance. Equations 8B-7 and 8B-7a adjust the effective internal gain input in the heating load equation based on daylighting control factor and glass visible light transmittance.

Proposed DLCF and VLT. Daylighting control factors (DLCFs) and visible light transmittance (VLT) are used as entered by the user. These are optional inputs, and remain set at 0.0 if not entered.

Budget DLCF and VLT. Daylighting control factors (DLCFs) and visible light transmittance (VLT) are set to 0.0 for consistency with Sections 8B.2(k) and 8B.2(1) of Standard 90.1-1989. 


\subsubsection{Window U-Factor}

Proposed U-Factor. Window U-factors are used in calculations exactly as entered by the user.

Budget U-Factor. U-factors are based on the equations in Section 8B.2j in Standard 90.1-1989.

\subsubsection{Mandatory U-Factor Limit}

Standard 90.1-1989, Section 8.6.10.2(b), Constraints on Thermal Transmittance Values, Fenestration Assemblies, as amended in Addendum F, contains a requirement that the U-factor of fenestration not exceed the value given by Equation 7-9 of the Standard 90.1-1989 except where the window-to-wall ratio for the entire building is $10 \%$ or less. This requirement is shown below as Equation 3.15. COMcheck enforces this as a mandatory requirement regardless of the value of the envelope compliance index.

$$
\begin{aligned}
& \text { If HDD65 > } 3000 \text { and WWR }>0.10 \\
& \mathrm{U}_{\text {of }}=0.72
\end{aligned}
$$

where $\mathrm{WWR}=$ window-to-wall ratio

$\mathrm{U}_{\mathrm{of}}=$ maximum overall conductance of fenestration assemblies.

\subsubsection{Window Default Values}

The software optionally provides suggested (default) values for vertical glass U-factors, SHGCs, and visible light transmittances (VLTs) for commercially available combinations of glazing layers (i.e., single, double, double low-e, triple, and triple low-e), glass type (i.e., clear, tinted, reflective), and frame type (i.e., wood or vinyl, metal, and metal with thermally broken frame). Tables 3.11 and 3.12 contain these suggested values and documentation of sources for both window and skylight glazings.

These typical values have been included in COMcheck for ease-of-use reasons. They enable users to check building compliance prior to having selected actual glazing products from manufacturers' literature. Given this use, the suggested values are most helpful if they are conservative; i.e., represent performance that is about as poor as can be found within a given class of products. For that reason, glazing U-factors and solar heat gain coefficients are intended to represent high values for the given glazing and frame combinations. Visible light transmittance was selected to reflect typical (or slightly adverse) relationships between solar heat gain coefficients and visible light transmittance for each glazing type.

Where possible, suggested glazing data were derived from readily-available published sources. The primary sources were 1997 ASHRAE Fundamentals Handbook (AHF), Chapter 9 Fenestration, Table 5, U-Factors for Various Fenestrations Products and Table 11, Visible Transmission, Shading Coefficient and Solar Heat Gain Coefficients at Normal Incidence for Single Pane Glass and Insulating Glass. However, because these tables contain data representing only a small portion of available products, it was necessary to supplement these data sources with other data that better reflect the range of currently available products. Data representing current products were drawn from Standard 90.1-1989R, $2^{\text {nd }}$ Public Review Draft, December 1997 (90.1R\#2) Table A-18 Assembly Solar Heat Gain Coefficients (SHGC) and Assembly Visible Light Transmittance (VLT) for Unlabeled Glazing Wall Systems (Site-Built Windows) and Unlabeled Skylights (I-P). In addition, some data that could not be found in published data sources were drawn from an unpublished database used in the development of Standard 90.1-1989R.

Technical Support Documentation for COMcheck Through Version 3.4.0 (Software) 
Table 3.12. Glazing U-Factors

\begin{tabular}{|c|c|c|c|c|}
\hline \multirow[b]{2}{*}{ Vertical (Windows) } & \multicolumn{3}{|c|}{ Window Frame Type } & \multirow[b]{2}{*}{ Source } \\
\hline & Metal & Metal w/ TB & Wood/Vinyl & \\
\hline \multicolumn{5}{|c|}{ For Use in COMcheck and COMcheck-Plus Software } \\
\hline Single & 1.13 & 1.07 & 0.98 & AHF Tbl 5, 1 (1/8” glass $)$ \\
\hline Double & 0.69 & 0.63 & 0.56 & AHF Tbl 5, 4 (1/4” air space) \\
\hline Double Low-e & 0.61 & 0.54 & 0.48 & AHF Tbl 5, 16 (1/4" air space) \\
\hline Triple & 0.55 & 0.48 & 0.41 & AHF Tbl 5, 28 (1/4" air space) \\
\hline Triple Low-e & 0.50 & 0.44 & 0.37 & AHF Tbl 5, 32 (1/4" air space) \\
\hline \multirow[b]{2}{*}{ Sloped (Skylights) } & & light Frame $T_{J}$ & & \multirow[b]{2}{*}{ Source } \\
\hline & Metal & Metal w/ TB & Wood/Vinyl & \\
\hline \multicolumn{5}{|c|}{ For Use in COMcheck and COMcheck-Plus Software } \\
\hline Single & 1.98 & 1.89 & 1.47 & AHF Tbl 5, 1 (1/8” glass) \\
\hline Double & 1.31 & 1.11 & 0.84 & AHF Tbl 5, 4 (1/4” air space) \\
\hline Double Low-e & 1.20 & 1.00 & 0.74 & AHF Tbl 5, 16 (1/4" air space) \\
\hline Triple & 1.12 & 0.89 & 0.64 & AHF Tbl 5, 28 (1/4" air space) \\
\hline Triple Low-e & 1.08 & 0.85 & 0.59 & AHF Tbl 5, 32 (1/4” air space) \\
\hline \multicolumn{5}{|c|}{$\begin{array}{l}\text { Notes: } \\
\text { (1) The defaults used in the COMcheck prescriptive packages have been rounded up to the nearest } 0.1 \text { values, which correspond } \\
\text { with the precision used in representing the prescriptive requirements. These values do not correspond exactly with the } \\
\text { suggested values used in the software. Rounding was judged to be helpful in a simplified, paper-based compliance method, } \\
\text { but unnecessary and inappropriate for a software-based method. }\end{array}$} \\
\hline
\end{tabular}

\subsection{Doors}

\subsubsection{Door Area}

Proposed Area. Standard 90.1-1989 has no separate requirements for exterior doors; doors are included in the calculation of overall conductance of opaque walls. COMcheck provides inputs for doors to eliminate the need for users to calculate overall conductance outside of the program. Menu options are available to identify door type and to provide default values for door conductance. In COMcheck, sliding-glass doors are entered by the user as doors, although the software treats them as windows. Doors entered as glass doors are assigned an SHGC of 0.87.

Budget Area. Exterior doors are not addressed separately in the calculation of allowable loads. Door area is included in the overall wall area.

\subsubsection{Door U-Factor}

Proposed U-Factor. Door U-factors are used as entered by the user.

Budget U-Factor. Doors have the same U-factor requirement as exterior opaque wall assemblies.

\subsubsection{Door Typical (Default) U-Factors}

Door U-factors in Table 3.13 have been drawn from Standard 90.1-1989R and are intended to reflect typical products (ASHRAE 1996). 
Table 3.13. Default Door U-Factor

\begin{tabular}{|l|c|}
\hline \multicolumn{1}{|c|}{ Door Type } & Default U-Factor \\
\hline Opaque Door & 0.7 \\
\hline Glass Door & 0.92 \\
\hline Overhead Door & 1.45 \\
\hline Air-Lock Entry Door & 0.5 \\
\hline Revolving Door & 0.5 \\
\hline Other & N/A \\
\hline
\end{tabular}

\subsection{Floors}

The Floor assembly type is used for any floor of a conditioned space whose underside is exposed to exterior conditions or unconditioned space, including crawl spaces.

\subsubsection{Floor Assembly Types}

COMcheck considers five types of floors:

All-Wood Joist Truss. The subfloor is attached directly to the top of the wood joist and insulation is located directly below the subfloor with a ventilated airspace below the insulation. The distance of the heat flow path through the joist is calculated to be the same as through the insulation. The assembly includes R-0.92 for interior air film--heat flow down, R-1.23 for carpet and pad, R-0.94 for 0.75-in. wood subfloor, and R-0.46 for semi-exterior air film, providing a total balance of assembly R-value of 3.55.

Nonwood Joist/Truss. The insulation is either placed between the metal joists or is sprayed on the underside of the metal floor deck. In both cases, the metal joist provides a thermal bypass to the insulation. The assembly includes R-0.92 for interior air film--heat flow down, R-1.23 for carpet and pad, R- 0.25 for 4-in. concrete, R-0 for metal deck, and R- 0.46 for semi-exterior air film. The total balance of assembly R-value of 2.88 includes an adjustment for metal framing construction. The performance of the insulation/framing layer is calculated using the parallel path correction factors found in Table $8 \mathrm{C}-1$ of Standard 90.1-1989.

Concrete (over unconditioned space). This assembly consists of continuous insulation under (or over) a structural concrete floor slab. The assembly includes R-0.92 for interior air film--heat flow down, R-1.23 for carpet and rubber pad, R- 0.50 for 8 -in. concrete, and R- 0.46 for semi-exterior air film, providing a total balance of assembly R-value of 3.11 .

Slab-on-grade. Slab-on-grade assemblies are listed with other floor types in COMcheck, but the U-factor and loads calculations are described in this TSD in a subsequent section. The calculations explained in this section do not apply to slab-on-grade assemblies.

Other. COMcheck allows the user to define a floor assembly by specifying its overall effective U-factor. This option permits the user to accurately describe the performance of any floor assembly not adequately covered by the predefined floor types. 


\subsubsection{Floor Area}

Proposed Area. Exposed floor area is used as entered by the user.

Budget Area. Exposed floor area is used as entered by the user.

\subsubsection{Floor U-Factor}

Proposed U-Factor. Cavity and continuous insulation inputs are used in calculating the U-factor for exposed floors using the following equation:

$$
\mathrm{U}_{\mathrm{EF}}=1 /\left(\mathrm{R}_{\mathrm{EFn}-\mathrm{BOA}}+\mathrm{R}_{\mathrm{EF}-\mathrm{CVI}} \times \mathrm{AF}_{\mathrm{EFn}}+\mathrm{R}_{\mathrm{EF}-\mathrm{CNI}}\right)
$$

where $\quad \mathrm{U}_{\mathrm{EF}}=\mathrm{U}$-factor for the exposed floor input to the trade-off engine

$\mathrm{R}_{\mathrm{EFn}-\mathrm{BOA}}=\mathrm{R}$-value for the balance of the assembly from Table 3.14

$\mathrm{R}_{\mathrm{EF}-\mathrm{CVI}}=\mathrm{R}$-value of the cavity insulation as input by the user

$\mathrm{AF}_{\mathrm{EFn}}=$ parallel path adjustment factor from Table 3.14

$\mathrm{R}_{\mathrm{EF}-\mathrm{CNI}}=\mathrm{R}$-value for continuous insulation as input by the user.

Table 3.14. Exposed Floor U-Factor Calculation Coefficients

\begin{tabular}{|l|c|c|}
\hline \multicolumn{1}{|c|}{ Floor Type } & $\mathbf{R}_{\text {EF-BOA }}$ & AF $_{\text {EF }}$ \\
\hline All-Wood Joist/Truss & 3.55 & 0.894 \\
\hline Nonwood Joist/Truss & 2.88 & $1-0.00738 \times \mathrm{R}_{\text {EF-CVI }}$ \\
\hline Structural Slab & 3.11 & None \\
\hline Other & \multicolumn{2}{|c|}{ User input is overall U-factor. } \\
\hline
\end{tabular}

Budget U-Factor. The U-factor is determined from the following equation, as provided in Figure 8-5 of Standard 90.1-1989:

For: $\mathrm{HDD} 65<=550, \mathrm{U}_{\mathrm{EF}}=0.40$

For: $550<\mathrm{HDD} 65<=8000, \mathrm{U}_{\mathrm{EF}}=1 /(0.84+0.00302 \times \mathrm{HDD} 65)$

For: $8000<\mathrm{HDD} 65<15000, \mathrm{U}_{\mathrm{EF}}=0.04$

where $\mathrm{U}_{\mathrm{EF}}=$ budget $\mathrm{U}$-factor for exposed floors

HDD65 $=$ heating degree-days base $65^{\circ} \mathrm{F}$.

Note: HDD65 $>=15000$ is not applicable.

\subsubsection{Floor Loads}

The cooling and heating loads for exposed floors $\left(\mathrm{CL}_{\mathrm{EF}}\right.$ and $\left.\mathrm{HL}_{\mathrm{EF}}\right)$ are calculated using Equations 3.18 and 3.19 .

$$
\begin{gathered}
\mathrm{CL}_{\mathrm{EF}}=\text { Area }_{\mathrm{EF}} \times \mathrm{CCoef}_{\mathrm{EF}} \times \mathrm{U}_{\mathrm{EF}} \times \mathrm{CDD} 50 \\
\mathrm{HL}_{\mathrm{EF}}=\text { Area }_{\mathrm{EF}} \times \mathrm{HCoef}_{\mathrm{EF}} \times \mathrm{U}_{\mathrm{EF}} \times \mathrm{HDD} 65
\end{gathered}
$$

where $\quad \mathrm{CL}_{\mathrm{EF}}=$ cooling load for floors 


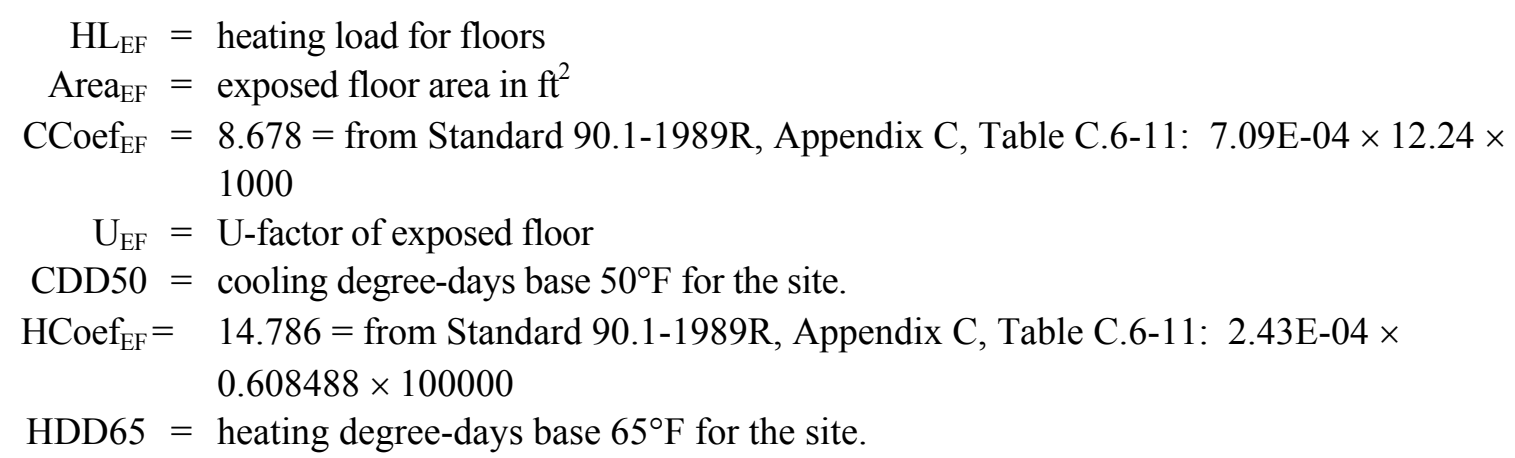

\subsection{Slab-On-Grade Floors}

\subsubsection{Slab-On-Grade Floor Perimeter}

Proposed Perimeter. Concrete slabs on grade are entered as the perimeter length of exposed slab edge. The perimeter is used for determining design and budget loads. Slab-on-grade floors input is used with conditioned space only; slabs associated with unconditioned spaces are ignored.

Budget Perimeter. The budget building perimeter is calculated the same as the proposed building.

\subsubsection{Slab-On-Grade Floor F-Factor}

Proposed F-Factor. The slab-on-grade floors are 6-in. concrete poured directly on earth. The bottom of the slab is at grade line; soil conductivity is $0.75 \mathrm{Btu} / \mathrm{h} \cdot \mathrm{ft}^{2} \cdot{ }^{\circ} \mathrm{F}$. Heat loss for the slab is expressed in terms of F-factors based on the perimeter of the slab rather than $U$-factors based on the area of the slab.

The slab-on-grade F-factor is determined based on whether the slab is heated or unheated, the insulation position (i.e., vertical or horizontal), the insulation depth in inches, and the insulation R-value. Table 3.15 contains both numbers and simple arithmetic functions that approximate the F-factor for slabs based on these inputs. The F-factor is the heat transfer coefficient of a slab edge per unit of perimeter length in units of Btu/h.ft ${ }^{\circ} \mathrm{F}$. The data on which Table 3.15 is based are from Table 5-89 in Standard 90.1-1989R. Using arithmetic approximations of the data in Standard 90.1-1989R, we have eliminated the need for complex interpolation of the tabular data.

Budget F-Factor. The F-factors used for calculating budget loads are based on Figure 8-6 in Standard 90.1-1989. Loads are based on user inputs for perimeter length, insulation position, and whether the slab is heated or unheated. The values for F-factors are determined using a two-step process. First, the required R-value is determined using Equation 3.20. Second, the F-factor is determined using the required R-value, position, and heating/unheated slab condition as lookup values in Table 3.16. The formulas in Table 3.16 are based on the combinations of insulation depth and R-value in Standard 90.11989, Figure 8-6, which lead to the lowest F-factor; i.e., the required values are based on the compliance options in Standard 90.1-1989 that tended to be the most thermally effective based on the data from Standard 90.1-1989R. For horizontal positions, the F-factor is based on a 48-in. depth and for vertical insulation positions, the F-factor is based on a 36-in. depth. For un-insulated slabs in locations that normally require slab-edge insulation (i.e., > 3000 HDD65), the allowable load is based on 36-in. depth of 
Table 3.15. Assembly F-Factors for Slab-on-Grade Floors for Proposed Design

\begin{tabular}{|c|c|c|}
\hline \multirow[b]{2}{*}{$\begin{array}{c}\text { Slab and Insulation } \\
\text { Description }\end{array}$} & \multicolumn{2}{|c|}{ F-Factor } \\
\hline & $\begin{array}{c}\text { R-0 to R-5 } \\
\text { Insulation R-Value }\end{array}$ & $\begin{array}{c}>\text { R- } 5 \\
\text { Insulation R-Value }\end{array}$ \\
\hline \multicolumn{3}{|l|}{ Unheated Slabs } \\
\hline None & 0.73 & 0.73 \\
\hline 12 in. horizontal & $0.73-0.002 * \mathrm{R}_{\mathrm{SBI}}{ }^{(a)}$ & 0.72 \\
\hline 24 in. horizontal & $0.73-0.006 * \mathrm{R}_{\mathrm{SBI}}$ & 0.70 \\
\hline 36 in. horizontal & $0.73-0.008 \mathrm{R}_{\mathrm{SBI}}$ & $0.69-0.003 * \mathrm{R}_{\mathrm{SBI}}$ \\
\hline 48 in. horizontal & $0.73-0.012 * \mathrm{R}_{\mathrm{SBI}}$ & $0.67-0.004 * \mathrm{R}_{\mathrm{SBI}}$ \\
\hline 12 in. vertical & $0.73-0.024 * \mathrm{R}_{\mathrm{SBI}}$ & $0.61-0.006 * \mathrm{R}_{\mathrm{SBI}}$ \\
\hline 24 in. vertical & $0.73-0.030 * \mathrm{R}_{\mathrm{SBI}}$ & $0.58-0.006 * \mathrm{R}_{\mathrm{SBI}}$ \\
\hline 36 in. vertical & $0.73-0.034 * \mathrm{R}_{\mathrm{SBI}}$ & $0.56-0.007 * \mathrm{R}_{\mathrm{SBI}}$ \\
\hline 48 in. vertical & $0.73-0.038 * \mathrm{R}_{\mathrm{SBI}}$ & $0.54-0.009 * \mathrm{R}_{\mathrm{SBI}}$ \\
\hline Fully insulated slab & $0.73-0.054 * \mathrm{R}_{\mathrm{SBI}}$ & $0.46-0.016^{*} \mathrm{R}_{\mathrm{SBI}}$ \\
\hline \multicolumn{3}{|l|}{ Heated Slabs } \\
\hline None & 1.35 & 1.35 \\
\hline 12 in. horizontal & $1.35-0.006 * \mathrm{R}_{\mathrm{SBI}}$ & 1.32 \\
\hline 24 in. horizontal & $1.35-0.014 * \mathrm{R}_{\mathrm{SBI}}$ & 1.28 \\
\hline 36 in. horizontal & $1.35-0.022 * \mathrm{R}_{\mathrm{SBI}}$ & $1.24-0.006 * \mathrm{R}_{\mathrm{SBI}}$ \\
\hline 48 in. horizontal & $1.35-0.030 * \mathrm{R}_{\mathrm{SBI}}$ & $1.20-0.009 * \mathrm{R}_{\mathrm{SBI}}$ \\
\hline 12 in. vertical & $1.35-0.058 * \mathrm{R}_{\mathrm{SBI}}$ & $1.06-0.013 * \mathrm{R}_{\mathrm{SBI}}$ \\
\hline 24 in. vertical & $1.35-0.072 * \mathrm{R}_{\mathrm{SBI}}$ & $0.99-0.013 * \mathrm{R}_{\mathrm{SBI}}$ \\
\hline 36 in. vertical & $1.35-0.080 * \mathrm{R}_{\mathrm{SBI}}$ & $0.95-0.016 * \mathrm{R}_{\mathrm{SBI}}$ \\
\hline 48 in. vertical & $1.35-0.088 * \mathrm{R}_{\mathrm{SBI}}$ & $0.91-0.019 * \mathrm{R}_{\mathrm{SBI}}$ \\
\hline Fully insulated slab & $1.35-0.122 * \mathrm{R}_{\mathrm{SBI}}$ & $0.74-0.030 * \mathrm{R}_{\mathrm{SBI}}$ \\
\hline
\end{tabular}

Table 3.16. Assembly F-Factors for Calculating Budget Loads for Slab-on-Grade Floors

\begin{tabular}{|c|c|c|}
\hline $\begin{array}{c}\text { Slab and Insulation } \\
\text { Description }\end{array}$ & \multicolumn{2}{|c|}{ Required Insulation R-value } \\
\cline { 2 - 3 } & $\mathbf{R - 0}$ to R-5 & $>\mathbf{R}-5$ \\
\hline Unheated Slabs & & \\
\hline Horizontal & $0.73-0.012 * \mathrm{R}_{\mathrm{SBI}}$ & $0.67-0.004 * \mathrm{R}_{\mathrm{SBI}}$ \\
\hline Vertical & $0.73-0.034 * \mathrm{R}_{\mathrm{SBI}}$ & $0.56-0.007 * \mathrm{R}_{\mathrm{SBI}}$ \\
\hline No insulation & $0.73-0.034 * \mathrm{R}_{\mathrm{SBI}}$ & $0.56-0.007 * \mathrm{R}_{\mathrm{SBI}}$ \\
\hline Heated Slabs & & \\
\hline 48 in. horizontal & $1.35-0.030 * \mathrm{R}_{\mathrm{SBI}}$ & $1.20-0.009 * \mathrm{R}_{\mathrm{SBI}}$ \\
\hline 36 in. vertical & $1.35-0.080 * \mathrm{R}_{\mathrm{SBI}}$ & $0.95-0.016 * \mathrm{R}_{\mathrm{SBI}}$ \\
\hline No insulation & $1.35-0.080 * \mathrm{R}_{\mathrm{SBI}}$ & $0.95-0.016 * \mathrm{R}_{\mathrm{SBI}}$ \\
\hline
\end{tabular}


vertical insulation. This method represents a conservative approach (i.e., tending to preserve stringency) to adding this new flexibility because it bases the loads on the most effective and cost-efficient position and depth for the insulation.

For unheated slabs:

for horizontal insulation:

$$
\begin{aligned}
& \text { for } \mathrm{HDD} 65<=3000, \mathrm{R}_{\mathrm{SBI}}=0.0 \\
& \text { for } 3000<\mathrm{HDD} 65<=5000, \mathrm{R}_{\mathrm{SBI}}=0.00135 \times \mathrm{HDD} 65+3.25 \\
& \text { for } 5000<\mathrm{HDD} 65<=8000, \mathrm{R}_{\mathrm{SBI}}=0.0004 \times \mathrm{HDD} 65+8.0 \\
& \text { for } \mathrm{HDD} 65>8000, \mathrm{R}_{\mathrm{SBI}}=11.2
\end{aligned}
$$

for vertical insulation:

$$
\begin{aligned}
& \text { for HDD65 }<=3000, \mathrm{R}_{\mathrm{SBI}}=0.0 \\
& \text { for } 3000<\mathrm{HDD} 65<=5000, \mathrm{R}_{\mathrm{SBI}}=0.0005 \times \mathrm{HDD} 65+3.2
\end{aligned}
$$$$
\text { for } 5000<\text { HDD } 65<=8000, \mathrm{R}_{\mathrm{SBI}}=0.0001 \times \mathrm{HDD} 65+5.2
$$$$
\text { for } \mathrm{HDD} 65>8000, \mathrm{R}_{\mathrm{SBI}}=6.0
$$

for no insulation:

same as vertical insulation.

For heated slabs:

for horizontal insulation:

$$
\begin{aligned}
& \text { for HDD65 }<=3000, \mathrm{R}_{\mathrm{SBI}}=0.0 \\
& \text { for } 3,000<\mathrm{HDD} 65<=5000, \mathrm{R}_{\mathrm{SBI}}=0.00135 \times \mathrm{HDD} 65+5.25 \\
& \text { for } 5,000<\mathrm{HDD} 65<=8000, \mathrm{R}_{\mathrm{SBI}}=0.0004 \times \mathrm{HDD} 65+10.0 \\
& \text { for HDD65 }>8000, \mathrm{R}_{\mathrm{SBI}}=13.2
\end{aligned}
$$

for vertical insulation:

for HDD65 $<=3000, \mathrm{R}_{\mathrm{SBI}}=0.0$

for $3000<\mathrm{HDD} 65<=5000, \mathrm{R}_{\mathrm{SBI}}=0.0005 \times \mathrm{HDD} 65+5.2$

for $5000<$ HDD65 $<=8000, \mathrm{R}_{\mathrm{SBI}}=0.0001 \times \mathrm{HDD} 65+7.2$

for $\mathrm{HDD} 65>8000, \mathrm{R}_{\mathrm{SBI}}=8.0$

for no insulation:

same as vertical insulation.

Note that this procedure provides credit for insulation that extends under the entire slab and permits the trade-off of insulation depths and R-values down to zero insulation levels. The justification for providing these additional trade-offs is found in Section 13, Building Energy Cost Budget Method in Standard 90.11989.

\subsubsection{Slab-On-Grade Floor Loads}

The cooling and heating loads for concrete slabs on grade $\left(\mathrm{CL}_{\mathrm{SB}}\right.$ and $\left.\mathrm{HL}_{\mathrm{SB}}\right)$ are calculated using Equations 3.21 and 3.22. Concrete slabs will have no effect on cooling loads. The cooling term $\left(\mathrm{CCoef}_{\mathrm{SB}}\right)$ is included so that alternate assumptions can be implemented easily in the future.

$$
\begin{aligned}
& \mathrm{CL}_{\mathrm{SB}}=\text { Perimeter }_{\mathrm{SB}} \times \mathrm{CCoef}_{\mathrm{SB}} \times \mathrm{F}_{\mathrm{SB}} \times \mathrm{CDD} 50 \\
& \mathrm{HL}_{\mathrm{SB}}=\text { Perimeter }_{\mathrm{SB}} \times \text { HCoef }_{\mathrm{SB}} \times \mathrm{F}_{\mathrm{SB}} \times \mathrm{HDD} 65
\end{aligned}
$$

where $\quad \mathrm{CL}_{\mathrm{SB}}=$ cooling load for slabs

$\mathrm{HL}_{\mathrm{SB}}=$ heating load for slabs

Perimeter $_{\mathrm{SB}}=$ length of exposed slab-on-grade floor perimeter in $\mathrm{ft}$ 


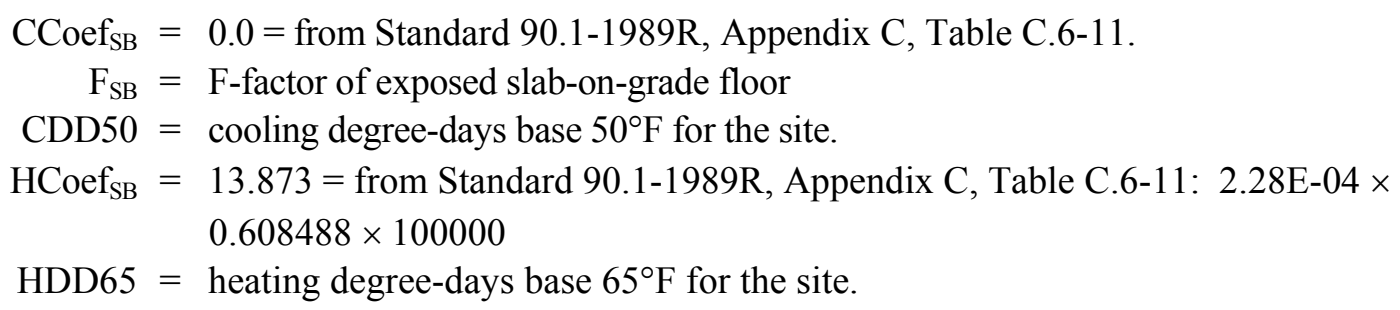

\subsection{Below-Grade Walls}

Below-grade walls are defined as walls below finish grade and not as below-grade wall assemblies, portions of which may be above finish grade. In COMcheck, user entry determines what part of a belowgrade wall assembly is assumed to be below grade, and the software uses that information to model part of the wall as below grade and part as above grade.

\subsubsection{Below-Grade Wall Assemblies}

COMcheck defines seven types of masonry walls that may be used either above grade or below grade. The seven types are

- solid concrete $\leq 8$ in.

- solid concrete $>8$ in.

- $\mathrm{CMU} \leq 8$ in. with empty cells

- $\mathrm{CMU}>8$ in. with empty cells

- $\mathrm{CMU} \leq 8$ in. with integral insulation

- $\mathrm{CMU}>8$ in. with integral insulation

- Other.

The balance of assembly R-values for basement walls were derived from the above-grade structural masonry wall types shown in Table 3.10 for above-grade walls. For below-grade walls, the balance of assembly R-value is calculated as a sum of the concrete/masonry R-value and the inside air film - outside air films (R-0.17) have been removed. Unfurred below-grade walls are assumed to have rigid insulation on the outside of the walls; hence, the balance of assemblies are lower than those with interior furring by the R-value of the assumed gypsum board finish (R-0.45).

Table 3.17. Balance of Assembly R-values for Below-Grade Walls

\begin{tabular}{|c|c|c|c|c|c|c|}
\hline \multirow[b]{2}{*}{ Layer Name } & \multicolumn{2}{|c|}{$\begin{array}{l}\text { Solid Concrete } \\
\text { or Masonry }\end{array}$} & \multicolumn{2}{|c|}{$\begin{array}{c}\text { CMU w/Empty } \\
\text { Cells }\end{array}$} & \multicolumn{2}{|c|}{$\begin{array}{l}\text { CMU w/Integral } \\
\text { Insulation }\end{array}$} \\
\hline & $<8 ”$ & $>\mathbf{8}^{\prime \prime}$ & $<\mathbf{8}^{\prime \prime}$ & $>8 ”$ & $<\mathbf{8}$ & $>8 ”$ \\
\hline Concrete/Masonry & 0.68 & 1.02 & 1.31 & 1.57 & 1.56 & 2.36 \\
\hline Inside Air Film & 0.68 & 0.68 & 0.68 & 0.68 & 0.68 & 0.68 \\
\hline Total Assembly R-Value (unfurred) & 1.36 & 1.70 & 1.99 & 2.25 & 2.24 & 3.04 \\
\hline 1/2-in. Gypsum Board & 0.45 & 0.45 & 0.45 & 0.45 & 0.45 & 0.45 \\
\hline Total Assembly R-Value (furred) & 1.81 & 2.15 & 2.44 & 2.70 & 2.69 & 3.49 \\
\hline
\end{tabular}




\subsubsection{Below-Grade Wall Area}

Proposed Area. Above-grade portions of below-grade wall assemblies are estimated from the average height and average depth below-grade inputs. Above-grade portions of below-grade walls are treated as above-grade walls. The definition of a below-grade wall in this document is different from the definition used with the prescriptive packages, which permits some above-grade wall area to be included in what is considered below-grade wall. For purposes of this document, the term "below-grade wall" applies only to the portion of the wall that is below grade.

Below-grade areas of below-grade walls $\left(\mathrm{A}_{\mathrm{BBW}}\right)$ are determined according to the following formula:

$$
\text { If, } \begin{aligned}
& \mathrm{H}_{\mathrm{BG}}<=\mathrm{D}_{\mathrm{BG}} \\
& \mathrm{A}_{\mathrm{BBW}}=\mathrm{A}_{\mathrm{BW}} \\
& \text { else, } \quad \mathrm{A}_{\mathrm{BBW}}=\mathrm{A}_{\mathrm{BW}} \times\left(\mathrm{D}_{\mathrm{BG}} / \mathrm{H}_{\mathrm{BG}}\right)
\end{aligned}
$$

where $\mathrm{A}_{\mathrm{BBW}}=$ below-grade area of below-grade wall assembly

$\mathrm{A}_{\mathrm{BW}}=$ opaque area of below-grade wall assembly

$\mathrm{H}_{\mathrm{BG}}=$ average height of below-grade wall

$\mathrm{D}_{\mathrm{BG}}=$ average depth of below-grade wall.

Budget Area. The wall area for determining budget loads for below-grade walls is identical to that used for calculating loads for the proposed building.

\subsubsection{Below-Grade Wall R-Values and Heat Capacity}

Proposed R-Values and Heat Capacity. Above-grade portions of below-grade wall assemblies are treated the same as above-grade walls. Heat capacity for the above-grade portion of all below-grade walls is set at 1.0. The heat capacity is used in the above-grade wall heating and cooling loads calculation. The $\mathrm{R}$-value for below-grade wall assembly $\left(\mathrm{R}_{\mathrm{BWA}}\right)$ is determined using the following equation:

$$
\mathrm{R}_{\mathrm{BWA}}=\mathrm{R}_{\mathrm{BW}-\mathrm{BOA}}+\mathrm{R}_{\mathrm{BW}-\mathrm{CVI}} \times \mathrm{AF}_{\mathrm{BW}}+\mathrm{R}_{\mathrm{BW}-\mathrm{CNI}}
$$

where $\quad R_{\mathrm{BWA}}=\mathrm{R}$-value of below-grade wall assembly

$\mathrm{R}_{\mathrm{BW}-\mathrm{BOA}}=\mathrm{R}$-value of balance of assembly (excluding insulation) for below-grade wall type

$\mathrm{R}_{\mathrm{BW}-\mathrm{CVI}}=\mathrm{R}$-value of cavity insulation as input by the user

$\mathrm{AF}_{\mathrm{BW}}=$ adjustment factor for parallel path conduction (from Table 3.18) based on belowgrade wall type

$\mathrm{R}_{\mathrm{BW}-\mathrm{CNI}}=\mathrm{R}$-value for continuous insulation as input by the user.

Budget Building R-value and Heat Capacity. The R-value for below-grade wall assemblies $\left(\mathrm{R}_{\mathrm{BWI}}\right)$ is as specified in the following equation, which is based on Figure 8-7 in Standard 90.1-1989:

$$
\begin{aligned}
& \text { for } \mathrm{HDD} 65<=3000, \mathrm{R}_{\mathrm{BWA}}=\mathrm{R}_{\mathrm{BW}-\mathrm{BOA}} \\
& \text { for } 3000<\mathrm{HDD} 65<15000, \mathrm{R}_{\mathrm{BWA}}=4.5+0.00075 \times \mathrm{HDD} 65 \\
& \text { for HDD65 }>=15000, \mathrm{R}_{\mathrm{BWA}}=18
\end{aligned}
$$


Table 3.18. Below-Grade Wall U-Factor Calculation Coefficients

\begin{tabular}{|c|c|c|}
\hline Wall Type & $\mathbf{R}_{\mathrm{BW}-\mathrm{BOA}}$ & $\mathbf{A F}_{\mathbf{B W}}$ \\
\hline \multicolumn{3}{|c|}{ Solid Concrete or Masonry, 8 in. or less } \\
\hline No Furring Strips & 1.36 & None \\
\hline Metal Furring & 1.81 & $\begin{array}{c}\text { (Eq. a) If } \mathrm{R}_{\mathrm{WL}-\mathrm{CVI}}<11, \mathrm{AF}=0.78814-0.03274 * \mathrm{R}_{\mathrm{WL}-\mathrm{CVI}} \\
\text { If } 11>=\mathrm{R}_{\mathrm{WL}-\mathrm{CVI}}<30, \mathrm{AF}=0.54564-0.01069 * \mathrm{R}_{\mathrm{WL}-\mathrm{CVI}} \\
\text { Else, } \mathrm{AF}=6.7482 / \mathrm{R}_{\mathrm{WL}-\mathrm{CVI}}\end{array}$ \\
\hline Wood Furring & 1.81 & $\begin{array}{l}\text { (Eq. d) If } \mathrm{R}_{\mathrm{WL}-\mathrm{CVI}}<11, \mathrm{AF}=0.9921-0.03297 * \mathrm{R}_{\mathrm{WL}-\mathrm{CVI}} \\
\text { Else, } \mathrm{AF}=0.78526-0.01417 * \mathrm{R}_{\mathrm{WL}-\mathrm{CVI}}\end{array}$ \\
\hline \multicolumn{3}{|c|}{ Solid Concrete or Masonry, $>8$ in. thick } \\
\hline No Furring Strips & 1.70 & None \\
\hline Metal Furring & 2.15 & Eq. a \\
\hline Wood Furring & 2.15 & Eq. d \\
\hline \multicolumn{3}{|c|}{ CMU, 8 in. or less w/ Empty Cells } \\
\hline No Furring Strips & 1.99 & None \\
\hline Metal Furring & 2.44 & Eq. a \\
\hline Wood Furring & 2.44 & Eq. d \\
\hline \multicolumn{3}{|l|}{ CMU, $>8$ in. w/ Empty Cells } \\
\hline No Furring Strips & 2.25 & None \\
\hline Metal Furring & 2.70 & Eq. a \\
\hline Wood Furring & 2.70 & Eq. d \\
\hline \multicolumn{3}{|c|}{ CMU, 8 in. or less w/ Integral Insulation } \\
\hline No Furring Strips & 2.24 & None \\
\hline Metal Furring & 2.69 & Eq. a \\
\hline Wood Furring & 2.69 & Eq. d \\
\hline \multicolumn{3}{|c|}{$\mathrm{CMU},>8$ in. $\mathrm{w} /$ Integral Insulation } \\
\hline No Furring Strips & 3.04 & None \\
\hline Metal Furring & 3.49 & Eq. a \\
\hline Wood Furring & 3.49 & Eq. d \\
\hline Other & & User input is assembly U-factor. \\
\hline
\end{tabular}

The expressions that we developed for below-grade wall assemblies and Figure 8-7 in Standard 90.1-1989 specify R-values for wall assemblies, which we have interpreted to include wall structural components; i.e., insulation, finishes, and interior air films. For locations where no insulation is required, we set the R-value of the assembly to the balance of assembly value for the particular assembly type, rather than to zero, as in Figure 8-7.

Above-grade portions of below-grade wall assemblies are treated the same as above-grade walls.

\subsubsection{Below-Grade Wall U-Factor}

Proposed U-Factor. The proposed below-grade wall $\mathrm{U}$-factor $\left(\mathrm{U}_{\mathrm{BW}}\right)$ is calculated using Equation 3.26. $\mathrm{R}_{\text {soil }}$ is selected from Table 3.19 based on the average depth of the bottom of the wall below the surface of the ground.

$$
\mathrm{U}_{\mathrm{BW}}=1 /\left(\mathrm{R}_{\mathrm{BWA}}+\mathrm{R}_{\mathrm{soil}}\right)
$$

where $\mathrm{R}_{\mathrm{BWA}}=\mathrm{R}$-value of the below-grade wall assembly

$\mathrm{R}_{\text {soil }}=$ effective $\mathrm{R}$-value of the soil from Table 3.17. 
Table 3.19. Effective R-Value of Soil for Below-Grade Walls

\begin{tabular}{|c|c|}
\hline Depth (ft) & $\mathbf{R}_{\text {soil }}$ \\
\hline 1 & 0.86 \\
\hline 2 & 1.6 \\
\hline 3 & 2.2 \\
\hline 4 & 2.9 \\
\hline 5 & 3.4 \\
\hline 6 & 4.0 \\
\hline 7 & 4.5 \\
\hline 8 & 5.1 \\
\hline 9 & 5.6 \\
\hline 10 or more & 6.1 \\
\hline
\end{tabular}

The original equation from Standard 90.1-1989R specified the use of the insulation R-value plus a fixed value of 0.85 for the non-insulation portions of below-grade walls for interior and exterior air film coefficients. We have chosen to use values for the entire below-grade wall assembly $\left(\mathrm{R}_{\mathrm{BWA}}\right)$ because they better reflect the actual performance variations in these assemblies.

Budget U-Factor. Values for the U-factor for standard walls are taken from Section 5 of Standard 90.1-1989R.

\subsubsection{Below-Grade Wall Loads}

The cooling and heating loads for below-grade walls $\left(\mathrm{CL}_{\mathrm{BW}}\right.$ and $\left.\mathrm{HL}_{\mathrm{BW}}\right)$ are calculated using Equations 3.27 and 3.28.

$$
\begin{aligned}
& \mathrm{CL}_{\mathrm{BW}}=\text { Area }_{\mathrm{BW}} \times \mathrm{CCoef}_{\mathrm{BW}} \times \mathrm{U}_{\mathrm{BW}} \times \mathrm{CDD} 50 \\
& \mathrm{HL}_{\mathrm{BW}}=\text { Area }_{\mathrm{BW}} \times \mathrm{HCoef}_{\mathrm{BW}} \times \mathrm{U}_{\mathrm{BW}} \times \mathrm{HDD} 65
\end{aligned}
$$

where $\quad \mathrm{CL}_{\mathrm{BW}}=$ the cooling load for the below-grade wall

$\mathrm{HL}_{\mathrm{BW}}=$ the heating load for the below-grade wall

Area $\mathrm{BW}_{\mathrm{BW}}=$ area of below-grade wall in $\mathrm{ft}^{2}$

$\mathrm{CCoef}_{\mathrm{BW}}=3.158=$ from Standard 90.1-1989R, Appendix C, Table C.6-11: $2.58 \mathrm{E}-04 \times 12.24$ $\times 1000$

$\mathrm{U}_{\mathrm{BW}}=\mathrm{U}$-factor for below-grade walls

CDD50 $=$ cooling degree-days base $50^{\circ} \mathrm{F}$ for the site.

Area $_{\mathrm{BW}}=$ area of below-grade wall in $\mathrm{ft}^{2}$

HCoef $_{\mathrm{BW}}=13.934=$ from Standard 90.1-1989R, Appendix C, Table C.6-11: 2.29E-04 $\times$ $0.608488 \times 100000$

HDD65 $=$ heating degree-days base $65^{\circ} \mathrm{F}$ for the site.

\subsection{Calculation of Envelope Compliance Index}

Cumulative annual space-conditioning coil loads (heating plus cooling) is the basis for both the prescriptive and system performance envelope compliance paths in the Standard 90.1 including ENVSTD, the ACP tables in Standard 90.1-1989, and the Appendix A tables in the 90.1-1989 Code. The term "coil" here refers to the heat exchanger coils in the HVAC system, which must meet both thermal 
loads in the space as well as loads created by system fans. The COMcheck software uses an index based on coil loads to determine compliance status and to convey information about performance relative to the code. This same index has been used in defining the prescriptive packages. The envelope compliance index (ECI) is defined in the following equation:

$$
\mathrm{ECI}=\left[\left(\mathrm{CL}_{\mathrm{REQ}}+\mathrm{HL}_{\mathrm{REQ}}\right)-\left(\mathrm{CL}_{\mathrm{DES}}+\mathrm{HL}_{\mathrm{DES}}\right)\right] /\left(\mathrm{CL}_{\mathrm{REQ}}+\mathrm{HL}_{\mathrm{REQ}}\right)
$$

where $C L_{R E Q}=$ required (i.e., maximum allowed) cumulative annual cooling coil load normalized a square foot of conditioned floor area basis $\left[\mathrm{Btu} /\left(\mathrm{y} \cdot \mathrm{ft}^{2}\right)\right]$

$\mathrm{CL}_{\mathrm{DES}}=$ cumulative annual cooling coil load for the proposed design normalized on a square foot of conditioned floor area basis $\left[\mathrm{Btu} /\left(\mathrm{y} \cdot \mathrm{ft}^{2}\right)\right]$

$\mathrm{HL}_{\mathrm{REQ}}=$ required (i.e., maximum allowed) cumulative annual heating coil load normalized on a square foot of conditioned floor area basis $\left[\mathrm{Btu} /\left(\mathrm{y} \cdot \mathrm{ft}^{2}\right)\right]$

$\mathrm{HL}_{\mathrm{DES}}=$ cumulative annual heating coil load for the proposed design normalized on a square foot of conditioned floor area basis $\left[\mathrm{Btu} /\left(\mathrm{y} \cdot \mathrm{ft}^{2}\right)\right]$.

COMcheck determines envelope compliance based on ECI and displays calculated ECI results in the performance field to the nearest $\%$ and to the nearest tenth of one $\%$ on the status line for ECI values between $-1 \%$ and $+1 \%$; e.g., $-0.7 \%$. Any design having an ECI displayed as $0.0 \%$ or higher is considered to comply, even though the actual design space-conditioning loads may be up to $0.05 \%$ greater than the required ECI--an insignificant margin. This provision ensures consistency between displayed numeric results and compliance messages.

The equations used in calculating cooling and heating load values for the proposed design and for calculating the requirements (i.e., the maximum loads permitted under the code) are expanded in the equations below and are specified fully in Section 3.2.3. The cooling and heating coil load terms are identical and are presented as a single set of equations.

$$
\mathrm{CL}=\left(\mathrm{CL}_{\mathrm{WW}}+\mathrm{CL}_{\mathrm{RF}}+\mathrm{CL}_{\mathrm{SK}}+\mathrm{CL}_{\mathrm{EF}}+\mathrm{CL}_{\mathrm{WU}}+\mathrm{CL}_{\mathrm{BW}}+\mathrm{CL}_{\mathrm{SB}}\right) / \mathrm{BFA}
$$

where $\mathrm{CL}_{\mathrm{WW}}=$ cooling coil load attributable to windows and opaque exterior above-grade walls and doors $(\mathrm{Btu} / \mathrm{y})$

$\mathrm{CL}_{\mathrm{RF}}=$ cooling coil load attributable to roofs (Btu/y)

$\mathrm{CL}_{\mathrm{SK}}=$ cooling coil load attributable to skylights (Btu/y)

$\mathrm{CL}_{\mathrm{EF}}=$ cooling coil load attributable to exposed floors $(\mathrm{Btu} / \mathrm{y})$

$\mathrm{CL}_{\mathrm{WU}}=$ cooling coil load attributable to walls next to unconditioned spaces (Btu/y)

$\mathrm{CL}_{\mathrm{BW}}=$ cooling coil load attributable to below-grade walls $(\mathrm{Btu} / \mathrm{y})$

$\mathrm{CL}_{\mathrm{SB}}=$ cooling coil load attributable to concrete slabs on grade $(\mathrm{Btu} / \mathrm{y})$

$\mathrm{BFA}=$ building conditioned floor area.

$$
\mathrm{HL}=\left(\mathrm{HL}_{\mathrm{WW}}+\mathrm{HL}_{\mathrm{RF}}+\mathrm{HL}_{\mathrm{SK}}+\mathrm{HL}_{\mathrm{EF}}+\mathrm{HL}_{\mathrm{WU}}+\mathrm{HL}_{\mathrm{BW}}+\mathrm{HL}_{\mathrm{SB}}\right) / \mathrm{BFA}
$$

where $\mathrm{HL}_{\mathrm{WW}}=$ heating coil load attributable to windows and opaque exterior above-grade walls and doors $(\mathrm{Btu} / \mathrm{y})$

$\mathrm{HL}_{\mathrm{RF}}=$ heating coil load attributable to roofs $(\mathrm{Btu} / \mathrm{y})$

$\mathrm{HL}_{\mathrm{SK}}=$ heating coil load attributable to skylights $(\mathrm{Btu} / \mathrm{y})$

$\mathrm{HL}_{\mathrm{EF}}=$ heating coil load attributable to exposed floors $(\mathrm{Btu} / \mathrm{y})$

Technical Support Documentation for COMcheck Through Version 3.4.0 (Software) 
$\mathrm{HL}_{\mathrm{WU}}=$ heating coil load attributable to walls next to unconditioned spaces $(\mathrm{Btu} / \mathrm{y})$

$\mathrm{HL}_{\mathrm{BW}}=$ heating coil load attributable to below-grade walls $(\mathrm{Btu} / \mathrm{y})$

$\mathrm{HL}_{\mathrm{SB}}=$ heating coil load attributable to concrete slabs on grade $(\mathrm{Btu} / \mathrm{y})$

$\mathrm{BFA}=$ building conditioned floor area. 


\subsection{Mechanical Documentation}

COMcheck reduces the complexity of the mechanical requirements in the supported codes. Because most requirements in the mechanical section of the energy code are mandatory, the Mechanical section of the software works somewhat differently than the Envelope and Lighting sections. Rather than generating a numeric compliance index, the Mechanical section generates a customized list of mandatory requirements applicable to the mechanical components identified by the user.

The Mechanical section of the COMcheck software was designed to provide a simplified and enforceable set of requirements for building heating, cooling, and hot-water systems. Buildings that comply with the COMcheck software requirements or the corresponding code-language sections in the IECC are deemed to comply with the building mechanical requirements in Sections 403 and 404 of the 90.1-1989 Code. The primary purpose of this section is to document the technical basis for the changes designed to simplify, clarify, and improve enforcement results in equivalent stringency with the 90.1-1989 Code. Where applicable, the 90.1-1989 Code sections are noted in the subsection headings.

\subsection{Scope and Permitted Equipment Types}

\subsubsection{Heating and Cooling Equipment}

The following list of most common heating and cooling equipment types are covered by COMcheck:

- Unitary-packaged absorption cooling equipment - electrically operated or fuel-fired

- Unitary-packaged, split-system or packaged terminal air-conditioners and heat pumps

- Central air handling units with any heating or cooling source

- Cooling sources: chilled water, refrigerant (direct expansion)

- Heating sources: electric resistance or fuel-fired furnace, hot water, steam

- Zonal fan distribution systems with hydronic or steam heating, hydronic cooling or both

- Hydronic heat pumps served by a circulating or ground-coupled water loop and central plant, if needed.

All common plant equipment types are supported, including:

- Electric and fuel-fired steam and hot water boilers

- Electric water chillers

- Refrigeration condensing units

- Absorption water chillers.

Both single-zone and multi-zone systems are covered by COMcheck for the following system types:

- Constant volume single-zone distribution systems

- Variable volume "changeover" multiple-zone distribution systems

- Radiant heating systems

- Single duct variable air volume with any of the following zone terminal devices:

- Standard VAV boxes with or without reheat

- Fan-powered VAV boxes with or without reheat 
- Dual duct variable air volume with any of the following zone terminal devices

$\circ$ Mixing boxes

- Standard VAV boxes with or without reheat

- Fan-powered VAV boxes with or without reheat

- Three duct constant volume with zone terminal mixing boxes.

The requirement for newly-purchased heating and cooling equipment was included to assure that equipment used will meet the efficiency requirements in EPAct or NAECA (Public Law 100-12) without the efficiencies needing to be checked. A review of available equipment manufacturers' literature as well as the Air Conditioning and Refrigeration Institute's (ARI) online database (ARI 1996) and the California Energy Commission's (CEC 1995) cooling equipment database did not show any large commercial package air-conditioners or heat pumps then being manufactured with energy efficiency eatio (EER) efficiencies below those required under the 90.1-1989 Code.

\subsubsection{Mechanical Equipment Efficiency (403.1)}

With the exception of boilers, the mechanical equipment efficiency for all single-zone, unitary equipment is addressed through EPAct (Public Law 102-486). Because reconditioned boilers are sometimes used in new construction, boilers must meet requirements of EPAct (Public Law 102-486) and the 90.1-1989 Code.

Research performed in 1996 (Baylon and Heller) showed that duct furnaces and unit heaters that do not meet the 90.1-1989 Code minimum efficiency levels are still readily available. Occasionally, used central plant and large, packaged equipment is specified in an otherwise completely new system. Therefore, all equipment not covered by EPAct or NAECA are required to meet the minimum efficiency requirements from the 90.1-1989 Code. Minimum efficiencies for these types of equipment are included in tables in the IECC. Equipment made up of components from different manufacturers, such as built-up DX cooling systems, is required to meet requirements found in the tables. For "custom" systems, calculations are required to demonstrate compliance with minimum equipment efficiencies.

\subsubsection{Economizer Trade-off}

COMcheck provides an economizer trade-off that is not specified in the 90.1-1989 Code. The use of economizers is required under the 90.1-1989 Code in specific climates with systems $>90,000 \mathrm{Btu} / \mathrm{h}$ cooling capacity. Although the cost of including an economizer for a given size of system can be assumed to be fairly consistent across the country, the efficiency benefits and hence cost effectiveness of economizers vary significantly with climate. The economizer trade-off allows building designers to trade-off use of an economizer in exchange for use of higher-efficiency air-conditioning equipment.

Table 4.1 shows the increased cooling efficiency required for an air-conditioner or heat pump to fully offset the absence of an air-side economizer in each climate zone in which economizers are required under COMcheck. These efficiencies generally result in levels of energy efficiency that are somewhat greater than with using minimum-efficiency-level cooling equipment (as defined by EPAct [Public Law 102-486] or NAECA [Public Law 100-12]) and air-side economizers.

The economizer trade-off was developed from the economizer trade-off tables shown in Section 4.1.36.3 of Standard 90.1-1989R. In that work, a single-story building was modeled in DOE2.1E to determine the 
Table 4.1. EER Requirements for Economizer Trade-off

\begin{tabular}{|c|c|c|c|c|}
\hline $\begin{array}{l}\text { Equipment Size } \\
\text { Category }\end{array}$ & $\begin{array}{l}\text { EER under } \\
\text { EPAct }\end{array}$ & $\begin{array}{c}\text { Zones 6a, 9a, 10a, 11a, } \\
\text { 12a, 12b, 12a, 13b, 14a, } \\
\text { 14b, 15 - 19 }\end{array}$ & $\begin{array}{c}\text { Zones } 4 a, 10 b, 11 b, 7 a, \\
9 b, 8,3 a\end{array}$ & Zones $4 b, 5 a, 5 b, 6 b, 7 b$ \\
\hline & & & $28 \%$ Increase in EER & $17 \%$ Increase in EER \\
\hline $\begin{array}{c}65,000 \mathrm{Btu} / \mathrm{h} \text { to } \\
135,000 \mathrm{Btu} / \mathrm{h}\end{array}$ & 8.9 & $\mathrm{~N} / \mathrm{A}$ & 11.4 & 10.4 \\
\hline $\begin{array}{c}135,000 \mathrm{Btu} / \mathrm{h} \text { to } \\
760,000 \mathrm{Btu} / \mathrm{h}\end{array}$ & 8.5 & N/A & 10.9 & 9.9 \\
\hline $\begin{array}{c}760,000 \mathrm{Btu} / \mathrm{h} \text { or } \\
\text { more }\end{array}$ & 8.2 & N/A & 10.5 & 9.6 \\
\hline
\end{tabular}

energy cost of foregoing the use of an economizer in 16 different U.S. locations. The difference in cooling energy between the economizer and no economizer simulations was calculated for each of the 16 cities using a base case energy efficiency ratio EER of 10.3. This cooling energy difference was multiplied by the ratio of the energy input ratio (EIR), calculated using the EER from the proposed Standard 90.1-1989R requirement, to the base case EIR actually used in the simulation. This method allowed for an estimate of the total difference in building cooling energy that would be required if different efficiency equipment had been used in the simulation. This estimate was necessary because of the changing base efficiency required by Standard 90.1-1989 for different size cooling equipment. The difference in energy cost was calculated by multiplying the energy savings by the assumed electrical energy price.

The change in EIR necessary to make up the economizer/no economizer cost difference was calculated by dividing the difference in energy cost used above by the no economizer cooling load and the electrical energy price. The result is the decrease in EIR (delta EIR) needed to make up the energy cost difference.

The above steps were done for the four packaged cooling equipment categories for each of the 16 climates. The resultant delta EIRs were regressed against a climate parameter (CDD65) using a robust regression technique. The regression was then used to calculate the delta EIR for various CDD65 values.

By subtracting the delta EIR from the original EIR (calculated from the Standard 90.1 EER values), and then converting the resultant EIR to an EER, the EER needed to make up for eliminating the economizer was computed for various CDD65 values. These values were then placed into Standard 90.1-1989R trade-off table for economizers vs. cooling efficiency.

The economizer requirement in COMcheck is based on the percentage improvements in EER in the heat pump section of the economizer trade-off table in Section 6.1.3 of Standard 90.1-1989R. In examining the 90,000 to $135,000 \mathrm{Btu} / \mathrm{h}$ and the 135,000 to $240,000 \mathrm{Btu} / \mathrm{h}$ categories, the Standard $90.1-1989 \mathrm{R}$ economizer trade-off shows a $28 \%$ average improvement in system EER for locations having CDD65 values between 901 and 1800, when all heat pump and air-conditioner categories are considered, and a $17 \%$ average improvement in system EER for locations having CDD65 values between 1801 and 2700. An examination of 4774 climate locations dispersed among the 33 COMcheck climate zones showed that the majority of locations in Zones 3a, 4a, 7a, 8, 9b, 10b, and 11b had CDD65 values between 901 and 1800. Similarly, the climate data show that Zones $4 \mathrm{~b}, 5 \mathrm{a}, 5 \mathrm{~b}, 6 \mathrm{~b}$, and $7 \mathrm{~b}$ all have the majority of climate locations in each zone falling between CDD65 values of 1801 and 2700. For the majority of locations with CDD65 values higher than 2700, economizers are not required under COMcheck and no trade-off was considered. For climate Zones 6a, 9a, 10a, 11a, 12a, 12b, 13a, 13b, 14a, 14b, 15, 16, 17, 18, and 19, 
the majority of locations in each climate zone have CDD65 values below 900 and are not candidates for an economizer trade-off because the energy savings from the economizer preclude a reasonable EER trade-off under Standard 90.1-1989R.

The COMcheck requirements for economizer trade-off show 28\% and 17\% improvements in EER relative to the minimum EERs as listed under EPAct (Public Law 102-486) for each size range of unitary packaged air-conditioning equipment. For simplicity, separate trade-off requirements are not listed for heat pumps (the tonnage of unitary air conditioning units shipped in these size ranges is several times that of heat pumps). The COMcheck table begins at $90,000 \mathrm{Btu} / \mathrm{h}$ because that is the smallest size for which an economizer is required. In addition, because the percentage efficiency improvement is essentially identical to that proposed under Standard 90.1-1989R, but is applied to the lower equipment efficiency levels in Standard 90.1-1989, the magnitude of energy savings from the trade-off is actually larger than that shown.

Because the supporting research for the trade-off was performed for unitary packaged equipment only, the economizer trade-off is not allowed for built-up systems.

\subsubsection{Load Calculations (403.2.1)}

Load calculations are an essential part of good mechanical design. They are used in the equipment selection process to assure that comfort conditions are maintained using the most economical piece of equipment. As such, there are many variations on the assumptions used in these calculations based on design intent, the experience of the designer, climate, future additions, etc. It is not possible to regulate the quantity of assumptions nor the judgment of the designer when it comes to load calculations.

Maintaining a legal standard of care helps to ensure that minimum engineering principles are observed for all system designs. Though most building inspectors will not review load calculations for accuracy, maintaining the requirement for load calculations underscores the designer's primary responsibility for load calculations.

\subsubsection{Equipment/System Sizing (403.2.2)}

Equipment selection and system sizing is also an essential part of good mechanical design. Selecting and sizing equipment requires a designer to consider a variety of parameters including air flow, duct design, sensible and latent loads, operating sequences (warm-up/cool-down), and equipment location to name a few. A designer must also take budget and equipment availability into account.

The requirements in Standard 90.1 take these parameters into account. But to accommodate the full range of flexibility necessary to properly select equipment, the rules become subject to such a broad range of possibilities that the requirement has no practical effect on energy consumption. For example, a designer could take a worse case set of assumptions into account for their load calculations, add warm-up/cooldown sizing factors to that load, and then select the "smallest" piece of equipment available to meet the load. This could be based on a specific manufacturer's product line that is lowest cost, but only manufacturers' units that substantially exceed justified loads. This has the effect of negating any energy benefits of the requirement.

As with load calculations, sizing requirements may not be explicitly enforceable by the local building department; however, they do establish legal responsibility for the engineer to properly size and specify

Technical Support Documentation for COMcheck Through Version 3.4.0 (Software) 
system equipment. As long as a plans examiner ensures that systems and equipment are completely specified on the plans, then a field inspector can still inspect to see if a system is built according to approved plans and specifications.

\subsubsection{Separate Air Distribution (403.2.3)}

Neither COMcheck nor the IECC requires special processes to be identified and served by separate air distribution systems. The required hardware and controls needed to serve special processes or maintain critical environments make these systems much more expensive than systems needed solely for comfort conditioning. In short, there are economic incentives to keep specialty systems as small as possible. In addition to economic reasons, enforcing or complying with this requirement requires knowledge about the use of the space prior to the building being constructed. For a large amount of square footage, particularly speculative office, commercial and light industrial construction, this information is not known until space is leased to tenants. In these cases, specialty and supplemental systems are usually added as tenant improvements and can be dealt with in terms of code compliance at the time they are constructed.

\subsubsection{Ventilation and Fan Power (403.2.4)}

COMcheck requires that all enclosed spaces where people are expected to remain for extended periods of time be continuously vented with outdoor air. Ventilation can be provided mechanically or through natural ventilation (passive ventilation strategies such as windows). For minimum ventilation requirements, COMcheck refers the user to the local code or, in the absence of local requirements, Chapter 4 of the International Mechanical Code (IMC) (ICC 1996).

Mechanically ventilated spaces are typically controlled by a thermostat. The 90.1-1989 Code requires a thermostat in each space. It also requires that the design comply with a ventilation requirement to be determined by the adopting authority. Most ventilation requirements are based on ASHRAE Standard 621989. This standard provides for the design of ventilation systems to achieve adequate air quality in buildings. It was intended by the SSPC 62 that once a system is designed in accordance with Standard 62, it would be operated as such. The IMC, Chapter 4, codified Standard 62 and extended the scope of its authority to include system operation, thereby codifying the intent of SSPC 62.

When operating a unitary system that provides heating, cooling, and ventilation, the supply-air fan is controlled by the thermostat. Temperature control is achieved by activating the heating or cooling subcomponent and the supply-air fan, thereby adding or removing heat from a space.

Most thermostats have a fan control setting that allows placing the fan in either a continuously ON mode or in an AUTO mode. When placed in the AUTO mode, the supply fan and subcomponent are automatically shut off when temperature conditions are satisfied. If a space is relying on the supply of ventilation air via a mechanical system, the supply of that air is then dependent on the rate of heat gain/loss of the space. In energy-efficient buildings designed to meet Standard 90.1 requirements, this dependency means that the rate of heat gain/loss is minimized through insulation, shading, etc. This also means that temperature conditions are more easily satisfied, and the system is likely to remain off a higher percentage of the time. Even a properly sized system will experience this situation during part-load conditions. While the system is off, ventilation air is not being supplied to the space, which violates the IMC Chapter 4 provisions. 
COMcheck requires that the fan system be operated continuously to meet the provisions of the IMC, Chapter 4, and the intent of ASHRAE Standard 62. "Continuously" in this context means continuously during occupied periods, and requires the use of a thermostat capable of being set to continuously run the supply fan (i.e., set to the fan ON mode).

As with the 90.1-1989 Code, systems capable of providing for higher ventilation rates than minimum levels must be able to reduce outdoor-air flow to minimum levels through the use of manual or automatic means such as control dampers or fan volume controls.

COMcheck allows the use of natural ventilation of building spaces through building openings (e.g., windows, doors, louvers) to ensure compliance. However, it refers the user to either the local code or to Section 402 of the IMC to find minimum opening area requirements to ensure adequate natural ventilation rates. The IMC, Chapter 4, allows natural ventilation as an acceptable alternative to continuous mechanical ventilation. The IMC contains specific provisions that must be met to provide the required levels of ventilation through non-mechanical means. The IMC also assumes that a design containing these provisions will provide sufficient opportunity for the occupant to ventilate the space if they feel a need for outdoor air. Because the occupant has the ability to directly control ventilation levels, the area of ventilation required by the IMC is not required to be permanently open.

COMcheck does not place limits on fan power in terms of W/cfm. We felt that the Standard 90.1-1989 requirements (based on $\mathrm{W} / \mathrm{cfm}$ ) are not effectively enforced in practice because they depend on design calculations. In system designs using the packaged HVAC equipment allowed under COMcheck, fan energy use is typically less than the maximum allowed under Standard 90.1-1989. In the allowed system types, higher fan energy use generally only occurs where extra filtration is needed, a situation for which Standard 90.1-1989 provides an exception. However, COMcheck does place limits on air handler design in variable flow systems with the following requirements:

- Discharge dampers are prohibited on individual fans with motors $\geq 25 \mathrm{hp}$.

- Variable volume fans must be driven by a mechanical or electrical variable speed drive, the fan must be a vane-axial type with variable pitch blades, or the fan motor must have controls or devices that result in fan motor demand of no more than $50 \%$ of their design wattage at $50 \%$ of design air flow when static pressure set point equals $1 / 3$ of the total design static pressure.

- Fan systems with no more than 50\% design wattage at 50\% design air flow must be supported by specifications and information sufficient for an inspector to verify conformance at the time of inspection.

No requirements for VAV fan partial-load energy use exist in COMcheck. VAV systems are not allowed in COMcheck with the exception of packaged VAV changeover systems. When properly designed, these systems operate at design conditions much like a constant volume system because the volume control dampers are in a fully open condition. These systems are assumed to reduce fan energy use at off-design conditions over their constant volume counterparts and so are allowed under COMcheck.

Air Transport Energy: Section 403.2.4 limits fan power in terms of watts per cfm. There are many ways to reduce fan power including efficient fan control technologies and designing for lower static pressure in the system. Enforcement of this type of requirement involves reviewing design calculations 
and inspecting in the field to ensure the system is built as designed. Small changes in the design, such as a change in the size of a duct, can move a system from complying to non-complying. Enforcement difficulty is the primary reason for not including air transport energy requirements.

Fan Control Technologies: COMcheck requires more efficient fan air flow controls starting at $25 \mathrm{hp}$ instead of $75 \mathrm{hp}$ as required in the 90.1-1989 Code Section 403.2.4. This difference is necessary to achieve energy equivalence with the 90.1-1989 Code. The lower motor horsepower threshold is required to offset the removal of limits on fan power.

The main impact of these two requirements is to explicitly prohibit discharge dampers on fans of $25 \mathrm{hp}$ and greater. It explicitly allows certain technologies and allows nearly all other technologies as long as they meet certain performance criteria. Enforcement of this provision is limited to the fan control technologies and need not involve the distribution system. Cost premiums for the prescriptive technologies in the proposed language have dropped significantly since Standard 90.1-1989 was adopted in 1989, and many other cost-effective fan control technologies have also become available.

\subsubsection{Pumping System Design (403.2.5)}

COMcheck requires hydronic systems of $600,000 \mathrm{Btu} / \mathrm{h}$ or greater design capacity (heating or cooling) to have part-load controls that:

(a) automatically reset the supply water temperatures based on zone return water temperature, building return water temperature, or outside air temperature as an indicator of building heating or cooling demand. The temperature shall be capable of being reset by at least $25 \%$ of the design supply-to-return water temperature difference; or

(b) reduce pump flow by at least $50 \%$ of design flow rate by: adjustable speed drive(s) on pump(s), multiple staged pumps where at least $1 / 2$ of the total pump horsepower is capable of being automatically turned off, or control valves designed to modulate or step down and close as a function of load.

These requirements are the result of combining the 90.1-1989 Code Section 403.2.5, Pumping System Design, and 403.2.6.8, Temperature Reset for Hydronic Systems. Exception 4 to 403.2 .5 states that systems that comply with 403.2.6.8 do not need to comply with 403.2.5. Exception 1 to 403.2.6.8 states that systems complying with 403.2.5 do not need to comply with 403.2.6.8. These two requirements can therefore be combined into one requirement, which gives the choice of either to the designer. 600,000 $\mathrm{Btu} / \mathrm{h}$ was chosen as the lower limit (instead of $10 \mathrm{hp}$ ) because a system of this capacity will rarely need more than $10 \mathrm{hp}$ of pumping capacity. This approach maintains design flexibility while maintaining equivalent stringency with the 90.1-1989 Code.

\subsubsection{System Controls (403.2.6.1)}

In COMcheck, the system control requirement was simplified to a single thermostatic control per HVAC system. Section 403.2.6.1 requires each system to have at least one temperature control device. Section 403.2.6.2 requires each zone to have its own temperature and humidity control. Therefore, any multizone system with zone controls will comply with Section 403.2.6.1 automatically. 
This thermostat must be in the building zone served by the HVAC system. The thermostat must also have a capability for automatic setback/shutdown, as in the 90.1-1989 Code, and an accessible override so occupants can operate the system during off-hours without having to disable or reprogram the thermostat. Standard programmable thermostats meet these requirements.

The 90.1-1989 Code does not require a thermostat setback capability on thermostats for systems serving areas that are expected to operate continuously. In addition, setback or shutoff control is not required on thermostats that control the temperature in residences, hotel/motel guestrooms, or areas where the heating and/or cooling system might normally be expected to operate continuously.

VAV changeover systems use multiple thermostats (one per controlled zone). However, a single-system control signal is developed from all zone thermostats. Hence, they are somewhat an exception to the one thermostat per system rule.

\subsubsection{Zone Controls (403.2.6.2)}

COMcheck maintains the 90.1-1989 Code requirements for zone control as already described in the System Controls section, including the exception that allows control in blocks of zones served by "perimeter systems."

\subsubsection{Zone Thermostat Capability (403.2.6.3)}

COMcheck maintains the 90.1-1989 Code requirements for zone control as already described in the System Controls Section 4.1.9. COMcheck allows many types of automatic control including programmable thermostats, manual thermostat/timeclock combinations, and fully automated energy management systems.

\subsubsection{Heat Pump Thermostat (403.2.6.4)}

COMcheck requires that heat pumps with supplementary electric resistance heaters shall use a thermostat designed for heat pump operation. Thermostats specifically designated for heat pumps are designed to control the use of backup electric resistance heat to minimize energy costs.

\subsubsection{Humidistats (403.2.6.5)}

COMcheck does not set specific design requirements for individual humidistats. Instead, individual humidistats are required for individual humidification systems. This requires zone-level humidity controls that can be modified or removed in the future without affecting other zones.

\subsubsection{Simultaneous Heating/Cooling (403.2.6.6)}

COMcheck-EZ limits simultaneous heating and cooling by requiring multi-zone systems to be variableair-volume with zone-level terminal equipment and controls to minimize reheating, recooling or simultaneously mixing air or water that has been mechanically heated or cooled. In contrast, the 90.1-1989 Code prohibits simultaneous heating and cooling except under specific conditions or applications, variable-air-volume systems being one of them. Today, variable-air-volume systems are the most prevalent type of systems used to serve multiple thermostatic zones. Explicitly requiring variable- 
air-volume systems and exempting multi-zone systems that do not simultaneously heat and cool (such as three-duct or "Texas" multi-zone systems), makes the requirements in the code more compatible with contemporary systems.

In addition to requiring variable-air-volume, COMcheck requires all zone terminal devices (VAV mixing boxes) to have controls that minimize simultaneous heating and cooling. Hydronic fan coils must have separate hot water and cold water supply and return lines to prevent mixing of hot and cold water, except for changeover systems, which are permitted to mix small amounts of water left in the coil at changeover from one mode to another.

\subsubsection{Automatic Setback/Shutdown (403.2.7.1)}

COMcheck allows many types of automatic control, including programmable thermostats, manual thermostat/timeclock combinations, and fully automated energy management systems. Controls must meet all of the 90.1-1989 Code requirements including:

- automatic setback capability

- 7 day time clock

- 2 hour occupant override

- ability to maintain program settings for 10 hours if power to the control is unexpectedly shut off, such as during a power failure.

COMcheck requires each zone to have automatic controls. Automatic controls at the zone level will comply with 403.2.7.1, Zone Isolation Controls, inherently. This allows a wide variety of control and building automation technologies to be used for complex systems.

\subsubsection{Shutoff Dampers (403.2.7.2)}

As in Standard 90.1-1989, systems with outdoor-air supply and exhaust flow rates $>3,000 \mathrm{cfm}$ of outdoor air must have dampers that automatically close when equipment is not operating. This requirement will mainly affect buildings with a dedicated ventilation system. The requirement does not apply to dampers restricted by health and life safety codes.

\subsubsection{Zone Isolation (403.2.7.3)}

The 90.1-1989 Code requires, at a minimum, groups of zones not exceeding 25,000 square feet, to have controls that can isolate and/or devices that can isolate and control these zones independently from other zones or zone groups. COMcheck requirements for automatic thermostatic controls also inherently serve to meet the 90.1-1989 Code requirements for zone isolation. In some cases, where a group of perimeter zones exceeds 25,000 square feet, or a group of continuously operating zones exceeds 25,000 square feet, automatic zone controls are less stringent than the 90.1-1989 Code. The expected effect of this simplification in terms of energy use is insignificant and results in a simple enforceable requirement for automatic zone controls, which will inherently meet the zone isolation requirements in most cases.

Technical Support Documentation for COMcheck Through Version 3.4.0 (Software) 


\subsubsection{Economizer Controls (403.2.8)}

Prescriptive requirements for economizers were developed from the economizer requirements in Standard 90.1-1989, which requires that all fan systems have either an air or water economizer system, with exceptions made for small fan systems (with a cooling capacity of $<90,000 \mathrm{Btu} / \mathrm{h}$ or with a supply capacity of $<3000 \mathrm{cfm}$ ). Exceptions are also made for climates with both $<2000$ heating degree-days (base $65^{\circ} \mathrm{F}$ ) and summer $2.5 \%$ design wet-bulb temperatures in excess of $72^{\circ} \mathrm{F}$. Other exceptions exist for envelope-dominated spaces, systems with extensive filtering requirements, systems where the introduction of outside air may affect the performance of other equipment, systems serving residential spaces (including hotel/motel space), systems where site-recovered or site-solar energy resources are used for cooling, or systems serving zones with high amounts of operable openings (i.e., windows and doors).

The economizer requirements in COMcheck provide significant simplification from the 90.1-1989 Code. The system size limitation was retained, so only systems with capacities $>90,000 \mathrm{Btu} / \mathrm{h}$ require economizers. No exception was made for systems $<3,000 \mathrm{cfm}$ because this requirement matches the $90,000 \mathrm{Btu} / \mathrm{h}$ requirement (assuming a typical $400 \mathrm{cfm}$ per ton of cooling) for typical packaged cooling equipment. An analysis of weather data for 4,774 cities scattered throughout the 33 COMcheck climate zones suggested that economizers would be required for all climate zones except Zones 1a, 1b, 2a, 2b, 3b, and $3 \mathrm{c}$. Almost all of the locations examined for these six climate zones have heating degree-days (base $65^{\circ} \mathrm{F}$ ) of $<2000$ hours and have summer $2.5 \%$ temperatures in excess of $72^{\circ} \mathrm{F}$ and thus would be exempt from economizer requirements under the 90.1-1989 Code.

The following exceptions included in the 90.1-1989 Code are implemented in COMcheck:

1. Systems with air or evaporatively cooled condensers that include extensive filtering equipment: This exception has been included and references IMC Chapter 4 for the criteria to determine outdoor air quality.

2. Systems with air or evaporatively cooled condensers where use of outdoor air will affect the operation of other systems. This exception has been incorporated for supermarket refrigeration systems only, thus making it easy to verify in the field.

3. Water-side economizers may be substituted for air-side economizers. This is a logical addition because hydronic system/equipment types are permitted.

4. Water-side economizers are required with three-duct and single-fan dual-duct systems. This requirement is necessary because these types of systems cannot isolate the supply of outside air from the warm-air duct because all supply air passes through a single fan. An air economizer operating in the fully open position would supply $100 \%$ outside air to both the cooling and heating ducts. This would not be in compliance with Section 403.2.8 of the 90.1-1989 Code, which prohibits economizer operation from increasing building heating energy use during normal operation. A water economizer coil can be placed directly in the cool air duct, overcoming this problem.

The other 90.1-1989 Code exceptions were removed from the economizer requirements under COMcheck because they were deemed overly complex or required detailed design information that would require extensive documentation or engineering judgment during compliance checking. 
Climate Zone $4 \mathrm{~b}$ appeared to encompass two distinct climate types: dry climates (e.g., Dagget, California and Tucson, Arizona) and relatively humid climates (Austin, Texas; San Antonio, Texas; Baton Rouge, Louisiana; Tallahassee, Florida; Savannah, Georgia; and Mobile, Alabama). Some consideration was given to breaking Zone $4 \mathrm{~b}$ into two separate zones based on the economizer requirements; however, given the county-based climates zones, the dry areas in Zone $4 \mathrm{~b}$ consisted of only one county in Arizona, one in California, and three in Texas. In previous work (i.e., with MECcheck [DOE 1995b, 1995c, 1995d]), we avoided adding a new zone to a state if applied to only one county. The final decision to not create an additional zone had conservative results with respect to preserving stringency because it resulted in the application of the economizer requirement to all of Zone $4 \mathrm{~b}$. Designers not wishing to use economizers in the humid parts of Zone $4 \mathrm{~b}$ can omit them by qualifying for the equipment-efficiency trade-off.

\subsubsection{Integrated Economizer Requirement}

The COMcheck integrated economizer requirement is considerably stricter than the integrated economizer requirements in the 90.1-1989 Code. In the 90.1-1989 Code, integrated economizers are required for all systems $>180,000 \mathrm{Btu} / \mathrm{h}$ installed capacity in climates that require an economizer and have more than 750 hours between 8 a.m. and 4 p.m. with dry-bulb temperatures between $55^{\circ} \mathrm{F}$ and $69^{\circ} \mathrm{F}$. An analysis of the 234 climate locations in Standard 90.1-1989 shows that the only climate zones where this requirement applies for the majority of the 234 sites in that zone are Zones 3a, 4a, 6a, 10a, and 11a. These sites represent primarily the California Coast, Willamette Valley and Oregon Coast, and Western Washington below Bellingham, all of which are very mild climate locations and can make good use of integrated economizers.

This requirement was simplified in COMcheck to require the use of an integrated economizer control strategy. Factory-supplied or factory-installed economizers supplied by major equipment manufacturers include integrated controls, which also prevent ice formation when very cold air is brought over the cooling coils. Non-integrated controls prevent ice formation by not allowing the use of the economizer if the outdoor-air temperature is below a set value (typically around $50^{\circ} \mathrm{F}$ ). Because controls using integrated strategies that also prevent ice formation are commonly used in packaged air-conditioning systems, they were included as a standard requirement for all situations in which an economizer is required.

While economizer sensor type requirements (e.g., differential, temperature, and enthalpy) were proposed in Standard 90.1-1989R, no such requirements were included in COMcheck because such requirements were not included in the 90.1-1989 Code.

\subsubsection{Pipe Insulation (403.2.9.1)}

The pipe insulation requirements cover three categories of piping:

1. Steam

$1-1 / 2$ in. insulation for pipes $<=1-1 / 2$-in. nominal diameter

3 in. insulation for pipes $>1-1 / 2-i n$. nominal diameter.

2. Hot water

1 in. insulation for pipes $<=1-1 / 2$-in. nominal diameter

$1-1 / 2$ in. insulation for pipes $>1-1 / 2$-in. nominal diameter.

Technical Support Documentation for COMcheck Through Version 3.4.0 (Software) 
3. Chilled water, refrigerant, brine.

1 -in. for pipes $<=1-1 / 2-$ in. nominal diameter

2 -in. for pipes $>1-1 / 2$-in. nominal diameter.

Requirements are based on these three categories and whether the pipe is above or below 1-1/2 inches in diameter. The pipe insulation requirements in COMcheck vary from those in the 90.1-1989 Code, however the difference, is never more than $1 / 2$ inch of required insulation, with some values higher and some values lower. These changes are expected to improve the ease and consistency of compliance, implementation, and field verification while the energy impacts of the changes are expected to be negligible.

\subsubsection{Duct/Plenum Insulation (403.2.9.2)}

Duct insulation levels in COMcheck are based on the minimum duct insulation requirements shown in the 90.1-1989 Code. In the 90.1-1989 Code, the insulation requirements for ducts outside of the building envelope are described explicitly in terms of R-value with cooling duct requirements based on cooling degree-days to a $65^{\circ} \mathrm{F}$ base and heating duct requirements based on heating degree-days to a $65^{\circ} \mathrm{F}$ base. The requirements for cooling or heating ducts inside the building envelope are based on the design temperature difference between the air inside the duct and the air surrounding the duct under design conditions. This provision requires a determination of design conditions and estimated temperatures inside different buildings spaces. In addition, duct insulation requirements for ducts used for both heating and cooling use the more stringent insulation requirement for either heating or cooling. Because most packaged equipment is designed for both heating and cooling applications and would be so used in the majority of simple buildings, the first simplification made to the Simple Systems section was to always use the more stringent (heating or cooling) criterion.

To simplify the duct insulation requirements, assumptions from Table 7-H of the Federal User's Manual - Performance Standards for New Commercial and Multi-Family High-Rise Residential Buildings were used (DOE 1994). This table shows default design dry-bulb temperatures, which result in different insulation levels for supply and return ducts inside different building spaces (specifically ventilated attics, unvented attics, other unconditioned spaces, indirectly conditioned spaces, and buried ductwork). Average design drybulb temperature for both heating and cooling seasons as well as the average CDD65 and HDD65 values were determined for each of the COMcheck climate zones using the 234 climate locations outlined in Standard 90.1-1989. Using these data, we were able to determine insulation requirements for interior ducts for each climate zone. Similarly, using the average degree-day data for each zone, exterior-duct insulation requirements were determined. The maximum heating or cooling duct insulation requirement for each zone was used. For all climate zones, this procedure yielded R-5 for the vented attic, unvented attic, and the other unconditioned space category and R-3.3 for indirectly conditioned spaces. For exterior ducts, the zones were grouped into larger HDD65 categories. Based on the resulting duct insulation requirements and common insulation R-values, insulation requirements were selected, resulting in an R-8 requirement for exterior ducts for Zones 1 through 4 (0 to 2000 HDD65), R-6.5 being required for Zones 5 through 14 (2000 to 7000 HDD65), and R-8 being required for Zones 15 through 19 (>7000 HDD65). For simplicity in COMcheck, all unconditioned spaces inside the building are treated the same way, requiring R-5 duct insulation. However, ducts located internal to HVAC equipment, exhaust air ducts, and ducts located anywhere the design temperature difference between air within the duct and air surrounding the duct is $<15^{\circ} \mathrm{F}$ do not require duct insulation. 


\subsubsection{Duct/Plenum Construction (403.2.9.3)}

COMcheck requires that transverse and longitudinal seams of all ducts be mechanically fastened and sealed using welds, gaskets, mastics (adhesives), mastic-plus-embedded-fabric systems or tapes. Additionally, duct connections to flanges or air distribution system equipment must be sealed and mechanically fastened. In comparison, the 90.1-1989 Code sets sealing requirements based on static pressure in the duct, a very difficult field observation, and according to a referenced standard published by the Sheet Metal and Air Conditioning Contractors National Association. The IECC requirements are generally considered to be the requirements that would apply to nearly all simple systems under strict application of the 90.1-1989 Code requirements. Tapes and mastics used to seal ductwork must be listed and labeled in accordance with UL 181A or UL 181B. In comparison, the 90.1-1989 Code prohibits the use of pressure sensitive tape on ducts operating at 1 inch of static pressure or greater. Field observation of a UL label is much easier than first determining if the tape is pressure sensitive and then determining the static pressure of the duct.

\subsubsection{Administration (403.2.10)}

Completion requirements under Standard 90.1-1989 have been adapted for easier verification in the field, and are summarized below.

1. Manuals - COMcheck incorporates language similar to that used in the second public review draft of Standard 90.1-1989R. This requires specific topics to be covered by the manuals that can be identified by quick review of the documentation. The new language is also more explicit than the 90.1-1989 Code language, so designers can easily understand what documentation is required.

2. Air Systems Balancing - COMcheck requires verification of dampers at each duct branch or zone terminal device. For complex air distribution systems, dampers are necessary for long-term energyefficient operation. Additionally, discharge dampers are prohibited on the full complement of zone controls (thermostats, reheat/recool, mixing, balancing dampers) to ensure that the most energyefficient operation sequence can be achieved should the space-conditioning needs of a zone change.

3. Hydronic Balancing - COMcheck requires verification of balancing valves and pressure test connections at each individual hydronic coil.

\subsection{Service Water Heating (SWH) Systems and Equipment}

COMcheck includes only water-heating equipment specifically covered by Federal efficiency regulation (primarily EPAct, Public Law 102-486). These types of equipment include:

- electric water heaters of all types

- fuel-fired storage water heaters

- fuel-fired packaged boilers used as water heaters

- fuel-fired instantaneous heaters (as defined under EPAct)

- fuel-fired pool and spa heaters. 
Gas or oil water heaters with a storage volume of $>140$ gal are not covered by Federal efficiency regulations; their use is allowed under the Complex Systems section but not under the Simple Systems section.

Water-heating equipment efficiency levels equivalent to those defined in Standard 90.1 are mandated as a manufacturing standard under EPAct. Thus, all above types of water-heating equipment will meet the 90.1-1989 Code efficiency levels. For the same reason, standby loss testing procedures (Sections 401.1, 401.2, and 401.3 in the 90.1-1989 Code [ASHRAE 1993b]) are not included.

\subsubsection{SWH Equipment Efficiency (404.1)}

Service water heating efficiency is addressed through EPAct (Public Law 102-486) legislation, which establishes minimum manufacturing standards for equipment efficiencies.

\subsubsection{Electric/Oil Standby Loss (404.1.1)}

Electric and oil service water heating standby losses are addressed through EPAct (Public Law 102-486) legislation.

\subsubsection{Unfired Storage Tanks (404.1.2)}

Unfired storage tanks are addressed through EPAct (Public Law 102-486) legislation.

\subsubsection{Storage Volume (404.1.3)}

Storage volume is addressed through EPAct (Public Law 102-486) legislation.

\subsubsection{Piping Insulation (404.2)}

Like Standard 90.1-1989, COMcheck has specific requirements for heat traps on noncirculating waterheating systems and vent or flue dampers on all water heaters. As in Standard 90.1-1989, the requirement for vent or flue dampers is waived for water heaters that do not have an electrical supply.

\subsubsection{Controls (404.3)}

Requirements for hot-water temperature settings were removed from COMcheck as they were deemed to be unenforceable. The Standard 90.1-1989 requirement for automatic time-switch controls on circulating hot-water systems was maintained in COMcheck. COMcheck also has a requirement for time-switch controls when heat tracer tape is used with circulating system. This requirement is meant to prevent the use of circulating water as a freeze protection method when unnecessary, since heat tracing is provided for.

\subsubsection{Water Conservation (404.4)}

No water conservation requirements are included in COMcheck. EPAct (Public Law 102-486) legislation addresses water-using appliances, so all new lavatories and shower heads are presumed to meet this manufacturing standard. 


\subsubsection{Swimming Pools (404.5)}

A requirement for readily-accessible shutoff controls, as well as time-clock switches, for swimming pool heaters and pumps was maintained in COMcheck. Exceptions to the time-clock requirement for solar or site-recovered heating are the same as in Standard 90.1-1989R. In Standard 90.1-1989, an exception was made for pools with over $70 \%$ of the annual energy for heat supplied from a site-recovered or site-solar system. This exception required a compliance official to certify the annual fraction of heating energy from different sources. By removing this exception, the COMcheck requirement is more restrictive and more enforceable.

Under COMcheck-EZ Version 1, pool covers were required for all heated swimming pools, but this requirement was removed from COMcheck-EZ Version 2.0. Pool covers are not addressed in the 1998 or 2000 IECC because they were deemed to not fall within the normal scope for a building code and because they have reportedly not been used in some commercial buildings out of concern for safety and liability.

\subsubsection{Combined Heating Systems (404.6)}

The 90.1-1989 Code requirements related to combined SWH and space-heating equipment is not addressed in COMcheck or the IECC. Section 404.6 of the 90.1-1989 Code serves to prohibit use of combined systems except where boilers are small or water and space-conditioning loads are similar in magnitude. These requirements were not included in COMcheck because it was not clear that the impact of such a requirement in discouraging inefficient combined-system applications would outweigh its potential adverse impact in discouraging highly-efficient combined-systems applications possible with current equipment and controls. 



\subsection{Lighting}

References to specific pertinent 90.1-1989 Code sections are shown in parentheses in the following section headings.

\subsection{Interior Lighting Calculation (401.3.2)}

COMcheck lighting requirements are based on the prescriptive requirements outlined in Section 401.3.2 of the 90.1-1989 Code. The software simply automates the calculation of the lighting power budget for the building and the connected load of the lighting systems specified in the proposed design. The implementation of this calculation in COMcheck is very similar to the corresponding procedure found in the 90.1-1989 Code, with some simplifications and with changes to the building use types and their corresponding lighting power density (LPD). Lighting power densities (LPDs) used to determine the lighting power budget are based on building use types entered by the user (refer to Section 2.4 of this document, Lighting Power Budgets).

\subsubsection{Lighting Control Credits (401.3.3)}

Lighting control credits were included in the 90.1-1989 Code as a trade-off for increased installed (proposed) lighting power. However, the lighting control credits were complicated to apply, and special lighting controls have been infrequently used in simple commercial buildings, for which COMcheck was initially targeted.

The control credit approach was also abandoned with Standard 90.1-1989R for reasons of simplicity. Some felt the credits in the 90.1-1989 Code had been ineffective in motivating use of advanced controls because users were able to show compliance without use of the credits. Although control credits were implemented in COMcheck for the Minnesota code, in the interest of simplicity and remaining conservative with respect to stringency, they are not made available for other COMcheck codes.

\subsubsection{Area Factors (401.3.2)}

One area of simplification to the procedure in COMcheck, which also served to enhance stringency, was the elimination of area factors. Area factors greatly complicate compliance if the area category method is used because ceiling height and room areas must be determined before the allowable wattage of each space can be determined. Area factors have also been eliminated from Standard 90.1-1989R for simplification and in recognition that acceptable power budgets can be established without that information. This change means that the COMcheck lighting power budgets are not directly comparable to code budgets calculated using area factors - the COMcheck values will be more stringent.

\subsection{Lighting Input Wattage Defaults}

Compliance with the lighting power budget in Standard 90.1 requires the calculation of installed (proposed) wattage of all covered lighting systems. This calculation depends on input wattage values for various lighting technologies and lamp-ballast combinations. The software provides typical wattage values for these lamp-ballast combinations, which can be useful when a specific fixture has not yet been selected or the exact input wattage of a selected fixture is not known. For these suggested input wattage

Technical Support Documentation for COMcheck Through Version 3.4.0 (Software) 
values to be helpful to the user in streamlining the compliance process, the input wattage values need to be representative of the current market and conservative with respect to efficiency. The user needs to be able to use the suggested values knowing that an actual product can easily be found and specified that will be at least as efficient as the suggested value.

A wide variety of similar lighting products is on the market today, and typical values for these products were needed. Three potential sources of this type of information were considered for use:

- industry/manufacturers' data

- Lighting Technology Screening Matrix (LTSM) software internal lighting database (Stucky et al. 1994)

- expanded default/wattage table originally based on 1993 Advanced Lighting Guidelines (ExCEC) (CEC 1993).

Industry/manufacturers' data necessarily formed the basis for default wattage values reflecting available products and technologies. However, much work has been done to create summaries of available products and associated characteristics, and much of it is considered representative of products currently on the market. Beginning with raw manufacturers' data was not considered a cost-effective or necessary approach. Rather, existing summaries of applicable data were considered the most appropriate for this purpose.

A search of available summaries found that the LTSM internal database and ExCEC tables were at the time the most current and comprehensive for the level of detail required in COMcheck. Other smaller and usually manufacturer-specific databases existed but were not considered comprehensive enough for this purpose.

The LTSM internal database was developed using a variety of product characteristic sources including manufacturers' data and summaries done by others. This database has a good variety of wattage values for fluorescent, incandescent, exit, and high-intensity discharge (HID) lighting with three fluorescent ballast categories. However, many less-common long fluorescent lamp types and newer compact fluorescent lamps are not yet represented in this database.

The ExCEC data are a collection of default wattage values that cover the majority of compact fluorescent, long fluorescent, and HID product sizes and types. The ExCEC data were initially based on the American National Standards Institute (ANSI) values from the Advanced Lighting Guidelines (CEC 1993). This set of wattage values is one of the most extensive and well documented, has had extensive public review, and has been disseminated and used throughout the United States. Since their inception, the ExCEC data have been updated and used as the model for a nationally accepted default lighting wattage source. Because this collection is likely to be considered and used by other organizations as the source for default wattage values, it was also expected to be the best maintained over time. For these reasons as well as the large variety of product types it covers, the ExCEC collection was chosen as the basis for the COMcheck suggested wattage values.

To ensure that these values are representative and conservative, the ExCEC data were compared where possible with the in-depth listings of manufacturer-specific electronic ballast-lamp combinations put 
together by the Lighting Design Lab (LDL) in Seattle--a well known source of reliable lighting information. These lists are extensive and thorough and represent currently available products that meet many energy conservation requirements (typically a power factor $>90 \%$ and total harmonic distortion $[\mathrm{THD}]<33 \%$ ). Because of this, the LDL list tends to exclude most of the really low-efficiency ballasts that are phased out by EPAct (Public Law 102-486), making it a valid benchmark for lighting systems installed in new construction. For the most common lamp types, the average of the electronic ballast-lamp wattage values in the LDL list, were found to be within $\pm 2 \%$ of the corresponding ExCEC numbers.

The only major category of lighting missing from the ExCEC data was incandescent. These values, which are commonly known and standardized, were included as a simple listing of wattage ratings. This listing, as well as the option of user input of an exact wattage, will cover the entire range of incandescent and halogen products because the wattage rating is considered an accurate measure of wattage input to the fixture.

\subsection{Exemptions (401.3.2)}

COMcheck allows exemptions for qualifying fixtures. When a lighting fixture is identified as exempt, the power for the fixture is excluded from the total proposed wattage for the building. The following exemptions are implemented in COMcheck:

- Art/Museum Display

- Emergency Lighting (Automatic Control)

- High-Risk Security Area

- Lighting for Physically/Visually Impaired

- Plant Growth Lighting

- Residential Dwelling Units

- Retail Store-Front Display Windows (Enclosed)

- Sign Lighting

- Special Medical/Dental/Research Lighting

- Theatrical/Broadcasting/Entertainment.

Eight of the above exemptions are listed in Section 401.3.2 of the 90.1-1989 Code. COMcheck includes two additional exemptions: (i) Retail Store-Front Display Windows (Enclosed), and (ii) Sign Lighting. These spaces were exempted in Section 6.2.2 of the 90.1-1989 Standard and are included in the list of exceptions to building exterior lighting in Section 401.3.1 of the 90.1-1989 Code. These spaces are deemed to meet the definition of exemptions for interior lighting and hence were included in COMcheck interior lighting exemptions.

\subsection{Mandatory Requirements}

The following sections describe mandatory requirements as listed in COMcheck. Some of these have also been included in the Lighting Compliance Certificate - these are identified below. 


\subsubsection{Check Metering Provisions (401.1.1)}

Current building practice already provides for electrical service configurations that meet many of these provisions. Hence check metering requirements are not included in COMcheck.

\subsubsection{Electrical Schematic (401.1.2)}

Providing electrical schematics to building owners is currently a requirement in building codes, so was not included as a mandatory requirement in COMcheck.

\subsubsection{Motor Efficiency (401.2.1)}

Minimum Federal efficiency requirements for electric motor efficiency that meet or exceed those in the 90.1-1989 Code took effect in October 1997 as a result of EPAct. At the time COMcheck was originally developed, electric motors being shipped and sold were already approaching compliance with those minimum efficiency requirements. Motor efficiency requirements have been omitted from COMcheck because they are redundant with the preemptive Federal requirements in EPAct.

\subsubsection{Building Exteriors (401.3.1)}

Exterior lighting is subject to local safety regulations and zoning rules and serves specific marketing functions. The 90.1-1989 Code provides for these requirements by restricting misuse of exterior lighting. COMcheck similarly restricts misuse by requiring that the designer use efficient sources to meet local safety, zoning, and marketing functions, setting a minimum lamp efficacy of 45 lumens per watt. In almost all cases, this requirement will result in a building that would comply with the 90.1-1989 Code using the exterior lighting power budget calculation.

According to efficacy graphs in the 1993 NLPIP report on compact fluorescents (NLPIP 1993) and the 1993 CEC lighting guideline on lighting design practice (CEC 1993), a limit of 45 lumens per watt precludes use of all incandescent lighting but would permit most compact fluorescents. A value of 60, which was originally proposed, would eliminate use of all but some very high wattage compact fluorescents and some small wattage metal halide and high pressure sodium fixtures. While the original 60 lumens per watt may have been appropriate for large exterior spaces such as parking lots, it precluded applications of smaller lamps (for example, under building overhangs), hence 45 lumens per watt was used.

\subsubsection{Manual Controls (401.3.4.2)}

The Interior-Lighting Controls section of the mandatory requirements along with the Bi-Level Switching section of the COMcheck Lighting Compliance Certificate provides the same requirement as the interior lighting controls in the 90.1-1989 Code. The bi-level requirement replaces the 90.1-1989 Code requirement for multiple controls based on task locations. It is considered common for most spaces with tasks required to have no more than two primary controls, which is provided by the bi-level requirement. 


\subsubsection{Control Accessibility (401.3.4.4)}

Control accessibility is covered under the Control, Switching, and Wiring Requirements section of the COMcheck Lighting Compliance Certificate.

\subsubsection{Hotel/Motel Guest Rooms (401.3.4.5)}

The Master Switches in Hotel and Motel Guest Rooms requirements in the Lighting Compliance Certificate and the mandatory requirements list are the same as found in the 90.1-1989 Code.

\subsubsection{Exterior Light Switching (401.3.4.6)}

The Exterior Lighting Controls requirements in the Lighting Compliance Certificate and mandatory requirements list are the same as found in the 90.1-1989 Code. Some specific references to the capability and backup provisions for timers have been eliminated because these characteristics are common features of current products.

\subsubsection{Ballast Tandem Wiring (401.3.5.1)}

The Tandem Wiring requirements in the Lighting Compliance Certificate and mandatory requirements list are the same as found in the 90.1-1989 Code. The COMcheck sections have simplified wording but cover the same installation configurations as are known to exist in buildings. These requirements exempt fixtures with high-frequency electronic ballasts because of their increased efficiency when operating one or three lamps compared to standard ballasts.

\subsubsection{Ballast Power Factor (401.3.5.2)}

Because of market pressures, most current products already meet the $90 \%$ or greater power factor requirement and hence, this is not included in the COMcheck requirements. 



\subsection{References}

Air-Conditioning and Refrigeration Institute (ARI). May 1996. Unitary and Applied Certification Directories [Online report]. Available URL: http://ari-directory.com/

American Society of Heating, Refrigerating and Air-Conditioning Engineers, Inc. (ASHRAE). 1985. 1985 ASHRAE Handbook: Fundamentals. Atlanta, Georgia.

American Society of Heating, Refrigerating and Air-Conditioning Engineers, Inc. (ASHRAE). 1989a. ASHRAE/IES Standard 90.1-1989, “Energy Efficient Design of New Buildings Except Low-Rise Residential Buildings." Atlanta, Georgia.

American Society of Heating, Refrigerating and Air-Conditioning Engineers, Inc. (ASHRAE). 1989b. ASHRAE Standard 62-1989, "Ventilation for Acceptable Indoor Air Quality." Atlanta, Georgia.

American Society of Heating, Refrigerating and Air-Conditioning Engineers, Inc. (ASHRAE). 1993a. 1993 ASHRAE Handbook: Fundamentals. Atlanta, Georgia.

American Society of Heating, Refrigerating and Air-Conditioning Engineers, Inc. (ASHRAE). 1993b. Energy Code for Commercial and High Rise Residential Buildings-Codification of ASHRAE/IES Standard 90.1-1989, "Energy Efficient Design of New Buildings Except Low-Rise Residential Buildings." Atlanta, Georgia.

American Society of Heating, Refrigerating and Air-Conditioning Engineers, Inc. (ASHRAE). 1996. BSR/ASHRAE/IESNA Standard 90.1-1989R, "Energy Code for Buildings Except Low-Rise Residential Building.” First Public Review Draft, March 1996, Atlanta, Georgia.

Baylon, D. and J. Heller. 1988. Super Good Cents Heat Loss Reference. Vol. I-IV, prepared by Ecotope for the Bonneville Power Administration, Portland, Oregon.

California Code of Regulations (CCR). 1995. "Prescriptive Requirements for Lighting - Calculation of Allowed Lighting Power Density - Area Category Method." Subchapter 5, Section 146 (b) 2, Sacramento, California.

California Energy Commission (CEC). 1993. Advanced Lighting Guidelines: 1993. Sacramento, California.

California Energy Commission (CEC). 1995. Energy Efficiency Standards for Residential and Nonresidential Buildings: July 1995. Sacramento, California.

Council of American Building Officials (CABO). 1993. Model Energy Code; 1993 Edition. Falls Church, Virginia.

Crawley, D.B., P.K. Riesen, and R.S. Briggs. 1989. Users Guide for ENVSTD program Version 2.0 and LTGSTD Program Version 2.0. PNL-6839 (includes software), Pacific Northwest Laboratory, Richland, Washington. 
Energy Information Administration (EIA). 1994. Commercial Buildings Characteristics 1992: Energy Consumption Survey. DOE/EIA-0246 (92), U.S. Department of Energy, Washington, D.C.

Energy Policy Act of 1992 (EPAct). Public Law 102-486, 106 Stat 2776, 16 USC 1531 et seq., as amended.

Hogan, J.F. 1995. "Code Compliance Considerations in the Development of the Building Envelope Requirements for ASHRAE/IESNA Standard 90.1-1989R." In “Thermal VI” Thermal Performance of the Exterior Envelopes of Buildings VI, p. 269. December 4-8, 1995, Clearwater Beach, Florida. U.S. Department of Energy (DOE), Office of Building Technologies; Oak Ridge National Laboratory (ORNL); The American Society of Heating, Refrigerating and Air-Conditioning Engineers (ASHRAE); and Building Environment and Thermal Envelope Council (BETEC).

International Code Council, Inc. (ICC). 1996. International Mechanical Code. ICC, Falls Church, Virginia.

International Code Council, Inc. (ICC). March 1998. International Energy Conservation Code 1998. ICC, Falls Church, Virginia.

Jones JW. October 1983. "Special Project 41: Development of Recommendations to Upgrade ASHRAE Standard 90A-1980, 'Energy Conservation in New Building Design.'” ASHRAE Journal 25(10):30-36.

Lighting Design Lab (LDL). Elegant Lighting for Elegant Dining. 1991. Bonneville Power Administration, Seattle, Washington.

National Appliance Energy Conservation Act of 1987 (NAECA). Public Law 100-12, 42 USC 6291 et seq., as amended.

National Fenestration Rating Council (NFRC). 1995. Certified Products Directory. Fifth Edition, Silver Spring, Maryland.

NLPIP. 1993. Report on compact fluorescents.

North American Insulation Manufacturers Association (NAIMA). 1998. ASHRAE 90.1 Compliance for Metal Buildings, MB304, Alexandria, VA.

Owenby, J.R., D.S. Ezell, and R.R. Heim, Jr. 1992. Annual Degree Days to Selected Bases Derived from the 1961 to 1990 Normals. Climatography of the United States No. 81 - Supplement No. 2, U.S.

Department of Commerce, National Oceanic and Atmospheric Administration, National Climatic Data Center, Asheville, North Carolina.

Sheet Metal and Air Conditioning Contractors National Association, Inc. (SMACNA). 1985. HVAC Duct Construction Standards: Metal and Flexible. Vienna, Virginia.

Stucky, D.S., S.A. Shankle, R.W. Schultz, E.E. Richman, and J.A. Dirks. 1994. "Pacific Northwest Laboratory's Lighting Technology Screening Matrix: Let There Be Energy-Efficient Light." Energy Engineering 91(6):23-41. 
U.S. Bureau of Census. 1988. County and City Data Book-1988-Places. U.S. Department of Commerce, Washington, D.C.

U.S. Department of Energy (DOE). 1994. Federal User's Manual - Performance Standards for New Commercial and Multi-Family High-Rise Residential Buildings. Office of Codes and Standards, Washington, D.C.

U.S. Department of Energy (DOE). 1995a. 90.1-1989 Code Compliance Manual. Prepared by Eley Associates under contract to the Building Standards and Guidelines Program, Pacific Northwest National Laboratory, Richland, Washington.

U.S. Department of Energy (DOE). 1995b. 1993 MECcheck ${ }^{T M}$ Manual - 1993 Model Energy Code Compliance Guide, Version 2.0. Building Standards and Guidelines Program, Pacific Northwest National Laboratory, Richland, Washington.

U.S. Department of Energy (DOE). 1995c. 1993 MECcheck ${ }^{\text {TM }}$ Prescriptive Packages - 1993 Model Energy Code, Version 2.0. Building Standards and Guidelines Program, Pacific Northwest National Laboratory, Richland, Washington.

U.S. Department of Energy (DOE). 1995d. 1993 MECcheck ${ }^{T M}$ Software User's Guide - 1993 Model Energy Code, Version 2.0. Building Standards and Guidelines Program, Pacific Northwest National Laboratory, Richland, Washington.

U.S. Department of Energy (DOE). 1997. COMcheck-EZ ${ }^{T M}$ Compliance Guides - Commercial and High-Rise Residential Energy Code Compliance; Version 1.0. DOE/EE/OBT-28432, Building Standards and Guidelines Program, Pacific Northwest National Laboratory, Richland, Washington.

U.S. Department of Energy (DOE). 2004. Methodology for Developing the REScheck ${ }^{T M}$ Software through Version 3.6. Building Energy Codes Program, Pacific Northwest National Laboratory, Richland, Washington. 

Appendix A 1998 IECC 



\section{Appendix A - 1998 IECC}

This appendix describes features that have been changed in COMcheck to support the 1998 International Energy Conservation Code (IECC). The 1998 IECC software implementation is almost identical to the 90.1-1989 Code version - the differences are discussed in this section.

\section{A.1 Building Use Types}

The 1998 IECC version uses the building use types and corresponding lighting power densities found in the printed 1998 IECC, with the exception of a correction of an erratum related to the Other category (misprinted as Theater-others).

\section{A.2 Envelope}

\section{A.2.1 Vapor Retarder Requirements}

The vapor barrier exception was translated into the 1998 (and 2000) IECC as "Buildings located in Climate Zone 1 through 7..." This significantly enlarged the areas subject to the exception compared to the 90.1-1989 Code requirements. There are 10 states that are impacted by the change, many of them substantially. Affected states are listed in Table A.1. Refer to the IECC for a list of counties and their corresponding climate zones.

Table A.1. Vapor Retarder Exemptions

\begin{tabular}{|l|l|}
\hline \multicolumn{1}{|c|}{ States Exempted } & \multicolumn{1}{c|}{ Affected Portion of State } \\
\hline Alabama & 10 counties in Climate Zone 7 \\
\hline Arizona & half the state \\
\hline California & half the state \\
\hline Georgia & one sixth of the state \\
\hline Nevada & Clark County \\
\hline New Mexico & seven counties \\
\hline North Carolina & one third of the state \\
\hline Oklahoma & $40 \%$ of the state \\
\hline South Carolina & one third of the state \\
\hline Texas & one quarter of the state. \\
\hline
\end{tabular}

It is unclear whether the difference is a result of an intentional reinterpretation of the 90.1-1989 Code language or a change that was made inadvertently during efforts to simplify the IECC language. Regardless of the reason for the difference, the 1998 and 2000 IECC versions of COMcheck were changed to make them fully consistent with the IECC language, but the 90.1-1989 Code version was not changed, because we believe it contains the preferred interpretation. 


\section{A.3 Mechanical}

\section{A.3.1 Economizer Requirements}

The 90.1-1989 Code version of COMcheck requires an integrated-control economizer and defines the term 'integrated-control'. The 1998 IECC contains the economizer requirement but does not require that it have integrated control.

All codes based on the 90.1-1989 Code exempt Climate Zones 1a, 1b, 2a, 2b, 3b, and 3c from the economizer requirement. However, the 1998 IECC exempts Climate Zones 1a, 1b, 2a, 2b, and $3 b$ but does not exempt 3c. Climate Zone 3c encompasses parts of Arizona (3 of 15 counties including Phoenix) and parts of south Texas (11 counties).

Both of these differences appear to be the result of inaccurate translation rather than deliberate technical revision. Regardless of the reason for the difference, the 1998 IECC version of COMcheck was changed to make it fully consistent with the 1998 IECC.

A mandatory requirement was added to require an air economizer for individual cooling systems over $90,000 \mathrm{Btu} / \mathrm{h}$ or $3,000 \mathrm{cfm}$ in the selected climate.

An appropriate test for this requirement is that under the 1998 and 2000 IECC versions of COMcheck, a building with a large DX cooling system in Phoenix should require an economizer, while under the 90.1-1989 Code version of COMcheck, the same building should not be required to have an economizer.

\section{A.3.2 Multiple-Zone Systems}

The scope for the mechanical section of the 1998 IECC version of COMcheck is potentially confusing because Chapter 7 of the 1998 IECC, Design by Acceptable Practice for Commercial Buildings, has a much narrower scope and covers only single-zone HVAC equipment, in comparison to the 90.1-1989 Code. Wherever possible, we have matched the COMcheck implementation to specific provisions in the Design by Acceptable Practice chapter of the IECC. However, in the case of mechanical requirements, we felt that removing the requirements for complex systems from the 1998 IECC version of COMcheck would unnecessarily limit its usefulness. Therefore, the 90.1-1989 Code requirements for complex systems were used to supplement the scope of the 1998 IECC Mechanical requirements in COMcheck.

The expanded scope is fully appropriate for use with the 1998 IECC under provisions of Sections 103 and 601. Section 103 of the 1998 IECC, Alternative Materials-Methods of Construction, Design or Insulating Systems, authorizes "the use of computer software, worksheets, compliance manuals and other similar materials when they have been approved by the building official as meeting the intent of the code." Section 601.1 of the 1998 IECC references the ASHRAE/IES Energy Code for Commercial and High-Rise Residential Buildings. The justification for using COMcheck for showing compliance with the IECC rests on the above two sections. The interpretations embedded in the software have the implied endorsement of the IECC Committee by virtue of their adoption into the 2000 IECC based on the justification of equivalence with the 90.1-1989 Code. 


\section{A.4 Lighting}

The following exemptions based on Section 705.4 of the 1998 IECC are available in the 1998 version of COMcheck:

- Art/Museum Display

- Special Medical/Dental/Research Lighting. 

Appendix B 2000 IECC 



\section{Appendix B - 2000 IECC}

This appendix describes features that have been changed in COMcheck to support the 2000 International Energy Conservation Code (IECC). The 2000 IECC version is very similar to the 90.1-1989 Code version. Areas not addressed in this appendix are the same as in the 90.1-1989 Code version of COMcheck. Major differences occur in only one area - lighting system requirements.

\section{B.1 Building Use Types}

The 2000 IECC uses the same whole building types and area categories as the 90.1-1989 Code and the 1998 IECC, except five new building use types were added to the 2000 IECC and the 90.1-1989 Code, but not the 1998 IECC. The new building use types were not added to the 1998 IECC version of COMcheck to keep it fully consistent with the 1998 IECC as published (see Section 2.2 of this document, for a list of these new building use types). Roughly $60 \%$ of the existing building use types have different lighting power densities, reflecting the 2000 IECC changes. The densities have decreased for some building use types and increased for others. Overall they appear to represent a modest increase in stringency. The 2000 IECC version of COMcheck uses the building use types and their corresponding lighting power densities exactly as listed in Table 805.4.2 of the 2000 IECC. Tables B.1 and B.2 list the lighting power density requirements for whole building types and area categories, respectively.

The 2000 IECC changes were based on what were proposed revisions to Standard 90.1-1989 at the time the IECC code changes were accepted. The changes were proposed by Jeff Johnson with the New Buildings Institute (NBI), and NBI prepared the technical justification for those changes.

Table B.1. Whole Building Type Lighting Power Density (LPD) Requirements

\begin{tabular}{|l|c|}
\hline \multicolumn{1}{|c|}{ Whole Building Type } & LPD (W/ft ${ }^{2}$ ) \\
\hline Exercise Center & 1.4 \\
\hline Grocery Store & 1.9 \\
\hline Library & 1.5 \\
\hline Medical and Clinical Care & 1.6 \\
\hline Museum & 1.6 \\
\hline Office & 1.3 \\
\hline Religious Worship & 2.2 \\
\hline Restaurant & 1.7 \\
\hline Retail Sales, Wholesale Showroom & 1.9 \\
\hline School & 1.5 \\
\hline Storage, Industrial and Commercial & 0.6 \\
\hline Theater-Motion Picture & 1.1 \\
\hline Theater-Performance & 1.4 \\
\hline Other & 0.6 \\
\hline
\end{tabular}


Table B.2. Area Category Lighting Power Density (LPD) Requirements

\begin{tabular}{|l|c|}
\hline \multicolumn{1}{|c|}{ Area Category } & LPD (W/ft' \\
\hline Auditorium & 1.6 \\
\hline Bank/Financial Institution & 2.0 \\
\hline Classroom/Lecture Hall & 1.6 \\
\hline Convention, Conference or Meeting Center & 1.5 \\
\hline Corridor, Restroom, Support Area & 0.8 \\
\hline Dining & 1.4 \\
\hline Exercise Center & 1.1 \\
\hline Exhibition Hall & 3.3 \\
\hline Grocery Store & 2.1 \\
\hline Gymnasium Playing Surface & 1.9 \\
\hline Hotel Function & 2.4 \\
\hline Industrial Work, $<20 \mathrm{ft}$ Ceiling Height & 2.1 \\
\hline Industrial Work, >=20 ft Ceiling Height & 3.0 \\
\hline Kitchen & 2.2 \\
\hline Library & 1.8 \\
\hline Lobby-Hotel & 1.9 \\
\hline Lobby-Other & 1.0 \\
\hline Mall, Arcade, or Atrium & 1.4 \\
\hline Medical and Clinical Care & 1.6 \\
\hline Museum & 1.6 \\
\hline Office & 1.5 \\
\hline Religious Worship & 3.2 \\
\hline Restaurant & 1.7 \\
\hline Retail Sales, Wholesale Showroom & 2.1 \\
\hline Storage, Industrial and Commercial & 1.0 \\
\hline Theaters-Motion Picture & 1.0 \\
\hline Theaters-Performance & 1.5 \\
\hline Other & 1.0 \\
\hline
\end{tabular}

The internal load values used in calculating envelope compliance are based in part on lighting power budgets. The internal loads in the 2000 IECC version of COMcheck were adjusted to reflect the revised lighting power densities described above. The methods and assumptions used in determining the internal load values were identical to those used in developing the values for the 90.1-1989 Code, except that the values in Table 805.4.2 of the 2000 IECC were substituted for the 90.1-1989 Code values.

\section{B.2 Envelope}

\section{B.2.1 Vapor Retarders}

The vapor retarder requirement in the 2000 IECC is the same as discussed in A.2.1 for the 1998 IECC. 


\section{B.3 Lighting}

\section{B.3.1 Exemptions and Allowances}

Each code version has exemptions for specific space uses, lighting applications, and/or equipment. Codes using exemptions and allowances based on Standard 90.1-1999 (i.e., 2000 IECC and the Massachusetts Code) also have power allowances. COMcheck allows exemptions or power allowances for qualifying fixtures.

\section{B.3.2 Exemptions}

The following exemptions based on Section 805.4.1 of the 2000 IECC are available in the 2000 IECC version of COMcheck:

- Special Medical/Dental/Research

- Professional Sports Arena Playing Field

- Gallery/Museum/Monument Exhibits

- Lighting in Residential Dwelling Units

- Emergency Lighting (Automatic Control).

\section{B.3.3 Allowances}

Additional lighting power allowances can be claimed under certain conditions resulting in the lighting power budget being increased, but only within limits and only to the extent the additional power is used for the qualifying application. Allowances in the 2000 IECC version of COMcheck are available with both the whole building type and area category methods. This differs from Standard 90.1-1999 and the Massachusetts commercial code, in which allowances are only available under the area category method.

When a fixture is identified as qualifying for an allowance, the user must provide the floor area qualifying for the allowance, the whole building type or area category corresponding with that floor or display area, and the type of allowance. The lighting power budget is increased by the product of the affected area and the wattage per square foot claimed up to the permitted maximum allowance, but not more than the total wattage of the selected fixtures.

COMcheck does not require space-by-space input of lighting fixtures. Without a space-by-space mapping of lighting fixtures to spaces, it is not possible to ensure that a space fully utilizes its lighting power budget before claiming the exemption or allowance. As a result, any unused budget for a space becomes usable elsewhere in the building, if the exemption or allowance is claimed. This was deemed to be a minor compromise relative to the large advantage of not requiring users to enter every fixture in the building on a space-by-space basis. In addition, both Massachusetts code and Standard 90.1-1989R language do not explicitly require the rigorous interpretation of these provisions.

Allowances can be obtained for any fixture by specifying the allowance type and its floor area. The budget lighting power is adjusted as below: 


$$
L P D_{\text {required }}=\sum \text { Area }_{\text {spacei }} \times L P D_{\text {spacei }}+\sum \text { Area }_{\text {allowance }} \times L P D_{\text {allowancei }}
$$

where $\quad$ space $^{\mathrm{i}}=$ area category types specified for the building

LPD = lighting power density

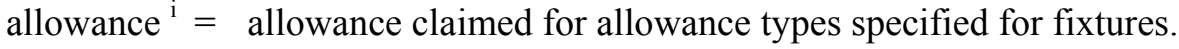

The allowances in Table B.3 are available in the 2000 IECC version of COMcheck and are based on the footnotes to Table 805.4.2 Interior Lighting Power in the 2000 IECC. The whole building types and area categories qualifying for these allowances are also listed.

Table B.3. Whole Building Types and Area Categories Qualifying for Allowances

\begin{tabular}{|l|c|l|}
\hline \multicolumn{1}{|c|}{ Allowance Type } & $\begin{array}{c}\text { Allowance Amount } \\
\left(\mathbf{W} / \mathbf{f t}^{2}\right)\end{array}$ & \multicolumn{1}{|c|}{ Whole Building Type/Area Category } \\
\hline Decorative & 1.0 & Bank/Financial Institution \\
\hline & & Convention, Conference or Meeting Center \\
\hline & & Dining \\
\hline & & Exercise Center \\
\hline & & Hotel Function \\
\hline & & Library \\
\hline & & Lobby - Hotel \\
\hline & & Lobby - Other \\
\hline & & Religious Worship \\
\hline Visual Display Terminals & & Restaurant \\
\hline & 0.35 & Theaters - Performance \\
\hline & & Classroom/Lecture Hall \\
\hline & & Medical and Clinical Care \\
\hline Merchandise Display & & Museum \\
\hline & 1.6 & Office \\
\hline Fine Merchandise Display & 3.9 & Retail Sales, Wholesale Showroom \\
\hline Emergency Medical/Pharmacy & 1.0 & Retail Sales, Wholesale Showroom \\
\hline
\end{tabular}

\section{B.4 Mechanical}

\section{B.4.1 Economizer Requirements}

In the 2000 IECC, buildings in Climate Zone $3 \mathrm{c}$ are not exempted from the economizer requirements. The integrated economizer requirement was included in the 2000 IECC, so COMcheck-EZ Version 2.0 and the 2000 IECC were already consistent; however, the Climate Zone $3 \mathrm{c}$ economizer requirement was included for the 2000 IECC version of COMcheck. All other requirements are identical to the 90.1-1989 Code. 


\section{Appendix C 2001 IECC}





\section{Appendix C - 2001 IECC}

This appendix describes the changes in COMcheck to support the 2001 International Energy Conservation Code (IECC). The Envelope and Lighting System requirements in the 2001 IECC are identical to the 2000 IECC, and no changes were made to the Envelope and Lighting compliance calculations. However, with the reference to Standard 90.1-1999 in Chapter 7, the trade-off requirements are no longer applicable across Chapter 7 and Chapter 8, which is based on Standard 90.1-1989. Hence, a warning message was added to alert users entering projects with a window-wall ratio $>50 \%$ to use either the Standard 90.11999 version of COMcheck or Section 806: Total Building Performance method in the 2001 IECC.

\section{C.1 Mechanical}

The Mechanical section has several changes in the 2001 IECC version of COMcheck affecting the equipment efficiency and economizer requirements.

1. Economizers are required for all cooling systems whose capacity is $>65 \mathrm{KBtu} / \mathrm{h}$. Climate Zones 1,2 , $3 \mathrm{~b}, 5 \mathrm{a}$ and $6 \mathrm{~b}$ are exempted from the economizer requirement (Section 803.2.6).

2. Economizers are exempted for systems with a cooling capacity $<135 \mathrm{KBtu} / \mathrm{h}$ in Climate Zones $3 \mathrm{c}$, 5b, 7, $13 \mathrm{~b}$ and 14 (Section 803.3.3.5).

3. All cooling plant efficiency requirements are revised as shown in Table C.1.

4. Heating equipment efficiency requirements are revised as shown in Table C.2.

Table C.1. Cooling Plant Efficiency Requirements

\begin{tabular}{|c|c|c|c|c|}
\hline $\begin{array}{c}\text { Cooling Plant } \\
\text { Type }\end{array}$ & Condenser Type & Capacity & $\begin{array}{l}\text { Efficiency } \\
\text { Required }\end{array}$ & $\begin{array}{c}2001 \text { IECC } \\
\text { Reference }\end{array}$ \\
\hline Water Chiller & $\begin{array}{l}\text { Air Cooled/ Evapo- } \\
\text { ratively Cooled }\end{array}$ & All & $\begin{array}{l}2.8 \mathrm{COP} \\
2.8 \mathrm{IPLV} \\
\end{array}$ & Table 803.3.2(2) \\
\hline Water Chiller & Water Cooled & $<150$ Tons & $\begin{array}{l}4.45 \text { COP } \\
4.50 \text { IPLV } \\
\end{array}$ & Table 803.3.2(2) \\
\hline Water Chiller & Water Cooled & $\begin{array}{l}>=150 \text { Tons } \\
<300 \text { Tons }\end{array}$ & $\begin{array}{l}\text { 4.90 COP } \\
\text { 4.95 IPLV }\end{array}$ & Table 803.3.2(2) \\
\hline Water Chiller & Water Cooled & $>=300$ Tons & $\begin{array}{l}5.5 \mathrm{COP} \\
5.6 \mathrm{IPLV}\end{array}$ & Table 803.3.2(2) \\
\hline Water Chiller & No Condenser & All & $\begin{array}{l}3.1 \mathrm{COP} \\
\text { 3.1 IPLV }\end{array}$ & Table 803.3.2(2) \\
\hline $\begin{array}{l}\text { Condenser } \\
\text { Unit }\end{array}$ & $\begin{array}{l}\text { Water/Evaporatively } \\
\text { Cooled }\end{array}$ & $>=135 \mathrm{KBtuh}$ & $\begin{array}{l}\text { 13.1 EER } \\
\text { 13.1 IPLV }\end{array}$ & Table 803.3.2(1) \\
\hline $\begin{array}{l}\text { Condenser } \\
\text { Unit }\end{array}$ & Air Cooled & $>=135$ KBtuh & $\begin{array}{c}\text { 10.1 EER } \\
11.2 \text { IPLV }\end{array}$ & Table 803.3.2(1) \\
\hline
\end{tabular}


Table C.2. Heating Equipment Efficiency Requirements

\begin{tabular}{|l|c|c|}
\hline \multicolumn{1}{|c|}{ Heating Equipment Type } & Efficiency & 2001 IECC Reference \\
\hline Unit heater (Oil) & $80 \% \mathrm{Ec}$ & Table $803.2 .2(4)$ \\
\hline Unit heater (Gas) & $80 \% \mathrm{Ec}$ & Table $803.2 .2(4)$ \\
\hline Unit heater (Propane) & $80 \% \mathrm{Ec}$ & Table $803.2 .2(4)$ \\
\hline Duct furnace (Gas) & $80 \% \mathrm{Ec}$ & Table $803.2 .2(4)$ \\
\hline Duct furnace (Gas) & $80 \% \mathrm{Ec}$ & Table $803.2 .2(4)$ \\
\hline Duct furnace (Propane) & $80 \% \mathrm{Ec}$ & Table $803.2 .2(4)$ \\
\hline
\end{tabular}

5. Heat pump efficiency requirements are revised in Table C.3.

Table C.3. Heat Pump Efficiency Requirements

\begin{tabular}{|c|c|c|c|c|}
\hline Condenser Type & Capacity & Heat Pump Type & $\begin{array}{l}\text { Efficiency } \\
\text { Required }\end{array}$ & $\begin{array}{c}2001 \text { IECC } \\
\text { Reference }\end{array}$ \\
\hline Air cooled & $<65$ KBtuh & Split system & $\begin{array}{l}\text { 10.0 SEER } \\
\text { 6.8 HSPF }\end{array}$ & Table 803.2.2(2) \\
\hline Air cooled & $<65 \mathrm{KBtuh}$ & Roof top unit & $\begin{array}{l}\text { 9.7 SEER } \\
\text { 6.6 HSPF }\end{array}$ & Table $803.2 .2(2)$ \\
\hline Air cooled & $\begin{array}{l}>=65 \mathrm{KBtuh} \\
<135 \mathrm{KBtuh}\end{array}$ & $\begin{array}{l}\text { Split system roof } \\
\text { top unit }\end{array}$ & $\begin{array}{l}\text { 10.1 EER } \\
3.2 \text { COP }\end{array}$ & Table 803.2.2(2) \\
\hline Air cooled & $\begin{array}{l}>=135 \mathrm{KBtuh} \\
<240 \mathrm{KBtuh}\end{array}$ & $\begin{array}{l}\text { Split system roof } \\
\text { top unit }\end{array}$ & $\begin{array}{ll}9.3 & \text { EER } \\
3.1 & \text { COP } \\
\end{array}$ & Table $803.2 .2(2)$ \\
\hline Air cooled & $>=240 \mathrm{KBtuh}$ & $\begin{array}{l}\text { Split system roof } \\
\text { top unit }\end{array}$ & $\begin{array}{lr}9.0 & \text { EER } \\
9.2 & \text { IPLV } \\
3.1 & \text { COP }\end{array}$ & Table 803.2.2(2) \\
\hline Water cooled & $<135$ KBtuh & All types & $\begin{array}{l}\text { 12.0 EER } \\
4.2 \text { COP } \\
\end{array}$ & Table 803.2.2(2) \\
\hline Groundwater & $<135$ KBtuh & All types & $\begin{array}{l}\text { 16.2 EER } \\
\text { 3.6 COP }\end{array}$ & \\
\hline
\end{tabular}

6. Cooling equipment efficiency requirements for split systems and roof top units in Table C.4.

Table C.4. Cooling Equipment Efficiency Requirements

\begin{tabular}{|c|c|c|c|}
\hline Condenser Type & Capacity & Efficiency & 2001 IECC Reference \\
\hline Air cooled & $<65$ KBtuh & 10.0 SEER & Table 803.2.2(1) \\
\hline Air cooled & $\begin{array}{l}>=65 \text { KBtuh } \\
<135 \text { KBtuh }\end{array}$ & 10.3 EER & Table 803.2.2(1) \\
\hline Air cooled & $\begin{array}{l}>=135 \mathrm{KBtuh} \\
<240 \mathrm{KBtuh}\end{array}$ & 9.7 EER & Table 803.2.2(1) \\
\hline Air cooled & $\begin{array}{l}>=240 \mathrm{KBtuh} \\
<760 \mathrm{KBtuh}\end{array}$ & $\begin{array}{l}\text { 9.5 EER } \\
\text { 9.7 IPLV }\end{array}$ & Table 803.2.2(1) \\
\hline Air cooled & $>=760 \mathrm{KBtuh}$ & $\begin{array}{l}\text { 9.2 EER } \\
\text { 9.4 IPLV }\end{array}$ & Table 803.2.2(1) \\
\hline Evaporatively cooled/ water cooled & $<65$ KBtuh & 12.1 EER & Table $803.2 .2(1)$ \\
\hline Evaporatively cooled/ water cooled & $\begin{array}{l}>=65 \mathrm{KBtuh} \\
<135 \mathrm{KBtuh}\end{array}$ & $11.5 \mathrm{EER}$ & Table 803.2.2(1) \\
\hline Evaporatively cooled/ water cooled & $\begin{array}{l}>=135 \mathrm{KBtuh} \\
<240 \mathrm{KBtuh}\end{array}$ & 11.0 EER & Table $803.2 .2(1)$ \\
\hline Evaporatively cooled/ water cooled & $>=240 \mathrm{KBtuh}$ & $\begin{array}{l}\text { 11.0 EER } \\
10.3 \text { IPLV }\end{array}$ & Table $803.2 .2(1)$ \\
\hline
\end{tabular}


Appendix D

90.1-1999 



\section{Appendix D - 90.1-1999}

This appendix describes changes that have been made to COMcheck to support Standard 90.1-1999. The major changes in the Envelope section are the trade-off calculation using cost factors, envelope prescriptive requirements, and assembly proposed U-factor calculations. The Lighting section has a new set of building use types and provides options for allowances and exemptions. The Mechanical section includes a new set of mandatory requirements and efficiency requirements for HVAC and SWH systems.

\section{D.1 Building Use Types}

The building use types were revised to be consistent with Standard 90.1-1999. This list is similar to the Massachusetts version of COMcheck, with changes to occupancy names and lighting power density (LPD) requirements as detailed below.

\section{D.1.1 Whole Building Types}

Table D.1. Whole Building Type Lighting Power Density Requirements

\begin{tabular}{|c|c|c|c|}
\hline Whole Building Type & $\begin{array}{c}\text { LPD } \\
\left(\mathbf{W} / \mathbf{f t}^{2}\right)\end{array}$ & Whole Building Type & $\begin{array}{c}\text { LPD } \\
\left(\mathbf{W} / \mathbf{f t}^{2}\right)\end{array}$ \\
\hline Automotive Facility & 1.5 & Museum & 1.6 \\
\hline Convention Center & 1.4 & Office & 1.3 \\
\hline Court House & 1.4 & Parking Garage & 0.3 \\
\hline Dining: Bar Lounge/Leisure & 1.5 & Penitentiary & 1.2 \\
\hline Dining: Cafeteria/Fast Food & 1.8 & Performing Arts Theater & 1.5 \\
\hline Dining: Family & 1.9 & Police/Fire Station & 1.3 \\
\hline Dormitory & 1.5 & Post Office & 1.6 \\
\hline Exercise Center & 1.4 & Religious Building & 2.2 \\
\hline Gymnasium & 1.7 & Retail & 1.9 \\
\hline Hospital/Health Care & 1.6 & School/University & 1.5 \\
\hline Hotel & 1.7 & Sports Arena & 1.5 \\
\hline Library & 1.5 & Town Hall & 1.4 \\
\hline Manufacturing Facility & 2.2 & Transportation & 1.2 \\
\hline Motel & 2.0 & Warehouse & 1.2 \\
\hline Motion Picture Theater & 1.6 & Workshop & 1.7 \\
\hline Multifamily & 1.0 & & \\
\hline
\end{tabular}

\section{D.1.2 Area Categories}

Table D.2 shows the area categories list from Table 9.3.1.2 of Standard 90.1-1999. 
Table D.2. Area Category Lighting Power Density (LPD) Requirements

\begin{tabular}{|c|c|c|c|}
\hline Area Category Name & LPD $\left(\mathbf{W} / \mathbf{f t}^{2}\right)$ & Area Category Name & LPD $\left(W / f^{2}\right)$ \\
\hline Athletics & & Hospitality and Food Service & \\
\hline Audience/Seating Area & 0.5 & Bar Lounge/Leisure Dining Area & 1.2 \\
\hline Court Sports Area & 4.3 & Cafeteria/Fast Food Dining Area & 1.4 \\
\hline Dressing/Locker/Fitting Room & 0.8 & Dormitory Living Quarters & 1.9 \\
\hline Exercise Area & 1.1 & Family Restaurant Dining Area & 2.2 \\
\hline Indoor Playing Field Area & 1.9 & Hotel Dining Area & 1.0 \\
\hline Playing Area & 1.9 & Hotel Lobby & 1.7 \\
\hline Ring Sports Area & 3.8 & Hotel/Motel Guest Rooms & 2.5 \\
\hline Common Space Types & & Motel Dining Area & 1.2 \\
\hline \begin{tabular}{|l} 
Active Storage \\
\end{tabular} & 1.1 & Multifamily Living Units & 0 \\
\hline Atrium - First Three Floors & 1.3 & Industrial and Auto Service & \\
\hline Atrium - Each Additional Floor & 0.2 & Automotive Facility Garage Service/Repair & 1.4 \\
\hline Classroom/Lecture/Training & 1.6 & Detailed Manufacturing & 6.2 \\
\hline Conference/Meeting/Multipurpose & 1.5 & Manufacturing Control Room & 0.5 \\
\hline Corridor/Transition & 0.7 & Manufacturing Corridor/Transition & 0.5 \\
\hline Dining Area & 1.4 & Manufacturing Equipment Room & 0.8 \\
\hline Electrical/Mechanical & 1.3 & Manufacturing General - High Bay & 3.0 \\
\hline Food Preparation & 2.2 & Manufacturing General - Low Bay & 2.1 \\
\hline Inactive Storage & 0.3 & Workshop & 2.5 \\
\hline Laboratory & 1.8 & Library and Museum & \\
\hline Lobby & 1.8 & Library Card File and Cataloging & 1.4 \\
\hline Lounge/Recreation & 1.4 & Library Reading Area & 1.8 \\
\hline Office - Enclosed & 1.5 & Library Stacks & 1.9 \\
\hline Office - Open Plan & 1.3 & Museum Active Storage & 1.4 \\
\hline Restrooms & 1.0 & Museum General Exhibition & 1.6 \\
\hline Stairs-Active & 0.9 & Museum Inactive Storage & 1.4 \\
\hline Government and Public Safety & & Museum Restoration & 2.5 \\
\hline Confinement Cell & 1.1 & Public Assembly & \\
\hline $\begin{array}{l}\text { Court House/Police Station/Town Hall } \\
\text { Audience/Seating Area }\end{array}$ & 1.6 & Convention Center Audience/Seating Area & 0.5 \\
\hline Courtroom & 2.1 & Convention Center Exhibit Space & 3.3 \\
\hline Fire Station Engine Room & 0.9 & Motion Picture Audience/Seating Area & 1.3 \\
\hline Fire Station Sleeping Quarters & 1.1 & Motion Picture Theater Lobby & 0.8 \\
\hline Judges Chamber & 1.1 & Performing Arts Audience/Seating Area & 1.8 \\
\hline Penitentiary Audience/Seating Area & 1.9 & Performing Arts Theater Lobby & 1.2 \\
\hline Penitentiary Classroom/Lecture/Training & 1.4 & Religious & \\
\hline Post Office Sorting Area & 1.7 & Audience/Seating Area & 3.2 \\
\hline Hospital and Healthcare & & Fellowship Hall & 2.3 \\
\hline Active Storage - Hospital & 2.9 & Worship - Pulpit/Choir & 5.2 \\
\hline Corridors /Transition - Hospital & 1.6 & Retail and Banking & \\
\hline Emergency & 2.8 & Banking Activity Area & 2.4 \\
\hline Exam/Treatment & 1.6 & General Retail Sales Area & 2.1 \\
\hline Laundry/Washing & 0.7 & Mall Concourse & 1.8 \\
\hline Medical Supplies & 3.0 & Transportation & \\
\hline Nurse Station & 1.8 & Air/Train/Bus Baggage Area & 1.3 \\
\hline Nursery & 1.0 & Airport Concourse & 0.7 \\
\hline Operating Room & 7.6 & Seating Area & 1.0 \\
\hline Patient Room & 1.2 & Terminal Ticket Counter & 1.8 \\
\hline Pharmacy & 2.3 & Warehouse and Parking & \\
\hline Physical Therapy & 1.9 & Fine Material Storage & 1.6 \\
\hline Radiology & 0.4 & Medium/Bulky Material Storage & 1.1 \\
\hline \multirow[t]{2}{*}{ Recovery } & 2.6 & Parking Garage - Attendant Only & 0.1 \\
\hline & & Parking Garage - Pedestrian & 0.2 \\
\hline
\end{tabular}


The grouping of area categories in COMcheck is different from that of Standard 90.1-1999, but it is simple to use and consistent with the Massachusetts version.

\section{D.2 Envelope}

\section{D.2.1 Trade-off Calculations}

The exterior wall/window trade-off calculation methodology in Standard 90.1-1999 is based on envelope performance factor (EPF) using cost factors and is significantly different from that of Standard 90.1-1989, which is based on normalized heating and cooling coil loads. Another important difference in the tradeoff calculation methodology between Standard 90.1-1989 and Standard 90.1-1999 is related to the budget window-to-wall ratio (WWR) and exclusion of the door area from the gross wall area. The trade-off calculations in Standard 90.1-1999 use the same WWR for both the budget and proposed design, whereas in Standard 90.1-1989, the WWR for the budget design is calculated as a function of the heating degree days, cooling degree hours, VSEW (annual average incident solar energy in east/west facades) and internal load density.

The envelope compliance index is calculated from the EPF for the proposed and budget designs using the EPF calculation procedure, as outlined in Appendix C of Standard 90.1-1999. EPF is the sum of heating factor, cooling factor and lighting for each zone considering the daylighting potential. The heating and cooling factors are calculated using the heating/cooling coefficients provided in Table C6.10.3 of Standard 90.1-1999. For each envelope component, the heating and cooling loads are calculated and added separately to determine the total heating and cooling loads for the building. The heating and cooling loads for exterior walls and vertical fenestration are calculated using the regression equations, as published in Standard 90.1-1989. The opaque door component is excluded from the regression equationbased load calculation and Standard 90.1-1999 provides heating and cooling coefficients for opaque doors identical to exterior walls. These loads are added with other component loads calculated using the heating/cooling coefficients, as described in Section 3.0 (Envelope Documentation), of this document, with the assumption of a SEER 12.24 for cooling and AFUE 0.608488 for heating equipment efficiencies. The cooling and heating coefficients in Table C6.10.3 of Standard 90.1-1999 are converted, as shown below for calculating the loads:

$$
\begin{array}{ll}
\text { Cooling coefficient } & =\text { Coeff } \times 12.24 \times 1000 \\
\text { Heating coefficient } & =\quad H_{\text {coeff }} \times 0.608488 \times 100000
\end{array}
$$

where $C_{\text {coeff }}=$ cooling coefficients from Table C6.10.3 of Standard 90.1-1999.

Hcoeff =heating coefficients from Table C6.10.3 of Standard 90.1-1999.

The total heating and cooling loads are divided by the equipment efficiencies and the following cost factors are applied to convert the loads and calculate the EPF:

$$
\begin{aligned}
& \text { Cooling cost factor }=0.08 \text { per } \mathrm{kW} \\
& \text { Heating cost factor }=0.66 \text { per therm }
\end{aligned}
$$

Technical Support Documentation for COMcheck Through Version 3.4.0 (Software) 
The cooling/heating load calculation assumes the following for the budget building:

1. All windows are assumed to be fixed.

2. The above-grade wall budget $U$-factor is area averaged based on the wall type and its corresponding budget U-factor, as specified in Appendix B of Standard 90.1-1999.

3. The WWR upper limit is set at 50\% instead of $40 \%$ as in C3.3 of Standard $90.1-1999$, because the proposed design could meet prescriptive requirements for WWR of 40 to $50 \%$ in the prescriptive tables of Appendix B of Standard 90.1-1999.

4. Skylight areas up to $3 \%$ of the total roof area are not included in load calculations.

At present, the daylighting potential is not included in the calculation of EPF and the envelope compliance index because of the unreliable and counter-intuitive results, as detailed in Section D.2.4 of this appendix. There are significant issues with the calculation of the lighting power density adjustment for daylighting potential. These issues were brought to the attention of the Envelope Committee for resolution.

\section{D.2.2 Budget U-Factors}

The required U-factor for each envelope assembly is obtained from the Envelope Requirements Tables in Appendix B of Standard 90.1-1999. The envelope U-factor requirements are based on the WWR, heating and cooling degree days, space-conditioning type and the assembly type. Based on an ASHRAE interpretation, below-grade wall areas are included in the calculation of WWR. See Section D.5 for details. The heating and cooling degree days are obtained from the weather data for the proposed building location, which falls under one of the 26 bin ranges, as provided in Figure B-1 of Standard 90.11999. The space-conditioning type is determined based on the building use type of the proposed design. All building types not listed in Table D.3 under residential are considered to be non-residential. Table D.4 lists occupancies that could be designated as 'semi-heated' if the building has no mechanical cooling and meets the heating equipment capacity limit specified by the Standard.

If the list of area categories contains a combination of residential and non-residential, then the area category with the largest floor area is used to determine the compliance requirement. If both residential and non-residential have the same floor area, then non-residential requirements apply.

Table D.3. Residential Occupancies

\begin{tabular}{|l|l|}
\hline Whole Building Type & Dormitory \\
& Hotel, Motel \\
& Multifamily \\
& Penitentiary \\
\hline Area Category & Confinement Cell \\
& Fire station Sleeping Quarters \\
& Patient Room \\
& Guest Rooms \\
& Multifamily Living Units \\
& Dormitory Living Quarters \\
\hline
\end{tabular}

Technical Support Documentation for COMcheck Through Version 3.4.0 (Software) 
Table D.4. Semi-Heated Occupancies

\begin{tabular}{|l|l|}
\hline Whole Building Type & Automotive Facility \\
& Manufacturing Facility \\
Parking Garage & Warehouse \\
& Workshop \\
\hline Area Category & Common Space Types: \\
Active and Inactive Storage \\
Hospital and Healthcare: \\
Active Storage - Hospital \\
Industrial and Auto Service: \\
Automotive Facility Garage Service/Repair \\
Detailed Manufacturing \\
Manufacturing Control Room \\
Manufacturing Corridor/Transition \\
Manufacturing Equipment Room \\
Manufacturing General - High Bay \\
Manufacturing General - Low Bay \\
Library and Museum: \\
Museum Active and Inactive Storage \\
Warehouse and Parking: \\
Fine Material Storage \\
Medium/Bulky Material Storage \\
Parking Garage - Attendant Only \\
Parking Garage - Pedestrian \\
\hline
\end{tabular}

The budget building envelope U-factors, C-factors, and F-factors are specified for approximately 19 assembly types in Appendix B of Standard 90.1-1999 and vary based on heating-degree-day (HDD65) and cooling-degree-day (CDD50) bins. For proposed building calculations, COMcheck uses precalculated assembly U-factors, C-factors, and F-factors, as given in Appendix A of Standard 90.1-1999. Table D.5 shows the mapping between the proposed assemblies, as presented in COMcheck, along with the Standard 90.1-1999 Appendix A table number used in computing U-factors for those assemblies (column 1) and the budget assemblies from Appendix B (column 2).

Some of the assembly types in Standard 90.1-1999 closely match those used in the 90.1-1989 Code version of COMcheck. Where assembly types are similar, the assemblies entered in the software by the user remain valid when the user switches from one code to another. Some of the Standard 90.1-1999 assembly types, however, could not be correlated to Standard 90.1-1989 assemblies. For these cases, a user changing from one code to the other must reselect the assembly type before a valid compliance calculation can be performed.

Table D.6 shows the mapping of the assembly types in the 90.1-1989 Code version of COMcheck to the Standard 90.1-1999 version -- some with a slight name change. The Standard 90.1-1999 assemblies not listed in this table were not mapped to the 90.1-1989 Code assemblies, and must be re-selected if the user switches between codes. 
Table D.5. Mapping Between Proposed and Required Assemblies

\begin{tabular}{|c|c|c|}
\hline \multicolumn{2}{|c|}{ Proposed Building } & \multirow{2}{*}{\begin{tabular}{|c|} 
Budget Building \\
Budget Building Assemblies from 90.1-1999 \\
Appendix B
\end{tabular}} \\
\hline COMcheck Proposed Building Assemblies & $\begin{array}{l}\text { 90.1-1999 Appendix A Table } \\
\text { Numbers } \\
\end{array}$ & \\
\hline Roof & & Roof \\
\hline Insulation Entirely Above Deck & A-1 & Insulation Entirely Above Deck \\
\hline Metal Building, Standing Seam & A-2 & Metal Building \\
\hline Metal Building, Screw Down & A-2 & Metal Building \\
\hline Attic Roof with Wood Joists & A-3 & Attic and Other \\
\hline Attic Roof with Steel Joists & A-4 & Attic and Other \\
\hline Other (U-factors provided by user) & & Attic and Other \\
\hline Skylight & & Skylight \\
\hline Skylight (U-factors provided by user.) & \begin{tabular}{|c|} 
A-17 \\
A-18 \\
(used for suggested U-factors, \\
SHGC for unlabeled skylights) \\
\end{tabular} & $\begin{array}{l}\text { Skylight required U-factors and SHGC vary } \\
\text { based on glass or plastic, curb type, } \\
\text { orientation, and ratio of skylight to roof area }\end{array}$ \\
\hline Other (U-factors provided by user) & & Same as above \\
\hline Exterior Wall & & Above-Grade Wall \\
\hline Wood-Framed, 16" o.c. & A-11 & Wood Framed and Other \\
\hline Wood-Framed, 24" o.c. & A-11 & Wood-Framed and Other \\
\hline Steel-Framed, 16" o.c. & A-10 & Steel-Framed \\
\hline Steel-Framed, 24" o.c. & A-10 & Steel-Framed \\
\hline Metal Building Wall & A-9 & Metal Building \\
\hline Solid Concrete & A-6 & Mass \\
\hline Concrete Block & A-7 & Mass \\
\hline Other (U-factors provided by user) & & Wood-Framed and Other \\
\hline \multicolumn{3}{|l|}{ Interior Wall } \\
\hline Same as Exterior Walls & & $\begin{array}{l}\text { Same as Exterior Walls, using Semi-Heated } \\
\text { Requirements }\end{array}$ \\
\hline Window & & Vertical Glazing \\
\hline Windows (U-factors provided by user) & $\begin{array}{c}\text { A-19 } \\
\text { (used for suggested U-factors, } \\
\text { SHGC, and VLT for unlabeled } \\
\text { skylights) }\end{array}$ & $\begin{array}{l}\text { Window required U-factors and SHGC vary } \\
\text { based on glass or plastic, curb type, } \\
\text { orientation, and window to wall ratio }\end{array}$ \\
\hline Door & & Door \\
\hline Uninsulated Single-Layer Metal & Section A7 & $\begin{array}{l}\text { Based on opening type (swinging or non- } \\
\text { swinging) }\end{array}$ \\
\hline Uninsulated Double-Layer Metal & Section A7 & \\
\hline Insulated Metal & Section A7 & \\
\hline Wood & Section A7 & \\
\hline Glass ( $>50 \%$ glazing) & Section A7 & \\
\hline \multicolumn{3}{|l|}{ Other } \\
\hline Basement & & Below-Grade Wall \\
\hline Solid Concrete & A-12 & Below-Grade Wall \\
\hline Concrete Block & $\mathrm{A}-12$ & Below-Grade Wall \\
\hline Other (U-factors provided by user) & & Below-Grade Wall \\
\hline Floor & & Floor/Slab-On-Grade Floor \\
\hline Concrete Floor (over unconditioned space) & A-13 & Mass \\
\hline Steel Joist & A-14 & Steel Joist \\
\hline COMcheck Proposed Building Assemblies & $\begin{array}{l}\text { 90.1-1999 Appendix A Table } \\
\text { Numbers }\end{array}$ & $\begin{array}{c}\text { Budget Building Assemblies from 90.1-1999 } \\
\text { Appendix B }\end{array}$ \\
\hline Wood-Framed & A-15 & Wood-Framed and Other \\
\hline Slab-On-Grade - Unheated & A-16 & Unheated Slab-On-Grade \\
\hline Slab-On-Grade - Heated & A-16 & Heated Slab-On-Grade \\
\hline Other & & Wood-Framed and Other \\
\hline
\end{tabular}


Table D.6. Mapping Between 90.1-1989 Code and Standard 90.1-1999 Assembly Names in COMcheck

\begin{tabular}{|l|l|l|}
\hline Category & $\mathbf{9 0 . 1 - 1 9 8 9}$ Code Assembly Name & $\mathbf{9 0 . 1 - 1 9 9 9}$ Assembly Name \\
\hline Roof & $\begin{array}{l}\text { All-Wood Joist/Rafter/Truss } \\
\text { Non-Wood Joist/Rafter/Truss }\end{array}$ & $\begin{array}{l}\text { Attic Roof with Wood Joists } \\
\text { Attic Roof with Steel Joists }\end{array}$ \\
\hline Windows & All Frame Types and Glass Types & $\begin{array}{l}\text { All frame types and glass types are retained } \\
\text { the same as in 90.1-1989 Code, and skylights } \\
\text { are assumed to be Skylights without Curb }\end{array}$ \\
\hline Above Grade Wall & $\begin{array}{l}\text { Wood Frame, Any Spacing } \\
\text { Metal Frame, 16" o.c. } \\
\text { Metal Frame, 24" o.c. }\end{array}$ & $\begin{array}{l}\text { Steel-Framed, 16" o.c. } \\
\text { Steel-Framed, 24" o.c. }\end{array}$ \\
\hline Windows & All Frame Types and Glass Types & $\begin{array}{l}\text { All frame types and glass types are retained } \\
\text { the same as in 90.1-1989 Code, and assumed } \\
\text { to be 'Fixed' (non-operable windows). }\end{array}$ \\
\hline Floor & $\begin{array}{l}\text { All-Wood Joist/Truss } \\
\text { Non-Wood Joist/Truss } \\
\text { Concrete Floor (over unconditioned space) } \\
\text { Unheated Slab-On-Grade } \\
\text { Heated Slab-On-Grade }\end{array}$ & $\begin{array}{l}\text { Steel Joist } \\
\text { Concrete Floor (over unconditioned space) } \\
\text { Unheated Slab-On-Grade } \\
\text { Heated Slab-On-Grade }\end{array}$ \\
\hline
\end{tabular}

\section{D.2.3 Proposed U-Factors}

This section contains the proposed U-factor calculation for all of the assembly types. The calculation methods have been derived from the tables in Appendix A of Standard 90.1-1999. Whenever possible, the table values have been calculated from equations found in the spreadsheets used in the Standard 90.11999 development process. For R-values not present in the following tables, U-factors are calculated using linear interpolation.

\section{D.2.3.1 Roof}

The following roof types found in Appendix A2 of Standard 90.1-1999 are included in the software:

- Insulation Entirely Above Deck

- Metal Building, Standing Seam

- Metal Building, Screw Down

- Attic with Wood Joists

- Attic with Steel Joists

- Other.

The proposed U-factor calculation for roof assemblies is based on the continuous and cavity R-values using the equations shown in Table D.7. 
Table D.7. Proposed U-Factors for Roofs

\begin{tabular}{|l|c|}
\hline \multicolumn{1}{|c|}{ Roof Type } & Proposed U-Factor \\
\hline Insulation Entirely Above Deck & $\frac{1}{0.78+R_{R F-C N I}}$ \\
\hline $\begin{array}{l}\text { Metal Building, Standing Seam } \\
\text { Metal Building, Screw Down }\end{array}$ & $\frac{1}{\mathrm{U}_{R_{R F-C V I}}}+R_{R F-C N I}$ \\
\hline Attic Roof with Wood Joists & $\frac{0.85}{1.63+R_{R F-C V I}+R_{R F-C N I}}+$ \\
& $\frac{0.05}{1.63+\left(0.5 * R_{R F-C V I}\right)+R_{R F-C N I}}+$ \\
\hline Attic Roof with Steel Joists & $\frac{0.10}{1.63+R_{R F-C V I-a d j}+R_{R F-C N I}}$ \\
\hline Other & $\frac{1}{0.78+\left(\mathrm{FF} * R_{R F-C V I}\right)+R_{R F-C N I}}$ \\
\hline
\end{tabular}

where $\quad R_{\mathrm{RF}-\mathrm{CVI}}=\mathrm{R}$-value for the cavity insulation as entered by the user

$\mathrm{R}_{\mathrm{RF}-\mathrm{CNI}}=\mathrm{R}$-value for continuous insulation input by the user

$\mathrm{R}_{\mathrm{RF}-\mathrm{CVI} \text {-adj }}=$ Adjusted R-value for the cavity insulation (4.38 for $\mathrm{R}_{\mathrm{RF}-\mathrm{CVI}}<=13 \quad$ or $4.38+\left(\mathrm{R}_{\mathrm{RF}-\mathrm{CVI}}-11\right)$ for $\left.\mathrm{R}_{\mathrm{RF}-\mathrm{CVI}}>13\right)$

$U_{\mathrm{R}_{\mathrm{RF}-\mathrm{CVI}}}=\mathrm{U}$-factor of base assembly for $\mathrm{R}_{\mathrm{RF}-\mathrm{CVI}}$ as in Table D.8 or Table D.9

$\mathrm{FF}=$ Framing factor from Table D.10.

Table D.8. Base Assembly Overall U-Factor for Metal Building, Standing Seam Roofs

\begin{tabular}{|l|l|}
\hline $\mathbf{R}_{\mathbf{R F}-\mathrm{CVI}}$ & $U_{\mathrm{R}_{\mathrm{RF}-\mathrm{CVI}}}$ \\
\hline 0.0 & 1.28 \\
\hline 6.0 & 0.167 \\
\hline 10.0 & 0.097 \\
\hline 11.0 & 0.092 \\
\hline 13.0 & 0.083 \\
\hline 16.0 & 0.072 \\
\hline 19.0 & 0.065 \\
\hline 20.0 & 0.063 \\
\hline 21.0 & 0.061 \\
\hline 22.0 & 0.060 \\
\hline
\end{tabular}

\begin{tabular}{|c|c|}
\hline $\mathbf{R}_{\mathbf{R F}-\mathbf{C V I}}$ & $U_{\mathrm{R}_{\mathrm{RF}-\mathrm{CVI}}}$ \\
\hline 23.0 & 0.058 \\
\hline 24.0 & 0.057 \\
\hline 26.0 & 0.055 \\
\hline 29.0 & 0.052 \\
\hline 30.0 & 0.051 \\
\hline 32.0 & 0.049 \\
\hline 35.0 & 0.139 \\
\hline 38.0 & 0.130 \\
\hline$>38.0$ & 0.130 \\
\hline
\end{tabular}


Table D.9. Base Assembly Overall U-Factor for Metal Building, Screw Down Roofs

\begin{tabular}{|l|l|}
\hline $\mathbf{R}_{\mathbf{R F}-\mathrm{CVI}}$ & $U_{\mathrm{R}_{\mathrm{RF}-\mathrm{CVI}}}$ \\
\hline 10.0 & 0.153 \\
\hline 11.0 & 0.139 \\
\hline 13.0 & 0.130 \\
\hline$>13.0$ & 0.130 \\
\hline
\end{tabular}

Table D.10. Framing Factor (FF) for Attic Roof with Steel Joists

\begin{tabular}{|l|l|}
\hline $\mathbf{R}_{\text {RF-CVI }}$ & FF \\
\hline 0.0 & 1.00 \\
\hline 4.0 & 0.97 \\
\hline 5.0 & 0.96 \\
\hline 8.0 & 0.94 \\
\hline 10.0 & 0.92 \\
\hline 11.0 & 0.91 \\
\hline 12.0 & 0.90 \\
\hline 13.0 & 0.90 \\
\hline 15.0 & 0.88 \\
\hline 16.0 & 0.87 \\
\hline 19.0 & 0.86 \\
\hline
\end{tabular}

\begin{tabular}{|l|l|}
\hline $\mathbf{R}_{\mathbf{R F}-\mathbf{C V I}}$ & $\mathbf{F F}$ \\
\hline 20.0 & 0.85 \\
\hline 21.0 & 0.84 \\
\hline 24.0 & 0.82 \\
\hline 25.0 & 0.81 \\
\hline 30.0 & 0.79 \\
\hline 35.0 & 0.76 \\
\hline 38.0 & 0.74 \\
\hline 40.0 & 0.73 \\
\hline 45.0 & 0.71 \\
\hline 50.0 & 0.69 \\
\hline 55.0 & 0.67 \\
\hline
\end{tabular}

\section{D.2.3.2 Exterior Wall}

The following exterior wall types from Appendix A3 of Standard 90.1-1999 are included in the software:

- Wood-Framed, 16" o.c.

- Wood-Framed, 24" o.c.

- Steel-Framed, 16" o.c.

- Steel-Framed, 24" o.c.
- Metal Building Wall

- Solid Concrete

- Concrete Block

- Other

User inputs for these assemblies are limited to cavity and continuous R-values for all framed walls. The mass walls are further described by density and furring details. The insulation position is assumed to be integral, and default heat capacity values are assumed based on the wall type, as already described in Table 3.10 of Section 3.0 of this document.

The proposed U-factor calculations for these assemblies are calculated using a combination of empirical equations and look-up tables. All framed-wall assembly U-factor calculations are listed in Table D.11. The mass wall types and their U-factor calculations are described later in this section. 
Table D.11. Proposed U-Factors for Exterior Walls

\begin{tabular}{|l|l|}
\hline \multicolumn{1}{|c|}{ Exterior Wall Type } & Proposed U-Factor \\
\hline Wood Frame, 16 in. o.c. & $\frac{0.75}{2.05+\left(F F^{*} \mathrm{R}_{\mathrm{WL}-\mathrm{CVI}}\right)+\mathrm{R}_{\mathrm{WL}-\mathrm{CNI}}}+$ \\
\hline & $\frac{0.21}{2.05+\mathrm{AC}_{1}+\mathrm{R}_{\mathrm{WL}-\mathrm{CNI}}}+$ \\
& $\frac{0.04}{2.05+\mathrm{AC}_{2}+\mathrm{R}_{\mathrm{WL}-\mathrm{CNI}}}$ \\
\hline Wood Frame, 24 in. o.c. & $\frac{0.78}{2.05+\left(F F^{*} \mathrm{R}_{\mathrm{WL}-\mathrm{CVI}}\right)+\mathrm{R}_{\mathrm{WL}-\mathrm{CNI}}+\mathrm{R}_{\mathrm{WL}-\mathrm{CNI}}}+$ \\
\hline Steel Frame, 16 in. o.c. & $\frac{0.04}{2.05+\mathrm{AC}+\mathrm{R}_{\mathrm{WL}-\mathrm{CNI}}}$ \\
Steel Frame, 24 in. o.c. & $\frac{1}{2.05+\left(F F^{*} \mathrm{R}_{\mathrm{WL}-\mathrm{CVI}}\right)+\mathrm{R}_{\mathrm{WL}-\mathrm{CNI}}}$ \\
\hline Metal Building Wall & $\frac{1}{U_{\mathrm{R}}}+\mathrm{R}_{\mathrm{WL}-\mathrm{CNI}}$ \\
\hline Other & As input by user \\
\hline
\end{tabular}

where $\quad \mathrm{R}_{\mathrm{WL}-\mathrm{CVI}}=\mathrm{R}$-value for the cavity insulation as input by the user

$\mathrm{R}_{\mathrm{WL}-\mathrm{CNI}}=\mathrm{R}$-value for continuous insulation input by the user

$\mathrm{FF}=$ framing factor (dependent on $\mathrm{R}_{\mathrm{RF}-\mathrm{CVI}}$ as in Table D.12 or Table D.13)

$\mathrm{AC}_{1}, \mathrm{AC}_{2}=$ adjusted equivalent cavity insulation based on $\mathrm{R}_{\mathrm{RF}-\mathrm{CVI}}$

$U_{\mathrm{R}_{\mathrm{WL}-\mathrm{CVI}}}=\mathrm{U}$-factor of base assembly for $\mathrm{R}_{\mathrm{RF}-\mathrm{CVI}}$ as in Table D.14.

Table D.12. Framing Factor and Adjusted Cavity Insulation R-Values for Wood-Frame Walls

\begin{tabular}{|c|c|c|c|}
\hline $\mathbf{R}_{\text {WL-CVI }}$ & FF & AC1 & AC2 \\
\hline$<19.0$ & 1.0 & 4.38 & 4.38 \\
\hline 19.0 & 0.95 & 6.88 & 4.65 \\
\hline$>19.0$ & 1.0 & 6.88 & 4.65 \\
\hline
\end{tabular}


Table D.13. Framing Factor for Steel-Frame Walls

\begin{tabular}{|c|c|c|}
\hline $\mathbf{R}_{\text {WL-CVI }}$ & FF (16 in. o.c.) & FF (24 in. o.c.) \\
\hline 0 & 0.87 & 1.0 \\
\hline 11 & 0.50 & 0.60 \\
\hline 13 & 0.46 & 0.55 \\
\hline 15 & 0.43 & 0.52 \\
\hline 19 & 0.37 & 0.45 \\
\hline$>=21$ & 0.35 & 0.43 \\
\hline
\end{tabular}

Table D.14. Base Assembly Overall U-Factor for Metal-Building Walls

\begin{tabular}{|c|l|}
\hline $\mathbf{R}_{\mathbf{W L}-\mathrm{CVI}}$ & $\boldsymbol{U}_{\boldsymbol{R}_{\mathrm{WL}-\mathrm{CVI}}}$ \\
\hline 0.0 & 1.18 \\
\hline 6.0 & 0.184 \\
\hline 10.0 & 0.134 \\
\hline 11.0 & 0.123 \\
\hline 13.0 & 0.113 \\
\hline 19.0 & 0.070 \\
\hline 23.0 & 0.061 \\
\hline 26.0 & 0.057 \\
\hline 32.0 & 0.048 \\
\hline$>32.0$ & $1.41 / R_{W L-C V I}$ \\
\hline
\end{tabular}

The proposed U-factor calculations for mass wall assemblies are calculated using Tables A-6, A-7 and A-8 of Standard 90.1-1999. For all mass walls, the user is required to provide wall thickness, concrete density and furring material type, if present. The overall U-factor of the proposed assembly is determined by combining the thermal resistance of the solid wall and the cavity and continuous insulations using Equation D.5.

$$
\mathrm{U}_{\mathrm{WL}}=1 /\left(\mathrm{R}_{\mathrm{WL}-\mathrm{BOA}}+\mathrm{R}_{\mathrm{WL}-\mathrm{CVI}} \times \mathrm{AF}_{\mathrm{WL}}+\mathrm{R}_{\mathrm{WL}-\mathrm{CNI}}\right)
$$

where $\quad \mathrm{U}_{\mathrm{WL}}=$ overall $\mathrm{U}$-factor for the mass wall

$\mathrm{R}_{\mathrm{WL}-\mathrm{BOA}}=\mathrm{R}$-value for the solid portion of the wall

$\mathrm{R}_{\mathrm{WL}-\mathrm{CVI}}=\mathrm{R}$-value for the furring cavity insulation input by the user

$\mathrm{AF}_{\mathrm{WL}}=$ parallel path adjustment factor for furring

$\mathrm{R}_{\mathrm{WL}-\mathrm{CNI}}=\mathrm{R}$-value for continuous insulation input by the user.

The R-value ( $\mathrm{R}_{\mathrm{WL}-\mathrm{BOA}}$ ) for the solid portion of the wall is obtained from the U-factor for a given concrete density and wall thickness from Tables A-6 and A-7 of Standard 90.1-1999. Standard 90.1-1999 provides thermal properties for 11 density levels for solid concrete walls and 6 density levels for concrete block walls. To simplify COMcheck, three common density ranges - light, medium and normal - are supported with the properties shown in Table D.15 (taken from ASTM C90-93, as provided by Bruce Wilcox, Berkley Solar Group). All thicknesses and block types provided in Tables A-6 and A-7 of Standard 90.11999 are included in the software. 
Table D.15. Density Ranges Provided by the Software

\begin{tabular}{|l|l|l|}
\hline \multicolumn{1}{|c|}{ Name } & \multicolumn{1}{|c|}{$\begin{array}{c}\text { Density Range } \\
\left(\mathbf{l b} / \mathbf{f t}^{\mathbf{3}} \mathbf{)}\right.\end{array}$} & \multicolumn{1}{c|}{$\begin{array}{c}\text { Assumed Density } \\
\left(\mathbf{l b} / \mathbf{f t}^{\mathbf{3}} \mathbf{)}\right.\end{array}$} \\
\hline Light Weight & $<105$ & 95 \\
\hline Medium Weight & $105-124$ & 115 \\
\hline Normal Weight & 125 or greater & $135-$ CMU \\
& & $144-$ Solid concrete \\
\hline
\end{tabular}

The parallel path adjustment factor $\left(\mathrm{AF}_{\mathrm{WL}}\right)$ is calculated assuming a standard framing size, based on framing material type and cavity insulation levels using the following equations. The framing thickness $\left(\mathrm{T}_{\mathrm{FR}}\right)$ is inferred from the cavity insulation level $\left(\mathrm{R}_{\mathrm{WL}-\mathrm{CVI}}\right)$.

Wood furring:

$$
\mathrm{AF}_{W L}=\frac{1}{\frac{0.88}{\mathrm{R}_{\mathrm{WL}-\mathrm{CVI}}}+\frac{0.12}{1.035 \mathrm{~T}_{\mathrm{FR}}}}
$$

Metal furring:

$$
\mathrm{AF}_{W L}=\frac{1}{\frac{0.998}{\mathrm{R}_{\mathrm{WL}-\mathrm{CVI}}}+\frac{0.002}{0.00318 \mathrm{~T}_{\mathrm{FR}}}}
$$

where $\mathrm{T}_{\mathrm{FR}}=$ thickness of framing assuming $3.5 \mathrm{in}$. for cavity $\mathrm{R}$-value $<=11$ and $5.5 \mathrm{in}$. for cavity Rvalue $>11$.

The above equations are empirical relations derived to match the values in Table A-8 of Standard 90.11999 and the adjusted cavity R-value does not include the gypsum board. There is a potential for discrepancy up to an R-2 as a result of compressed insulation or very large thickness of studs.

\section{D.2.3.3 Basement}

The basement wall types include solid concrete wall and concrete block wall assemblies, as described in the previous section, Exterior Wall. The user inputs for basement walls include the height of the basement wall and the depth below grade. All basement walls are assumed to have full height insulation. Basement wall $\mathrm{U}$-factor is calculated from the $\mathrm{C}$-factor of the mass wall, insulation thermal resistances and soil thermal resistance. C-factor represents the thermal conductivity of the wall assembly without inclusion of the soil or air film thermal resistance. The $\mathrm{C}$-factor calculation uses the mass wall assembly U-factor calculation of an exterior wall, with the air film thermal resistance subtracted, as given in Equation D.8:

$$
\mathrm{C}_{\mathrm{WL}}=1 /\left(\mathrm{R}_{\mathrm{WL}-\mathrm{BOA}}-0.85+\mathrm{R}_{\mathrm{WL}-\mathrm{CVI}} \times \mathrm{AF}_{\mathrm{WL}}+\mathrm{R}_{\mathrm{WL}-\mathrm{CNI}}\right)
$$


where $\quad \mathrm{C}_{\mathrm{WL}}=\mathrm{C}$-factor for the mass wall assembly without the soil R-value

$\mathrm{R}_{\mathrm{WL}-\mathrm{CVI}}=\mathrm{R}$-value for the furring cavity insulation input by the user

$\mathrm{AF}_{\mathrm{WL}}=$ parallel path adjustment factor for furring

$\mathrm{R}_{\mathrm{WL}-\mathrm{CNI}}=\mathrm{R}$-value for continuous insulation input by the user.

The overall U-factor of the basement wall assembly is calculated using Equation C-20 in Appendix A of Standard 90.1-1999, reproduced here as Equation D.9:

$$
\mathrm{U}_{\mathrm{WL}}=1 /\left(\left(1 / \mathrm{C}_{\mathrm{WL}}\right)+0.85+\mathrm{R}_{\text {soil }}\right)
$$

where $\mathrm{U}_{\mathrm{WL}}=$ overall $\mathrm{U}$-factor for the mass wall

$\mathrm{R}_{\text {soil }}=$ The soil R-value, which is dependent on the depth of the wall below grade, as given in Table C6.10.1 of Standard 90.1-1999.

The budget C-factor from the envelope requirements table is also adjusted using Equation C-20 of Standard 90.1-1999 to include the soil R-value in the trade-off calculations.

\section{D.2.3.4 Floor}

Floors over unconditioned spaces and slabs-on-grade are combined as one category of envelope component. The following floor types are included in the software:

- Concrete Floor (over unconditioned space)

- Steel Joist

- Wood-Framed

- Slab-on-Grade (Heated / Unheated)

- Other

Slab-on-grade floor calculations are described in the next section. All other floor types are assumed to be exposed to outdoor conditions or unconditioned space. The proposed U-factor calculation for floor assemblies is given in Table D.16:

Table D.16. Proposed U-Factors for Exposed Floors

\begin{tabular}{|l|l|}
\hline \multicolumn{1}{|c|}{ Floor Type } & Proposed U-Factor \\
\hline Concrete Floor & $\frac{1}{3.11+R_{E F-C N I}}$ \\
\hline Steel Joist Floor & $\frac{1}{2.86+\left(\mathrm{FF}^{*} R_{E F-C V I}\right)+R_{E F-C N I}}$ \\
\hline Wood-Framed Floor & $\frac{0.91}{3.55+\left(\mathrm{FF}^{*} R_{E F-C V I}\right)+R_{E F-C N I}}+$ \\
\hline Other & $\frac{0.09}{3.55+R_{E F-C V I-a d j}+R_{E F-C N I}}$ \\
\hline
\end{tabular}


where $\quad \mathrm{R}_{\mathrm{EF}-\mathrm{CVI}}=\mathrm{R}$-value for the cavity insulation

$\mathrm{R}_{\mathrm{EF}-\mathrm{CNI}}=\mathrm{R}$-value for continuous insulation input by the user

$\mathrm{FF}=$ framing factor (dependent on $\mathrm{R}_{\mathrm{EF}-\mathrm{CVI}}$ as in Table D.17 or Table D.18)

$\mathrm{R}_{\mathrm{EF}-\mathrm{CVI} \text {-adj }}=$ adjusted $\mathrm{R}$-value of cavity insulation for joists (dependent on $\mathrm{R}_{\mathrm{EF}-\mathrm{CVI}}$ as in Table D.19)

Table D.17. Framing Factor for Steel-Joist Floors

\begin{tabular}{|c|c|}
\hline $\boldsymbol{R}_{\boldsymbol{E F - C V I}}$ & Framing Factor (FF) \\
\hline 0.0 & 0.0 \\
\hline 4.0 & 0.97 \\
\hline 8.0 & 0.94 \\
\hline 12.0 & 0.90 \\
\hline 16.0 & 0.87 \\
\hline 20.0 & 0.85 \\
\hline 24.0 & 0.82 \\
\hline 30.0 & 0.79 \\
\hline$>=38.0$ & 0.74 \\
\hline
\end{tabular}

Table D.18. Framing Factor for Wood-Framed Floors

\begin{tabular}{|c|c|}
\hline \multicolumn{1}{|c|}{$\boldsymbol{R}_{\text {EF-CVI }}$} & Framing Factor (FF) \\
\hline 19.0 & 0.95 \\
\hline For all other values except $R-19$ & 1.0 \\
\hline
\end{tabular}

Table D.19. Adjusted Cavity Insulation R-Values for Wood-Framed Floors

\begin{tabular}{|c|c|}
\hline $\boldsymbol{R}_{\text {EF-CVI }}$ & $\boldsymbol{R}_{\text {EF-CVI-adj }}$ \\
\hline 0.0 & 0.0 \\
\hline 11.0 & 4.38 \\
\hline 13.0 & 4.38 \\
\hline 15.0 & 4.38 \\
\hline 19.0 & 6.88 \\
\hline 21.0 & 6.88 \\
\hline 25.0 & 9.06 \\
\hline 30.0 & 11.56 \\
\hline$>=38.0$ & 16.58 \\
\hline
\end{tabular}

\section{D.2.3.5 Slab-On-Grade Floors}

Slab-on-grade floors do not have a proposed U-factor, but have an F-factor representing the heat transfer coefficient per linear foot of the slab edge. The software supports the following three insulation configurations:

- Horizontal with Vertical Slab Insulation

- Horizontal without Vertical Slab Insulation

- Vertical Insulation. 
The slab F-factor calculation for horizontal and vertical insulations is based on Table A-16 of Standard 90.1-1999. The horizontal insulation description in Standard 90.1-1999 does not include vertical insulation along the slab edge. Table D.20 contains empirical equations for F-factor calculations for slabs with 'Horizontal without Vertical' and 'Vertical' insulation. These equations are the same as used in the 90.1-1989 Code version of COMcheck. For slabs with both horizontal and vertical slab edge insulation, an adjustment factor was developed. Assuming that the horizontally insulated slabs with 48 in. depth and fully insulated slab F-factor values can be interpolated, the adjustment factors in Table D.21 were developed. This adjustment factor and the corresponding F-factor for 'Horizontal without Vertical' insulation values are multiplied to get the F-factor for 'Horizontal with Vertical Slab Insulation'.

Table D.20. Assembly F-Factors for Slab-on-Grade Floors for Proposed Design

\begin{tabular}{|c|c|c|}
\hline \multirow[b]{2}{*}{$\begin{array}{c}\text { Slab and Insulation } \\
\text { Description }\end{array}$} & \multicolumn{2}{|c|}{ F-Factor } \\
\hline & $\begin{array}{c}\text { R-0 to } R-5 \\
\text { Insulation } R-\text { Value }\end{array}$ & $\begin{array}{c}>\text { R-5 } \\
\text { Insulation R-Value }\end{array}$ \\
\hline \multicolumn{3}{|l|}{ Unheated Slabs } \\
\hline None & 0.73 & 0.73 \\
\hline 12 in. horizontal without vertical & $0.73-0.002 * \mathrm{R}_{\mathrm{SBI}}{ }^{\text {(a) }}$ & 0.72 \\
\hline 24 in. horizontal without vertical & $0.73-0.006 * \mathrm{R}_{\mathrm{SBI}}$ & 0.70 \\
\hline 36 in. horizontal without vertical & $0.73-0.008 \mathrm{R}_{\mathrm{SBI}}$ & $0.69-0.003 * \mathrm{R}_{\mathrm{SBI}}$ \\
\hline 48 in. horizontal without vertical & $0.73-0.012 * \mathrm{R}_{\mathrm{SBI}}$ & $0.67-0.004 * \mathrm{R}_{\mathrm{SBI}}$ \\
\hline 12 in. vertical & $0.73-0.024 * \mathrm{R}_{\mathrm{SBI}}$ & $0.61-0.006 * \mathrm{R}_{\mathrm{SBI}}$ \\
\hline 24 in. vertical & $0.73-0.030 * \mathrm{R}_{\mathrm{SBI}}$ & $0.58-0.006 * \mathrm{R}_{\mathrm{SBI}}$ \\
\hline 36 in. vertical & $0.73-0.034 * \mathrm{R}_{\mathrm{SBI}}$ & $0.56-0.007 * \mathrm{R}_{\mathrm{SBI}}$ \\
\hline 48 in. vertical & $0.73-0.038 * \mathrm{R}_{\mathrm{SBI}}$ & $0.54-0.009 * \mathrm{R}_{\mathrm{SBI}}$ \\
\hline Fully insulated slab & $0.73-0.054 * \mathrm{R}_{\mathrm{SBI}}$ & $0.46-0.016 * \mathrm{R}_{\mathrm{SBI}}$ \\
\hline \multicolumn{3}{|l|}{ Heated Slabs } \\
\hline None & 1.35 & 1.35 \\
\hline 12 in. horizontal without vertical & $1.35-0.006 * \mathrm{R}_{\mathrm{SBI}}$ & 1.32 \\
\hline 24 in. horizontal without vertical & $1.35-0.014 * \mathrm{R}_{\mathrm{SBI}}$ & 1.28 \\
\hline 36 in. horizontal without vertical & $1.35-0.022 * \mathrm{R}_{\mathrm{SBI}}$ & $1.24-0.006 * \mathrm{R}_{\mathrm{SBI}}$ \\
\hline 48 in. horizontal without vertical & $1.35-0.030 * \mathrm{R}_{\mathrm{SBI}}$ & $1.20-0.009 * \mathrm{R}_{\mathrm{SBI}}$ \\
\hline 12 in. vertical & $1.35-0.058 * \mathrm{R}_{\mathrm{SBI}}$ & $1.06-0.013 * \mathrm{R}_{\mathrm{SBI}}$ \\
\hline 24 in. vertical & $1.35-0.072 * \mathrm{R}_{\mathrm{SBI}}$ & $0.99-0.013 * \mathrm{R}_{\mathrm{SBI}}$ \\
\hline 36 in. vertical & $1.35-0.080 * \mathrm{R}_{\mathrm{SBI}}$ & $0.95-0.016 * \mathrm{R}_{\mathrm{SBI}}$ \\
\hline 48 in. vertical & $1.35-0.088 * \mathrm{R}_{\mathrm{SBI}}$ & $0.91-0.019 * \mathrm{R}_{\mathrm{SBI}}$ \\
\hline Fully insulated slab & $1.35-0.122 * \mathrm{R}_{\mathrm{SBI}}$ & $0.74-0.030 * \mathrm{R}_{\mathrm{SBI}}$ \\
\hline
\end{tabular}

Table D.21. F-Factor Adjustment Multiplier for 'Horizontal with Vertical’ Insulation

\begin{tabular}{|c|c|c|}
\hline \multirow{2}{*}{ Insulation Depth } & \multicolumn{2}{|c|}{ Adjustment Factor } \\
\cline { 2 - 3 } & Unheated Slab & Heated Slab \\
\hline $1 \mathrm{ft}$ & 0.69 & 0.62 \\
\hline $2 \mathrm{ft}$ & 0.63 & 0.55 \\
\hline $3 \mathrm{ft}$ & 0.56 & 0.49 \\
\hline $4 \mathrm{ft}$ & 0.48 & 0.40 \\
\hline
\end{tabular}




\section{D.2.3.6 Door}

The following door types are supported by the software as provided in Section A7 of Appendix A7 of Standard 90.1-1999:

- Uninsulated Single-Layer Metal

- Uninsulated Double-Layer Metal

- Insulated Metal

- Wood

- Glass (>50\% glazing)

- Other.

Although the user enters doors with more than 50\% glazing as glass doors in the software, the software handles them as windows as per Standard 90.1-1999. In addition to the door type, the user is required to select the opening type - swinging or non-swinging. The opening type is used to determine the budget Ufactor.

Default U-factors for these assemblies are given in Section A7 of Appendix A of Standard 90.1-1999 (and shown in Table D.22).

Table D.22. Default U-Factor for Standard Door Assemblies

\begin{tabular}{|l|c|}
\hline \multicolumn{1}{|c|}{ Assembly Name } & U-Factor \\
\hline Uninsulated Single-Layer Metal & 1.45 \\
\hline Uninsulated Double-Layer Metal & 0.70 \\
\hline Insulated Metal & 0.50 \\
\hline Wood & 0.50 \\
\hline Other & 0.60 \\
\hline
\end{tabular}

\section{D.2.3.7 Window}

The glazing and frame types for windows remain unchanged for the Standard 90.1-1999 version of COMcheck. In addition, the user is required to specify whether the window is operable or fixed. The opening type is used to determine the budget U-factor.

Default values for U-factors, SHGC, and VLT of windows are provided only for fixed windows consistent with Table A-17 of Standard 90.1-1999 for a select number of glazing types and thickness of air spaces, as described in Tables 3.11 and 3.12 of this document.

\section{D.2.3.8 Skylight}

The glazing and frame types for skylights remain unchanged for the Standard 90.1-1999 version of COMcheck. An additional input is required for specifying skylight curb characteristics. Standard 90.11999 differentiates the skylight budget U-factor based on the glazing material - either glass or plastic. Because all the current menu items are glass, an additional option is provided for the 'Other' skylight category for the user to specify plastic skylights. 
Default values for U-factors of skylights are provided only for metal frames with glass skylights either with or without curbs; and for wood/vinyl frames with glass skylights without curb using the U-factors provided in Tables 3.11 and 3.12 of this document.

\section{D.2.4 Daylight Credit in Envelope Trade-off}

According to Equation C-2 of Standard 90.1-1999, the envelope performance factor (EPF) includes lighting load calculations providing adjustments for daylighting potential. During software testing, it was found that the lighting load calculations result in counter-intuitive compliance results while changing the SHGC, VLT and the WWR parameters. The major issue is with the ratio of HVAC and lighting loads and the difficulty in defining the floor area of zones for determining daylighting load adjustments. Hence this VLT trade-off option is not yet made available to users of COMcheck, although it is implemented in the software. The lighting load calculations are as provided below:

The EPF used in COMcheck includes adjusted lighting load converted to cost assuming $0.08 \$ / \mathrm{kWh}$. To maintain the same calculation units as the heating and cooling loads, Equation C-4 of Standard 90.1-1999 is implemented as shown below:

$$
\mathrm{LL}_{\text {zone }}=\operatorname{LPDadj}_{\text {zone }} \mathrm{x} \text { Area }_{\text {zone }} \mathrm{x} 2700
$$

where $\quad L_{\text {zone }}=$ the calculated lighting load for the zone

$\operatorname{LPDadj}_{\text {zone }}=$ lighting power density for the zone adjusted for daylighting potential

Area $_{\text {zone }}=$ gross floor area of the zone as defined in Section C5 of Appendix of Standard 90.1-1999.

2700 represents the number of hours for lighting occupancy (assuming that the cost of electricity is $0.08 \$ / \mathrm{kWh}, 2700 * 0.08=216$, given in Standard 90.1-1999).

The adjusted lighting power density is calculated using Equations C-5, C-8, C-9 and C-10 of Standard 90.1-1999. The following assumptions are used in this calculation:

Zone Definition. The zone area assigned to each wall/roof component depends on the total floor area and the perimeter zone areas. If the total wall area to conditioned floor area ratio is $>1.25$, then a zone factor of 1.25 is used to determine the area of perimeter zones as in Equation D.11:

$$
\mathrm{Area}_{\mathrm{zone}}=\mathrm{ZF} \times \text { Area }_{\text {wall }}
$$

where $\quad \mathrm{ZF}=$ ratio of total conditioned floor area to the gross wall area. This ratio is subject to a maximum limit of 1.25 .

Area $_{\text {wall }}=$ the gross area of all exterior above-grade walls as entered by the user.

The interior zone area is calculated by subtracting the perimeter zone area from the total conditioned floor area entered by the user. If the calculated interior zone area is greater than the total roof area, then the total roof area is used as the interior zone area for the calculations. The total zone area is the addition of interior zone area and the perimeter zone area.

Technical Support Documentation for COMcheck Through Version 3.4.0 (Software) 
Lighting Power Density. According to Section C5.4 of Standard 90.1-1999, the lighting power density is based on the building type, as listed in Table D.23.

Table D.23. Lighting Power Density

\begin{tabular}{|l|c|}
\hline \multicolumn{1}{|c|}{ Building Type } & LPD \\
\hline Non-residential buildings & $1.20 \mathrm{~W} / \mathrm{ft}^{2}$ \\
\hline Residential buildings & $1.00 \mathrm{~W} / \mathrm{ft}^{2}$ \\
\hline Semi-heated buildings & $0.50 \mathrm{~W} / \mathrm{ft}^{2}$ \\
\hline
\end{tabular}

Visible Light Transmittance (VLT). The VLT requirement is based on the SHGC requirement for the fenestration/skylight multiplied by the VLT factor, as provided in Table C3.5 of Standard 90.1-1999. If no orientation-specific input or VLT is provided, then a VLT factor of 1.0 is assumed for both the budget and proposed designs, thus providing no adjustments for daylighting potential, but including the lighting load in the EPF calculation.

Vertical Fenestration. If no orientation-specific input is provided, the fenestration area is assumed to be equally distributed along the four cardinal directions.

Skylight Geometry. If skylights are present, they are assumed to be square, with a 3-foot well depth for calculating the visible aperture.

Design Illuminance. Continuous daylight dimming is assumed according to Equation C5.4 of Standard 90.1-1999 in all spaces and set at $50 \mathrm{fc}$ for residential/non-residential and $30 \mathrm{fc}$ for semi-heated spaces.

\section{D.3 Mechanical}

Equipment efficiency requirements are identical to the 2001 IECC version of COMcheck, as the 2001 IECC mechanical equipment efficiency requirements are the same as Standard 90.1-1999. The following changes to the user inputs were made:

1. HVAC equipment description includes the input for heating capacity and fan power and a revised limit for economizer requirement at 135,000 Btu.

2. Water loop heat pump system and two-pipe change over system input were added to the plant equipment description.

3. The plant inputs were revised to include non-standard chiller efficiency calculations.

4. Heated swimming pool and combined space/SWH system options were added to the SWH system description. Water heater type and capacity input fields were added, and the SWH efficiency calculation was implemented.

The mechanical requirements checklist was revised to be consistent with these Standard 90.1-1999 requirements. 


\section{D.4 Lighting}

\section{D.4.1 Exemptions}

The following exemptions based on exceptions to Section 9.3.1 of Standard 90.1-1999 are provided in COMcheck:

- Advertising/Directional Signage

- Athletic TV Broadcasting

- Casino Gaming

- Display Lighting in Galleries/Museums

- Exit Signs

- Food Preparation Equipment

- Lighting in Refrigerator/Freezer Cases

- Lighting for Visually Impaired
- Lighting Integral to Equipment

- Lighting Sales or Education

- Medical/Dental Procedure Lighting

- Plant Growth Lighting

- Registered Historical Landmark

- Retail Display Window

- Theatrical Lighting

\section{D.4.2 Allowances}

Additional power allowances are provided by Standard 90.1-1999 under the Area Category method of lighting compliance. Table D.24 shows the space functions and the additional power allowances available. In the first publication of Standard 90.1-1999, lighting power allowances were permitted only for a limited number of identified area categories, but the Standard was later amended removing that limitation. COMcheck does not restrict the choice of lighting allowance space types as per the amendment (published in Standard 90.1-2001). These power allowances are allowed only if the specified lighting is installed and used for the specified purpose.

Table D.24. Lighting Power Allowances

\begin{tabular}{|l|c|}
\hline \multicolumn{1}{|c|}{ Space Type } & Power Allowance $\mathbf{( W / f t} \mathbf{~}^{\mathbf{}} \mathbf{\text { }}$ \\
\hline Decorative Appearance & 1.0 \\
\hline Visual Display Terminal Use & 0.35 \\
\hline Retail Merchandise Highlighting & 1.6 \\
\hline Retail Fine Merchandise Highlighting & 3.9 \\
\hline
\end{tabular}

\section{D.5 Window-to-Wall Ratio (WWR)}

A change was made to the WWR calculation with the release of COMcheck version 3.1. Based on an official ASHRAE interpretation, the area of below-grade walls is now included as wall area when WWR is calculated. This change affects the 90.1-1999, 90.1-2001, and 90.1-2004 versions of COMcheck. The interpretation states that based on the definitions of building envelope, wall, and gross wall area in Section 3.2 of the Standard, "...for buildings with conditioned space below-grade, the gross wall area extends from the top of the surface of the floor of the lowest conditioned space to the bottom of the roof of the highest conditioned space". 

Appendix E

90.1-2001 



\section{Appendix E - 90.1-2001}

This appendix describes changes that have been made to COMcheck to support Standard 90.1-2001. The Standard 90.1-2001 version of COMcheck is based on the requirements and trade-off calculations as implemented for Standard 90.1-1999.

\section{E.1 Envelope}

Standard 90.1-2001 includes changes to the slab-on-grade floor insulation requirements.

\section{E.1.1 Unheated Slabs}

The maximum F-factor requirement for unheated slabs in residential buildings in Climate Zones 19 and 20 is 0.730 . There are no minimum insulation R-value requirements for unheated slabs in these climate zones.

\section{E.1.2 Heated Slabs}

The maximum F-factor requirement for heated slabs in residential buildings in Climate Zones 19 through 26 is 0.780 . The minimum insulation requirement is R-10 with an insulation depth of 48 inches.

The required F-factor for non-residential buildings for heated slabs in Climate Zones 23, 24, 25, and 26 is set to be 0.780 . The insulation requirement is set to be R-10 with an insulation depth of 48 inches.

\section{E.2 Mechanical}

All mechanical equipment efficiency requirements in Standard 90.1-2001 are the same as in Standard 90.1-1999 with the exception of non-standard centrifugal chillers. The COP and IPLV requirements for non-standard centrifugal chillers are calculated using the following equations provided as footnotes to Tables 6.2.1H-M of Standard 90.1-2001.

$$
\begin{aligned}
\mathrm{COP}_{\mathrm{adj}} & =\mathrm{k}_{\mathrm{adj}} \times \mathrm{COP}_{\text {std }} \\
\mathrm{IPLV}_{\mathrm{adj}} & =\mathrm{k}_{\text {adj }} \times \operatorname{IPLV}_{\text {std }}
\end{aligned}
$$

where $\quad \mathrm{k}_{\mathrm{adj}}=6.1507-0.30244(\mathrm{X})+0.0062692(\mathrm{X})^{2}-0.000045595(\mathrm{X})^{3}$

$\mathrm{X}=$ Condenser DT + LIFT

Condenser DT $=$ Leaving Condenser Water Temp.(F) - Entering Condenser Water Temp.(F) (obtained from Table 6.2.1H for any given condenser flow rate)

The Standard COP and IPLV are calculated at a condenser flow rate of 3 gpm and LIFT $=41$ degrees F.

Requirements Checklist items were modified as needed to meet the requirements of Standard 90.1-2001.

\section{E.2.1 Window-to-Wall Ratio}


A formal ASHRAE interpretation affected the WWR calculation in COMcheck with the release of Version 3.1. See Section D.5 for details. 


\section{Appendix F}

2003 IECC 



\section{Appendix F- 2003 IECC}

This appendix describes features that have been changed in COMcheck to support the 2003 International Energy Conservation Code (IECC). The 2003 IECC is based on 2001 IECC with the changes identified in the following sections.

\section{F.1 Building Use Types}

The 2003 IECC building use types were revised according to Table 805.5.2 of the 2003 IECC. The list contains 26 whole building types and 28 area categories as provided in Table 805.5.2.

\section{F.2 Envelope}

The envelope trade-off calculations and requirements remain the same as the 2001 IECC version of COMcheck. The internal load densities were recalculated based on the lighting power densities from Table 805.5.2 of the 2003 IECC. The methods and assumptions used to determine the internal loads are the same as those used in developing the values for the 90.1-1989 Code version of COMcheck, except based on the 2003 IECC lighting power densities.

The envelope requirements checklist items were revised to be consistent with these 2003 IECC requirements: stair, elevator shaft vents, and other dampers integral to the building envelope; cargo doors and loading dock doors; vestibules; and recessed lighting fixtures. The vestibule requirement in Section 802.3.6 of the 2003 IECC is exempted and is not required in Climate Zones 1a through $4 \mathrm{~b}$.

\section{F.3 Mechanical}

The mechanical section contains no software changes from the 2001 IECC for HVAC equipment and plant system requirements, but new requirements for service water heating system efficiencies were added. The 2003 IECC service water heating efficiencies are the same as Standard 90.1-1999. The service water heating equipment efficiency requirement is determined based on water heater type, fuel type, and capacity.

Additional changes include minor revisions to the Mandatory Requirements and Requirements Checklist to address the requirements in the 2003 IECC. These revisions are related to: two-pipe changeover systems, water loop heat pump systems, heat rejection devices as part of the plant equipment, and duct construction.

\section{F.4 Lighting}

The allowable lighting power densities were changed significantly along with the update to building use types as per Table 805.5.2 in the 2003 IECC. The option to claim lighting power allowances for the whole building method was removed in the 2003 version of the software to reflect changes to Section 805.5.2.1 in the 2003 IECC. Mandatory Requirements text and Requirements Checklist were changed to reflect the requirements in the 2003 IECC for manual controls for uniform light reduction and separate metering of individual dwelling units. 



\title{
Appendix G
}

\author{
Massachusetts
}





\section{Appendix G - Massachusetts}

This appendix documents features that have been added to COMcheck at the request of the Massachusetts Board of Building Regulations and Standards (MBBRS) to support the Massachusetts Code implemented in 1999. The following features having been added or modified:

- Space conditioning option for Both Heating and Cooling, Heating Only, and Cooling Only

- Climate data revisions

- Minimum opaque wall U-factor requirement (necessitating the use of insulating sheathing with metal-frame walls)

- Daylighting control credits

- Massachusetts lighting power density criteria

- $\quad$ Lighting exemptions and additional power allowances.

\section{G.1 Building Use Types}

\section{G.1.1 Massachusetts Lighting Power Density}

The Massachusetts Code lighting power density (LPD) requirements are based on and nearly identical to those in Standard 90.1-1989R.

Table G.1 contains LPDs and equipment and occupancy assumptions for the Massachusetts whole building types found in Table 1307.3.1.1 Lighting Power Densities Using the Building Area Method of the Massachusetts Code. Table G.2 contains LPDs and equipment and occupancy assumptions for the Massachusetts area categories found in Table 1307.3.1.2 Lighting Power Densities Using the Space-bySpace Method of the Massachusetts Code. Values from these tables are used in both lighting and envelope compliance calculations. 
Table G.1. Massachusetts Whole Building Type Lighting Power Density and Internal Load Assumptions

\begin{tabular}{|c|c|c|c|c|c|c|c|c|}
\hline \multirow[b]{2}{*}{ Whole Building Type } & \multirow[b]{2}{*}{$\begin{array}{c}\text { Source for } \\
\text { Lighting }\end{array}$} & \multirow[b]{2}{*}{$\begin{array}{l}\text { LPD } \\
\mathbf{W} / \mathrm{ft}^{2}\end{array}$} & \multirow{2}{*}{$\begin{array}{c}\text { Source for } \\
\text { Equipment } \\
\text { Power } \\
\text { Densities }\end{array}$} & \multirow{2}{*}{\begin{tabular}{|c} 
Equipment \\
Power \\
Density \\
W/ft ${ }^{2}$
\end{tabular}} & \multirow[b]{2}{*}{$\begin{array}{c}\text { Source for } \\
\text { Occupant Densities }\end{array}$} & \multicolumn{2}{|c|}{ Occupants } & \multirow[b]{2}{*}{ Total W/ft ${ }^{2}$} \\
\hline & & & & & & $\mathrm{ft}^{2} /$ person & $\mathbf{W} / \mathbf{f t}^{2}$ & \\
\hline Automotive Facility & $\begin{array}{l}\text { MA Code } \\
12-3-98\end{array}$ & 1.5 & \begin{tabular}{|l|} 
90.1R, WD\#5, \\
Table 7.1B - \\
Auto Repair \\
\end{tabular} & 0.50 & $\begin{array}{l}\text { 90.1R, WD\#5, Table } \\
\text { 7.1B - Auto Repair }\end{array}$ & 200 & 0.34 & 1.74 \\
\hline Convention Center & $\begin{array}{l}\text { MA Code } \\
12-3-98\end{array}$ & 1.4 & \begin{tabular}{|l|}
90.1, \\
Table 8-4, \\
Assembly
\end{tabular} & 0.25 & $\begin{array}{l}\text { 90.1, Table 13-2, } \\
\text { Assembly }\end{array}$ & 50 & 1.35 & 2.40 \\
\hline Courthouse & $\begin{array}{l}\text { MA Code } \\
12-3-98\end{array}$ & 1.4 & $\begin{array}{l}90.1, \\
\text { Table 8-4, } \\
\text { Office }\end{array}$ & 0.75 & $\begin{array}{l}\text { 90.1, Table 13-2, } \\
\text { Office }\end{array}$ & 275 & 0.25 & 1.80 \\
\hline $\begin{array}{l}\text { Dining: Bar } \\
\text { Lounge/Leisure }\end{array}$ & $\begin{array}{l}\text { MA Code } \\
12-3-98\end{array}$ & 1.5 & \begin{tabular}{|l}
90.1, \\
Table 8-4, \\
Restaurant \\
\end{tabular} & 0.10 & $\begin{array}{l}\text { 90.1, Table 13-2, } \\
\text { Restaurant }\end{array}$ & 100 & 0.67 & 1.67 \\
\hline $\begin{array}{l}\text { Dining: Cafeteria/Fast } \\
\text { Food }\end{array}$ & $\begin{array}{l}\text { MA Code } \\
12-3-98\end{array}$ & 1.8 & $\begin{array}{l}90.1, \\
\text { Table 8-4, } \\
\text { Restaurant } \\
\end{array}$ & 0.10 & $\begin{array}{l}\text { 90.1, Table 13-2, } \\
\text { Restaurant }\end{array}$ & 100 & 0.67 & 1.97 \\
\hline Dining: Family & $\begin{array}{l}\text { MA Code } \\
12-3-98\end{array}$ & 1.9 & $\begin{array}{l}90.1, \\
\text { Table 8-4, } \\
\text { Restaurant } \\
\end{array}$ & 0.10 & $\begin{array}{l}\text { 90.1, Table 13-2, } \\
\text { Restaurant }\end{array}$ & 100 & 0.67 & 2.07 \\
\hline Dormitory & $\begin{array}{l}\text { MA Code } \\
12-3-98\end{array}$ & 1.5 & \begin{tabular}{|l|}
90.1, \\
Table 8-4, \\
Hotel or Motel \\
\end{tabular} & 0.25 & $\begin{array}{l}\text { 90.1, Table 13-2, } \\
\text { Hotel or Motel }\end{array}$ & 250 & 0.27 & 1.42 \\
\hline Exercise Center & $\begin{array}{l}\text { MA Code } \\
12-3-98\end{array}$ & 1.4 & $\begin{array}{l}\text { 90.1R, WD\#5, } \\
\text { Table 7.1B - } \\
\text { Exercise Area }\end{array}$ & 0.10 & $\begin{array}{l}\text { 90.1R, WD\#5, } \\
\text { Table 7.1B - } \\
\text { Exercise Area }\end{array}$ & 50 & 1.35 & 2.25 \\
\hline Gymnasium & $\begin{array}{l}\text { MA Code } \\
12-3-98\end{array}$ & 1.7 & $\begin{array}{l}\text { 90.1R, WD\#5, } \\
\text { Table 7.1B - } \\
\text { Exercise Area }\end{array}$ & 0.10 & $\begin{array}{l}\text { 90.1R, WD\#5, } \\
\text { Table 7.1B - } \\
\text { Exercise Area }\end{array}$ & 50 & 1.35 & 2.55 \\
\hline Hospital/Healthcare & $\begin{array}{l}\text { MA Code } \\
12-3-98\end{array}$ & 1.6 & \begin{tabular}{|l|}
90.1, \\
Table 8-4, \\
Health \\
\end{tabular} & 1.00 & $\begin{array}{l}\text { 90.1, Table 13-2, } \\
\text { Health }\end{array}$ & 200 & 0.34 & 2.34 \\
\hline Hotel (1) & $\begin{array}{l}\text { MA Code } \\
12-3-98\end{array}$ & 1.7 & \begin{tabular}{|l|}
90.1, \\
Table 8-4, \\
Hotel or Motel \\
\end{tabular} & 0.25 & $\begin{array}{l}\text { 90.1, Table 13-2, } \\
\text { Hotel or Motel }\end{array}$ & 250 & 0.27 & 1.62 \\
\hline Library & $\begin{array}{l}\text { MA Code } \\
12-3-98\end{array}$ & 1.5 & \begin{tabular}{|l|} 
90.1R, WD\#5, \\
Table 7.1B - \\
Library \\
\end{tabular} & 0.25 & $\begin{array}{l}\text { 90.1R, WD\#5, } \\
\text { Table 7.1B - Library }\end{array}$ & 200 & 0.34 & 1.49 \\
\hline Manufacturing & $\begin{array}{l}\text { MA Code } \\
12-3-98\end{array}$ & 2.2 & $\begin{array}{l}\text { 90.1R, WD\#5, } \\
\text { Table 7.1B - } \\
\text { Manufacture - } \\
\text { General } \\
\text { workshop }\end{array}$ & 1.00 & $\begin{array}{l}\text { 90.1R, WD\#5, } \\
\text { Table 7.1B - } \\
\text { Manufacture - } \\
\text { General workshop }\end{array}$ & 300 & 0.22 & 2.82 \\
\hline Motel (1) & $\begin{array}{l}\text { MA Code } \\
12-3-98\end{array}$ & 2.0 & \begin{tabular}{|l|}
90.1, \\
Table $8-4$, \\
Hotel or Motel
\end{tabular} & 0.25 & $\begin{array}{l}\text { 90.1, Table 13-2, } \\
\text { Hotel or Motel }\end{array}$ & 250 & 0.27 & 1.92 \\
\hline Motion Picture Theatre & $\begin{array}{l}\text { MA Code } \\
12-3-98\end{array}$ & 1.6 & \begin{tabular}{|l|}
90.1, \\
Table 8-4, \\
Assembly \\
\end{tabular} & 0.25 & $\begin{array}{l}\text { 90.1, Table 13-2, } \\
\text { Assembly }\end{array}$ & 50 & 1.35 & 2.60 \\
\hline Multifamily (2) (3) & $\begin{array}{l}\text { MA Code } \\
12-3-98\end{array}$ & 1.0 & $\begin{array}{l}90.1, \\
\text { Table 8-4, } \\
\text { Multifamily } \\
\end{array}$ & 0.75 & $\begin{array}{l}\text { 90.1, Table 13-2, } \\
\text { Hotel or Motel }\end{array}$ & 250 & 0.27 & 1.42 \\
\hline Museum & $\begin{array}{l}\text { MA Code } \\
12-3-98\end{array}$ & 1.6 & $\begin{array}{l}\text { 90.1R, WD\#5, } \\
\text { Table 7.1B - } \\
\text { Gen. Exhibit. } \\
(.5), \text { Active } \\
\text { Storage }(.5)\end{array}$ & 0.15 & $\begin{array}{l}90.1 \mathrm{R}, \mathrm{WD} \# 5, \\
\text { Table } 7.1 \mathrm{~B} \text { - Gen. } \\
\text { Exhibit. (.5), Active } \\
\text { Storage (.5) }\end{array}$ & 100 & 0.67 & 1.82 \\
\hline
\end{tabular}


Table G.1. (contd.)

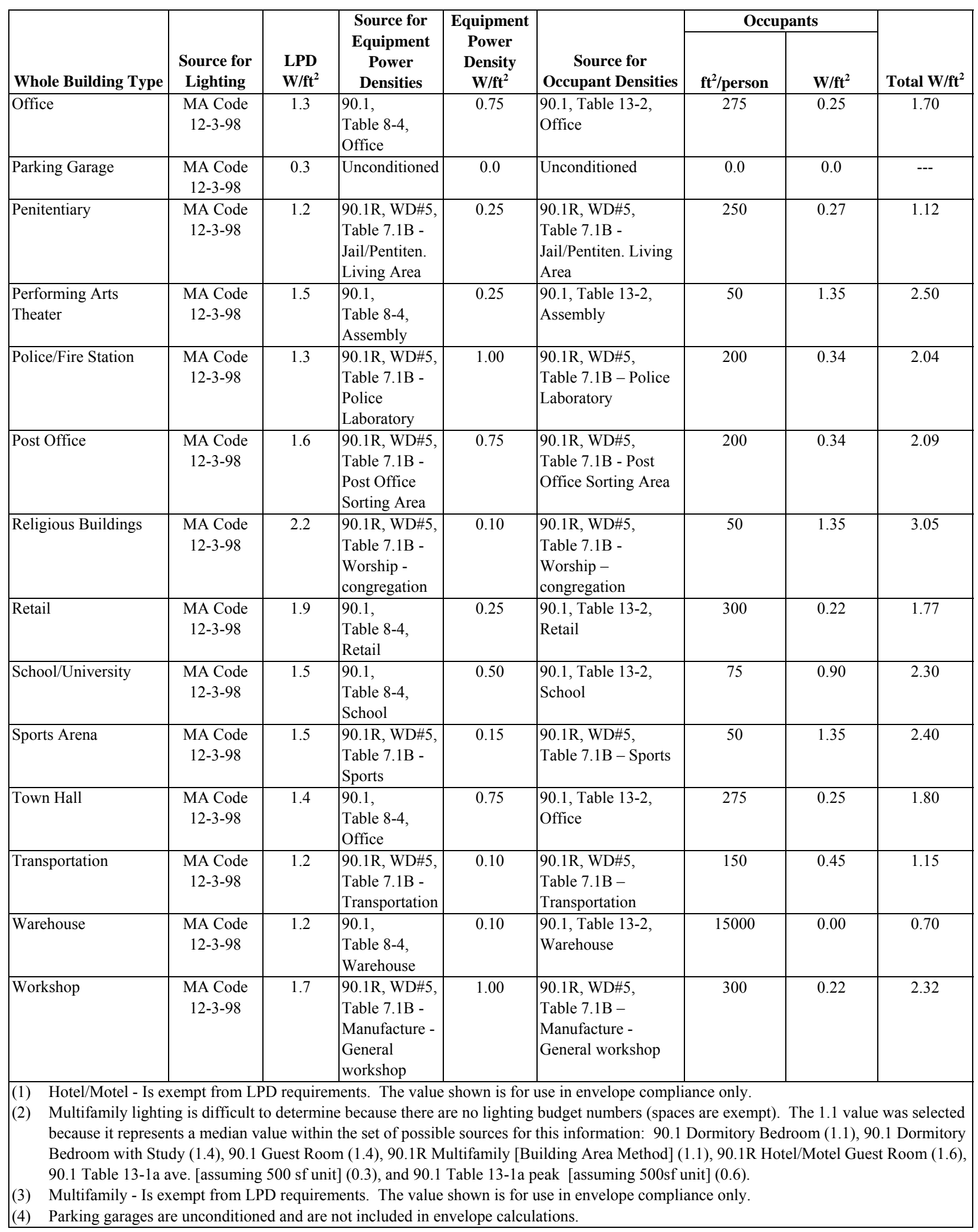


Table G.2. Massachusetts Area Category Lighting Power Density and Internal Load Assumptions

\begin{tabular}{|c|c|c|c|c|c|c|c|}
\hline \multirow[b]{2}{*}{ Area Category } & \multirow{2}{*}{$\begin{array}{l}\text { Source for } \\
\text { Lighting }\end{array}$} & \multirow{2}{*}{$\begin{array}{l}\text { LPD } \\
\text { W/ft } t^{2}\end{array}$} & \multirow{2}{*}{$\begin{array}{l}\text { Source for Equipment and } \\
\text { Occupant Densities }\end{array}$} & \multirow{2}{*}{$\begin{array}{l}\text { EPD } \\
\text { W/ft }\end{array}$} & \multicolumn{2}{|c|}{ Occupants } & \multirow{2}{*}{$\begin{array}{l}\text { Total } \\
\mathrm{W} / \mathrm{ft}^{2}\end{array}$} \\
\hline & & & & & $\mathrm{ft}^{2} /$ person & $\mathbf{W} / \mathbf{f t}^{2}$ & \\
\hline \multicolumn{8}{|c|}{ Common Space Types } \\
\hline Active Storage & $\begin{array}{l}\text { MA Code } \\
\text { (Rev. 2-2-99) }\end{array}$ & 1.1 & $\begin{array}{l}\text { 90.1R, WD\#5, Table 7.1B - } \\
\text { COMMON TASKS, Active storage }\end{array}$ & 0 & 500 & 0.13 & 0.63 \\
\hline $\begin{array}{l}\text { Atrium - First Three } \\
\text { Floors }\end{array}$ & $\begin{array}{l}\text { MA Code } \\
(\text { Rev. 2-2-99) }\end{array}$ & 1.3 & $\begin{array}{l}\text { 90.1R, WD\#5, Table 7.1B - } \\
\text { COMMON TASKS, Atria- 1st three } \\
\text { floors }\end{array}$ & 0.25 & 100 & 0.67 & 1.62 \\
\hline $\begin{array}{l}\text { Atrium - Each } \\
\text { Additional Floor }\end{array}$ & $\begin{array}{l}\text { MA Code } \\
\text { (Rev. 2-2-99) }\end{array}$ & 0.2 & $\begin{array}{l}\text { N/A - no additional equipment or } \\
\text { occupancy for additional floors }\end{array}$ & 0 & 0 & 0 & 0 \\
\hline $\begin{array}{l}\text { Classroom/Lecture/ } \\
\text { Training }\end{array}$ & $\begin{array}{l}\text { MA Code } \\
(\text { Rev. 2-2-99) }\end{array}$ & 1.6 & $\begin{array}{l}\text { 90.1R, WD\#5, Table 7.1B - } \\
\text { COMMON TASKS, } \\
\text { Classrm./lecture/training }\end{array}$ & 0.5 & 75 & 0.90 & 2.40 \\
\hline $\begin{array}{l}\text { Conference/Meeting/ } \\
\text { Multipurpose }\end{array}$ & $\begin{array}{l}\text { MA Code } \\
(\text { Rev. 2-2-99) }\end{array}$ & 1.5 & $\begin{array}{l}\text { 90.1R, WD\#5, Table 7.1B - } \\
\text { COMMON TASKS, } \\
\text { Conf./mtg./multi-use }\end{array}$ & 0.1 & 50 & 1.35 & 2.35 \\
\hline Corridor/Transition & $\begin{array}{l}\text { MA Code } \\
\text { (Rev. 2-2-99) }\end{array}$ & 0.7 & $\begin{array}{l}\text { 90.1R, WD\#5, Table 7.1B - } \\
\text { COMMON TASKS, } \\
\text { Corridor/transition } \\
\end{array}$ & 0 & 1000 & 0.07 & 0.17 \\
\hline Dining Area & $\begin{array}{l}\text { MA Code } \\
\text { (Rev. 2-2-99) }\end{array}$ & 1.4 & $\begin{array}{l}\text { 90.1R, WD\#5, Table 7.1B - } \\
\text { COMMON TASKS, Dining area }\end{array}$ & 0.1 & 100 & 0.67 & 1.57 \\
\hline Electrical/Mechanical & $\begin{array}{l}\text { MA Code } \\
(\text { Rev. 2-2-99) }\end{array}$ & 1.3 & $\begin{array}{l}\text { 90.1R, WD\#5, Table 7.1B - } \\
\text { COMMON TASKS, } \\
\text { Mechanical/electrical }\end{array}$ & 0.1 & 2000 & 0.03 & 0.83 \\
\hline Food Preparation & $\begin{array}{l}\text { MA Code } \\
\text { (Rev. 2-2-99) }\end{array}$ & 2.2 & $\begin{array}{l}\text { 90.1R, WD\#5, Table 7.1B - } \\
\text { COMMON TASKS, Food } \\
\text { preparation }\end{array}$ & 1 & 200 & 0.34 & 2.94 \\
\hline Inactive Storage & $\begin{array}{l}\text { MA Code } \\
\text { (Rev. 2-2-99) }\end{array}$ & 0.3 & $\begin{array}{l}\text { 90.1R, WD\#5, Table 7.1B - } \\
\text { COMMON TASKS, Inactive } \\
\text { storage }\end{array}$ & 0 & 1000 & 0.07 & -0.23 \\
\hline Lobby & $\begin{array}{l}\text { MA Code } \\
(\text { Rev. 2-2-99) }\end{array}$ & 1.8 & $\begin{array}{l}\text { 90.1R, WD\#5, Table 7.1B - } \\
\text { COMMON TASKS, Lobby }\end{array}$ & 0.25 & 100 & 0.67 & 2.12 \\
\hline Lounge/Recreation & $\begin{array}{l}\text { MA Code } \\
\text { (Rev. 2-2-99) }\end{array}$ & 1.4 & $\begin{array}{l}\text { 90.1R, WD\#5, Table 7.1B - } \\
\text { COMMON TASKS, } \\
\text { Lounge/recreation }\end{array}$ & 0.1 & 100 & 0.67 & 1.57 \\
\hline Office - Enclosed & $\begin{array}{l}\text { MA Code } \\
\text { (Rev. 2-2-99) }\end{array}$ & 1.5 & $\begin{array}{l}\text { 90.1R, WD\#5, Table 7.1B - } \\
\text { COMMON TASKS, Office - } \\
\text { enclosed }\end{array}$ & 0.75 & 200 & 0.34 & 1.99 \\
\hline Office - Open Plan & $\begin{array}{l}\text { MA Code } \\
\text { (Rev. 2-2-99) }\end{array}$ & 1.3 & $\begin{array}{l}\text { 90.1R, WD\#5, Table 7.1B - } \\
\text { COMMON TASKS, Office - open }\end{array}$ & 0.75 & 200 & 0.34 & 1.79 \\
\hline Restroom & $\begin{array}{l}\text { MA Code } \\
\text { (Rev. 2-2-99) }\end{array}$ & 1.0 & $\begin{array}{l}\text { 90.1R, WD\#5, Table 7.1B - } \\
\text { COMMON TASKS, Restrooms }\end{array}$ & 0.1 & 300 & 0.22 & 0.72 \\
\hline Stairway & $\begin{array}{l}\text { MA Code } \\
\text { (Rev. 2-2-99) }\end{array}$ & 0.9 & $\begin{array}{l}\text { 90.1R, WD\#5, Table 7.1B - } \\
\text { COMMON TASKS, Stairs- active }\end{array}$ & 0 & 1000 & 0.07 & 0.37 \\
\hline Laboratory & $\begin{array}{l}\text { MA Code } \\
(\text { Rev. 2-2-99) }\end{array}$ & 1.8 & $\begin{array}{l}\text { 90.1R, WD\#5, Table 7.1B - OFFICE } \\
\text { (BUSINESS), Laboratory/research }\end{array}$ & 1 & 200 & 0.34 & 2.54 \\
\hline \multicolumn{8}{|l|}{ Athletics } \\
\hline Audience/Seating Area & $\begin{array}{l}\text { MA Code } \\
\text { (Rev. 2-2-99) }\end{array}$ & 0.5 & $\begin{array}{l}\text { 90.1R, WD\#5, Table 7.1B - Sports, } \\
\text { Indoor athletics seating }\end{array}$ & 0 & 50 & 1.35 & 1.25 \\
\hline Court Sports Area & $\begin{array}{l}\text { MA Code } \\
(\text { Rev. 2-2-99) }\end{array}$ & 4.3 & $\begin{array}{l}\text { 90.1R, WD\#5, Table 7.1B - } \\
\text { Recreational, Gymnasium playing } \\
\text { area }\end{array}$ & 0.1 & 50 & 1.35 & 5.15 \\
\hline $\begin{array}{l}\text { Dressing/Locker/ } \\
\text { Fitting Room }\end{array}$ & \begin{tabular}{|l|} 
MA Code \\
(Rev. 2-2-99)
\end{tabular} & 0.8 & $\begin{array}{l}\text { 90.1R, WD\#5, Table 7.1B - Sports, } \\
\text { Locker room/shower }\end{array}$ & 0.25 & 100 & 0.67 & 1.12 \\
\hline Exercise Area & $\begin{array}{l}\text { MA Code } \\
\text { (Rev. 2-2-99) }\end{array}$ & 1.1 & $\begin{array}{l}\text { 90.1R, WD\#5, Table 7.1B - } \\
\text { Recreational, Exercise area }\end{array}$ & 0.1 & 50 & 1.35 & 1.95 \\
\hline Indoor Playing Field & $\begin{array}{l}\text { MA Code } \\
\text { (Rev. 2-2-99) }\end{array}$ & 1.9 & $\begin{array}{l}\text { 90.1R, WD\#5, Table 7.1B - } \\
\text { Professional, Jaialai/tennis/hockey }\end{array}$ & 0.15 & 50 & 1.35 & 2.80 \\
\hline Playing Area & $\begin{array}{l}\text { MA Code } \\
\text { (Rev. 2-2-99) }\end{array}$ & 1.9 & $\begin{array}{l}\text { 90.1R, WD\#5, Table 7.1B - } \\
\text { Professional, Jaialai/tennis/hockey }\end{array}$ & 0.15 & 50 & 1.35 & 2.80 \\
\hline
\end{tabular}


Table G.2. (contd.)

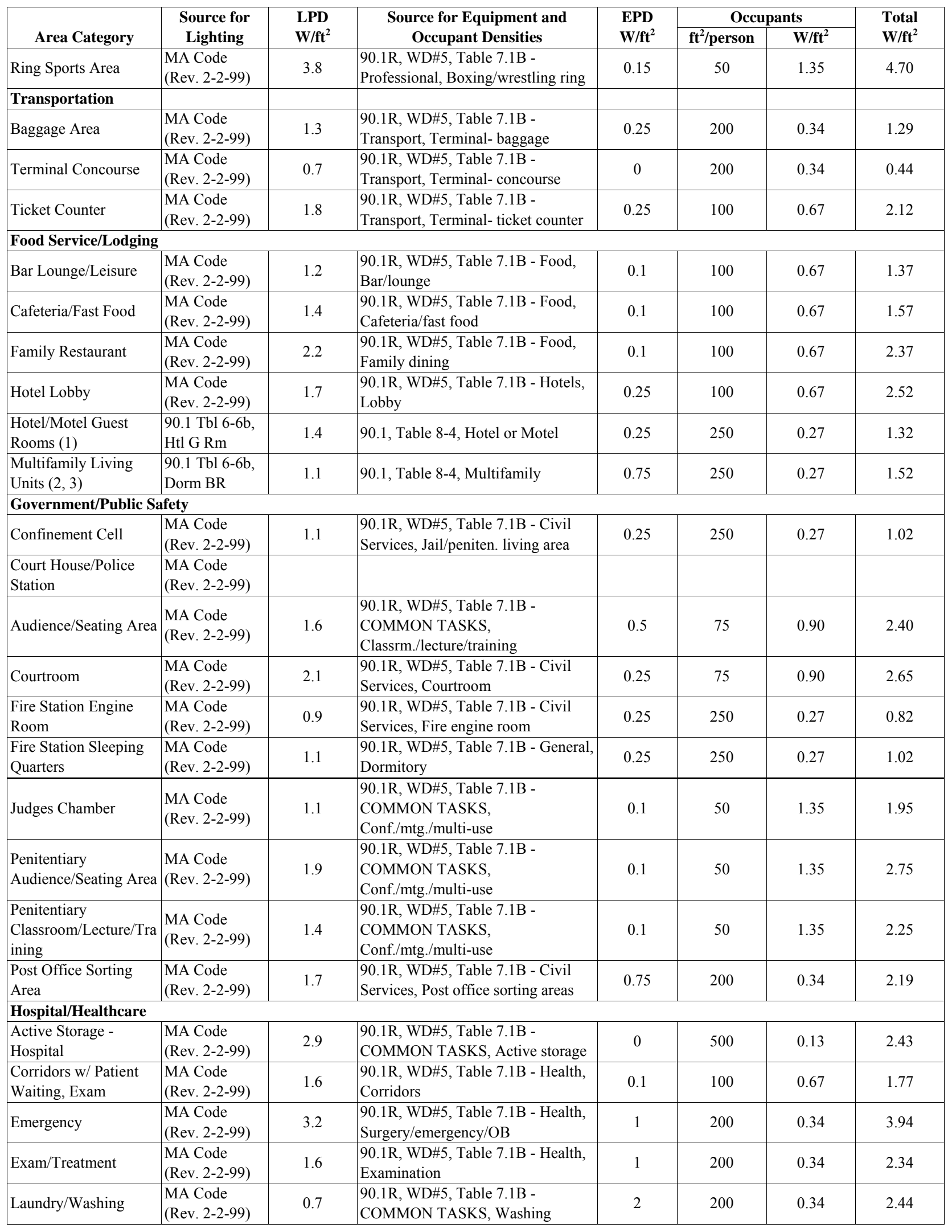


Table G.2. (contd.)

\begin{tabular}{|c|c|c|c|c|c|c|c|}
\hline \multirow[b]{2}{*}{ Area Category } & \multirow{2}{*}{$\begin{array}{l}\text { Source for } \\
\text { Lighting }\end{array}$} & \multirow{2}{*}{$\begin{array}{c}\text { LPD } \\
\mathbf{W} / \mathbf{f t}^{2}\end{array}$} & \multirow{2}{*}{$\begin{array}{l}\text { Source for Equipment and } \\
\text { Occupant Densities }\end{array}$} & \multirow{2}{*}{$\begin{array}{l}\text { EPD } \\
\mathbf{W} / \mathbf{f t}^{2}\end{array}$} & \multicolumn{2}{|c|}{ Occupants } & \multirow{2}{*}{$\begin{array}{l}\text { Total } \\
\text { W/ft }\end{array}$} \\
\hline & & & & & $\mathrm{ft}^{2} /$ person & $\mathbf{W} / \mathbf{f t}^{2}$ & \\
\hline Medical Supplies & $\begin{array}{l}\text { MA Code } \\
(\text { Rev. 2-2-99) }\end{array}$ & 3.0 & $\begin{array}{l}\text { 90.1R, WD\#5, Table 7.1B - Health, } \\
\text { Medical supplies }\end{array}$ & 0.1 & 200 & 0.34 & 2.84 \\
\hline Nurse Station & $\begin{array}{l}\text { MA Code } \\
(\text { Rev. 2-2-99) }\end{array}$ & 1.8 & $\begin{array}{l}\text { 90.1R, WD\#5, Table 7.1B - Health, } \\
\text { Nurse station/ Pharmacy }\end{array}$ & 0.25 & 200 & 0.34 & 1.79 \\
\hline Nursery & $\begin{array}{l}\text { MA Code } \\
(\text { Rev. 2-2-99) }\end{array}$ & 1.0 & $\begin{array}{l}\text { 90.1R, WD\#5, Table 7.1B - Health, } \\
\text { Patient rooms/nursery }\end{array}$ & 1 & 200 & 0.34 & 1.74 \\
\hline Operating Room & $\begin{array}{l}\text { MA Code } \\
(\text { Rev. 2-2-99) }\end{array}$ & 7.6 & $\begin{array}{l}\text { 90.1R, WD\#5, Table 7.1B - Health, } \\
\text { Surgery/emergency/OB }\end{array}$ & 1 & 200 & 0.34 & 8.34 \\
\hline Patient Room & $\begin{array}{l}\text { MA Code } \\
(\text { Rev. 2-2-99) }\end{array}$ & 1.2 & $\begin{array}{l}\text { 90.1R, WD\#5, Table 7.1B - Health, } \\
\text { Patient rooms/nursery }\end{array}$ & 1 & 200 & 0.34 & 1.94 \\
\hline Pharmacy & $\begin{array}{l}\text { MA Code } \\
(\text { Rev. 2-2-99) }\end{array}$ & 2.3 & $\begin{array}{l}\text { 90.1R, WD\#5, Table 7.1B - Health, } \\
\text { Nurse station/ Pharmacy }\end{array}$ & 0.25 & 200 & 0.34 & 2.29 \\
\hline Physical Therapy & $\begin{array}{l}\text { MA Code } \\
(\text { Rev. 2-2-99) }\end{array}$ & 1.9 & $\begin{array}{l}\text { 90.1R, WD\#5, Table 7.1B - Health, } \\
\text { Therapy }\end{array}$ & 1 & 200 & 0.34 & 2.64 \\
\hline Radiology & $\begin{array}{l}\text { MA Code } \\
(\text { Rev. 2-2-99) }\end{array}$ & 0.4 & $\begin{array}{l}\text { 90.1R, WD\#5, Table 7.1B - Health, } \\
\text { Examination }\end{array}$ & 1 & 200 & 0.34 & 1.14 \\
\hline Recovery & $\begin{array}{l}\text { MA Code } \\
(\text { Rev. 2-2-99) }\end{array}$ & 2.6 & $\begin{array}{l}\text { 90.1R, WD\#5, Table 7.1B - Health, } \\
\text { Recovery }\end{array}$ & 1 & 200 & 0.34 & 3.34 \\
\hline \multicolumn{8}{|c|}{ Industrial/Auto Service } \\
\hline $\begin{array}{l}\text { Automobile Garage } \\
\text { Service/Repair }\end{array}$ & $\begin{array}{l}\text { MA Code } \\
(\text { Rev. 2-2-99) }\end{array}$ & 1.4 & $\begin{array}{l}\text { 90.1R, WD\#5, Table 7.1B - } \\
\text { Automotive, Auto repair }\end{array}$ & 0.5 & 200 & 0.34 & 1.64 \\
\hline $\begin{array}{l}\text { Detailed } \\
\text { Manufacturing }\end{array}$ & $\begin{array}{l}\text { MA Code } \\
(\text { Rev. 2-2-99) }\end{array}$ & 6.2 & $\begin{array}{l}\text { 90.1R, WD\#5, Table 7.1B - } \\
\text { Manufacture, Electronic/detail }\end{array}$ & 1 & 300 & 0.22 & 6.82 \\
\hline $\begin{array}{l}\text { Manufacturing Control } \\
\text { Room }\end{array}$ & $\begin{array}{l}\text { MA Code } \\
(\text { Rev. 2-2-99) }\end{array}$ & 0.5 & $\begin{array}{l}\text { 90.1R, WD\#5, Table 7.1B - } \\
\text { Manufacture, Control room }\end{array}$ & 0 & 17500 & 0.00 & -0.10 \\
\hline $\begin{array}{l}\text { Manufacturing } \\
\text { Corridor/Transition }\end{array}$ & $\begin{array}{l}\text { MA Code } \\
(\text { Rev. 2-2-99) }\end{array}$ & 0.5 & $\begin{array}{l}\text { 90.1R, WD\#5, Table 7.1B - } \\
\text { COMMON TASKS, } \\
\text { Corridor/transition }\end{array}$ & 0 & 1000 & 0.07 & -0.03 \\
\hline $\begin{array}{l}\text { Manufacturing } \\
\text { Equipment Room }\end{array}$ & $\begin{array}{l}\text { MA Code } \\
(\text { Rev. 2-2-99) }\end{array}$ & 0.8 & $\begin{array}{l}\text { 90.1R, WD\#5, Table 7.1B - } \\
\text { Manufacture, Equipment room }\end{array}$ & 0 & 17500 & 0.00 & 0.20 \\
\hline $\begin{array}{l}\text { Manufacturing General } \\
\text { - High Bay }\end{array}$ & $\begin{array}{l}\text { MA Code } \\
(\text { Rev. 2-2-99) }\end{array}$ & 3.0 & $\begin{array}{l}\text { 90.1R, WD\#5, Table 7.1B - } \\
\text { Manufacture, General workshop }\end{array}$ & 1 & 300 & 0.22 & 3.62 \\
\hline $\begin{array}{l}\text { Manufacturing General } \\
\text { - Low Bay }\end{array}$ & $\begin{array}{l}\text { MA Code } \\
(\text { Rev. 2-2-99) }\end{array}$ & 2.1 & $\begin{array}{l}\text { 90.1R, WD\#5, Table 7.1B - } \\
\text { Manufacture, General workshop }\end{array}$ & 1 & 300 & 0.22 & 2.72 \\
\hline Workshop & $\begin{array}{l}\text { MA Code } \\
(\text { Rev. 2-2-99) }\end{array}$ & 2.5 & $\begin{array}{l}\text { 90.1R, WD\#5, Table 7.1B - } \\
\text { Manufacture, General workshop }\end{array}$ & 1 & 300 & 0.22 & 3.12 \\
\hline \multicolumn{8}{|l|}{ Library/Museum } \\
\hline $\begin{array}{l}\text { Library Card File \& } \\
\text { Cataloguing }\end{array}$ & $\begin{array}{l}\text { MA Code } \\
(\text { Rev. 2-2-99) }\end{array}$ & 1.4 & $\begin{array}{l}\text { 90.1R, WD\#5, Table 7.1B - Library, } \\
\text { Card file/cataloging }\end{array}$ & 0.25 & 200 & 0.34 & 1.39 \\
\hline Library Reading Area & $\begin{array}{l}\text { MA Code } \\
(\text { Rev. 2-2-99) }\end{array}$ & 1.8 & $\begin{array}{l}\text { 90.1R, WD\#5, Table 7.1B - Library, } \\
\text { Reading area }\end{array}$ & 0.25 & 200 & 0.34 & 1.79 \\
\hline Library Stacks & $\begin{array}{l}\text { MA Code } \\
(\text { Rev. 2-2-99) }\end{array}$ & 1.9 & $\begin{array}{l}\text { 90.1R, WD\#5, Table 7.1B - Library, } \\
\text { Stacks }\end{array}$ & 0.25 & 200 & 0.34 & 1.89 \\
\hline $\begin{array}{l}\text { Museum Active } \\
\text { Storage }\end{array}$ & $\begin{array}{l}\text { MA Code } \\
(\text { Rev. 2-2-99) }\end{array}$ & 1.4 & $\begin{array}{l}\text { 90.1R, WD\#5, Table 7.1B - } \\
\text { Museum, Storage (artifacts)- active }\end{array}$ & 0.1 & 1000 & 0.07 & 0.97 \\
\hline $\begin{array}{l}\text { Museum General } \\
\text { Exhibition }\end{array}$ & $\begin{array}{l}\text { MA Code } \\
(\text { Rev. 2-2-99) }\end{array}$ & 1.6 & $\begin{array}{l}\text { 90.1R, WD\#5, Table 7.1B - } \\
\text { Museum, General exhibition }\end{array}$ & 0.25 & 50 & 1.35 & 2.60 \\
\hline $\begin{array}{l}\text { Museum Inactive } \\
\text { Storage }\end{array}$ & $\begin{array}{l}\text { MA Code } \\
(\text { Rev. 2-2-99) }\end{array}$ & 1.4 & $\begin{array}{l}\text { 90.1R, WD\#5, Table 7.1B - } \\
\text { Museum, Storage (artifacts)- } \\
\text { inactive }\end{array}$ & 0 & 10000 & 0.01 & 0.81 \\
\hline Museum Restoration & $\begin{array}{l}\text { MA Code } \\
(\text { Rev. 2-2-99) }\end{array}$ & 2.5 & $\begin{array}{l}\text { 90.1R, WD\#5, Table 7.1B - } \\
\text { Museum, Restoration }\end{array}$ & 0.5 & 200 & 0.34 & 2.74 \\
\hline \multicolumn{8}{|l|}{ Retail and Banking } \\
\hline Banking Activity Area & $\begin{array}{l}\text { MA Code } \\
(\text { Rev. 2-2-99) }\end{array}$ & 2.4 & $\begin{array}{l}\text { 90.1R, WD\#5, Table 7.1B - OFFICE } \\
\text { (BUSINESS), Banking activity }\end{array}$ & 0.75 & 200 & 0.34 & 2.89 \\
\hline $\begin{array}{l}\text { General Retail Sales } \\
\text { Area }\end{array}$ & $\begin{array}{l}\text { MA Code } \\
(\text { Rev. 2-2-99) }\end{array}$ & 2.1 & $\begin{array}{l}\text { 90.1R, WD\#5, Table 7.1B - } \\
\text { RETAIL, Department store }\end{array}$ & 0.25 & 300 & 0.22 & 1.97 \\
\hline
\end{tabular}


Table G.2. (contd.)

\begin{tabular}{|c|c|c|c|c|c|c|c|}
\hline \multirow[b]{2}{*}{ Area Category } & \multirow{2}{*}{$\begin{array}{l}\text { Source for } \\
\text { Lighting }\end{array}$} & \multirow{2}{*}{$\begin{array}{l}\text { LPD } \\
\text { W/ft }\end{array}$} & \multirow{2}{*}{$\begin{array}{l}\text { Source for Equipment and } \\
\text { Occupant Densities }\end{array}$} & \multirow{2}{*}{$\begin{array}{l}\text { EPD } \\
\text { W/ft }\end{array}$} & \multicolumn{2}{|c|}{ Occupants } & \multirow{2}{*}{$\begin{array}{l}\text { Total } \\
\text { W/ft }\end{array}$} \\
\hline & & & & & $\mathrm{ft}^{2} /$ person & $\mathbf{W} / \mathbf{f t}^{2}$ & \\
\hline Mall Concourse & $\begin{array}{l}\text { MA Code } \\
\text { (Rev. 2-2-99) }\end{array}$ & 1.8 & $\begin{array}{l}\text { 90.1R, WD\#5, Table 7.1B - } \\
\text { RETAIL, Mall concourse }\end{array}$ & 0 & 200 & 0.34 & 1.54 \\
\hline \multicolumn{8}{|l|}{ Public Assembly } \\
\hline Audience/Seating Area & $\begin{array}{l}\text { MA Code } \\
\text { (Rev. 2-2-99) }\end{array}$ & 0.5 & $\begin{array}{l}\text { 90.1R, WD\#5, Table 7.1B - Sports, } \\
\text { Indoor athletics seating }\end{array}$ & 0 & 50 & 1.35 & 1.25 \\
\hline $\begin{array}{l}\text { Convention Center } \\
\text { Exhibit Space }\end{array}$ & $\begin{array}{l}\text { MA Code } \\
(\text { Rev. 2-2-99) }\end{array}$ & 3.3 & \begin{tabular}{|l|} 
90.1R, WD\#5, Table 7.1B - \\
Exhibition Hall, Exhibit space
\end{tabular} & 0.25 & 50 & 1.35 & 4.30 \\
\hline $\begin{array}{l}\text { Motion Picture } \\
\text { Audience/Seating Area }\end{array}$ & $\begin{array}{l}\text { MA Code } \\
\text { (Rev. 2-2-99) }\end{array}$ & 1.3 & $\begin{array}{l}\text { 90.1R, WD\#5, Table 7.1B - } \\
\text { Theaters, Motion picture seating }\end{array}$ & 0.25 & 50 & 1.35 & 2.30 \\
\hline $\begin{array}{l}\text { Motion Picture Theatre } \\
\text { Lobby }\end{array}$ & $\begin{array}{l}\text { MA Code } \\
\text { (Rev. 2-2-99) }\end{array}$ & 0.8 & $\begin{array}{l}\text { 90.1R, WD\#5, Table 7.1B - } \\
\text { Theaters, Lobby - other theaters }\end{array}$ & 0.1 & 100 & 0.67 & 0.97 \\
\hline $\begin{array}{l}\text { Performing Arts } \\
\text { Audience/Seating Area }\end{array}$ & $\begin{array}{l}\text { MA Code } \\
\text { (Rev. 2-2-99) }\end{array}$ & 1.8 & $\begin{array}{l}\text { 90.1R, WD\#5, Table 7.1B - } \\
\text { Theaters, Performing arts seating }\end{array}$ & 0.25 & 75 & 0.90 & 2.35 \\
\hline $\begin{array}{l}\text { Performing Arts } \\
\text { Theatre Lobby }\end{array}$ & \begin{tabular}{|l|} 
MA Code \\
(Rev. 2-2-99)
\end{tabular} & 1.2 & $\begin{array}{l}\text { 90.1R, WD\#5, Table 7.1B - } \\
\text { Theaters, Lobby - performing arts }\end{array}$ & 0.1 & 100 & 0.67 & 1.37 \\
\hline \multicolumn{8}{|l|}{ Religious } \\
\hline $\begin{array}{l}\text { Religious } \\
\text { Audience/Seating Area }\end{array}$ & \begin{tabular}{|l|l|} 
MA Code \\
(Rev. 2-2-99)
\end{tabular} & 3.2 & \begin{tabular}{|l|}
$90.1 \mathrm{R}, \mathrm{WD} \# 5$, Table 7.1B - \\
Religious, Worship- congregation
\end{tabular} & 0.1 & 50 & 1.35 & 4.05 \\
\hline Fellowship Hall & $\begin{array}{l}\text { MA Code } \\
\text { (Rev. 2-2-99) }\end{array}$ & 2.3 & $\begin{array}{l}\text { 90.1R, WD\#5, Table 7.1B - } \\
\text { Religious, Worship- congregation }\end{array}$ & 0.1 & 50 & 1.35 & 3.15 \\
\hline $\begin{array}{l}\text { Worship - Pulpit, } \\
\text { Choir }\end{array}$ & $\begin{array}{l}\text { MA Code } \\
\text { (Rev. 2-2-99) }\end{array}$ & 5.2 & \begin{tabular}{|l|} 
90.1R, WD\#5, Table 7.1B - \\
Religious, Worship- pulpit, choir
\end{tabular} & 0.1 & 50 & 1.35 & 6.05 \\
\hline \multicolumn{8}{|l|}{ Warehouse/Parking } \\
\hline Fine Material Storage & $\begin{array}{l}\text { MA Code } \\
\text { (Rev. 2-2-99) }\end{array}$ & 1.6 & $\begin{array}{l}\text { 90.1R, WD\#5, Table 7.1B - } \\
\text { Warehouse, Fine material }\end{array}$ & 0.1 & 500 & 0.13 & 1.23 \\
\hline $\begin{array}{l}\text { Garage Parking Area - } \\
\text { Attendant Only (4) }\end{array}$ & $\begin{array}{l}\text { MA Code } \\
\text { (Rev. 2-2-99) }\end{array}$ & 0.1 & $\begin{array}{l}\text { 90.1R, WD\#5, Table 7.1B - Garage, } \\
\text { Parking Garage }\end{array}$ & 0 & 0 & 0 & --- \\
\hline $\begin{array}{l}\text { Garage Parking Area - } \\
\text { Pedestrian (4) }\end{array}$ & $\begin{array}{l}\text { MA Code } \\
\text { (Rev. 2-2-99) }\end{array}$ & 0.2 & $\begin{array}{l}\text { 90.1R, WD\#5, Table 7.1B - Garage, } \\
\text { Parking Garage }\end{array}$ & 0 & 0 & 0 & --- \\
\hline $\begin{array}{l}\text { Medium/Bulky } \\
\text { Material Storage }\end{array}$ & $\begin{array}{l}\text { MA Code } \\
\text { (Rev. 2-2-99) }\end{array}$ & 1.1 & $\begin{array}{l}\text { 90.1R, WD\#5, Table 7.1B - } \\
\text { Warehouse, Inactive stor./elec/mech }\end{array}$ & 0 & 17500 & 0.00 & 0.50 \\
\hline \\
\hline \multicolumn{8}{|c|}{$\begin{array}{l}\text { (1) Hotel/Motel Guest Rooms are exempt from LPD requirements. The value shown is for use in envelope compliance only. } \\
\text { (2) Multifamily lighting is difficult to determine because there are no lighting budget numbers (spaces are exempt). The } 1.1 \text { value was selected } \\
\text { because it represents a median value within the set of possible sources for this information: } 90.1 \text { Dormitory Bedroom (1.1), } 90.1 \text { Dormitory } \\
\text { Bedroom with Study (1.4), 90.1 Guest Room (1.4), 90.1R Multifamily [Building Area Method] (1.1), 90.1R Hotel/Motel Guest Room (1.6), } \\
\text { 90.1 Tbl 13-1a ave. [assuming 500sf unit] (0.3), and 90.1 Tbl 13-1a peak [assuming 500sf unit] (0.6). }\end{array}$} \\
\hline
\end{tabular}

\section{G.2 Envelope}

\section{G.2.1 Space Conditioning Switch}

At the request of the MBBRS, the user must select the type of space conditioning provided in the building - 'Heating Only', 'Cooling Only', or 'Both'. The default for this option is 'Both'. It was the judgment of the Massachusetts Code Committee that this feature was appropriate to preserve stringency for buildings with heating only in Massachusetts's heating-dominated climate. This feature is available in the ENVSTD 2 program; however, for the reasons discussed in Section 3.1.3, Space Conditioning, of this document, it has not been made available in COMcheck except for the Massachusetts version.

COMcheck determines envelope compliance based on a calculated envelope compliance index (ECI) and displays ECI results in the performance field at the bottom of the envelope screen. The space conditioning causes the calculation of ECI to be modified as specified in the following equations: 
Both Heating and Cooling:

$$
\mathrm{ECI}_{\mathrm{BOTH}}=\left[\left(\mathrm{CL}_{\mathrm{REQ}}+\mathrm{HL}_{\mathrm{REQ}}\right)-\left(\mathrm{CL}_{\mathrm{DES}}+\mathrm{HL} \mathrm{DES}_{\mathrm{DS}}\right)\right] /\left(\mathrm{CL}_{\mathrm{REQ}}+\mathrm{HL}_{\mathrm{REQ}}\right)
$$

Heating Only:

$$
\mathrm{ECI}_{\mathrm{HEAT}}=\left[\left(\mathrm{HL}_{\mathrm{REQ}}\right)-\left(\mathrm{HL}_{\mathrm{DES}}\right)\right] /\left(\mathrm{HL}_{\mathrm{REQ}}\right)
$$

Cooling Only:

$$
\mathrm{ECI}_{\mathrm{COOL}}=\left[\left(\mathrm{CL}_{\mathrm{REQ}}\right)-\left(\mathrm{CL}_{\mathrm{DES}}\right)\right] /\left(\mathrm{CL}_{\mathrm{REQ}}\right)
$$

where $\mathrm{CL}_{\mathrm{REQ}}=$ required (i.e., maximum allowed) cumulative annual cooling coil load normalized on a square foot of conditioned floor area $\left[\mathrm{Btu} /\left(\mathrm{y} \cdot \mathrm{ft}^{2}\right)\right]$

$\mathrm{CL}_{\mathrm{DES}}=$ cumulative annual cooling coil load for the proposed design normalized on a square foot of conditioned floor area $\left[\mathrm{Btu} /\left(\mathrm{y} \cdot \mathrm{ft}^{2}\right)\right]$

$\mathrm{HL}_{\mathrm{REQ}}=$ required (i.e., maximum allowed) cumulative annual heating coil load normalized on a square foot of conditioned floor area $\left[\mathrm{Btu} /\left(\mathrm{y} \cdot \mathrm{ft}^{2}\right)\right]$

$\mathrm{HL}_{\mathrm{DES}}=$ cumulative annual heating coil load for the proposed design normalized on a square foot of conditioned floor area $\left[\mathrm{Btu} /\left(\mathrm{y} \cdot \mathrm{ft}^{2}\right)\right]$.

\section{G.2.2 Climate Data Revisions}

The revisions to the climate data were designed to achieve several objectives:

- Utilizing three Massachusetts climate zones (12a, 13a, and 14a) as defined in the IECC prescriptive envelope requirements.

- Having the list of locations in the software match the city list used in MAScheck, the Massachusetts residential software product based on MECcheck (later named REScheck).

- Eliminating inconsistencies across metropolitan areas.

- Maintaining as much consistency as possible between the climate data used with COMcheck and that used with COMcheck-Plus.

- Improving consistency between climate data used in COMcheck and the actual characteristics of climates in the state. None of the cities used in developing the COMcheck and IECC requirements were actually in Massachusetts. Climate Zone 12a is actually based on Yakima, Washington, a location with similar heating-degree-days to Cape Cod but with a much dryer and sunnier climate.

Climate data were reviewed for approximately 35 Massachusetts sites having National Oceanic Atmospheric Administration (NOAA) data and nearby cities having typical meteorological year (TMY) weather files. Climate data for all locations in each of the three Massachusetts climate zones from the TMY city offering the best match to that zone's various climate parameters. This decision reflected a preference for a clear, simple, and consistent mapping of climate data to locations in the state over using more sites and gaining a more precise match to climate data for specific locations. This approach resulted 
in mapping Climate Zone 12a to Providence, RI; Climate Zone 13a to Boston, MA; and Climate Zone 14a to Albany, NY. Hartford, CT and Concord, NH were also considered for use with Climate Zone 14a, but were determined to offer poorer matches than Albany for the climate zone as a whole.

Table G.3 contains the climate data for the three Massachusetts climate zones used in COMcheck. Each of the 351 Massachusetts cities that appear in COMcheck were mapped to one of these three sets of climate data.

\section{G.2.3 Minimum Opaque Wall U-Factor Requirement}

The Massachusetts energy code prescriptive requirements mandate insulating sheathing for opaque walls with light-weight metal-framing. This requirement further helps address reported moisture and corrosion problems with metal-frame construction, where insulating sheathing had been omitted.

Standard 90.1-1989 contains a maximum U-factor requirement for all light-weight walls with $\mathrm{HC}<7$ that effectively requires insulating sheathing on metal-frame walls for climates with greater than about 6,500 heating-degree-days. That requirement is contained in Figure 8-8 Maximum Overall Transmittance of Opaque Wall Sections with HC $<7$ in Standard 90.1-1989. The impact of this requirement under Standard 90.1-1989 is to require insulating sheathing with metal-frame walls in the colder Massachusetts locations but to not require it in the warmer Massachusetts locations.

To ensure consistency between prescriptive requirements and to prevent future moisture-related problems with metal-frame wall assemblies, the maximum U-factor requirement for light-weight wall sections was set to a constant value of 0.11 for all locations in Massachusetts. Table G.4 shows the calculated U-factors for several configurations of light-weight framed wall sections using the algorithms in COMcheck. The values in the table correspond with default wall assemblies, which are designed to be conservative; i.e., to represent poor performance for an assembly fitting the assembly description. The maximum U-factor of 0.11 was selected to necessitate use of insulating sheathing with metal-framed walls but to not necessitate its use with most wood-framed wall assemblies. This is implemented as a mandatory maximum $U$-factor requirement even though the trade-off compliance requirement may permit the use of higher U-factors.

\section{G.2.4 Slab Insulation Requirements}

The Massachusetts Code contains slab insulation requirements that differ significantly from those in the 90.1-1989 Code. A mandatory minimum R-5 insulation, $4 \mathrm{ft}$. depth, is required continuously under slabs. Trade-offs below the minimum requirement are not permitted. The following two changes were implemented in the Massachusetts version of COMcheck to address these requirements:

Modification of Slab Options. The Massachusetts slab insulation requirements exceed those in Standard 90.1-1999 and include perimeter and under-slab insulation combinations not supported by the Standard 90.1-1999 version of COMcheck. The 'No Insulation' option in the Standard 90.1-1999 version of COMcheck has been removed. 
Table G.3. Climate Data for Massachusetts Commercial Code

\begin{tabular}{|c|c|c|c|c|c|c|c|c|c|c|c|c|c|c|c|c|}
\hline $\begin{array}{c}\text { Zone } \\
\text { No. }\end{array}$ & \begin{tabular}{|c|} 
Representative \\
City
\end{tabular} & Lat. & Long. & Bin & Elev. & VSN & VSEW & VSS & DR & HDD65 & HDD50 & CDD65 & CDD50 & CDH80 & DB 1\% & WB 1\% \\
\hline $12 \mathrm{a}$ & Providence & 41.73 & 71.43 & 39 & 51 & 393 & 677 & 874 & 16.8 & 5884 & 2553 & 606 & 2743 & 939 & 86 & 74 \\
\hline $13 a$ & Boston & 42.37 & 71.03 & 39 & 20 & 387 & 659 & 849 & 16.5 & 5641 & 2399 & 678 & 2897 & 1299 & 87 & 74 \\
\hline $14 a$ & Albany & 42.75 & 73.80 & 45 & 275 & 395 & 719 & 942 & 19.7 & 6894 & 3448 & 507 & 2525 & 409 & 86 & 73 \\
\hline
\end{tabular}

Zone No. = climate zone number

Representative

City $\quad=$ representative city from which the data were drawn

Lat. $\quad=$ latitude

Long. $\quad=$ longitude

Bin. $\quad=$ ASHRAE bin number (a climate zone designation used in Standard 90.1-1989R)

Elev. $\quad=$ elevation

VSN $\quad=$ vertical solar north-facing surface

VSEW = vertical solar east- or west-facing surfaces

VSS $\quad=$ vertical solar south-facing surface

DR $=$ diurnal temperature range

HDD65 $=$ heating degree days base $65^{\circ} \mathrm{F}$

HDD50 $=$ heating degree days base $50^{\circ} \mathrm{F}$

CDD65 $=$ cooling degree days base $65^{\circ} \mathrm{F}$

CDD50 $=$ cooling degree days base $50^{\circ} \mathrm{F}$

$\mathrm{CDH} 80=$ cooling degree hours base $80^{\circ} \mathrm{F}$

DB $1 \%=1 \%$ annual dry bulb temperature in ${ }^{\circ} \mathrm{F}$

WB $1 \%=1 \%$ annual wet bulb temperature in ${ }^{\circ} \mathrm{F}$. 
Table G.4. Calculated U-Factors for Light-Weight Wall Sections

\begin{tabular}{|l|c|}
\hline Assembly Description & Calculated Assembly U-Factor \\
\hline Metal Frame 16" o.c., R-11 Batt & 0.143 \\
\hline Metal Frame 16" o.c., R-13 Batt & 0.132 \\
\hline Metal Frame 24" o.c., R-11 Batt & 0.124 \\
\hline Metal Frame 24" o.c., R-13 Batt & 0.114 \\
\hline Wood Frame 16" o.c. R-11 Batt & 0.103 \\
\hline Metal Frame 16" o.c., R-11 Batt, R-3 sheathing & 0.100 \\
\hline Metal Frame 16" o.c., R-13 Batt, R-3 sheathing & 0.095 \\
\hline Wood Frame 16" o.c. R-13 Batt & 0.091 \\
\hline Metal Frame 24" o.c., R-11 Batt, R-3 sheathing & 0.090 \\
\hline Based on Standard 90.1-1989, Figure 8-8: & Maximum Budget U-Factor \\
\hline Providence, RI & 0.140 \\
\hline Boston, MA & 0.143 \\
\hline Albany, NY & 0.127 \\
\hline Based on Massachusetts Commercial Code: & Maximum Budget U-Factor \\
\hline All Zones & 0.110 \\
\hline
\end{tabular}

Below-grade slabs are not included in the trade-off calculations because the Standard 90.1-1999 based model used in COMcheck does not include them, but the user is informed of the mandatory requirement of R-5 continuous insulation for certain building use types. For purposes of the software input for assembly type, a slab four or more feet below-grade is considered below-grade.

\section{G.3 Lighting}

\section{G.3.1 Exemptions and Allowances}

The exemptions and allowances in the Massachusetts Code are based on Standard 90.1-1989R, Public Review Draft \#2. The software implementation is similar to Standard 90.1-1999 exemptions and allowances, as described in Section D.4 of this document with the following changes:

- The Massachusetts list of exemptions contains all spaces identified in Section D.4.1 except 'Lighting in Refrigerator/Freezer Cases'.

- The Massachusetts code does not provide allowances for visual display terminal use. In addition, the allowances for merchandise display areas can be claimed only for 'General Retail Sales Area' spaces. 

Appendix H

Minnesota 



\section{Appendix H - Minnesota}

This section describes changes that have been made to COMcheck to support the Minnesota Commercial Code. The Envelope and Mechanical requirements are the same as the 90.1-1989 Code. Lighting compliance is based on a Minnesota-specific list of whole building types and area categories and provides lighting control credits.

\section{H.1 Building Use Types}

\section{H.1.1 Whole Building Types}

In the Minnesota version of COMcheck, each whole building type is further defined by the gross lighted area, as shown in Table H.1. The Minnesota lighting whole building types are similar to the 90.1-1989 Code Table 401.3.2a, but with different lighting power densities.

The Minnesota Code allows the use of multiple whole building types to be specified for the whole building method, unlike the 90.1-1989 Code in which only one whole building type can be specified. If the building has secondary functions that are $10 \%$ or more of the gross lighted area, these secondary portions must also be listed. The software uses an area-weighted average of the power densities for each portion of the building listed.

\section{H.1.2 Area Categories}

The Minnesota Code provides a list of area categories different from that of the 90.1-1989 Code. The area category LPDs are similar to the 1992 Federal Commercial Code. The Minnesota area category LPD table was implemented in COMcheck as a two-level structured list under two major headings: Common Activity Areas and Specific Building Area/Activity, as shown in Table H.2. The Minnesota

Table H.1. Minnesota Whole Building Types and Lighting Power Densities

\begin{tabular}{|c|c|c|c|c|c|c|}
\hline Building Use Type & $\begin{array}{c}0 \text { to } \\
2,000 \mathrm{ft}^{2}\end{array}$ & $\begin{array}{c}2,001 \text { to } \\
10,000 \mathrm{ft}^{2}\end{array}$ & $\begin{array}{l}10,001 \text { to } \\
25,000 \mathrm{ft}^{2}\end{array}$ & $\begin{array}{l}25,001 \text { to } \\
50,000 \mathrm{ft}^{2}\end{array}$ & \begin{tabular}{c|}
50,001 to \\
$250,000 \mathrm{ft}^{2}$
\end{tabular} & $>250,000 \mathrm{ft}^{2}$ \\
\hline Food Service - Fast Food/Cafeteria & 0.92 & 0.85 & 0.82 & 0.81 & \begin{tabular}{l|}
0.81 \\
\end{tabular} & 0.8 \\
\hline Garages & 0.25 & 0.24 & 0.23 & 0.22 & 0.21 & 0.2 \\
\hline Leisure Dining/Bar & 1.6 & 1.56 & 1.52 & 1.48 & 1.44 & 1.4 \\
\hline Mall Concourse/Public Spaces & 0.69 & 0.68 & 0.65 & 0.63 & 0.61 & 0.6 \\
\hline Offices & 1.4 & 1.34 & 1.27 & 1.22 & 1.16 & 1.11 \\
\hline Retail $^{(\mathrm{a})}$ & 2.7 & 2.52 & 2.32 & 2.05 & 1.87 & 1.72 \\
\hline Service Establishment & 2.81 & 2.03 & 1.78 & 1.65 & 1.54 & 1.46 \\
\hline Schools & 1.77 & 1.72 & 1.6 & 1.49 & 1.36 & 1.26 \\
\hline Warehouse/Storage & 0.6 & 0.5 & 0.42 & 0.36 & 0.32 & 0.3 \\
\hline
\end{tabular}


Table H.2. Minnesota Area Categories

\begin{tabular}{|c|c|c|c|}
\hline & Activity Type & $\begin{array}{c}\text { MN LPD } \\
\text { W/ft }\end{array}$ & $\begin{array}{c}\text { Area } \\
\text { Factors }\end{array}$ \\
\hline \multicolumn{4}{|c|}{ COMMON ACTIVITY AREAS } \\
\hline \multirow{17}{*}{ Common/Misc. } & Auditorium & 1.4 & 1.32 \\
\hline & Classrooms/Lecture Hall & 1.7 & 1.32 \\
\hline & Computer/Office Equipment & 2.1 & 1.32 \\
\hline & Conference/Meeting Room & 1.3 & 1.32 \\
\hline & Conference/Meeting Room (Multifunction) & 1.95 & 1.32 \\
\hline & Corridor & 0.8 & 1 \\
\hline & Electrical/ Mechanical Room - Control Room & 1.5 & 1 \\
\hline & Electrical/ Mechanical Room - General & 0.7 & 1 \\
\hline & Filing - Inactive & 1.0 & 1.54 \\
\hline & Laboratory & 2.2 & 1 \\
\hline & Locker Rm./Shower & 0.6 & 1.32 \\
\hline & Mail Room & 1.8 & 1.32 \\
\hline & Recreation/Lounge & 0.5 & 1.32 \\
\hline & Stair - Active Traffic & 0.6 & 1.54 \\
\hline & Stair - Emergency Exit & 0.4 & 1.54 \\
\hline & Toilet \& Washing & 0.5 & 1.54 \\
\hline & Unlisted Space & 0.2 & 1 \\
\hline \multirow[t]{4}{*}{ Food Service } & Fast Food & 0.8 & 1.32 \\
\hline & Leisure Dining & 1.4 & 1.32 \\
\hline & Bar/Lounge & 1.3 & 1.32 \\
\hline & Kitchen & 1.4 & 1.32 \\
\hline \multirow[t]{2}{*}{ Garage } & Auto/Pedestrian. Circulation & 0.25 & 1 \\
\hline & Parking Area & 0.2 & 1 \\
\hline \multirow[t]{4}{*}{ Library } & Audio Visual & 1.1 & 1.32 \\
\hline & Stack Visual & 1.5 & 1.54 \\
\hline & Card Filing \& Cataloging & 0.8 & 1.32 \\
\hline & Reading Area & 1.0 & 1.32 \\
\hline \multirow[t]{4}{*}{ Lobby (General) } & Reception \& Waiting & 0.55 & 1.32 \\
\hline & Elevator lobbies & 0.4 & 1.54 \\
\hline & Atrium - First three floors & 0.4 & 1.54 \\
\hline & Atrium - Each additional floor & 0.15 & 1.54 \\
\hline \multirow[t]{9}{*}{ Office } & Category 1 - Reading, Typing and Filing & 1.3 & 1.32 \\
\hline & Category 1 - Drafting & 2.2 & 1.32 \\
\hline & Category 1 - Accounting & 1.8 & 1.32 \\
\hline & Category 2 - Reading, Typing and Filing & 1.5 & 1.0 \\
\hline & Category 2 - Drafting & 2.6 & 1.0 \\
\hline & Category 2 - Accounting & 2.1 & 1.0 \\
\hline & Category 3 - Reading, Typing and Filing & 1.7 & 1.0 \\
\hline & Category 3 - Drafting & 3.0 & 1.0 \\
\hline & Category 3 - Accounting & 2.4 & 1.0 \\
\hline \multirow[t]{5}{*}{ Shop (Non-Industrial) } & Machinery & 2.5 & 1.32 \\
\hline & Electrical/Electronics & 2.5 & 1.32 \\
\hline & Painting & 1.6 & 1.32 \\
\hline & Carpentry & 2.3 & 1.32 \\
\hline & Welding & 1.2 & 1.32 \\
\hline
\end{tabular}


Table H.2. (contd.)

\begin{tabular}{|c|c|c|c|}
\hline & Activity Type & $\begin{array}{c}\text { MN LPD } \\
W / f^{2}\end{array}$ & $\begin{array}{c}\text { Area } \\
\text { Factors }\end{array}$ \\
\hline \multirow[t]{4}{*}{ Storage/Warehouse } & Inactive Storage & 0.2 & 1.54 \\
\hline & Active Storage/Bulky & 0.3 & 1.54 \\
\hline & Active Storage/Fine & 0.9 & 1.54 \\
\hline & Material Handling & 1.0 & 1.54 \\
\hline \multicolumn{4}{|c|}{ SPECIFIC BUILDING AREA/ACTIVITY } \\
\hline \multirow{4}{*}{ Airport, Bus \& Rail Station } & Baggage Area & 0.75 & 1.32 \\
\hline & Concourse/Main Throughway & 0.45 & 1.54 \\
\hline & Ticket Counter & 1.3 & 1.32 \\
\hline & Waiting and Lounge Area & 0.6 & 1.0 \\
\hline \multirow[t]{2}{*}{ Bank } & Customer Area & 0.8 & 1.32 \\
\hline & Banking Activity Area & 2.2 & 1.32 \\
\hline \multirow[t]{2}{*}{ Church/Synagogue/Chapel } & Worship/Congregational & 1.3 & 1.54 \\
\hline & Preaching and Sermon/Choir & 1.8 & 1.54 \\
\hline \multirow[t]{3}{*}{ Dormitory } & Bedroom & 0.6 & 1.32 \\
\hline & Bedroom with Study & 1.3 & 1.32 \\
\hline & Study Hall & 0.9 & 1.32 \\
\hline \multirow{2}{*}{ Fire \& Police Dept. } & Fire Engine Room & 0.7 & 1.32 \\
\hline & \begin{tabular}{|l|} 
Jail Cell \\
\end{tabular} & 0.4 & 1.32 \\
\hline \multirow[t]{15}{*}{ Hospital/Nursing Home } & Corridor & 0.9 & 1.54 \\
\hline & Dental Suite/Exam/Treatment & 1.4 & 1.32 \\
\hline & Emergency & 2.0 & 1.32 \\
\hline & Laboratory & 1.7 & 1.0 \\
\hline & Lounge/Waiting Room & 0.6 & 1.32 \\
\hline & \begin{tabular}{|l|} 
Medical Supplies \\
\end{tabular} & 2.4 & 1.32 \\
\hline & Nursery & 1.6 & 1.0 \\
\hline & Nurse Station & 1.8 & 1.32 \\
\hline & Occupational/Physical Therapy & 1.4 & 1.32 \\
\hline & Patient Room & 0.9 & 1.32 \\
\hline & \begin{tabular}{|l|} 
Pharmacy \\
\end{tabular} & 1.5 & 1.32 \\
\hline & Radiology & 1.8 & 1.32 \\
\hline & Surgical and OB Suites - General & 1.8 & 1.32 \\
\hline & Surgical and OB Suites - Operating & 6.0 & 1.32 \\
\hline & Surgical and OB Suites - Recovery & 2.0 & 1.32 \\
\hline \multirow[t]{8}{*}{ Hotel/Conference Center } & Banquet Room/Multifunction & 1.4 & 1.32 \\
\hline & Bathroom/Powder Room & 0.6 & 1.54 \\
\hline & Guest Room & 0.7 & 1.32 \\
\hline & Public Area & 0.8 & 1.32 \\
\hline & Exhibition Hall & 1.3 & 1.0 \\
\hline & Conference/Meeting & 1.5 & 1.0 \\
\hline & Lobby & 1.3 & 1.0 \\
\hline & Reception Desk & 2.4 & 1.32 \\
\hline \multirow[t]{4}{*}{ Museum \& Gallery } & General Exhibition & 1.2 & 1.32 \\
\hline & Inspection/Restoration & 3.0 & 1.32 \\
\hline & Storage (Artifacts) - Inactive & 0.25 & 1.54 \\
\hline & Storage (Artifacts) - Active & 0.5 & 1.54 \\
\hline \multirow[t]{2}{*}{ Post Office } & Lobby & 0.8 & 1.32 \\
\hline & Sorting \& Mailing & 2.1 & 1.32 \\
\hline
\end{tabular}


Table H.2. (contd.)

\begin{tabular}{|c|c|c|c|}
\hline & Activity Type & $\begin{array}{c}\text { MN LPD } \\
\text { W/ft }\end{array}$ & $\begin{array}{c}\text { Area } \\
\text { Factors }\end{array}$ \\
\hline \multirow[t]{4}{*}{ Service } & Barber \& Beauty Parlor & 1.6 & 1.32 \\
\hline & Laundry - Washing & 0.6 & 1.0 \\
\hline & Laundry - Ironing \& Sorting & 1.3 & 1.0 \\
\hline & Service Station/Auto Repair & 0.8 & 1.32 \\
\hline \multirow[t]{3}{*}{ Theater } & Performing Arts & 1.1 & 1.32 \\
\hline & Motion Picture & 0.75 & 1.32 \\
\hline & Lobby & 1.0 & 1.32 \\
\hline \multirow[t]{9}{*}{ Retail Establishments } & Type A & 6.0 & 1.32 \\
\hline & Type B & 2.9 & 1.32 \\
\hline & Type C & 2.7 & 1.32 \\
\hline & Type D & 2.5 & 1.0 \\
\hline & Type E & 2.4 & 1.0 \\
\hline & Type F & 2.6 & 1.32 \\
\hline & Mall Concourse & 0.6 & 1.32 \\
\hline & Retail Support Area - Tailoring & 2.1 & 1.0 \\
\hline & Retail Support Area - Dressing/Fitting Room & 1.1 & 1.0 \\
\hline \multirow{24}{*}{ Indoor Athletic Area/Activity } & Seating Area (All Sports) & 0.4 & 1.0 \\
\hline & Badminton Club & 0.5 & 1.0 \\
\hline & Badminton Tournament & 0.8 & 1.0 \\
\hline & Basketball/Volleyball - Intramural & 0.8 & 1.0 \\
\hline & Basketball/Volleyball - College/Pro & 1.9 & 1.0 \\
\hline & Bowling - Approach Area & 0.5 & 1.0 \\
\hline & Bowling - Lanes & 1.1 & 1.0 \\
\hline & Boxing or Wrestling (Platform) - Amateur & 2.4 & 1.0 \\
\hline & Boxing or Wrestling (Platform) - Professional & 4.8 & 1.0 \\
\hline & Gymnasium - Gen. Exercise \& Recreation & 1.0 & 1.0 \\
\hline & Handball/Racquetball/Squash - Club & 1.3 & 1.0 \\
\hline & Handball/Racquetball/Squash - Tournament & 2.6 & 1.0 \\
\hline & Ice Hockey - Amateur & 1.3 & 1.0 \\
\hline & Ice Hockey - College or Pro & 2.6 & 1.0 \\
\hline & Skating Rink - Recreational & 0.6 & 1.0 \\
\hline & Skating Rink - Exhibition/Pro & 2.6 & 1.0 \\
\hline & Swimming - Recreational & 0.9 & 1.0 \\
\hline & Swimming - Exhibition & 1.5 & 1.0 \\
\hline & Swimming - Underwater & 1.0 & 1.0 \\
\hline & Tennis - Recreational (Class III) & 1.3 & 1.0 \\
\hline & Tennis - Club/College (Class II) & 1.9 & 1.0 \\
\hline & Tennis - Professional (Class I) & 2.6 & 1.0 \\
\hline & Table Tennis - Club & 1.0 & 1.0 \\
\hline & Table Tennis - Tournament & 1.6 & 1.0 \\
\hline
\end{tabular}

version of COMcheck includes default area factors for all area categories and these are used to adjust the lighting power density. These area factors were derived from three standard room geometries used by the 90.1 Lighting Subcommittee for development of Standard 90.1-1999. The budget LPD used in the software is given by Equation H.1. 


$$
\mathrm{LPD}_{\mathrm{BUDGET}}=\mathrm{LPD} \times \mathrm{AF}
$$

where LPD = Lighting Power Density (MN LPD) from Table H.2

$\mathrm{AF}=$ Area Factor from Table H.2

\section{H.2 Lighting}

\section{H.2.1 Controls Credit}

The Minnesota version of COMcheck implements the control credits available for luminaires automatically controlled by occupancy sensors, daylight sensors, programmable timing controls, or lumen maintenance controls. Table H.3 lists the lighting controls and their corresponding power adjustment factors available in the software. The user can select the type of control from a list, and the proposed fixture wattage will be reduced using the appropriate power adjustment factor.

Table H.3. Minnesota Control Types and Power Adjustment Factors

\begin{tabular}{|l|c|}
\hline \multicolumn{1}{|c|}{ Control Type } & $\begin{array}{c}\text { Adjustment } \\
\text { Factor }\end{array}$ \\
\hline Daylight Sensing Controls (DS), continuous dimming & 0.30 \\
\hline DS, multiple step dimming & 0.20 \\
\hline DS, ON/OFF & 0.10 \\
\hline DS, continuous dimming, programmable timing & 0.35 \\
\hline DS, multiple step dimming, programmable timing & 0.25 \\
\hline DS, ON/OFF, programmable timing & 0.15 \\
\hline DS, continuous dimming, programmable timing, lumen maintenance & 0.40 \\
\hline DS, multiple step dimming, programmable timing, lumen maintenance & 0.30 \\
\hline DS, ON/OFF, programmable timing, lumen maintenance & 0.20 \\
\hline Lumen maintenance & 0.10 \\
\hline Lumen maintenance, programmable timing & 0.15 \\
\hline Programmable timing & 0.15 \\
\hline Occupancy sensor & 0.30 \\
\hline Occupancy sensor, DS, continuous dimming & 0.40 \\
\hline Occupancy sensor, DS, multiple step dimming & 0.35 \\
\hline Occupancy sensor, DS, ON/OFF & 0.35 \\
\hline Occupancy sensor, DS, continuous dimming, lumen maintenance & 0.45 \\
\hline Occupancy sensor, DS, multiple step dimming, lumen maintenance & 0.40 \\
\hline Occupancy sensor, DS, ON/OFF, lumen maintenance & 0.35 \\
\hline Occupancy sensor, lumen maintenance & 0.35 \\
\hline Occupancy sensor, programmable timing & 0.35 \\
\hline
\end{tabular}





\section{Appendix I}

New York 



\section{Appendix I - New York}

This appendix describes changes that have been made to COMcheck to support the New York Energy Conservation Construction Code, which is based on the 2001 IECC Amendments.

\section{I.1 Building Use Types}

All building use types are the same as the 2001 IECC version of COMcheck.

\section{I.2 Envelope}

All envelope trade-off calculations and requirements are the same as the 2001 IECC. An 'Electric Resistance' or 'Other' heating type option is available for multifamily dwellings. If a multifamily dwelling with electric resistance heating is indicated, the New York residential electric requirements are applied. This option is applicable to envelope and mechanical compliance only, as lighting compliance isn't required for multifamily dwellings.

The envelope compliance report includes a requirements checklist item requiring fireplaces (solid fuel type) to be installed with tight fitting non-combustible fireplace doors.

\section{I.3 Mechanical}

All mechanical equipment efficiencies are the same as the 2001 IECC requirements, as listed in Appendix $\mathrm{C}$ of this document. Requirements specific to hydronic system controls and water source heat pump systems were added.

\section{I.4 Lighting}

All lighting requirements are the same as the 2000 IECC version of COMcheck. The Lighting and Power Compliance Certificate was modified to include requirements for metering individual dwelling units and transformer efficiency requirements according to Tables 805.6.1 and 805.6.2 of the New York Commercial Code. 

Appendix $\mathbf{J}$

\section{Vermont}





\section{Appendix J - Vermont}

This appendix describes changes that have been made to COMcheck to support the 2005 Vermont Guidelines for Energy Efficient Commercial Construction. The envelope requirements are based on the 2004 IECC with Vermont-specific amendments, and lighting system requirements are based on Standard 90.1-2004 lighting power densities and 2004 IECC exemptions and allowances. Mechanical requirements are based on the 2004 IECC and Vermont-specific amendments. All mandatory requirements were updated to reflect the Vermont amendments to the 2004 IECC and Standard 90.1-2004.

\section{J.1 Building Use Types}

The Vermont whole building types and area categories are identical to those in the Standard 90.1-2004 version of COMcheck.

\section{J.2 Envelope}

All envelope requirements are based on the prescriptive table provided in the Vermont guidelines. The R-value requirements in the Vermont prescriptive requirements Tables 802.2(1) and 802.2(2) are converted to budget $U$-factors based on the assembly type. These budget $U$-factors are used in the envelope trade-off calculations. Glass doors (doors exceeding 50\% of glazing area) are treated as windows, and all other doors are treated as opaque doors. All non-swinging doors are required to meet a U-factor requirement of R-10.85 (including the interior and exterior air films). The maximum area of skylights is limited to $5 \%$ of the gross roof area. The skylight $U$-factor requirements are independent of the curb type, but default values for skylight $U$-factors are provided based on the curb type according to Table A8.1A of Standard 90.1-2004. All envelope assembly U-factor calculations are consistent with Appendix A of Standard 90.1-2004. Burlington weather data is used in trade-off calculations for all locations. All Vermont envelope compliance checklist items are the same as the 2004 IECC, and the mandatory requirements were revised to include reference to Tables 102.1.3(1), 102.1.3(2), and 102.1.3(3) of the 2004 IECC.

To check compliance for buildings with window and glazed door area exceeding 50\% of the gross abovegrade wall area, users are required to use the Section 11: Energy Cost Budget Method of Standard 90.1-2004, which requires the use of energy simulation software. The Vermont guidelines limit the use of prescriptive tables and COMcheck trade-off compliance to buildings with a window-wall ratio (WWR) $<50 \%$.

\section{J.3 Mechanical}

All mechanical equipment efficiencies and requirements checklist items are the same as the 2004 IECC requirements, which in turn are based on the 2003 IECC, as listed in Appendix F of this document, with the exception of air conditioners and heat pumps $<65 \mathrm{kBtu} / \mathrm{h}$, which are required to meet Standard 90.12004 efficiency requirements that became effective in January 2006. In addition, the following changes were made to the mechanical section:

- All references to electrical resistance heating were removed.

- No high efficiency equipment exception is provided for the economizer requirement.

Technical Support Documentation for COMcheck Through Version 3.4.0 (Software) 
- Electric service water heating units are limited to a maximum of $5 \mathrm{~kW}$ total power input.

- Heat trace tape option was removed from service water heating because the Vermont Energy Office does not have any field inspectors to verify the controls and preferred not to provide the option.

\section{J.4 Lighting}

The Vermont requirements for lighting power densities and the list of building use types for whole building and area category methods are the same as Standard 90.1-2004. Lighting allowances are also based on Standard 90.1-2004 without video display terminals. Lighting exemptions are the same as the 2004 IECC.

The Vermont lighting requirements checklist includes the following items:

- Exterior lighting requirements need to be documented separately and should comply with Section 805.6 of the Vermont Guidelines, which is the same as Standard 90.1-2004.

- Transformers are required to meet the minimum efficiency requirements as per Tables 806.2 and 806.3 of the Vermont Guidelines.

- Voltage drop requirements are included and these are same as the Standard 90.1-2004 requirements. 


\section{Appendix K}

\section{Georgia}





\section{Appendix K - Georgia}

This appendix describes changes that have been made to COMcheck to support the Georgia Commercial Code. The Georgia version of COMcheck uses the envelope trade-off calculations, lighting power densities and mechanical requirements of Standard 90.1-2004, which is referenced in the Georgia Code.

\section{K.1 Envelope}

The following mandatory requirements were implemented for envelope requirements as per Table 701 of the Georgia Code:

1. Metal building roof systems are required to have minimum R-19 insulation.

2. All roof systems, except metal building roof, are required to have a minimum R-15 insulation.

3. All above-grade, framed cavity walls are required to have R-13 insulation. The mass wall insulation requirement of R-7, originally implemented, was later withdrawn at the request of the Georgia Energy Code Committee and replaced with a requirement for other above-grade walls to meet a mandatory maximum $\mathrm{U}$-factor of 0.15 , which is the $\mathrm{U}$-factor requirement for mass walls.

4. All windows are required to meet the maximum $\mathrm{U}$-factor of 0.65 and maximum SHGC of 0.60.

Unlike versions prior to 3.2.0, the U-factor limits are not imposed as mandatory requirements, but are used as budget requirements in the trade-off calculations. In addition to checking mandatory requirements during trade-off compliance calculations, Table 701 of the Georgia Code requirements are included in the software mandatory requirements text.

The envelope requirements checklist item for unlabeled fenestration requires the manufacturer to site label the fenestration components using default U-factors and SHGCs.

In 2006, Georgia amendments provided assembly U-factors for metal building roofs taking into account the purlin spacing and a lab-tested U-factor of R-19 for screw down roofs without thermal blocks. A new Figure 9-3 was included in the Georgia amendments to calculate the effect of purlin spacing on the overall assembly U-factor. Table K.1 lists the adjustment factors derived from Figure 9-3. This adjustment factor was applied to assembly U-factors provided in Table A2.3 of Standard 90.1-2004 for standing seam and screw-down metal roofs.

Table K.1. Adjustment Factors for Calculating Assembly U-factors of Standing Seam and Screwdown Roofs

\begin{tabular}{|c|c|}
\hline Purlin Spacing (d) & Adjustment Factor \\
\hline$d \leq 2$ & 1.729 \\
\hline $2<d \leq 2.5$ & 1.482 \\
\hline $2.5<d \leq 3.0$ & 1.329 \\
\hline $3.0<d \leq 3.5$ & 1.212 \\
\hline $3.5<d \leq 4.0$ & 1.118 \\
\hline $4.0<d \leq 4.5$ & 1.047 \\
\hline $4.5<d \leq 5.0$ & 1.0 \\
\hline
\end{tabular}



Appendix L

90.1-2004 



\section{Appendix L-90.1-2004}

This appendix documents changes that have been made to COMcheck to support Standard 90.1-2004. New minimum equipment efficiencies went into effect in January 2006.

\section{L.1 Building Use Types}

\section{L.1.1 Whole Building Types}

The whole building types are identical to Standard 90.1-1999, although the internal load densities (ILDs) and lighting power densities (LPDs) were revised to be consistent with Standard 90.1-2004.

Table L.1. Whole Building Use Types

\begin{tabular}{|l|l|l|}
\hline Whole Building Use Type & $\begin{array}{l}\text { ILD } \\
\text { W/ft }\end{array}$ & $\begin{array}{l}\text { LPD } \\
\text { W/ft }\end{array}$ \\
\hline Automotive Facility & 0.75 & 0.9 \\
\hline Convention Center & 1.95 & 1.2 \\
\hline Court House & 1.95 & 1.2 \\
\hline Dining: Bar Lounge/Leisure & 1.95 & 1.3 \\
\hline Dining: Cafeteria/Fast Food & 1.95 & 1.4 \\
\hline Dining: Family & 1.95 & 1.6 \\
\hline Dormitory & 1.25 & 1 \\
\hline Exercise Center & 1.95 & 1 \\
\hline Gymnasium & 1.95 & 1.1 \\
\hline Health Care-Clinic & 1.95 & 1 \\
\hline Hospital & 1.95 & 1.2 \\
\hline Hotel & 1.25 & 1 \\
\hline Library & 1.95 & 1.3 \\
\hline Manufacturing Facility & 0.75 & 1.3 \\
\hline Motel & 1.25 & 1 \\
\hline Motion Picture Theater & 1.95 & 1.2 \\
\hline Multifamily & 1.25 & 0.7 \\
\hline Museum & 1.95 & 1.1 \\
\hline Office & 1.95 & 1 \\
\hline Parking Garage & 0.75 & 0.3 \\
\hline Penitentiary & 1.25 & 1 \\
\hline Performing Arts Theater & 1.95 & 1.6 \\
\hline Police/Fire Station & 1.95 & 1 \\
\hline Post Office & 1.95 & 1.1 \\
\hline Religious Building & 1.95 & 1.3 \\
\hline Retail & 1.95 & 1.5 \\
\hline School/University & 1.95 & 1.2 \\
\hline Sports Arena & 1.95 & 1.1 \\
\hline Town Hall & 1.95 & 1.1 \\
\hline Transportation & 1.95 & 1 \\
\hline Warehouse & 0.75 & 0.8 \\
\hline Workshop & 0.75 & 1.4 \\
\hline & & \\
\hline
\end{tabular}

\section{L.1.2 Area Categories}

Table L.2 shows the Standard 90.1-2004 area categories. 
Table L.2. Area Categories

\begin{tabular}{|c|c|c|c|c|c|}
\hline Area Category Type & $\begin{array}{l}\text { ILD } \\
\text { W/ft }^{2}\end{array}$ & $\begin{array}{l}\text { LPD } \\
\mathrm{W} / \mathrm{ft}^{2}\end{array}$ & Area Category Type & $\begin{array}{l}\text { ILD } \\
\text { W/ft }^{2}\end{array}$ & $\begin{array}{l}\text { LPD } \\
\mathrm{W} / \mathrm{ft}^{2}\end{array}$ \\
\hline \multicolumn{3}{|l|}{ Common Space Types } & \multicolumn{3}{|l|}{ Hospital } \\
\hline Active Storage & 0.75 & 0.8 & Active Storage & 0.75 & 0.9 \\
\hline Atrium - Each Additional Floor & 1.95 & 0.2 & Corridors /Transition & 1.95 & 1 \\
\hline Atrium - First Three Floors & 1.95 & 0.6 & Emergency & 1.95 & 2.7 \\
\hline Audience/Seating Area & 1.95 & 0.9 & Exam/Treatment & 1.95 & 1.5 \\
\hline Classroom/Lecture/Training & 1.95 & 1.4 & Laundry - Washing & 1.95 & 0.6 \\
\hline Conference/Meeting/Multipurpose & 1.95 & 1.3 & Lounge/Recreation & 1.95 & 0.8 \\
\hline Corridor/Transition & 1.95 & 0.5 & Medical Supply & 1.95 & 1.4 \\
\hline Dining Area - General & 1.95 & 0.9 & Nurse Station & 1.95 & 1 \\
\hline Dining Area - Bar Lounge/Leisure & 1.95 & 1.4 & Nursery & 1.95 & 0.6 \\
\hline Dining Area - Family Restaurant & 1.95 & 2.1 & Operating Room & 1.95 & 2.2 \\
\hline Dressing/Locker/Fitting Room & 1.95 & 0.6 & Patient Room & 1.25 & 0.7 \\
\hline Electrical/Mechanical & 1.95 & 1.5 & Pharmacy & 1.95 & 1.2 \\
\hline Food Preparation & 1.95 & 1.2 & Physical Therapy & 1.95 & 0.9 \\
\hline Inactive Storage & 0.75 & 0.3 & Radiology & 1.95 & 0.4 \\
\hline Laboratory & 1.95 & 1.4 & Recovery & 1.95 & 0.8 \\
\hline Lobby & 1.95 & 1.3 & \multicolumn{3}{|l|}{ Automotive } \\
\hline Lounge/Recreation & 1.95 & 1.2 & Service/Repair & 0.75 & 0.7 \\
\hline Office - Enclosed & 1.95 & 1.1 & \multicolumn{3}{|l|}{ Manufacturing } \\
\hline Office - Open Plan & 1.95 & 1.1 & Detailed Manufacturing & 0.75 & 2.1 \\
\hline Restrooms & 1.95 & 0.9 & Control Room & 0.75 & 0.5 \\
\hline Stairs-Active & 1.95 & 0.6 & Corridor/Transition & 0.75 & 0.5 \\
\hline Workshop & 0.75 & 1.9 & Equipment Room & 0.75 & 1.2 \\
\hline \multicolumn{3}{|l|}{ Gymnasium/Exercise Center } & Low Bay (<25 ft. Floor to Ceiling Height) & 0.75 & 1.2 \\
\hline Playing Area & 1.95 & 1.4 & $\begin{array}{l}\text { High Bay (>= } 25 \mathrm{ft} . \text { Floor to Ceiling } \\
\text { Height) }\end{array}$ & 0.75 & 1.7 \\
\hline Exercise Area & 1.95 & 0.9 & \multicolumn{3}{|l|}{ Hotel/Motel } \\
\hline Gymnasium Audience/Seating Area & 1.95 & 0.4 & Hotel Dining Area & 1.95 & 1.3 \\
\hline Exercise Center Audience/Seating Area & 1.95 & 0.3 & Hotel Lobby & 1.95 & 1.1 \\
\hline \multicolumn{3}{|l|}{ Courthouse/Police Station/Penitentiary } & Guest Rooms & 1.25 & 1.1 \\
\hline Courtroom & 1.95 & 1.9 & Motel Dining Area & 1.95 & 1.2 \\
\hline Confinement Cell & 1.25 & 0.9 & \multicolumn{3}{|l|}{ Dormitory } \\
\hline Judges Chambers & 1.95 & 1.3 & Living Quarters & 1.5 & 1.1 \\
\hline Penitentiary Audience/Seating Area & 1.95 & 0.7 & \multicolumn{3}{|l|}{ Museum } \\
\hline Penitentiary Classroom/Lecture/Training & 1.95 & 1.3 & Active Storage & 0.75 & 0.8 \\
\hline Penitentiary Dining Area & 1.95 & 1.3 & General Exhibition & 1.95 & 1 \\
\hline \multicolumn{3}{|l|}{ Fire Stations } & Inactive Storage & 0.75 & 1.4 \\
\hline Fire Station Engine Room & 1.95 & 0.8 & Restoration & 1.95 & 1.7 \\
\hline Fire Station Sleeping Quarters & 1.25 & 0.3 & \multicolumn{3}{|l|}{ Bank/Office } \\
\hline \multicolumn{3}{|l|}{ Post Office } & Banking Activity Area & 1.95 & 1.5 \\
\hline Sorting Area & 1.95 & 1.2 & \multicolumn{3}{|l|}{ Religious Buildings } \\
\hline Convention Center & & & Audience/Seating Area & 1.95 & 1.7 \\
\hline Exhibit Space & 1.95 & 1.3 & Fellowship Hall & 1.95 & 0.9 \\
\hline Audience/Seating Area & 1.95 & 0.7 & Worship Pulpit, Choir & 1.95 & 2.4 \\
\hline \multicolumn{3}{|l|}{ Library } & \multicolumn{3}{|l|}{ Retail } \\
\hline Card File and Cataloging & 1.95 & 1.1 & Sales Area & 1.95 & 1.7 \\
\hline Reading Area & 1.95 & 1.2 & Mall Concourse & 1.95 & 1.7 \\
\hline Stacks & 1.95 & 1.7 & & & \\
\hline
\end{tabular}


Table L.2. (contd.)

\begin{tabular}{|l|l|l|}
\hline Area Category Type & $\begin{array}{l}\text { ILD } \\
\text { W/ft }\end{array}$ & $\begin{array}{l}\text { LPD } \\
\text { W/ft }\end{array}$ \\
\hline Sports Arena & 1.95 & 0.4 \\
\hline Audience/Seating Area & 1.95 & 2.3 \\
\hline Court Sports Area & 1.95 & 1.4 \\
\hline Indoor Playing Field Area & 1.95 & 2.7 \\
\hline Ring Sports Area & 0.75 & 1.4 \\
\hline Warehouse & 0.75 & 0.9 \\
\hline Fine Material Storage & 0.75 & 0.2 \\
\hline Medium/Bulky Material Storage & & \\
\hline Parking Garage & \\
\hline Garage Area &
\end{tabular}

\begin{tabular}{|l|l|l|}
\hline Area Category Type & $\begin{array}{l}\text { ILD } \\
\text { W/ft }\end{array}$ & $\begin{array}{l}\text { LPD } \\
\text { W/ft }^{2}\end{array}$ \\
\hline Transportation & 1.95 & 1 \\
\hline Air/Train/Bus - Baggage Area & 1.95 & 0.6 \\
\hline Airport - Concourse & 1.95 & 0.5 \\
\hline Seating Area & 1.95 & 1.5 \\
\hline Terminal - Ticket Counter & 1.95 & 1.2 \\
\hline Motion Picture Theater & 1.95 & 1.1 \\
\hline Audience/Seating Area & 1.95 & 2.6 \\
\hline Lobby & 1.95 & 3.3 \\
\hline Performing Arts Theater
\end{tabular}

\section{L.2 Envelope}

New DOE climate zones were mapped to Standard 90.1-1999 based bins, and the envelope requirements were obtained from Standard 90.1-1999 Appendix B tables. The climate zone mapping is listed in Table L.3.

Table L.3. Climate Zone Mapping

\begin{tabular}{|c|c|}
\hline $\begin{array}{c}\text { 90.1-2004 } \\
\text { Requirements Table } \\
\end{array}$ & $\begin{array}{c}\text { 90.1-1999 } \\
\text { Appendix-B Tables } \\
\end{array}$ \\
\hline $5.5-1$ & B. 2 \\
\hline $5.5-1$ & B-5 \\
\hline $5.5-3 a, b$ & B-10 \\
\hline $5.53 c$ & B-9 \\
\hline $5.5-4$ & B-13 \\
\hline $5.5-4$ & B-17 \\
\hline $5.5-4$ & B-19 \\
\hline $5.5-4$ & B-22 \\
\hline $5.5-4$ & B-24 \\
\hline
\end{tabular}

The envelope requirements in Standard 90.1-2004 are the same for all moisture regimes (moist, dry, and marine) within each climate zone, except for fenestration requirements in Climate Zone 3 marine.

\section{L.3 Mechanical}

Equipment efficiency requirements were modified for applicable air-cooled (split systems and roof top) $\mathrm{AC}$ units and heat pump systems with capacity $<65 \mathrm{kBtu} / \mathrm{h}$ to reflect the changes required in January 2006. Additional changes include:

- SPV (single package vertical) AC and SPVHP (single package vertical heat pump) were added. 
- Air cooled (split systems and roof top) AC units with capacity $<65 \mathrm{kBtu} / \mathrm{h}$, the cooling efficiency requirement was revised to be 10.0 SEER, effective January 2006.

- Air cooled (split systems and roof top) heat pump systems with capacity $<65 \mathrm{kBtu} / \mathrm{h}$, the efficiency requirement was revised to be 12.0 SEER and 7.4 HSPF, effective January 2006.

- Fan power limitation was reduced from $30 \mathrm{hp}$ to $15 \mathrm{hp}$.

- Supply and return air duct insulation requirements were revised according to the new climate zones (implemented in the Requirements Checklist).

- Economizer requirements were updated based on Table 6.5.1 in Standard 90.1-2004.

- The high-efficiency equipment exception is now based on Table 6.3.2, which does not allow this exception to be claimed in Climate Zones 5, 6, 7, and 8. For all economizers in Climate Zones 2, 3, and 4, a new set of efficiency requirements was implemented according to Table 6.3.2.

\section{L.4 Lighting}

The lighting power densities (LPDs) were changed and the lighting menu structure was revised to be consistent with the new format in Standard 90.1-2004. The revised list of whole building types, area categories and internal load densities (ILD) and LPDs is given in Tables L.1 and L.2.

The Mandatory Requirements text was modified to reflect the changes in Standard 90.1-2004 related to interior space controls, exterior lighting controls and new exceptions were added to the interior automatic lighting shut off requirements. Standard 90.1-2004 revised the requirements for exterior lighting power densities and provides a trade-off calculation methodology. This has not been implemented in the software, but a reference to comply with these requirements was added to the Requirements Checklist.

\section{L.5 Window-to-Wall Ratio (WWR)}

A formal ASHRAE interpretation affected the WWR calculation in COMcheck with the release of Version 3.1. See Section D.5 for details. 
Appendix M

\section{IECC}





\section{Appendix M - 2004 IECC}

This appendix documents changes that have been made to COMcheck to support the 2004 International Energy Conservation Code (IECC). The envelope requirements in the 2004 IECC are based on new climate zones and assembly types. The lighting requirements are the same as the 2003 IECC. The mechanical requirements are based on the 2003 IECC with minor changes to economizer requirements and other prescriptive requirements.

\section{M.1 Building Use Types}

The building use types for the 2004 IECC are the same as the 2003 IECC for both the whole building and area category types.

\section{M.2 Envelope}

The envelope requirements in the 2004 IECC are specified as R-values for generic assembly types. The trade-off calculations require assembly U-factors, and these are calculated based on the R-value requirements in Tables 802.2(1) and 802.2(2) of the 2004 IECC. The U-factor calculations are based on assembly types described in Appendix A tables in Standard 90.1-2001. The envelope assembly types in the 2004 IECC version of COMcheck are different from the earlier IECC versions of COMcheck. These are same as the Standard 90.1-2001 version, and the mapping table described in Table D.5 is used to calculate the required assembly U-factors for each proposed assembly type. For example, if an 'Attic Roof with Wood Joists' roof is selected, the R-value requirement from Table 802.2(1) for 'Attic and Other' for that climate zone is used in the assembly U-factor calculation for 'Attic Roof with Wood Joists'. This approach maintains consistency in assembly U-factor calculations for the proposed and budget building. For windows and glazed doors, the requirements are determined based on whether these are factory assembled or site-built. Whenever there are no requirements specified for an assembly in Table 802.2(1) of the 2004 IECC, the base assembly U-factor is used as the code requirement such that no trade-off is provided for the uninsulated assembly.

The Standard 90.1-2001 based envelope performance factor calculations are used for determining tradeoff compliance. The budget building is based on proposed window-to-wall ratio (WWR). For buildings with WWR $>40 \%$, users are advised to use the Standard 90.1-2001 version of COMcheck, IECC Section 806: Total Building Performance, or Standard 90.1 Section 11: Energy Cost Budget Method.

\section{M.3 Mechanical}

The mechanical requirements description report and requirements checklist were revised to be consistent with the following 2004 IECC requirements:

- For all plant equipment with heat capacity exceeding $300 \mathrm{kBtu} / \mathrm{h}$, hydronic system control requirements based on 803.3.3.7 already implemented in COMcheck are added to the compliance report. 
- Economizer requirements were revised according to Table 803.2.6(1) using the new climate zones. The high-efficiency equipment exception is based on Table 803.2.6(2) and the required efficiency (EER and IPLV) are increased by the percentages specified by this table.

- The Requirements Checklist and descriptive requirements for duct sealing tapes and mastics were revised to include reference to UL standards based on duct type.

- The heated swimming pool option was added to the service water heating system description and the requirements for controls and pool covers were added.

\section{M.4 Lighting}

The requirements checklist item for the manual controls requirement was changed to include an exemption for 'guest rooms'. 
Appendix N

\section{IECC}





\section{Appendix N - 2006 IECC}

This appendix documents changes that have been made to the 2004 IECC version of COMcheck to support the 2006 International Energy Conservation Code (IECC). The most significant change affecting the software is the elimination of the area category method of interior lighting compliance.

\section{N.1 Building Use Types}

The building use types for the 2006 IECC are significantly changed from the 2004 IECC. Instead of having both whole building and area category types, the 2006 IECC includes only "building area types". This new method requires users to specify the building by the Building Area Types, which are provided in Table 505.5.2 of the 2006 IECC.

\section{N.2 Envelope}

The envelope requirements in the 2006 IECC are specified as R-values for generic assembly types. The trade-off calculations require assembly U-factors, and these are calculated based on the R-value requirements in Tables 502.2(1) of the 2006 IECC. The U-factor calculations are based on assembly types described in the Appendix A tables in Standard 90.1-2004. For windows and glazed doors, the requirements are determined based on the framing material (metal or non-metal). Glazed doors must be specified as either "entrance" or "non-entrance" doors. The proposed and required assembly U-factor calculations use the same balance of assembly U-factors. All COMcheck assembly types are mapped to equivalent generic assembly types in Table 502.2(1).

The Standard 90.1-2004 based envelope performance factor calculations are used for determining tradeoff compliance. The budget building is based on proposed window-to-wall ratio (WWR). For buildings with WWR $>40 \%$, users are advised to use the Standard 90.1-2004 version of COMcheck, IECC Section 506: Total Building Performance, or Standard 90.1 Section 11: Energy Cost Budget Method.

The 2006 IECC introduced a skylight area limit of 3\% of the gross roof area. The interior wall requirements were removed. Curtain walls are a new window assembly type, with the applicable Ufactors taken from Table 502.3 of the 2006 IECC. These changes were all implemented in the 2006 IECC version of COMcheck.

\section{N.3 Mechanical}

The software was modified to require variable speed drives for all fan systems over $10 \mathrm{hp}$ and also to exempt the automatic bypass valve requirement in Climate Zones 1 and 2. The 2006 IECC EF calculation for gas storage water heaters was implemented as per Table 504.2 of the 2006 IECC. The mechanical requirements were revised to be consistent with the following 2006 IECC requirements:

- Economizer requirements were revised to include the new requirement for providing a means of relieving outdoor air to prevent building over pressurization during economizer operation. The economizer requirement was reduced from $65 \mathrm{kBtu} / \mathrm{h}$ to $54 \mathrm{kBtu} / \mathrm{h}$. 
- The shut-off damper control exceptions were modified to include gravity dampers as per Section 503.2.4.4 of the 2006 IECC.

- The heat pump pool heater option was added to the service water heating inputs and the heat pump water heater efficiency requirement of 4.0 COP was added.

\section{N.4 Lighting}

The list of building area types and associated lighting power densities are implemented as provided in Table 505.5.2 of the 2006 IECC. Lighting allowances and exemptions for Retail are implemented. Allowances are limited to Retail buildings, as per Table 505.5.2, Footnote 'b'. Only merchandise and fine merchandise display allowances are supported.

For the merchandise display allowance, the maximum allowance is the smaller of:

- the actual wattage of the lighting equipment installed specifically for merchandise, or

- $\quad 1.6 \mathrm{~W} / \mathrm{ft}^{2}$ times the area of the specific display, but not to exceed $50 \%$ of the floor area.

For the fine merchandise display allowance, the maximum allowance is the smaller of:

- the actual wattage of the lighting equipment installed specifically for fine merchandise, or

- $\quad 3.9 \mathrm{~W} / \mathrm{ft}^{2}$ times the actual case or shelf area for displaying and selling jewelry, china or silver. Additionally, up to two times the floor area of fine merchandise display areas is permitted.

The automatic lighting shutoff requirements were modified to include the exemptions as per Section 505.2.2.2 of the 2006 IECC. Exterior lighting requirement compliance calculations are not currently implemented in the software. 
Appendix 0

Pima County, AZ 



\section{Appendix O - Pima County, AZ}

This appendix documents changes that have been made to COMcheck to support the implementation of the 2006 International Energy Conservation Code (IECC) for Pima County, AZ, and the Sustainable Energy Standard. The Pima County version is identical to the 2006 IECC, but certain location and corresponding weather data restrictions have been applied.

- For the code selection: "2006 IECC $<4000 \mathrm{ft}$ ", Tucson weather data is used.

- For the code selection: "2006 IECC for locations $>=4000 \mathrm{ft}$ ", McNary weather data is used.

- For the code selection: "Sustainable Energy Standard", McNary weather data is used. 